UNIVERSIDADE DE SÃO PAULO

FACULDADE DE ECONOMIA, ADMINISTRAÇÃO E CONTABILIDADE DEPARTAMENTO DE ADMINISTRAÇÃO PROGRAMA DE PÓS-GRADUAÇÃO EM ADMINISTRAÇÃo

\title{
EXPLICANDO O COMPORTAMENTO EM RELAÇÃO À SEGURANÇA NO TRABALHO ATRAVÉS DA TEORIA DA AÇÃo PLANEJADA
}

\author{
Aluno: Marcio Braz Amorosino \\ Orientador: Profa. Dra. Liliana Vasconcellos Guedes \\ Versão Corrigida \\ (versão original disponível na Faculdade de Economia, Administração e Contabilidade) \\ SÃO PAULO \\ 2014
}


Prof. Dr. Marco Antonio Zago

Reitor da Universidade de São Paulo

Prof. Dr. Adalberto Américo Fischmann

Diretora da Faculdade de Economia, Administração e Contabilidade

Prof. Dr. Roberto Sbragia

Chefe do Departamento de Administração

Prof. Dr. Moacir de Miranda Oliveira Júnior Coordenador do Programa de Pós-Graduação em Administração 


\title{
EXPLICANDO O COMPORTAMENTO EM RELAÇÃO À SEGURANÇA NO TRABALHO ATRAVÉS DA TEORIA DA AÇÃO PLANEJADA
}

\author{
Dissertação apresentada à Faculdade de \\ Economia e Administração da \\ Universidade de São Paulo para a \\ obtenção do título de Mestre em \\ Ciências da Administração.
}

Orientadora: Profa. Dra. Liliana Vasconcellos Guedes

Versão Corrigida

(versão original disponível na Faculdade de Economia, Administração e Contabilidade)

SÃO PAULO

2014 


\section{FICHA CATALOGRÁFICA}

Elaborada pela Seção de Processamento Técnico do SBD/FEA/USP

Amorosino, Marcio Braz
Explicando o comportamento em relação à segurança no trabalho
através da teoria da açẫo planejada / Marcio Braz Amorosino. -- Sẫo
Paulo, 2014.
143 p.
Dissertação (Mestrado) - Universidade de Sâo Paulo, 2014.
Orientadora: Liliana Vasconcellos Guedes.


Dedico este trabalho a minha esposa Miriam pelo seu carinho, paciência, companheirismo e apoio em todos os tempos, E a meus filhos Marcio e Danilo. 


\section{AGRADECIMENTOS}

Agradeço em primeiro lugar a minha família pelo suporte dado durante o desenvolvimento deste trabalho, em especial para minha esposa Miriam, que lidou com minhas ausências e meu isolamento mesmo estando dentro de casa. Sem seu apoio a realização desse trabalho seria impossível. Obrigado por sua paciência. Obrigado por acreditar no trabalho.

Agradeço aos meus filhos pelos mesmos motivos. Por muitas e muitas vezes meus filhos me viram debruçado sobre os livros, concentrado, pensativo e distante. Com a realização dessa pesquisa, espero deixar para eles um bom exemplo de pai. A eles quero transmitir a mensagem de que estudar é importante, é um privilégio, é desafiador e é útil.

Um especial agradecimento à Profa. Liliana Vasconcellos Guedes, minha orientadora, sempre empenhada em colaborar, em mostrar os caminhos para realização de um trabalho de qualidade e em me desafiar. Obrigado por sua postura positiva e pelos feed-backs. Deste tempo espero levar sua amizade. 


\title{
Resumo
}

A Segurança no Trabalho no Brasil é um tema que merece ser explorado. Todos os anos milhares de trabalhadores sofrem lesões durante a realização de suas atividades laborais. Diversos estudos demonstram a influência do ambiente sobre o comportamento das pessoas, sendo o Clima de Segurança um construto bastante explorado. Este trabalho tem como objetivo geral identificar fatores que explicam o comportamento dos trabalhadores em relação à segurança bem como analisar a relação existente entre esses fatores. Tendo em vista a importância do ambiente organizacional nas questões relacionadas à segurança do trabalho, foi escolhida uma empresa industrial brasileira de grande porte para a realização desta pesquisa. Foi realizada uma análise do contexto organizacional, bem como uma avaliação do comportamento dos trabalhadores em relação à segurança com base na Teoria da Ação Planejada. Com base no modelo proposto, também foi avaliada a relação entre a Supervisão direta dos operadores como fator que explica o comportamento desses em relação à segurança. Os resultados da pesquisa demonstraram que o comportamento dos trabalhadores pode ser explicado com base na Teoria da Ação Planejada e que a Supervisão tem relação com o comportamento, mediada pelos construtos do modelo proposto.

Palavras-chave: Segurança no Trabalho, Clima de Segurança, Teoria da Ação Planejada, Supervisão;

\begin{abstract}
Occupational Safety and Health issue in Brazil in a subject that matters. Every year thousands of workers get injuries along its working activities. Several researches demonstrate the environment influence over people behavior, being Safety Climate a well explored construct. This research brings as general objective identify the factors that explain the worker's behavior toward safety and also analyze the relationship among these factors. Considering the organizational environment relevance regarding safety issues, a large industrial Brazilian company was selected to contribute to this study. Its organizational context was evaluated, as well as the worker's behavior toward safety based on the Theory of Planned Behavior. Based on the proposed model, it was also evaluated the relationship between worker's direct Supervision as a factor that explain their behaviors toward safety. The results demonstrated that the worker's behavior can be explained based on Theory of Planned Behavior and that Supervision set influence on worker's behavior, mediated by TPB constructs.
\end{abstract}

Key-words: Occupational Safety and Health, Safety Climate, Theory of Planned Behavior, Supervision; 


\section{SUMÁRIO}

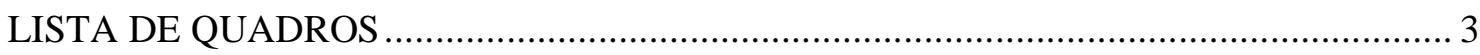

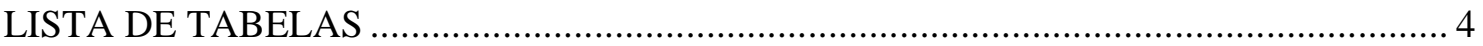

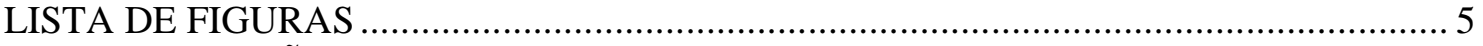

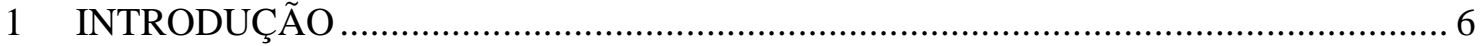

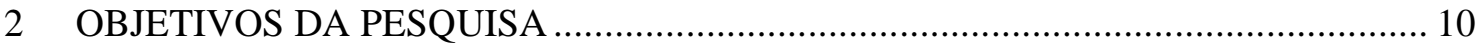

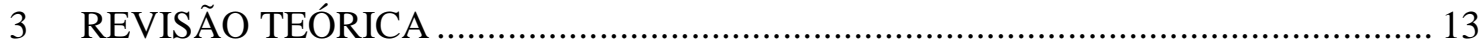

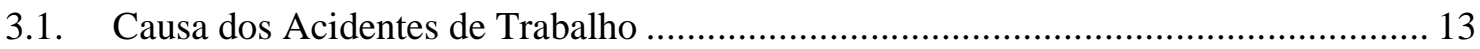

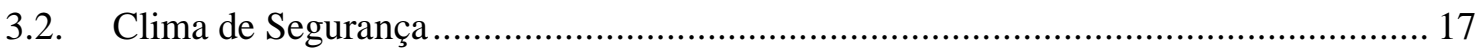

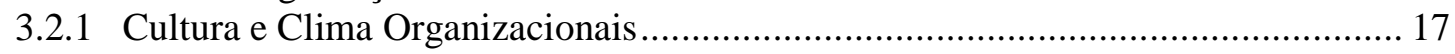

3.2.2 Dimensões do Clima de Segurança................................................................... 20

3.2.3 Relação entre Clima de Segurança e Comportamento......................................... 22

3.2.4 Relação entre Clima de Segurança e Liderança ................................................... 28

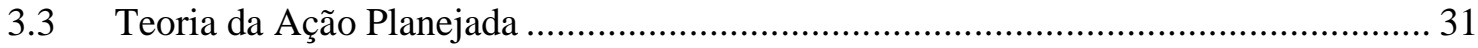

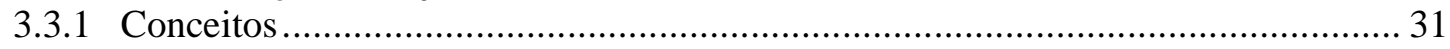

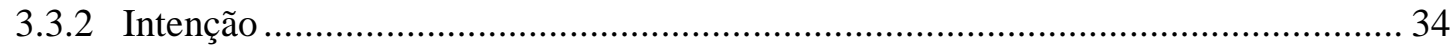

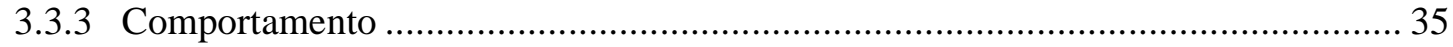

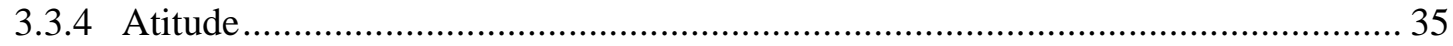

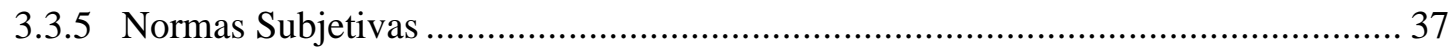

3.3.6 Controle Comportamental Percebido..................................................................... 38

3.4 Modelos de Comportamento em relação à Segurança ............................................... 39

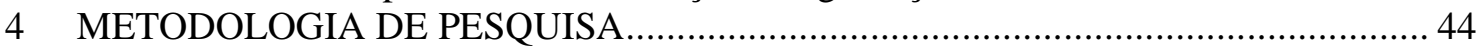

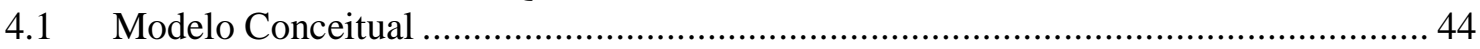

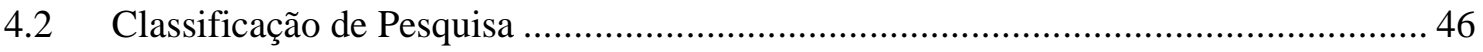

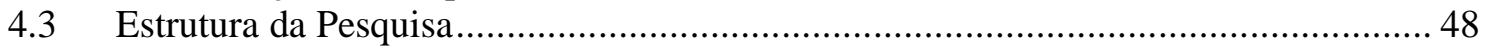

4.4 Necessidades e Fontes de Coleta de Dados ............................................................. 49

4.5 Técnicas e Instrumentos de Coleta de Dados............................................................ 50

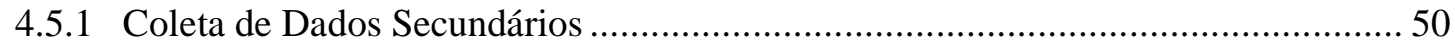

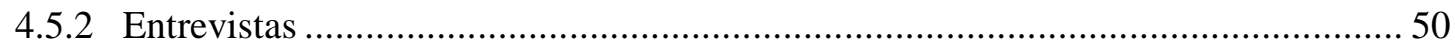

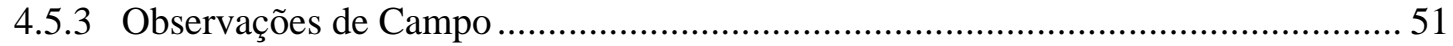

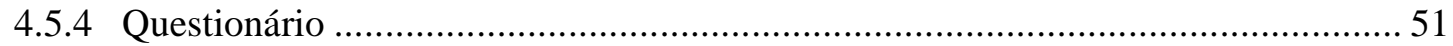

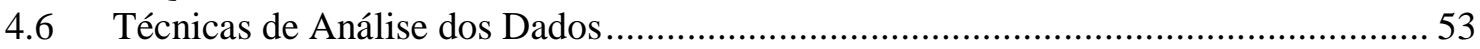

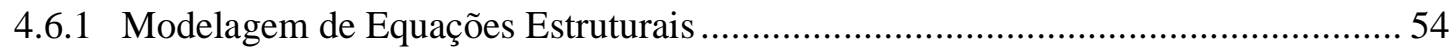

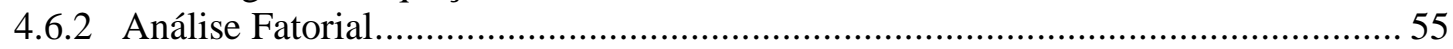

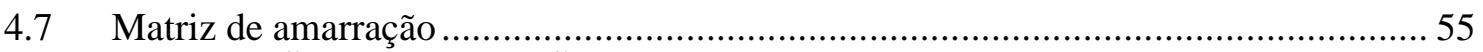

5 PREPARAÇÃO E APLICAÇÃO DA PESQUISA .................................................. 58

5.1 Descrição do Perfil da Empresa Pesquisada ....................................................... 58

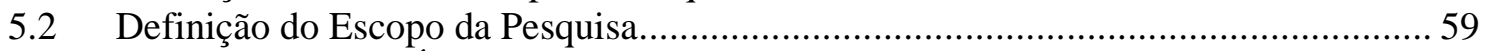

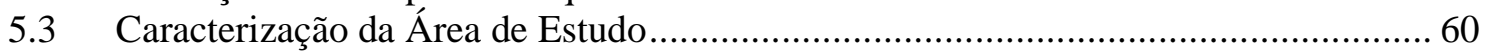

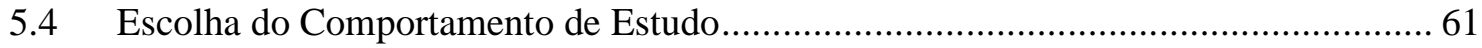

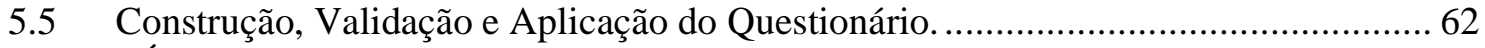

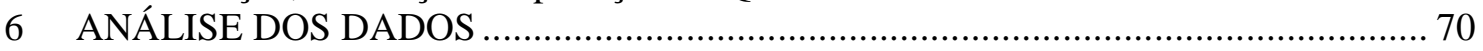

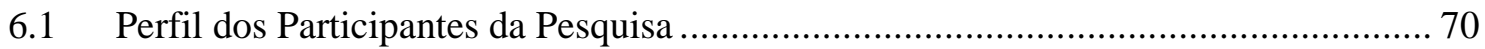

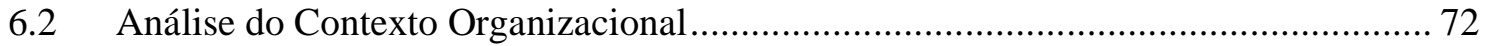

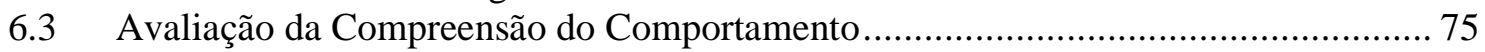

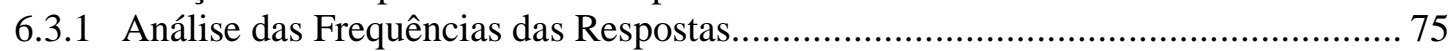

6.3.2 Avaliação do Modelo de Mensuração................................................................ 79

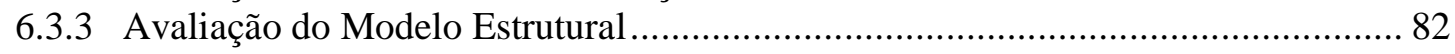




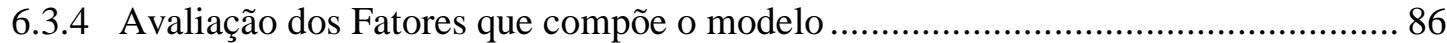

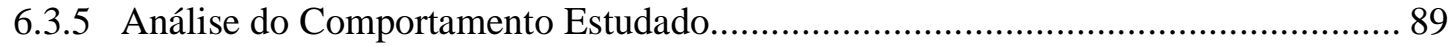

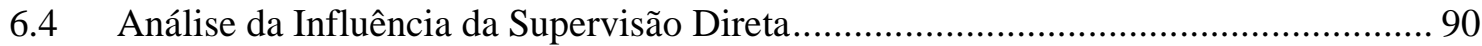

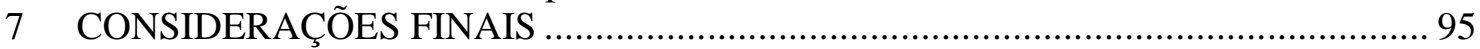

7.1 Conclusões e Contribuições da Pesquisa ................................................................. 95

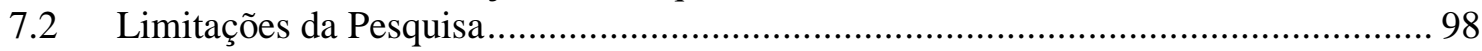

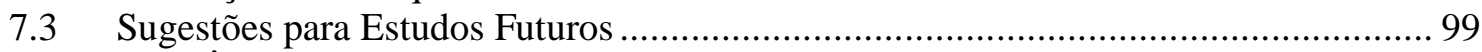

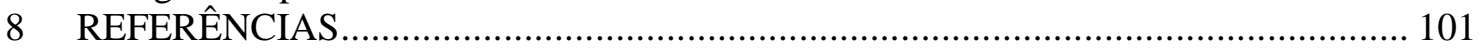

APÊNDICE 1 - ESTUDOS DE CLIMA DE SEGURANÇA (SEO, 2004) ....................... 105

APÊNDICE 2 - ROTEIRO DE ENTREVISTAS ….................................................. 109

APÊNDICE 3 - QUESTIONÁRIO APLICADO POR JOHNSON E HALL (2005) .......... 111

APÊNDICE 4 - QUESTIONÁRIO APLICADO POR FOGARTY $(2010) \ldots \ldots \ldots \ldots \ldots \ldots \ldots \ldots . . . . . . . . . . .112$

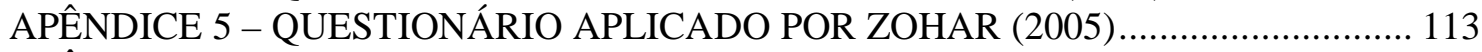

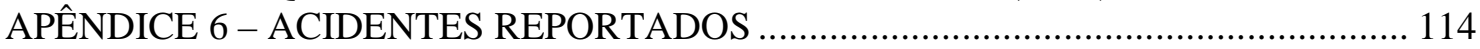

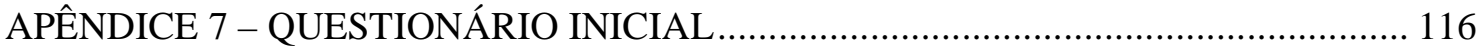

APÊNDICE 8 - MATRIZ ROTACIONADA PRÉ-TESTE .............................................. 118

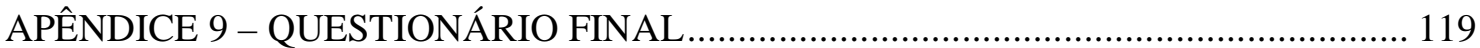

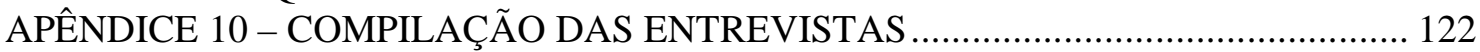

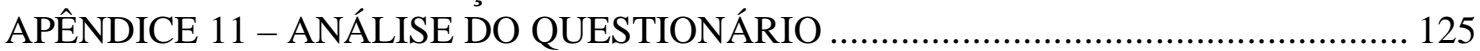

APÊNDICE 12 - MATRIZ ROTACIONADA E QUESTÕES (FINAL) ............................. 137

APÊNDICE 13 - VARIÂNCIA TOTAL EXPLICADA ................................................. 138 


\section{LISTA DE QUADROS}

Quadro 1 - Dimensões Agrupadas de Clima de Segurança ............................................... 21

Quadro 2- Variáveis utilizadas no estudo de Rundmo et al. (1998) ..................................... 23

Quadro 3 - Construtos utilizados no estudo de Tomas et al. (1999)..................................... 24

Quadro 4 - Construtos utilizados no estudo de Oliver et al. (2000) ..................................... 25

Quadro 5 - Construtos utilizados no estudo de Seo et al. (2005) .......................................... 27

Quadro 6 - Construtos utilizados no estudo de Fogarty (2010)........................................ 41

Quadro 7 - Definições Operacionais do Modelo Proposto .................................................. 45

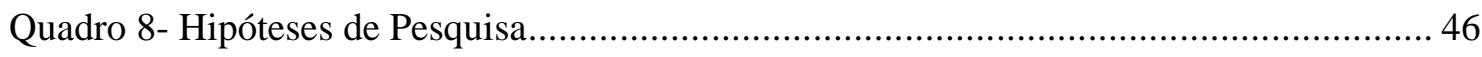

Quadro 9 - Necessidades e Fontes de Coleta de Dados..................................................... 49

Quadro 10 - Matriz de Amarração ................................................................................... 56

Quadro 11 - Questões Adaptadas e Referências (Teoria da Ação Planejada) ....................... 64

Quadro 12 - Questões Adaptadas - Compromisso Percebido da Supervisão......................... 66

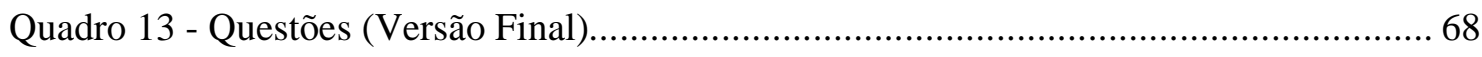

Quadro 14 - Participantes das Entrevistas e Observações de Campo ................................. 70

Quadro 15- Validação das Hipóteses de Pesquisa ............................................................ 86 


\section{LISTA DE TABELAS}

Tabela 3 - Alfa de Cronbach (Questionário Versão Inicial) ............................................... 67

Tabela 4 - Tempo de Trabalho na Empresa ..................................................................... 70

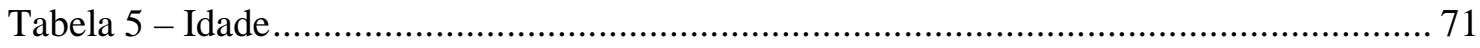

Tabela 6 - Acidentes no Trabalho .................................................................................... 71

Tabela 7 - Frequências das Respostas sobre o Comportamento de Estudo......................... 76

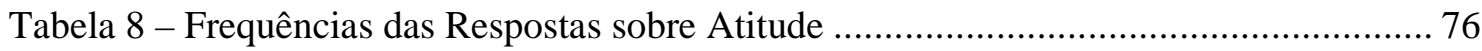

Tabela 9 - Frequências das Respostas sobre Controle Percebido ...................................... 77

Tabela 10 - Frequências das Respostas sobre Normas Subjetivas ...................................... 77

Tabela 11 - Frequências das Respostas sobre Intenção.................................................. 78

Tabela 12 - Valores de AVE, Raiz AVE, Confiabilidade Composta e Alfa de Cronbach..... 80

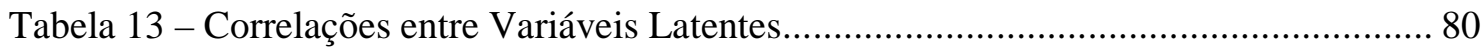

Tabela 14 - Matriz de Cross-Loading - Modelo 1 ........................................................... 81

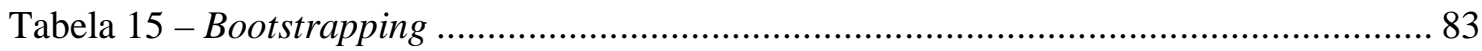

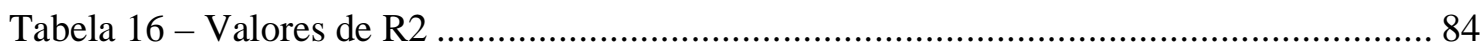

Tabela 17 - Valores de Cargas Fatoriais obtidos em outros estudos.................................. 85

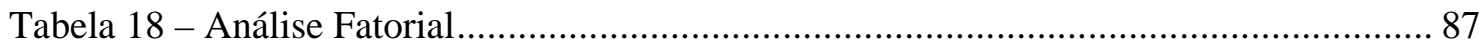

Tabela 19 - Frequências das Respostas - Compromisso Percebido ................................... 91 


\section{LISTA DE FIGURAS}

Figura 1 - Os cinco fatores na sequência de acidentes.................................................... 15

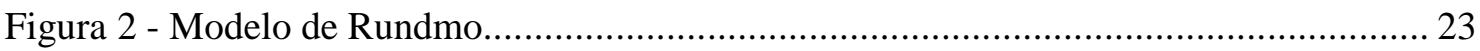

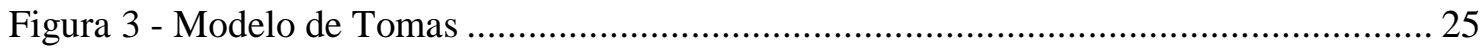

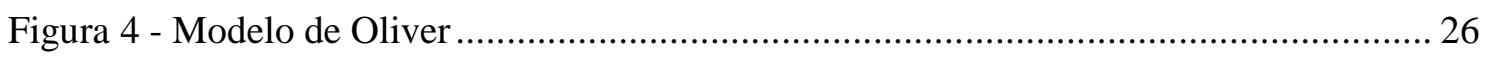

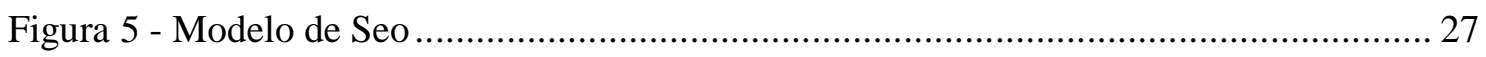

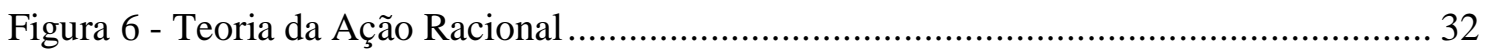

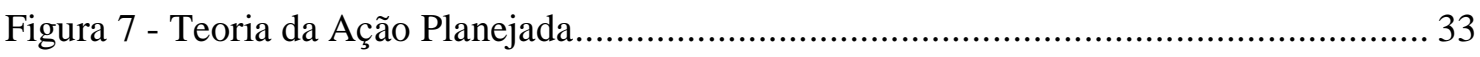

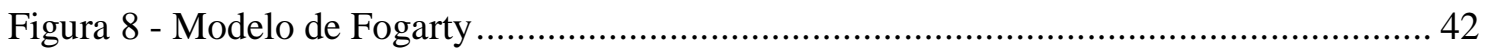

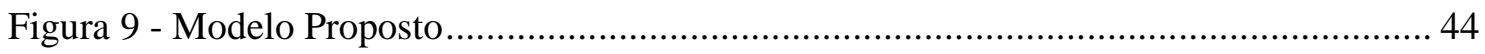

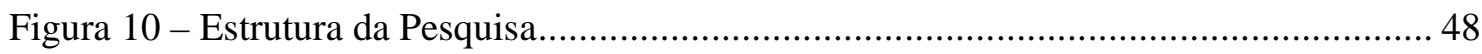

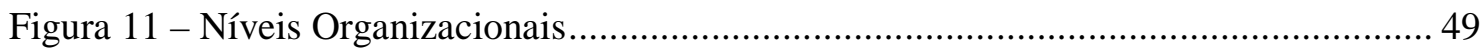

Figura 12 - Taxa de Frequência de Acidentes $(*)$.......................................................... 58

Figura 14 - Número de Acidentes por Gerência no Setor X............................................... 60

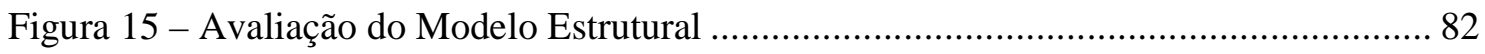

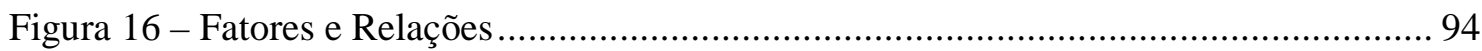




\section{INTRODUÇÃO}

Todos os anos no Brasil milhares de trabalhadores sofrem lesões durante a realização de suas atividades laborais. De acordo com dados extraídos do Anuário de Acidentes do Trabalho (2011), publicado pelo Ministério da Previdência Social, em 2011 no Brasil foram registrados 711,2 mil acidentes de trabalho sendo que destes aproximadamente 730 foram fatais. Os custos previdenciários associados a estes acidentes são da ordem de 600 milhões de reais por ano ao governo, sem contabilizar outros que recaem diretamente sobre as empresas e aos próprios acidentados.

De modo a reduzir este custo para a sociedade bem como todo o sofrimento humano envolvido na ocorrência de acidentes de trabalho, esforços tem sido realizados no campo da Segurança do Trabalho, principalmente a partir dos anos 70 .

Observa-se que "O campo da segurança e da saúde industriais deu um salto gigantesco nos Estados Unidos no início da década de 1970" (ASFAHL, 1999, p.79). A OSHAOccupational Safety and Health Administration trouxe para a indústria americana "[...] um conjunto de regras obrigatórias para a segurança e saúde do trabalhador, prescritas pelo governo federal" (ASFAHL, 1999, p.80), formando assim a base para a realização de inspeções, notificações e estabelecimento de penalidades. Em 1978 o Ministério do Trabalho do Brasil promulga um conjunto de Normas Regulamentadoras que definem as responsabilidades dos empregadores, empregados e o do governo, a função dos profissionais de segurança e um conjunto de requisitos técnicos mínimos em relação às condições e práticas de segurança do trabalho no país.

Em meados dos anos 1980 os elementos chamados essenciais nos programas tradicionais de segurança eram constituídos por reuniões, inspeções, investigações de acidentes e análises de segurança nas tarefas (PETERSEN, 1996, p.66). "A OSHA publicou um guia em 1980 sugerindo que todas as companhias americanas deveriam seguir todas essas práticas." 1 .

\footnotetext{
${ }^{1}$ OSHA published a guideline in the 1980s suggesting that all companies should follow all of these practices. (PETERSEN, 1996, p.66)
} 
Tradicionalmente a Segurança no Trabalho e a Saúde Ocupacional têm colocado foco sobre o controle do ambiente físico e também em procedimentos de trabalho como esforços para prevenir a ocorrência de acidentes (FOGARTY, 2010), o que reforça o foco sobre os sistemas de gestão.

\begin{abstract}
"Exemplos incluem a documentação de procedimentos detalhados desenhados para prover a forma mais segura de realizar tarefas, padrões que orientam como dar continuidade a tarefas não completas entre colegas de trabalho, elaboração de guias de segurança bastante específicos sobre como operar equipamentos e o uso de equipamentos de proteção individual". ${ }^{2}$
\end{abstract}

Ampliando a discussão, Petersen (1996, p. 29) nos anos 1980 desenvolve modelo para a ocorrência de acidentes no qual afirma que estes são causados por de falhas de sistema e erros humanos. Falhas de sistema significam falhas de gestão "[...] para identificar e corrigir os perigos; todo o conjunto de condições inseguras; e inclui a falta de sistemas, padrões e procedimentos necessários para lidar com as causas de acidentes.” 3 . Erros humanos estão ligados à sobrecarga de trabalho (física, fisiológica ou psicológica), tomada de decisões erradas e a "armadilhas" relacionadas à incompatibilidade da situação do trabalho com o trabalhador e ao desenho do ambiente físico de trabalho (PETERSEN, 1999, p. 32).

Estudos suportados por diversos autores entre 1971 e 1996 demostram que a maior parte das causas dos acidentes está relacionada ao comportamento inseguro no trabalho ou a erros humanos, onde mais de $90 \%$ dos acidentes estudados tiveram estas causas como sendo as principais (SEO, 2005). O termo fator humano "[...] foi utilizado em estudos com diversos significados, tais como o comportamento em relação à segurança, a predisposições e a características cognitivas e motivacionais." 4 (TOMAS, 1999).

Assim, uma abordagem que considere os fatores humanos no estudo dos acidentes de trabalho deve procurar contextualizar o comportamento no ambiente de trabalho, reconhecer diferenças individuais entre os trabalhadores e analisar fatores psicológicos como influenciadores do comportamento em relação à segurança. (FOGARTY, 2010).

\footnotetext{
2 "Examples include the documentation of detailed procedures designed to provide the safest way of completing tasks, procedures for handing over uncompleted tasks to colleagues, strict safety guidelines for the operation of machinery, and the wearing of personal protective equipment." (FOGARTY, 2010).

3 "[...] to identify and correct the hazard/it includes the whole range of unsafe conditions/ and it includes the lack of systems, standards, and procedures needed to deal with accident causes. (PETERSEN, 1996, p. 37).

4 "[...] has had different meanings, such as safe behaviors, proneness, cognitive and motivational characteristics” (TOMAS, 1999).
} 
Petersen (1996, p.63) também considera as "[...] causas sistêmicas de incidentes sob duas perspectivas: (1) quando o sistema de gestão não lida de forma adequada com situações e condições que podem ferir pessoas, e causar perdas; (2) quando o sistema de gestão cria um ambiente que torna mais provável uma pessoa errar." 5 .

Uma questão que ainda persiste é a razão que leva os trabalhadores a se comportarem de modo inseguro (TOMAS, 1999).

Pesquisadores por volta de 1980 começam a publicar estudos em relação a programas de segurança no trabalho, afirmando que não existem elementos essenciais em um programa. Segundo esse autor cada organização deve determinar o que melhor deve ser a ela aplicado e que a cultura organizacional é o que determina sua efetividade. (PETERSEN, 1996, p. 66).

As questões culturais podem transformar-se em entraves ou obstáculos significativos para as mudanças requeridas nas organizações quando da implantação de um Sistema de Gestão da Segurança do Trabalho (FILHO, ANDRADE e MARINHO, 2011).

Assim, "características organizacionais parecem ser um fator importante na explicação de acidentes" ${ }^{6}$ (TOMAS, 1999). As investigações de grandes desastres industriais nos anos 80 abriram um novo campo de estudos e perspectivas, pois revelaram que as causas raiz envolviam mais do que falhas técnicas ou humanas (SEO, 2005).

Em 1986 com a publicação do relatório de investigação do acidente ocorrido na usina nuclear de Chernobyl, o ambiente organizacional foi considerado como fator contribuinte nas causas de acidentes. A ocorrência de falhas organizacionais, humanas e administrativas foi relacionada à cultura da organização, não apenas em relação ao pessoal diretamente envolvido com a operação da planta de Chernobyl, mas também de toda a indústria nuclear na União Soviética nesta época. (IAEA,1986).

\footnotetext{
5 "[...] system causes of incidents from two standpoints: (1) when the management system does not adequately deal with situations and conditions that might hurt people, and causes loss; and (2) when the management system creates an environment that makes it more likely for a person to err.” (PETERSEN, 1996, p. 63).

6 "Organizational characteristcs seems to be an important factor in the explanation of accidents"
} 
A investigação desse acidente e outros abriram espaço para estudos relacionados à cultura e clima de segurança nas organizações bem como sobre a relação destes com o comportamento das pessoas.

Os estudos de clima de segurança se destacam na literatura e algumas das principais dimensões analisadas estão relacionadas à importância de programas de treinamento, à adoção de práticas de segurança, medidas de controle e reconhecimento de riscos e ao envolvimento da alta liderança e da supervisão com questões relacionadas à segurança (ZOHAR, 1980; BROWN e HOLMES, 1986; WILLIAMSON et al.,1997; SEO, 2004).

O envolvimento da liderança na Segurança do Trabalho tem sido objeto de vários estudos ao longo das últimas três décadas. Zohar (1980) utilizou o termo "clima de segurança" em seus trabalhos e demonstrou que as atitudes percebidas da liderança em relação à segurança é um dos seus mais importantes fatores.

Trazendo uma abordagem da Psicologia para esta discussão, a Teoria da Ação Planejada foi desenvolvida com o interesse por predizer e entender o comportamento, ao definir a intenção em realizá-lo considerando o controle que o indivíduo possui sobre esse comportamento (FISHBEIN e AJZEN, 1975). Esta teoria provê um “[...] enquadramento teórico que pode ser utilizado para determinar em que extensão as percepções capturadas no clima de segurança influenciam as atitudes e os comportamentos em relação à segurança" 7 (SWARTZ e DOUGLAS, 2009). Essa pode, portanto servir como referencial para um modelo que explique o comportamento dos trabalhadores.

\footnotetext{
7 “[...] provides a sound framework to determine the extent to which perceptions of safety climate influence various safety atitudes and behaviors.”
} 


\section{OBJETIVOS DA PESQUISA}

Este trabalho tem como objetivo geral identificar fatores que explicam o comportamento dos trabalhadores em relação à segurança bem como analisar a relação existente entre esses fatores. O comportamento dos trabalhadores em relação à segurança é um aspecto crítico na prevenção de acidentes. A compreensão dos fatores que o explicam pode conduzir a ações que contribuam com a redução dos acidentes nas organizações.

A Teoria da Ação Planejada foi desenvolvida com o interesse em predizer comportamentos intencionais das pessoas e tem como base a existência de três tipos de crenças: crenças comportamentais, crenças normativas e crenças sobre controle (AJZEN, 1991). Outro aspecto relevante no estudo de um comportamento relacionado à segurança é o papel do compromisso da gerência e do suporte dos supervisores diretos no conjunto de esforços de prevenção de acidentes (SEO, 2004).

Tendo em vista a importância do ambiente organizacional nas questões relacionadas à segurança do trabalho, foi escolhida uma empresa industrial de grande porte para a realização desta pesquisa.

Para a operacionalização deste estudo foram definidos três objetivos específicos:

(1) Analisar o contexto organizacional relacionado à segurança no trabalho na empresa estudada;

(2) Avaliar a compreensão do comportamento dos trabalhadores em relação à segurança, utilizando os construtos e relações propostos pela Teoria da Ação Planejada;

(3) Avaliar a influência da supervisão direta como fator que explique o comportamento dos subordinados em relação à segurança;

O primeiro objetivo específico deste estudo consiste em entender as práticas de segurança na organização estudada através do levantamento de suas políticas, procedimentos e regras de segurança e do levantamento de algumas atividades de risco realizadas pelos trabalhadores. 
O segundo objetivo específico procura investigar as relações entre os construtos que compõe a Teoria da Ação Planejada, ou seja, como as Atitudes dos trabalhadores, as Normas Subjetivas às quais os mesmos estão sujeitos e o Controle Percebido que os mesmos têm sobre determinados comportamentos em relação à segurança, influenciam a Intenção em realizá-los e a percepção em relação à sua realização propriamente dita.

O terceiro objetivo específico consiste em avaliar a influência que o compromisso da supervisão direta em relação à segurança, sob o ponto de vista da percepção dos trabalhadores, tem em relação ao comportamento desses.

Como contribuição desta pesquisa para a teoria, este trabalho procura avaliar um modelo baseado na Teoria da Ação Planejada como ferramenta para explicar o comportamento em relação à segurança dos trabalhadores dentro de uma organização brasileira.

Como contribuição para os gestores da organização estudada, este trabalho procura fornecer informações sobre o ambiente organizacional que tenham relação com o comportamento dos trabalhadores e que possam fundamentar a tomada de ações gerenciais para melhorar seu desempenho em questões relativas à Segurança do Trabalho.

A relevância deste estudo pode ser justificada considerando o aumento no número de acidentes registrados no Brasil entre os anos de 2010 e 2011 (ANUÁRIO DE ACIDENTES DO TRABALHO, 2011). Este estudo também pode ser justificado, pois não foram encontrados estudos no Brasil baseados na Teoria da Ação Planejada com o objetivo de entender o comportamento dos trabalhadores em relação à segurança.

Este trabalho está estruturado em sete partes: a primeira seção tratou da introdução. A segunda parte trouxe os objetivos da pesquisa, suas contribuições e justificativas.

Com base nos objetivos propostos, a terceira parte do trabalho apresenta uma pesquisa bibliográfica dividida em três seções: uma sobre diferentes abordagens de Segurança do Trabalho ao longo do tempo; a seguinte sobre o conceito de Clima de Segurança; e a última sobre a Teoria da Ação Planejada. 
A revisão da literatura foi desenvolvida através da consulta a artigos acadêmicos divulgados em revistas especializadas, tais como Journal of Applied Psychology, Journal of Organizational Behavior, Journal of Safety Research, Safety Science, Journal of Occupational and Organizational Psychology, The Academy of Management Review, Journal of Operations Management e livros especializados nos temas relacionados.

A quarta parte trata sobre a metodologia de pesquisa proposta, começando pela apresentação do modelo conceitual utilizado neste estudo, seguidos pela classificação da pesquisa, sua estruturação, necessidades, fontes, técnicas e instrumentos de coleta de dados bem como as técnicas de análises de dados utilizadas.

A quinta parte trata das etapas de preparação e execução da pesquisa, onde foram levantados dados secundários para a definição de seu escopo, caracterização da área de estudo na organização e levantamento dos possíveis comportamentos de estudo. Nessa parte também são descritas as etapas de construção, validação e aplicação do questionário utilizado para a coleta dos dados primários.

$\mathrm{Na}$ sexta parte são analisados os dados obtidos tendo em vista os objetivos propostos para esse trabalho. São analisadas as respostas dos questionários aplicados, a compilação das entrevistas realizadas e os dados secundários.

A sétima e última parte traz as conclusões do trabalho, suas limitações e sugestões para estudos futuros. Por fim são apresentadas as referências e apêndices. 


\section{REVISÃO TEÓRICA}

Este capítulo apresenta-se dividido em três partes: a primeira traz uma evolução histórica da Segurança no Trabalho; a segunda parte apresenta conceitos e estudos sobre Clima de Segurança, suas relações com o comportamento dos trabalhadores e de suas lideranças; a terceira parte apresenta a Teoria da Ação Planejada, incluindo seus fundamentos e estudos que a utilizaram em aplicações relacionadas à Segurança no Trabalho.

\subsection{Causa dos Acidentes de Trabalho}

O termo "Segurança" no trabalho segundo Benite (2004, p.19) refere-se ao estado de "estar livre de riscos inaceitáveis que causem danos", que é compatível com a definição da OSHAS (1999, p.9) que define Segurança como "condições e fatores que afetam o bem-estar de funcionários, trabalhadores temporários, pessoal contratado, visitantes e qualquer outra pessoa no local de trabalho".

Até 1931, os profissionais de segurança "[...] tendiam a concentrar seus trabalhos na identificação e implantação de medidas físicas preventivas como forma de evitar a ocorrência de acidentes, atuando na colocação de proteções de máquinas, limpeza e organização das áreas de trabalho, planos de inspeção nas áreas de trabalho, aparentemente na crença de que as condições físicas do local de trabalho eram causadoras dos acidentes." 8

Em 1931, Heinrich, em seu livro Industrial Accident Prevention, apresenta a Teoria dos Dominós que é baseada na crença de que a principal razão por traz dos acidentes estava relacionada às pessoas e apresenta dez axiomas para a segurança industrial, bem como propõe um modelo causal para a ocorrência de danos e acidentes. Para sua época, o autor foi considerado um revolucionário no campo da Segurança no Trabalho (PETERSEN, 1996, p. xiv).

\footnotetext{
8 “[...] tended to concentrate on physical preservative measures such as machine guarding, housekeeping, and inspection, apparently in the belief that physical conditions cause accidents" (PETERSEN,1996)
} 
s axiomas apresentados pelo autor são:

1. A ocorrência de um dano invariavelmente foi resultante de uma completa sequência de fatores, sendo o seu antecessor um acidente;

2. Os atos inseguros das pessoas são responsáveis pela maioria dos acidentes;

3. A pessoa que sofre uma lesão incapacitante (permanente) causada por um ato inseguro escapou desta lesão por pelo menos 300 vezes antes de se ferir, repetindo o mesmo ato inseguro;

4. Não há controle sobre a gravidade de uma lesão. A ocorrência de um acidente pode ser prevenida;

5. As quatro razões básicas para a ocorrência de atos inseguros (atitude imprópria do trabalhador, falta de conhecimento ou habilidade, inadequação de condições físicas e ambiente mecânico ou físico inadequado) proveem um guia para a seleção da medida corretiva apropriada;

6. São quatro os métodos para prevenir acidentes: revisão de engenharia, persuasão e apelo, ajuste de conduta pessoal e disciplina;

7. Métodos que são válidos para controlar a qualidade, custos e quantidade de produção são análogos aos métodos para prevenir acidentes;

8. Os gestores têm a melhor oportunidade e habilidade de iniciar um trabalho de prevenção, portanto devem assumir esta responsabilidade;

9. O Supervisor é o homem chave na prevenção de acidentes industriais. Sua aplicação na arte de supervisionar e controlar o desempenho dos trabalhadores é o fator de maior influência na prevenção de acidentes;

10. O incentivo humanitário na prevenção de lesões causadas por acidentes é suplementado por dois fortes fatores econômicos: (1) o estabelecimento seguro é eficiente em relação à produtividade e o inseguro é ineficiente; (2) o custo total de um acidente é cinco vezes maior que os custos diretos envolvidos no mesmo (Heinrich, 1959, p.13-14).

Segundo Petersen (1996, p. xiv), os axiomas trazem a dica mais valiosa já descoberta para o controle de acidentes que é o comportamento humano. Heinrich (1959) traz também algumas abordagens na tentativa de controlá-lo que, segundo Petersen (1996, p. xiv) foram em sua maioria condenadas a falhar.

Baseados nos axiomas de Heinrich, Petersen,(1996, p. xv) destaca ações ou programas de Segurança no Trabalho que envolvem o treinamento dos empregados, em que assumem que esses não sabem reconhecer a diferença entre o que é certo ou errado em relação a procedimentos operacionais bem como o modo seguro de realizar o trabalho. O treinamento dos Supervisores também é ponto recorrente nos programas de Segurança o que tem relação com o nono axioma de Heinrich. O autor também destaca a utilização de sistemas de informações e a utilização de meios para alertar os trabalhadores sobre os riscos do trabalho.

Como desdobramento dos axiomas, a Teoria dos Dominós é formulada com base na existência de cinco fatores que ao ocorrerem em sequência resultam em lesões para os trabalhadores (HEINRICH, 1959, p.14), conforme apresentado na figura 1. 


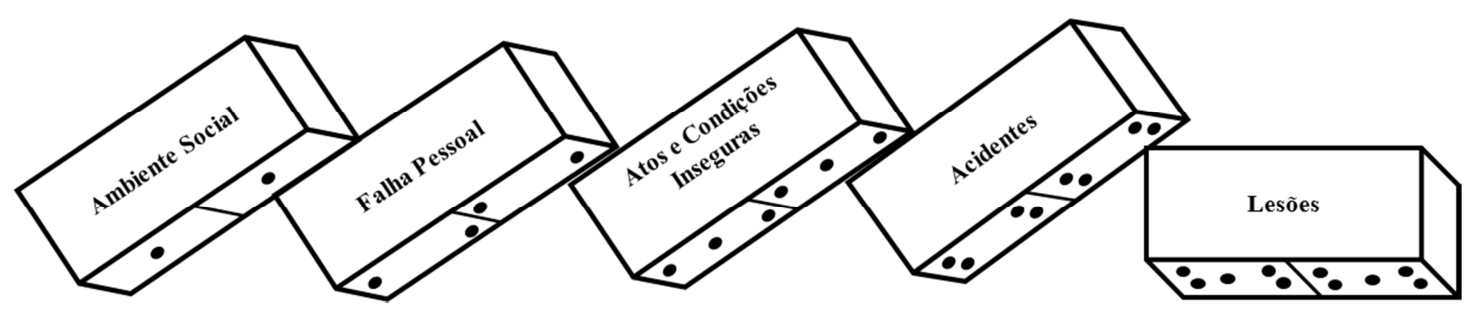

Figura 1 - Os cinco fatores na sequência de acidentes

FONTE: adaptado de HEINRICH (1959, p.13)

A teoria postula que uma lesão é causada por um acidente e que este por sua vez é causado por condições ou atos inseguros. Condições ou atos inseguros são causados por falhas de pessoas que podem ser adquiridas ou herdadas tais como imprudência, temperamento violento, nervosismo, excitação, desconsideração ou ignorância de práticas seguras. Estas por sua vez são causadas pelo ambiente social (HEINRICH, 1959, p.14).

Nessa lógica, a ocorrência de uma lesão que pode ser evitada é a consequência natural de uma série de eventos ou circunstâncias, que ocorrem em ordem fixa. Um fator é dependente do outro e ocorre devido ao outro, assim podendo ser comparado a uma fila de dominós que colocados e alinhados um em relação ao outro faz com que a queda do primeiro dominó inicia a queda da fila inteira (HEINRICH, 1959, p. 15).

O mesmo autor traz também os conceitos de condição insegura e ato inseguro fundamentando toda sua teoria com base em estudos realizados nos registros de acidentes de trabalho realizados na década de 1950 .

Os dados levantados pelo autor mostram que em mais de $85 \%$ dos acidentes os atos inseguros, ou seja, o comportamento do trabalhador em relação à segurança esteve presente pelo menos como uma das causas dos acidentes. (HEINRICH, 1959, p.21)

Outra abordagem sobre as causas dos acidentes de trabalho considera que falhas no sistema de gestão podem levar à ocorrência de acidentes. 


\begin{abstract}
"Teorias mais novas sobre Segurança disputam com a Teoria dos Dominós e a substituem com uma teoria de múltiplas causas. Essa teoria afirma que os acidentes são causados pela combinação de diversos fatos, todos errados, que combinam em um ponto no tempo resultando assim um dano. Essa teoria sugere que atos, condições e o acidente em si são sintomas de algo errado no sistema de gestão da organização. Nesse caso a função da Segurança do Trabalho não é remover o sintoma, mas sim descobrir o que está errado no sistema" 9 (PETERSEN, 1996, p.xiv).
\end{abstract}

Em estudo realizado por Benite (2004, p.162) em empresas de construção civil, afirma-se que um Sistema de Gestão de Segurança e Saúde no Trabalho pode propiciar a melhoria do desempenho em relação a este tema na empresa, como intuitivamente pode se esperar.

Atualmente ainda perduram dois princípios elaborados por Heinrich: o primeiro de que a causa primária dos acidentes são as pessoas; o segundo de que segurança é um problema da gestão e que deve ser resolvido através do gerenciamento. Uma área de grande influência está relacionada à teoria do gerenciamento particularmente nos quais novos conceitos de teoria comportamental são utilizados (PETERSEN, 1996, p. xvi). Nesta linha, “[...] enquanto a gestão deve controlar as condições de trabalho e o comportamento dos empregados, a área prioritária de preocupação para os profissionais de segurança é o controle comportamental". ${ }^{10}$

Petersen (1996, p.63) também considera as "[...] causas sistêmicas de incidentes sob duas perspectivas: (1) quando o sistema de gestão não lida de forma adequada com situações a condições que podem ferir pessoas, e causar perdas; (2) quando o sistema de gestão cria um ambiente que torna mais provável uma pessoa errar." ${ }^{11}$.

O ambiente social onde os indivíduos trabalham já havia sido apontado por Heinrich com o fator que inicia a sequência que culmina com uma lesão no trabalhador. Petersen (1996, p. 66) afirma que "a cultura da organização determina o tom para tudo em relação à

\footnotetext{
9 "Newer safety theory disputes this domino theory and replaces it with a multiple-causation theory. The multiple-causation theory states that accidents are caused by the combination of a number of things, all wrong, which combine at one point in the time in an injury. This theory suggests that the act, the conditions, and the accident itself are all symptoms of something wrong in the management system. The role of safety is not to remove the symptom, but to find out what is wrong with the system." (PETERSEN, 1996, p. xiv)

10 "[...] while management must control both the condition that exist and the behavior of employees, the area of primary concern for safety professionals is behavior control”. (PETERSEN,1996, p.xvii)

11 "[...] system causes of incidents from two standpoints: (1) when the management system does not adequately deal with situations and conditions that might hurt people, and causes loss; and (2) when the management system creates an environment that makes it more likely for a person to err." (PETERSEN, 1996, p. 63).
} 
segurança". ${ }^{2}$. Complementa que em algumas culturas segurança é considerado fator chave e que em outras não é considerada importante. (PETERSEN, 1996, p. 66)

\subsection{Clima de Segurança}

A investigação de grandes desastres industriais nos anos 1980 abriu um novo campo de estudos e perspectivas quando suas respectivas investigações revelaram que as "causas raízes desses desastres envolveram mais do que falhas técnicas ou humanas" (HALE et al.1998, p.4).

Segundo o relatório da IAEA (1986) sobre o acidente na usina nuclear de Chernobyl em 1980, o acidente ocorreu devido a uma cultura de segurança deficiente, não apenas na planta de Chernobyl, mas de todo o complexo soviético em relação ao projeto, à operação e às organizações reguladoras de usinas nucleares que existiram naquele tempo. $\mathrm{O}$ documento traz também que uma cultura de segurança requer dedicação total, complementando que nas usinas nucleares esta é primeiramente gerada pela atitude dos gestores das organizações envolvidas em seu desenvolvimento e operação.

A utilização do termo "cultura de segurança" no relatório abre precedente para uma discussão semântica e acadêmica sobre o termo, que merece aprofundamento. A discussão diz respeito à utilização de dois conceitos relativos às ciências comportamentais, que são os conceitos de cultura organizacional e clima organizacional.

A seguir são apresentados os conceitos de Cultura e Clima Organizacionais.

\subsubsection{Cultura e Clima Organizacionais}

Vários autores têm debatido a utilização, validade e limitações destes conceitos, na tentativa de entender o modo como pessoas que participam das organizações as vivenciam. (SCHNEIDER, 2000, p. Xvii).

Cultura organizacional pode ser definida como

12 "The culture of the organization sets the tone for everything in safety". (PETERSEN, 1996, p. 65) 
um conjunto de pressupostos básicos que um dado grupo inventou, descobriu ou desenvolveu, como aprendizado da solução de problemas de adaptação externa ou de integração interna, que funcionaram bem o bastante para serem considerados válidos e, sendo assim, ensinados aos novos membros como a forma correta de perceber, sentir e pensar em relação a estes problemas. (SCHEIN, 1984). ${ }^{13}$.

Schein (1984) através de sua interação com um grande número de organizações suporta que a cultura de uma organização deve ser analisada considerando-se diferentes níveis, iniciando com o que é chamado de artefatos visíveis. $\mathrm{O}$ ambiente da organização, a arquitetura de seus prédios, a disposição física das pessoas, do mobiliário, a maneira como as pessoas se vestem, os jargões de linguagem que são utilizados, os documentos que publicam e as estórias contadas na organização. Neste nível, a análise da cultura de uma organização é "perigosa", pois os dados são fáceis de serem coletados, mas difíceis de serem interpretados. Observando os artefatos visíveis é possível descrever como um grupo constrói seu ambiente e quais padrões de comportamento são discernidos entre os membros, mas frequentemente não é possível entender a lógica (o porquê) por traz destes comportamentos.

A análise das razões pelas quais os indivíduos se comportam passa pela análise de um segundo nível de formação da cultura, que são os valores. Os valores são difíceis de observar diretamente, e são frequentemente inferidos por entrevistas com os membros-chave da organização ou no conteúdo de artefatos como quadros de aviso e documentos. Durante a identificação destes valores observa-se que eles são apenas o que é uma expressão manifesta, refletindo o que as pessoas dizem a respeito dentro de um grau expressivo de racionalização que procura explicar os comportamentos das pessoas na organização. Como os valores levam a comportamentos e os comportamentos se iniciam para resolver problemas que são formulados em primeira instância, os valores vão gradualmente se transformando em hipóteses que justificam as coisas como elas realmente são. Assim as hipóteses que inicialmente são racionais e conscientes, passam pouco a pouco a serem incorporadas pelos membros da organização e tornam-se inconscientes. Estas tornam se os chamados pressupostos básicos da cultura organizacional. (SCHEIN, 1984).

\footnotetext{
13 " [...] is the pattern of basic assumptions that a gives group has invented, discovered, or developed in learning to cope with its problems of external adaptation and internal integration, and the have worked well enough to be considered valid, and, therefore, to be taught to new members as the correct way to perceive, think and feel in relation to those problems". (SCHEIN, 1984)
} 
Uma forma de identificar pressupostos básicos de uma cultura é perceber que determinados temas não estão abertos à discussão. Aqueles que questionarem tais temas podem ser vistos como "ignorantes" ou "insanos" pelos membros de uma organização. (SCHEIN, 1984).

Trazendo para a discussão o conceito de clima organizacional, Schneider (2000) coloca que o comportamento deve ser conceituado como o resultado de um processo de criação de significados (sensemaking) onde estímulos são processados pelos humanos que então se comportam ou talvez até construam as situações nas quais eles respondem.

Segundo Schneider (1975) o conceito de clima organizacional faz referência às percepções que as pessoas têm de seus ambientes de trabalho. Essas percepções são baseadas em eventos reais ou inferidos, ou em práticas e procedimentos que ocorrem no dia a dia da organização.

De acordo com Hammami (2013) existem vários autores que documentam a importância do clima organizacional como determinante em resultados organizacionais. Tais estudos sugerem a existência de certas características do ambiente de trabalho que podem facilitar ou encorajar o processo de aprendizagem organizacional em termos de geração, compartilhamento e aplicação de conhecimento.

Schein (2000) concebe clima organizacional como um conceito que precede a cultura. O clima organizacional é um reflexo e uma manifestação de suposições culturais. O autor coloca que o clima organizacional pode ser mudado somente no grau em que o clima desejado é compatível com os pressupostos básicos da cultura da organização.

Um ponto de destaque em relação ao clima é que este pode ser focado, avaliando assim alguma área de interesse. O clima é manifestado sobre variadas dimensões e deve ser estrategicamente focado para ser útil. Pode se falar em clima de "alguma coisa" tal como clima para serviços, para segurança, para aprendizagem, etc. (SCHNEIDER, 2000).

O clima tem sido avaliado metodologicamente através de questionários e posterior análise quantitativa, utilizando estatística complexa. $\mathrm{O}$ foco das pesquisas de clima tem sido mais em mensurar as percepções. Em relação à cultura as pesquisas utilizam métodos em geral qualitativos e apresentam limitações em relação à documentação utilizada. O clima pode ser entendido pelas situações que ocorrem nas organizações que são percebidas pelas pessoas, 
enquanto que a cultura pode ser entendida como sendo os motivos que explicam as situações descritas (SCHNEIDER, 2000).

\subsubsection{Dimensões do Clima de Segurança}

Em 1980, Zohar publica uma pesquisa na qual utiliza o termo clima de segurança e define as dimensões que compõe este construto. Seo (2004) apresenta um compêndio de 16 estudos de clima de segurança realizados entre 1980 e 2003 bem como comentários sobre a validação das escalas de clima propostas.

No campo da Segurança do Trabalho o Clima de Segurança tem importância devido a sua utilização como um indicador confiável e válido que pode oferecer vantagens em relação aos indicadores mais tradicionais utilizados nesta área tais como a taxa de frequência dos acidentes e os relatórios de investigação. (SEO, 2004). O clima de segurança como indicador

pode oferecer informações sobre problemas de segurança antes que eles se tornem acidentes e ferimentos. (SEO, 2004).

Sendo os indicadores tradicionais reativos (tratam sobre algo que já ocorreu, um acidente ou lesão, por exemplo), estes não fornecem informações sobre problemas específicos dos locais de trabalho, principalmente considerando o fato de que os acidentes em geral são eventos raros quando comparados aos perigos e aos incidentes que ocorrem de forma dispersa nos locais de trabalho. Os indicadores tradicionais também não fornecem um meio para avaliar a exposição ao risco dos empregados. (SEO, 2004).

Pesquisas têm revelado crescentes evidências de que o clima de segurança está associado a práticas de segurança, acidentes e comportamentos em relação à segurança (SEO, 2004).

O Quadro 1 apresenta um sumário das principais dimensões tratadas nos estudos de clima de segurança citados por Seo (2004), agrupadas por semelhança. 
Quadro 1 - Dimensões Agrupadas de Clima de Segurança

\begin{tabular}{|c|c|c|}
\hline Dimensão Agrupada & Descrição das Dimensões utilizadas nos estudos & Autor \\
\hline \multirow{18}{*}{$\begin{array}{l}\text { Compromisso } \\
\text { Percebido da Liderança } \\
\text { com Segurança }\end{array}$} & Management attitudes toward safety & Zohar (1980) \\
\hline & $\begin{array}{l}\text { Employee perception of how concerned management is } \\
\text { with their well-being. }\end{array}$ & \multirow[t]{2}{*}{ Brown e Holmes (1986) } \\
\hline & $\begin{array}{l}\text { Employee perception of how active management is in } \\
\text { responding to this concern }\end{array}$ & \\
\hline & Management commitment to safety & $\begin{array}{l}\text { Dedobbeleer e Beland } \\
\text { (1991) }\end{array}$ \\
\hline & Maintenance and management issues & \multirow{2}{*}{ Coyle et al. (1995) } \\
\hline & Training and management attitudes & \\
\hline & Safety management & Cheyne et al. (1998) \\
\hline & Supervisor commitment to safety & \multirow{2}{*}{ Mearns et al. (1998) } \\
\hline & Manager commitment to safety & \\
\hline & Upper management's influence on safety & Brown et al. (2000) \\
\hline & Management commitment & Cox e Cheyne (2000) \\
\hline & Management's concern for safety & \multirow{2}{*}{ Lee e Harrison (2000) } \\
\hline & Management's concern for health & \\
\hline & Management commitment to safety & O’Toole (2002) \\
\hline & Perceived management commitment & \multirow{4}{*}{ Mearns et al. (2003) } \\
\hline & Perceived supervisor competence & \\
\hline & Perceived manager competence & \\
\hline & Perceived supervisor competence & \\
\hline \multirow{5}{*}{ Treinamento } & Importance of safety training programs & Zohar (1980) \\
\hline & Training and management attitudes & \multirow{2}{*}{ Coyle et al. (1995) } \\
\hline & Training and enforcement of policy & \\
\hline & Education and knowledge & O’Toole (2002) \\
\hline & Safety policy knowledge & Mearns et al. (2003) \\
\hline \multirow{11}{*}{$\begin{array}{c}\text { Políticas e } \\
\text { Procedimentos }\end{array}$} & Company policy & Coyle et al. (1995) \\
\hline & Company policies towards safety & Diaz e Cabrera (1997) \\
\hline & Policy/procedures & Coyle et al. (1995) \\
\hline & Safety regulation & Mearns et al. (1998) \\
\hline & Safety standards and goals & Cheyne et al. (1998) \\
\hline & Safety rules & Cox e Cheyne (2000) \\
\hline & Quality of training induction & \multirow{2}{*}{ Lee e Harrison (2000) } \\
\hline & General quality of training & \\
\hline & Adequacy of procedures & Glendon e Litherland \\
\hline & Safety rules & $(2001)$ \\
\hline & Written rules and procedures & Mearns et al. (2003) \\
\hline \multirow{6}{*}{$\begin{array}{c}\text { Condições Físicas de } \\
\text { Trabalho }\end{array}$} & Level of risk at workplace & Zohar (1980) \\
\hline & Work environment & Cox e Cox (1991) \\
\hline & Work environment & Coyle et al. (1995) \\
\hline & Hazards to the installation & \multirow{2}{*}{ Mearns et al. (1998) } \\
\hline & Occupational hazards & \\
\hline & Work environment & Cox e Cheyne (2000) \\
\hline \multirow{11}{*}{$\begin{array}{c}\text { Atitude em relação à } \\
\text { Segurança }\end{array}$} & Personal skepticism & \multirow{2}{*}{ Cox e Cox (1991) } \\
\hline & Individual responsibility & \\
\hline & Attitude toward safety in the organization & Niskanen (1994) \\
\hline & Personal motivation for safe behavior & Williamson et al. (1997) \\
\hline & Personal involvement & \multirow{2}{*}{ Cheyne et al. (1998) } \\
\hline & Individual responsibility & \\
\hline & Personal responsibility for safety & Mearns et al. (1998) \\
\hline & Employee involvement and commitment & O’Toole (2002) \\
\hline & Personal priorities and need for safety & \multirow{2}{*}{ Cox e Cheyne (2000) } \\
\hline & Personal appreciation of risk & \\
\hline & Confidence in safety standards & Lee e Harrison (2000) \\
\hline
\end{tabular}




\begin{tabular}{|c|c|c|}
\hline Dimensão Agrupada & Descrição das Dimensões utilizadas nos estudos & Autor \\
\hline & Involvement in safety & \\
\hline & Satisfaction with safety activities & Mearns et al. (2003) \\
\hline \multirow{5}{*}{ Normas de Grupo } & Effects of safe conduct on promotion & \multirow{2}{*}{ Zohar (1980) } \\
\hline & Effects of safe conduct on social status & \\
\hline & Workers' involvement in safety & $\begin{array}{c}\text { Dedobbeleer e Beland } \\
\text { (1991) }\end{array}$ \\
\hline & Group attitudes towards safety & Diaz e Cabrera (1997) \\
\hline & Supportive environment & Cox e Cheyne (2000) \\
\hline
\end{tabular}

FONTE: baseado em SEO (2004)

Um detalhamento dos estudos de Clima de Segurança citados por Seo (2004), seus autores, as amostras utilizadas nos estudos, as dimensões de clima de segurança consideradas e suas limitações estão apresentados no APÊNDICE 1.

\subsubsection{Relação entre Clima de Segurança e Comportamento}

Utilizando o conceito de clima de segurança, alguns autores desenvolveram estudos com o objetivo de relacioná-lo com o comportamento dos trabalhadores em relação à segurança.

Seo (2005) cita estudos (OLIVER et al., 2002; RUNDMO et al., 1998; TOMAS et al., 1999) que tentaram examinar relações estruturais entre o clima de segurança e o comportamento dos trabalhadores em relação à segurança.

O estudo desenvolvido por Rundmo et al. (1998) tinha como objetivo detectar como os funcionários de uma empresa que explora petróleo em alto mar avaliavam os fatores sociais e organizacionais da empresa em dois momentos diferentes: em 1990 e após a intervenção de um programa de segurança em 1994.

Para a realização do estudo foi utilizado um questionário que relacionava construtos relativos ao estresse no trabalho, à carga de trabalho, e à satisfação com relação a medidas de segurança e de contingência, bem como suas atitudes em relação à segurança. (RUNDMO, 1998)

O Quadro 2 apresenta as variáveis de pesquisa utilizadas no trabalho de Rundmo et al. (1998), bem como as dimensões destas variáveis. 
Quadro 2- Variáveis utilizadas no estudo de Rundmo et al. (1998)

\begin{tabular}{|c|c|}
\hline Variáveis & Dimensões \\
\hline Estresse no trabalho & $\begin{array}{ll}\text { - } & \text { Independência } \\
\text { - } & \text { Informação e participação } \\
\text { - } & \text { Expectativas em relação à função desempenhada }\end{array}$ \\
\hline Carga de Trabalho & - Condições Físicas de Trabalho \\
\hline $\begin{array}{l}\text { Satisfação com relação a medidas de segurança e de } \\
\text { contingência. }\end{array}$ & $\begin{array}{ll}\text { - } & \text { Equipamentos de Proteção Individual } \\
\text { - } & \text { Itens contendo instruções de segurança e rotinas } \\
\text { de controle } \\
\text { - } \quad \text { Treinamento em segurança }\end{array}$ \\
\hline $\begin{array}{l}\text { Comprometimento e Envolvimento com relação à } \\
\text { Segurança }\end{array}$ & - $\quad$ Percepção do compromisso próprio e de outros \\
\hline Atitudes em relação à segurança. & $\begin{array}{ll}\text { - } & \text { Metas de produção x segurança } \\
\text { - } & \text { Prioridades de gestão } \\
\text { - } & \text { Fatalismo }\end{array}$ \\
\hline
\end{tabular}

FONTE: adaptado de (RUNDMO et al, 1998)

O objetivo do trabalho de Rundmo et al.(1998) era mostrar se houve mudança nas variáveis acima em relação a dois momentos da organização, antes e depois de um intervenção gerencial através de um programa de segurança.

Os dados foram submetidos a uma análise fatorial e posterior Modelagem de Equações Estruturais utilizando o programa LISREL que resultou no modelo apresentado na Figura 2. O autor concluiu que a Satisfação com a Gerência tem relação positiva sobre a Satisfação da Tripulação e sobre o Compromisso e Envolvimento. Esse apresenta relação positiva com a prioridade de Segurança em relação à Produção, que por sua vez apresenta relação com a não realização de Comportamentos de Risco.

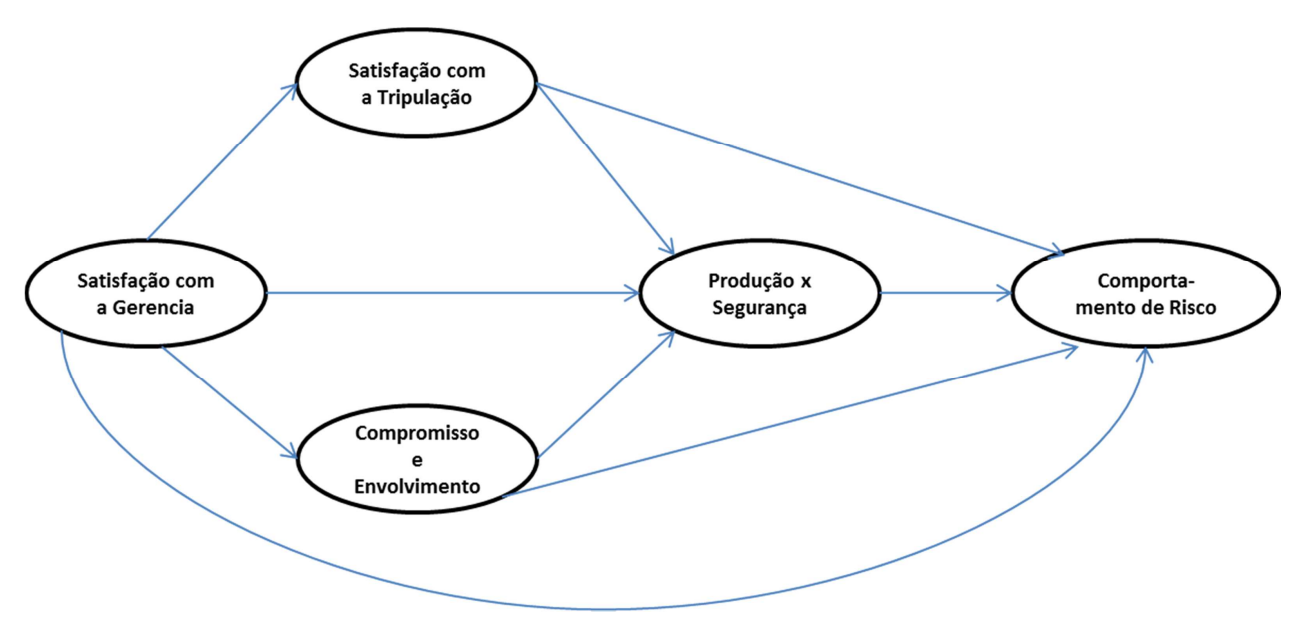

Figura 2 - Modelo de Rundmo

FONTE: adaptado de Rundmo et al.(1998). 
Já o trabalho de Tomas et al. (1999) trazia 3 objetivos: (1) apresentar informações sobre um conjunto de questionários desenvolvidos para medir variáveis dentro de um modelo de equações estruturais; (2) apresentar um modelo de equações estruturais genéricas o bastante para explicar a ocorrência de acidentes em uma grande gama de organizações; (3) buscar a validação deste modelo através de sua aplicação em duas amostras de empresas.

O Quadro 3 apresenta as definições dos construtos utilizados no trabalho de Tomas et al. (1999).

Quadro 3 - Construtos utilizados no estudo de Tomas et al. (1999)

\begin{tabular}{|l|l|}
\hline \multicolumn{1}{|c|}{ Construto } & \multicolumn{1}{c|}{ Definição } \\
\hline Clima de Segurança & $\begin{array}{l}\text { Conjunto de ações empreendidas pela companhia para } \\
\text { melhorar a segurança, incluindo treinamento e } \\
\text { informações sobre segurança, estrutura de segurança e } \\
\text { metas. }\end{array}$ \\
\hline Resposta dos Supervisores em relação a Segurança & $\begin{array}{l}\text { Atitudes dos supervisores em relação a Segurança, } \\
\text { posicionamentos positivos ou negativos dos } \\
\text { supervisores em relação a Segurança e o desempenho } \\
\text { dos supervisores em relação a Segurança. }\end{array}$ \\
\hline $\begin{array}{l}\text { Resposta dos Colegas de Trabalho em relação a a } \\
\text { Segurança }\end{array}$ & $\begin{array}{l}\text { Atitudes dos colegas em relação a Segurança, } \\
\text { posicionamentos positivos ou negativos dos colegas } \\
\text { em relação a Segurança e o desempenho dos colegas } \\
\text { em relação a Segurança. }\end{array}$ \\
\hline Atitude dos Trabalhadores em relação a Segurança & $\begin{array}{l}\text { Própria predisposição dos trabalhadores em relação ao } \\
\text { tema. }\end{array}$ \\
\hline
\end{tabular}

FONTE: adaptado de (TOMAS et al, 1999)

Este trabalho levantou três hipóteses, a saber:

1. A atitude em relação à segurança exerce influência sobre o comportamento inseguro dos trabalhadores;

2. O comportamento inseguro tem relação direta com a ocorrência de acidentes;

3. Os perigos das instalações predizem a real probabilidade de acidentes acontecerem.

Com base nas análises realizadas o autor concluiu que há relação significante entre Clima de Segurança, a Resposta dos Supervisores, a Atitude dos Trabalhadores, o Comportamento Seguro dos trabalhadores, Riscos e a Ocorrência de Acidentes, formando um fluxo lógico, que explica a ocorrência dos mesmos. 
A Figura 3 apresenta o modelo desenvolvido por Tomas et al. (1999), utilizando o programa EQS 3.0 para a Modelagem de Equações Estruturais.

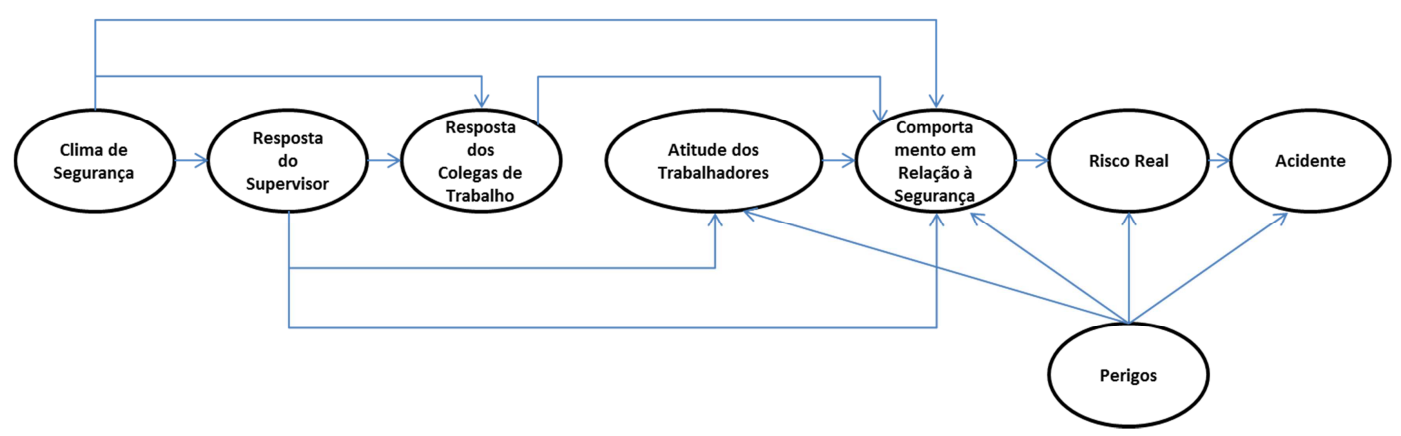

Figura 3 - Modelo de Tomas

FONTE: adaptado de Tomas et al. (1999).

Em seu estudo Oliver et al. (2000) examinou as relações entre fatores psicológicos individuais, variáveis relacionadas ao ambiente de trabalho e à organização, bem como a ocorrência de acidentes.

Os dados foram coletados através de uma amostra randômica da população de trabalhadores da província de Valência na Espanha. Os trabalhadores foram entrevistados com base em questionário durante consulta anual para testes na instituição de saúde "Segurança e Saúde Executiva de Valência”. Médicos da agência foram responsáveis pela aplicação do questionário. Este estudo foi baseado em dados coletados de 525 entrevistas completas.

O Quadro 4 apresenta as definições dos construtos utilizados no trabalho de Oliver et al. (2000).

Quadro 4 - Construtos utilizados no estudo de Oliver et al. (2000)

\begin{tabular}{|c|c|}
\hline Variáveis & Descrição \\
\hline Informações demográficas e sócio demográficas. & $\begin{array}{l}\text { Idade, gênero, nível educacional, ocupação profissional, } \\
\text { tamanho da organização e setor. }\end{array}$ \\
\hline Acidentes no trabalho & $\begin{array}{l}\text { Perguntas sobre a ocorrência de acidentes nos últimos dois } \\
\text { anos de trabalho. }\end{array}$ \\
\hline Envolvimento da organização com segurança & $\begin{array}{l}\text { Perguntas relacionadas a percepções sobre a organização } \\
\text { incluindo itens de suporte social e clima de segurança }\end{array}$ \\
\hline Qualidade das condições de trabalho & $\begin{array}{l}\text { Perguntas relativas à luminosidade, umidade, ruído, carga de } \\
\text { trabalho e rotinização das condições de trabalho. }\end{array}$ \\
\hline Condições de saúde & $\begin{array}{l}\text { Perguntas relativas às condições gerais de saúde dos } \\
\text { entrevistados. }\end{array}$ \\
\hline $\begin{array}{l}\text { Comportamento em relação à segurança no } \\
\text { trabalho }\end{array}$ & $\begin{array}{l}\text { Perguntas relativas à utilização de equipamentos de proteção } \\
\text { individual, realização de atalhos em procedimentos, } \\
\text { aderência às regras de segurança e incompatibilidade entre } \\
\text { trabalhar de forma rápida e segura. }\end{array}$ \\
\hline
\end{tabular}


FONTE: adaptado de (TOMAS et al, 1999)

Utilizando o programa EQS 5.1 foi realizada a Modelagem de Equações Estruturais onde vários modelos foram avaliados com os construtos definidos. $\mathrm{O}$ modelo apresentado na Figura 4 foi o que melhor se ajustou aos dados obtidos.

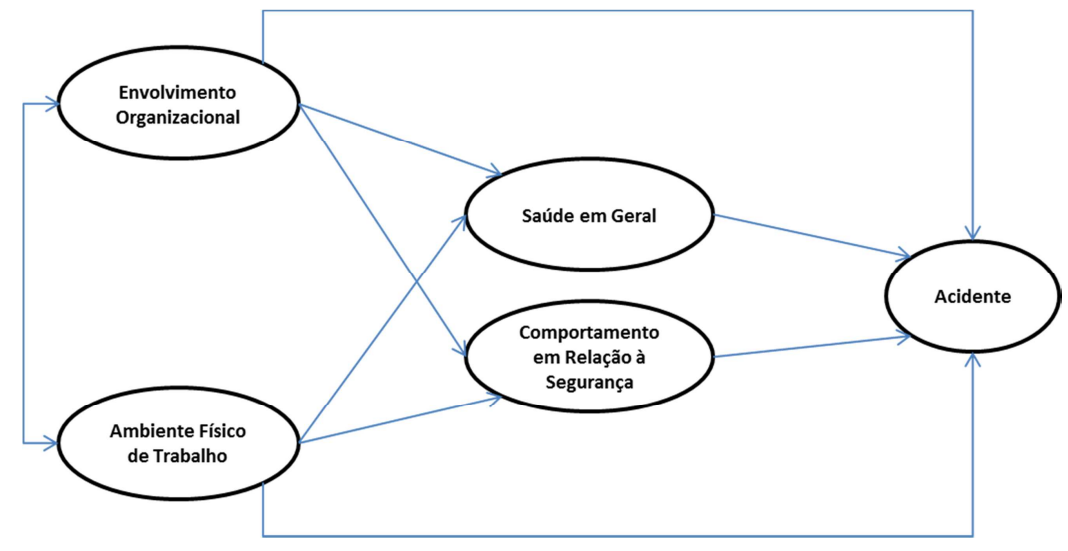

Figura 4 - Modelo de Oliver

FONTE: adaptado de OLIVER et al.(2000).

Este modelo inclui indivíduos, ambiente de trabalho e variáveis organizacionais e, sugere as atitudes em relação ao gerenciamento de segurança e o suporte social têm papel chave em relação à ocorrência de acidentes (OLIVER et al, 2000).

Já em sua abordagem Seo et al. (2005) tentou construir e testar um modelo explicativo para o Comportamento em relação à segurança (comportamento inseguro) no trabalho de modo a revelar os mecanismos pelos quais os fatores apresentados a seguir influenciam o comportamento inseguro de trabalhadores.

O Quadro 5 apresenta as definições dos construtos utilizados no trabalho de Seo et al. (2005). 
Quadro 5 - Construtos utilizados no estudo de Seo et al. (2005)

\begin{tabular}{|l|l|}
\hline \multicolumn{1}{|c|}{ Construto } & \multicolumn{1}{c|}{ Variáveis/Definição } \\
\hline Clima de Segurança Percebido & $\begin{array}{l}\text { Comprometimento da gerência com segurança } \\
-\quad \text { Suporte da supervisão com segurança } \\
\text { - Suporte dos colegas de trabalho com segurança } \\
\text { - Nível de participação dos empregados nos } \\
\text { programas e iniciativas de segurança } \\
\text { Nível de competência dos empregados em relação } \\
\text { ao tema }\end{array}$ \\
\hline Pressão de Trabalho Percebida & $\begin{array}{l}\text { Está relacionado com o excesso de carga de trabalho, } \\
\text { ritmo de trabalho e pressão de tempo. }\end{array}$ \\
\hline Risco Percebido & $\begin{array}{l}\text { Conceito é similar ao conceito de ameaça percebida, } \\
\text { desenvolvido pelo Health Belief Model (HBM) e diz } \\
\text { que as pessoas têm comportamentos de proteção } \\
\text { quando são capazes de antecipar consequências } \\
\text { negativas e desejam se prevenir de ocorrências. }\end{array}$ \\
\hline Perigo Percebido & $\begin{array}{l}\text { Percepção das condições gerais de trabalho como } \\
\text { possíveis causadoras de lesões. }\end{array}$ \\
\hline Barreiras Percebidas & $\begin{array}{l}\text { Conceito relativo à imunidade pessoal e ceticismo em } \\
\text { relação à segurança no trabalho. }\end{array}$ \\
\hline
\end{tabular}

FONTE: adaptado de (SEO et al, 2005)

Os dados foram coletados de 722 trabalhadores da indústria de grãos nos Estados Unidos em 102 diferentes locais de uma companhia multinacional produtora de grãos usando um questionário de 98 itens. Um modelo fatorial de segunda ordem foi utilizado para explicar o comportamento inseguro no trabalho usando modelagem de equações estruturais.

Através da análise dos dados coletados foi obtido o modelo apresentado na Figura 5.

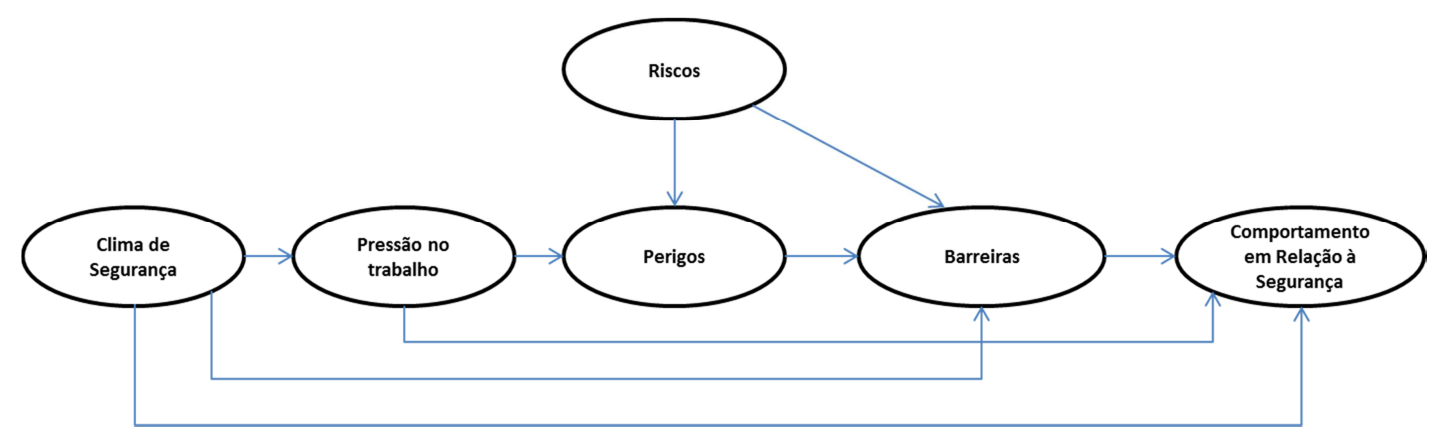

Figura 5 - Modelo de Seo

FONTE: adaptado de Seo et al. (2005) 
Os resultados indicaram que o Clima de Segurança Percebido foi o melhor preditor do comportamento inseguro entre os fatores estudados. (SEO et. al,2005). Nota-se que variáveis relacionadas ao Comprometimento da Gerência com Segurança e ao Suporte da Supervisão com Segurança compõem o Clima de Segurança Percebido, indicando assim a relevância das lideranças em relação ao desempenho em Segurança nas organizações.

\subsubsection{Relação entre Clima de Segurança e Liderança}

Segundo Asfahl $(1999$, p.1) as pessoas em geral desejam ter um local de trabalho seguro e saudável, mas o que estão dispostas a fazer para atingir este valioso objetivo pode variar muito.

Sendo assim, “[...] a direção de cada empresa deverá decidir até que ponto, dentro de um quadro amplo, pretende dar atenção aos aspectos de segurança e saúde”. (ASFAHL, 1999, p.1). "O comportamento do trabalhador é o determinante mais importante para sua segurança, mas esse comportamento não pode sozinho tornar segura uma atividade perigosa" ${ }^{14}$. Assim, “[...] quando a direção não está comprometida com a segurança e a saúde, ela apresenta inúmeras razões sobre a produção e outros argumentos bastante naturais que minam as atitudes em prol da segurança" (ASFAHL, 1999, p.1).

Estudos mostram que o compromisso e o envolvimento dos gestores com segurança no trabalho é o fator mais importante para alcançar um nível satisfatório de segurança (COHEN, 1975; COHEN et al., 1975; SMITH et al., 1978; RUNDMO E SAARI, 1988 apud RUNDMO, 1998).

Muitos estudos foram realizados com foco na identificação de dimensões de clima de segurança como forma de prover um esforço de intervenção efetivo nas organizações em relação à Segurança no Trabalho. Estas pesquisas demonstraram que o comprometimento dos gestores com segurança é uma dimensão presente no clima de segurança. (SEO et al., 2005).

Com o objetivo de buscar a validação de um modelo de intervenção em relação à segurança, Zohar (2002) realizou um experimento em um centro de reparo e manutenção de

14 (ASFAHL, 1999, p.1). 
equipamentos pesados e demonstrou que a atuação dos gestores no nível de Supervisão tem influencia no desempenho do Comportamento dos trabalhadores em relação à segurança, no Clima de Segurança e na utilização de Equipamentos de Proteção Individual. (ZOHAR, 2002).

Zohar (2002) também estudou a influência de características de liderança dos gestores no clima de segurança. Diversas teorias de liderança tem tentado explicar qual o melhor estilo ou a melhor abordagem para maximizar o desempenho de uma pessoa como líder na busca de resultados mais eficazes e produtivos.

Zohar (2002) utiliza conceitos definidos nas teorias acima apresentadas para caracterizar estilos de liderança e relacioná-los com o clima de segurança. Emprestados do Behaviorismo o autor utilizou os conceitos de liderança construtiva (democrática), corretiva (autocrática) e laissez-faire. Definiu liderança transformacional como sendo aquela relacionada a promover a motivação dos empregados em relação às questões de segurança, associando-a aos papéis da alta liderança. Também utilizou em seu trabalho o conceito de liderança transacional como sendo aquela relacionada à aplicação de procedimentos e práticas de trabalho, associando-a ao papel dos supervisores.

Algumas hipóteses validadas pelo estudo de Zohar (2000) foram as seguintes:

- "Uma liderança transformacional e construtiva afetará positivamente o clima de segurança";

- "Uma liderança corretiva e laissez-faire afetará negativamente o clima de segurança;"

- "Uma liderança transformacional estará positivamente relacionada com o clima de segurança e esta relação será mais forte caso a prioridade em segurança seja alta;"

- "Uma liderança construtiva (democrática) estará positivamente relacionada com o clima de segurança e esta relação será mais forte caso a prioridade em segurança seja alta e não relevante caso a prioridade em segurança baixa;"

- “Uma liderança corretiva (autocrática) estará positivamente relacionada com o clima de segurança caso a prioridade em segurança seja alta e negativa caso a prioridade em segurança baixa." 
- "Uma liderança laissez-faire estará negativamente relacionada com o clima de segurança caso a prioridade em segurança seja alta e não relevante caso a prioridade em segurança baixa;"

Este trabalho também demonstra a importância do nível de supervisão na formação do clima de segurança quando comparado aos níveis hierárquicos mais altos da organização.

\begin{abstract}
"Em outras palavras, a liderança transformacional ou construtiva de gerentes seniores pode não exercer o mesmo efeito no clima de segurança e nos resultados de segurança reportados aqui por causa do aumento da distância do poder entre estes líderes e os empregados do chão de fábrica. Assim, o padrão de relacionamento entre liderança e segurança pode depender do nível hierárquico dos líderes" ${ }^{15}$ (ZOHAR, 2000).
\end{abstract}

De modo a complementar às questões levantadas em relação à influência dos níveis hierárquicos, Zohar (2005) realiza estudo em que verifica a existência de alinhamento entre níveis organizacionais diferentes em relação ao clima de segurança.

O autor verifica neste trabalho que existe alinhamento entre os climas de segurança que são percebidos no nível de alta liderança e no nível de supervisão. Estes climas são chamados pelo autor de clima de nível organizacional e clima ao nível de grupo. Este estudo também demonstrou que os efeitos do clima de nível organizacional no comportamento em relação à segurança são mediados pelo clima ao nível de grupo, o que demonstra a relevância do papel da Supervisão na implantação de procedimentos formais e no balanço entre as demandas de produção versus produtividade. (ZOHAR, 2005).

Esse estudo é importante, pois vários autores mencionam a "liderança" ou a "gestão" da empresa como dimensões relevantes do clima de segurança sem deixar clara a existência de alinhamento entre os diversos níveis dessa liderança. Zohar (2005) demonstrou esta ligação.

A literatura também apresenta pesquisas que visam entender o comportamento em relação à segurança a partir da Teoria da Ação Planejada, como é o caso de Swartz (2009), Eliot (2009) e Fogarty (2010).

\footnotetext{
15 "In other words, transformational or constructive leadership of .senior managers may not exert the same effect on safety climate and safety records us reported here because of the increased distance between leaders and shop-floor employees. Thus, the pattern of relationships between leadership and safety may depend on the hierarchical level of the leaders." (ZOHAR,2000)
} 


\subsection{Teoria da Ação Planejada}

As pesquisas em relação à segurança tem utilizado o clima de segurança como um paradigma em si mesmo. Essas utilizam a literatura relacionada à cultura e a clima de segurança explorando apenas temas dentro destes paradigmas. Em áreas da Psicologia ainda existem alguns pontos de conexão que podem ser utilizados em pesquisas sobre o tema. A Teoria da Ação Planejada parece bem adaptada para estabelecer uma relação entre clima e tipos particulares de comportamentos intencionais. (FOGARTY, 2010).

\subsubsection{Conceitos}

A Teoria da Ação Racional e a Teoria da Ação Planejada têm se colocado como ferramentas teórico-metodológicas que apontam relações entre variáveis e se apresentam como capazes de discutir a questão da previsibilidade do comportamento humano em diversos campos do conhecimento como saúde, educação, sociologia, prática clínica, demonstrando poder preditivo significativo. (MOUTINHO et al., 2010).

A Teoria da Ação Planejada surgiu como uma evolução a Teoria da Ação Racional.

“A Teoria da Ação Racional foi inicialmente desenvolvida na década de 1960, por Martin Fishbein $(1963,1967)$, sendo posteriormente revista e expandida em colaboração com Icek Ajzen e outros estudiosos." (MOUTINHO et al., 2010). A teoria admite que os seres humanos são racionais e que avaliam as consequências de seus comportamentos na tomada de decisão em realizá-los. (MOUTINHO et al., 2010).

De acordo com Moutinho et al. (2010), dentre os objetivos principais da Teoria da Ação Racional podem ser destacados o interesse em predizer e entender o comportamento humano em relação a um dado objeto bem como precisar a intenção em realizar tal comportamento.

Considerando os fatores que compõe o modelo em relação ao comportamento deve se

"[...] identificar os determinantes das intenções comportamentais, a saber, as atitudes que dizem respeito ao aspecto pessoal e as normas subjetivas que se referem a influencia social. A teoria traça considerações ainda sobre as crenças dos indivíduos, a avaliação das 
consequências do comportamento, a motivação para concordar com as pessoas que lhe são importantes e as variáveis externas." (MOUTINHO et al., 2010).

O modelo da Teoria da Ação Racional é apresentado na Figura 6.

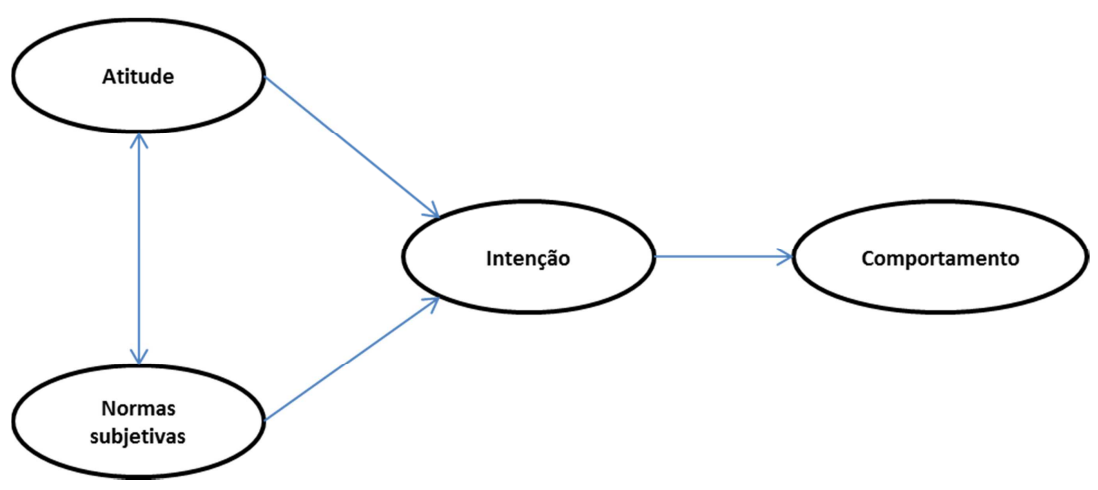

Figura 6 - Teoria da Ação Racional

FONTE: adaptado de (AJZEN, 1985) apud (CARO, 2010, p.51)

Segundo a Teoria da Ação Racional, enquanto a Intenção exerce poder determinante sobre o Comportamento, alguns fatores por sua vez atuam sobre a Intenção, a saber, as Atitudes em relação ao comportamento e as Normas Subjetivas.

Apesar do sucesso da Teoria da Ação Racional, o modelo apresenta limitações, visto que as Intenções e o Comportamento parecem ser influenciados por outros fatores, como por exemplo, os hábitos que foram desenvolvidos no passado. As Intenções refletem de fato somente a motivação a agir, enquanto a execução de uma ação não depende somente desta, mas também do maior ou menor Controle sobre o comportamento. Assim, se um indivíduo possui o pleno controle de uma situação, pode decidir por executar ou não uma ação. (MOUTINHO et al., 2010).

A Teoria da Ação Planejada pode ser considerada como uma extensão da Teoria da Ação Racional, pois mantém sua estrutura original adicionando um terceiro fator que precede a Intenção, chamado de Controle Percebido. (AJZEN, 1991, p.181).

O modelo da Teoria da Ação Planejada é apresentado na Figura 7. 


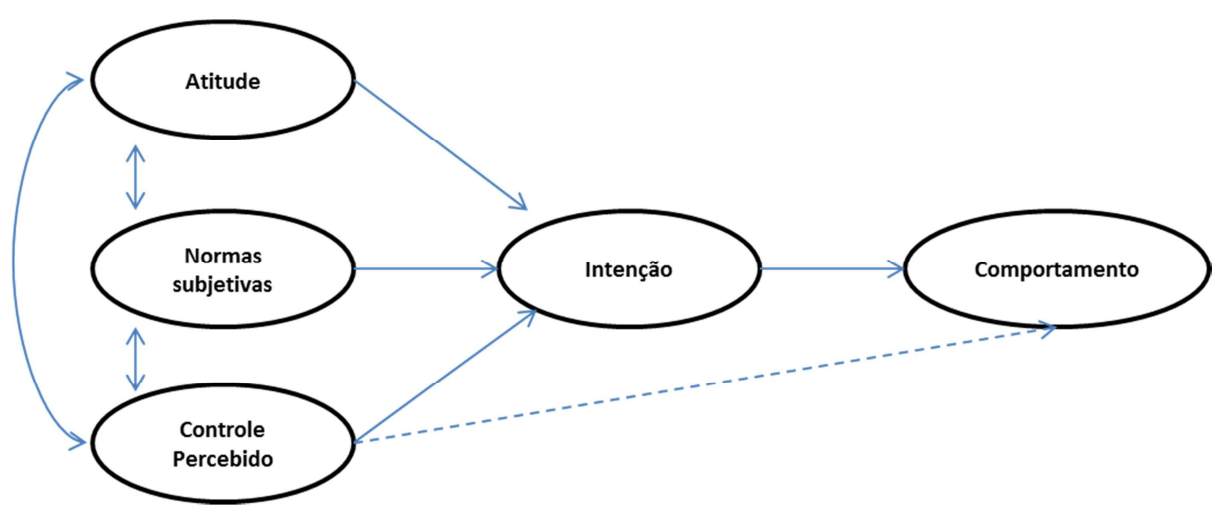

Figura 7 - Teoria da Ação Planejada

FONTE: adaptado de Ajzen (1991, p.182)

Segundo a teoria,

\begin{abstract}
"as pessoas podem carregar uma grande quantidade de crenças em relação a qualquer comportamento, mas elas podem responder a apenas um número relativamente pequeno delas em um dado momento. São estas crenças chamadas salientes que são consideradas predominantes das intenções e ações das pessoas". (AJZEN, 1991, p.189) ${ }^{16}$
\end{abstract}

Para Ajzen (1991, p. 189), de acordo com a Teoria da Ação Planejada, as ações humanas "[...] podem ser influenciada por três tipos de crenças: comportamentais, normativas e de controle".

- Comportamentais: “[...] estas crenças conectam o comportamento com certos resultados ou com atributos relacionados a estes resultados;" ${ }^{17}$.

- Normativas: “[...] dizem respeito à probabilidade de que pessoas importantes ou grupos aprovem ou desaprovam a realização de determinado comportamento" ${ }^{18}$.

- Controle: “[...] são baseadas em parte em experiências passadas de comportamento, mas são usualmente influenciadas por informações de terceiros sobre o comportamento, por experiências adquiridas por amigos, ou por outros fatores que

16 “[...] People can hold a great many beliefs about any given behavior, but they can attend to only a relatively small number at any given moment (see Miller, 1956). It is these salient beliefs that are considered to be the prevailing determinants of a person's intentions and actions." (AJZEN, 1991, p.189)

17 "[...] links the behavior to a certain outcome, or to some other attribute such as the cost incurred by performing the behavior." (AJZEN, 1991, p. 191)

18 "[...] are concerned with the likelihood that important referent individuals or groups approve or disapprove of performing a given behavior.” (AJZEN, 1991, p. 195) 
aumentam ou reduzem a dificuldade percebida de realizar o comportamento em questão". ${ }^{19}$.

\subsubsection{Intenção}

O elemento central do modelo é a Intenção em realizar um Comportamento. As Intenções capturam fatores motivacionais que influenciam o Comportamento. (AJZEN, 1991, p.181).

Ou seja, “[...] As Intenções são indicadores do quanto as pessoas se esforçam para tentar, ou do quanto elas planejam de esforço para realizar determinado comportamento." ${ }^{20} \mathrm{e}$ "[...] são assumidas como disposições para realização do comportamento, estando este sob controle volitivo". (TUCK, 1978 apud MOUTINHO, 2010).

Evidências em relação à influência das Intenções nos Comportamentos foram coletadas em vários estudos (AJZEN, 1991, p.181). "Como regra geral quanto mais forte for a Intenção em realizar um comportamento maior será a probabilidade de realização deste. No entanto, tem se que a Intenção em realizar um comportamento apenas pode refletir a realização deste comportamento se este especificamente depender apenas da vontade das pessoas." ${ }^{21}$.

Desta forma, "Sabe-se que não há uma perfeita correspondência entre Intenções e Comportamento, no entanto, as pessoas geralmente agem em acordo com suas Intenções." (MOUTINHO et al., 2010).

As Intenções podem ser medidas de diversas formas tratando-se de comportamentos relativos

a ações únicas. É preferível escolher um instrumento de medição em que a Intenção do respondente em realizar determinado comportamento possa ser manifesta de forma precisa. Assim, "Uma forma de medição indicada é através de escala bipolar, que pode ser avaliada

19 “[...] based in part on past experience with the behavior, but they will usually also be influenced by secondhand information about the behavior, by the experiences of acquaintances and friends, and by other factors that increase or reduce the perceived difficulty of performing the behavior in question." (AJZEN, 1991, p.196)

20 " [...] they are indications of how hard people are willing to try, of how much of an effort they are planning to exert, in order to perform the behavior." (AJZEN, 1991, p.181)

21 "As a general rule, the stronger the intention to engage in a behavior, the more likely should be its performance. It should be clear, however, that a behavioral intention can lind expression in behavior only if the behavior in question is under volitional control," (AJZEN, 1991, p.181) 
em alternativas de resposta que variam entre totalmente impossível a totalmente possível." (MOUTINHO et al., 2010).

\subsubsection{Comportamento}

Já em relação ao Comportamento, também é questão relevante o modo de mensurá-lo.

"O entendimento e a predição do Comportamento tornam-se demasiadamente arriscados se sua definição não for clara.”. (MOUTINHO et al., 2010).

Deve se atentar na investigação de um comportamento estudado sobre se o que está em observação são atos observáveis ou uma consequência do comportamento. Estes requerem abordagens diferentes. Para serem mensurados é preciso que os comportamentos sejam claramente definidos e exista concordância entre observadores sobre sua ocorrência. (MOUTINHO et al., 2010).

Aspectos relativos ao contexto local e ao tempo onde determinado comportamento ocorre devem ser considerados em sua investigação. A consideração destes aspectos permite uma maior especificação do comportamento. (MOUTINHO et al., 2010).

Seo et al.(2005) utilizou uma escala de porcentagem entre $0 \%$ e $100 \%$ para avaliar o comportamento declarado em relação à segurança. Oliver et al.(2000) e Tomas et al.( 1999) em seus estudos utilizaram escalas para medir comportamentos auto declarados. Também de modo declarado, no trabalho de Rundmo et al. (1998) os respondentes foram perguntados o quão frequente eles estavam engajados em comportamentos de risco.

\subsubsection{Atitude}

Continuando a descrever os fatores que compõe a Teoria da Ação Planejada, temos que Fishbein (1967, p. 257) propõe o fator Atitude. Este autor considera as Crenças Comportamentais na formação das Atitudes dos indivíduos bem como a intensidade relativa das mesmas em relação ao objeto ou atributo associado. 
Segundo o autor, as pessoas passam a ser favoráveis aos objetos quando acreditam que estes possuam características positivas. A "[...] Atitude em relação a determinado comportamento refere-se ao grau em que a pessoa avalia de forma favorável ou não favorável o comportamento em questão." ${ }^{22}$. (AJZEN, 1991, p. 188)

Deste modo, para determinação indireta das atitudes são consideradas as seguintes variáveis: Força das Crenças Comportamentais que o indivíduo possui em relação a um dado comportamento; Avaliação (positiva ou negativa) que o individuo faz das Consequências do comportamento. (MOUTINHO et al., 2010).

\section{Atitude $=\sum$ (Força das Crenças Comportamentais) $\mathbf{x}$ (Avaliação das Consequências)}

De acordo com a equação acima, a força de cada Crença Comportamental deve ser multiplicada pela Avaliação das Consequências de cada crença e todos os produtos resultantes devem ser somados. (MOUTINHO et al., 2010).

Para predizer as atitudes a partir das crenças, faz-se necessário definir os instrumentos de medição de cada uma destas variáveis. "Sugere-se que, num primeiro momento, sejam determinadas as crenças salientes. Como já mencionado anteriormente, dentre o amplo número de crenças que o indivíduo possui, uma quantidade restrita destaca-se como sua base de informações para cada objeto." (MOUTINHO et al., 2010).

Conhecendo as crenças, é importante saber sua força, ou seja, definir "[...] quão confiante é a pessoa de que o comportamento em questão está relacionado a uma dada consequência." ${ }^{23}$ (MOUTINHO et al., 2010).

Sugere-se para a avaliação das crenças medição através de escala bipolar e as alternativas devem variar entre totalmente impossível e totalmente possível. Já para se medir a avaliação das consequências do comportamento, a escala sugerida envolve uma questão do tipo: "tomar determinada ação é", que deve ser avaliada numa variação entre totalmente ruim e totalmente bom. "De posse dos resultados da aplicação de ambas as escalas, a equação apresentada anteriormente pode então ser manipulada e a medição indireta da atitude realizada". (MOUTINHO et al., 2010).

\footnotetext{
22 "[...] attitude toward the behavior and refers to the degree to which a person has a favorable or unfavorable evaluation or appraisal of the behavior in question." (AJZEN, 1991, p. 188)

${ }^{23}$ (MOUTINHO et al., 2010).
} 


\title{
3.3.5 Normas Subjetivas
}

A Intenção em relação a determinado comportamento será mais positiva quando uma pessoa perceber que outras que lhe são importantes acham que esse comportamento deve ser adotado (MOUTINHO et al., 2010). Assim, outro influenciador das Intenções são as Normas Subjetivas.

As Normas Subjetivas dizem respeito à "[...] percepção da pessoa quanto à pressão social exercida sobre a mesma para que realize ou não realize o comportamento em questão". ${ }^{24}$. Elas são determinadas pelas Crenças Normativas e pela Motivação para Concordar com determinado comportamento. (MOUTINHO et al., 2010).

As Crenças Normativas são relacionadas à probabilidade que pessoas ou grupos considerados importantes têm em aprovar ou desaprovar a realização de um determinado comportamento. (MOUTINHO et al., 2010). As crenças normativas reportam-se às pessoas que fazem esta pressão social: família, amigos, professores, etc. (CARO, 2010, p. 50),

Já a Motivação para Concordar com o referente trata se o individuo está motivado ou não em aceitar a pressão exercida pelos seus pares quanto à realização de determinado comportamento. (MOUTINHO et al., 2010).

“As Normas Subjetivas podem ser preditas através do resultado do somatório dos produtos das forças das Crenças Normativas pela a Motivação para concordar com os referentes de cada crença normativa." (MOUTINHO et al., 2010).

\section{Norma Subjetiva $=\sum($ Força das Crenças Normativa $) \times($ Motivação $)$}

Assim,

\begin{abstract}
"Para realizar a medição das Crenças Normativas, deverá ser realizado um procedimento semelhante àquele referente às Crenças Comportamentais. Em primeiro lugar, eliciar as Crenças Normativas salientes através de questionamento livre em que o respondente é convidado a mencionar pessoas e/ou grupos que logo lhe vêm à mente quanto à realização de um dado comportamento. Em seguida, há que se mensurar a força das crenças normativas salientes através de escala bipolar, onde o sujeito deverá indicar o quão provável é o referente assumir dada posição em relação ao comportamento." (MOUTINHO et al., 2010).
\end{abstract}

24 “[...] it refers to the perceived social pressure to perform or not to perform the behavior." (AJZEN, 1999, p. 188) 


\subsubsection{Controle Comportamental Percebido}

A Teoria da Ação Planejada considera que a Intenção de realizar determinado comportamento é resultado, não só da avaliação que o indivíduo faz deste comportamento e da pressão social para exercê-lo, mas de mais um elemento que é o Controle Percebido. (AJZEN, 1991, p.188)

Desta forma, o terceiro influenciador das Intenções é o Controle comportamental Percebido.

O Controle Percebido "[...] refere-se à facilidade ou dificuldade percebida de desempenhar determinado comportamento e assume-se que este reflita experiências passadas bem como impedimentos e obstáculos antecipados". ${ }^{25}$. Assim, "Quanto mais recursos o indivíduo acredita que possua e quanto menos obstáculos ele antecipa, maior será seu controle percebido sobre o comportamento." 26 (AJZEN, 1991, p. 196).

O Controle Percebido é obtido multiplicando-se as Crenças de Controle que o indivíduo tem sobre a presença de fatores Facilitadores ou Bloqueadores de comportamento pela Força Percebida destes fatores. (AJZEN, 1991, p. 196).

\section{Controle Percebido $=\sum$ (Crença em Fatores Bloqueadores ou Facilitadores) $\mathbf{x}$ (Força Percebida de cada Fator)}

Se a percepção de controle sobre determinado comportamento for muito baixa, a probabilidade que um indivíduo tem em efetuá-lo também é baixa, apesar do fato de que a pessoa está de acordo sobre a importância em adotar aquele comportamento e avalie positivamente as consequências do mesmo. Assim, o Controle Percebido irá influenciar a Intenção de executar um determinado comportamento e efetivá-lo. (MOUTINHO et al., 2010).

A percepção de controle tem se demonstrado um importante elemento preditor do Comportamento por estar relacionado "tanto por via indireta com o Comportamento através

\footnotetext{
25 "[...] refers to the perceived ease or difficulty of performing the behavior and it is assumed to reflect past experience as well as anticipated impediments and obstacles.” (AJZEN, 1991, p.188)

26 "[...] the more resources and opportunities individuals believe they possess, and the fewer obstacles or impediments they anticipate, the greater should be their perceived control over the behavior." (AJZEN, 1991, p.196)
} 
da Intenção comportamental, como diretamente ao mesmo sem a mediação intencional." (MOUTINHO et al., 2010).

Finalmente, "dado um nível suficiente de controle atual sobre o comportamento, as pessoas têm expectativas de concluir suas intenções quando a oportunidade surge." (CARO, 2010, p. $55)$.

Como aplicação prática desta teoria, tem-se que a Teoria da Ação Planejada é "[...] particularmente útil e crucial em circunstâncias/projetos/programas nas quais o comportamento das pessoas precisa ser modificado." (MOUTINHO et al., 2010).

\subsection{Modelos de Comportamento em relação à Segurança}

A Teoria da Ação Planejada também tem sido utilizada dentro do campo da Segurança do Trabalho como base de modelos para predizer comportamentos das pessoas em relação a esse tema.

Fogarty,(2010) utilizou a Teoria da Ação Planejada como base para a elaboração de um modelo que relaciona variáveis características de Clima de Segurança com a Intenção dos funcionários em violar procedimentos de manutenção de aeronaves na Força de Defesa da Austrália.

Swartz, (2009) procurou validar que a Teoria de Ação Planejada poderia ser utilizada como mediadora entre o comportamento seguro de motoristas de caminhão de uma companhia de transporte americana e o Clima de Segurança nesta empresa.

Eliot, (2009) utilizou construtos da Teoria da Ação Planejada para explicar a Intenção de motociclistas em correr em diferentes tipos de vias.

Estudo similar foi realizado por Chorlton, (2010) onde a Teoria da Ação Planejada e conceitos relativos a normas morais, comportamentos passados, auto-identidade e 
suscetibilidade percebida foram aplicados para predizer a Intenção de motociclistas em pilotarem acima do limite de velocidade e em velocidades inapropriadas.

De certa forma, “[...] os construtos que constituem a Teoria da Ação Planejada espelham as variáveis em nível individual, grupal e organizacional, mensuradas nos estudos de clima de segurança." ${ }^{27}$, quando são relacionados às Atitudes, Normas Subjetivas e Controle Percebido respectivamente.

No nível individual a Atitude em relação à segurança é frequentemente utilizada como uma variável nos estudos de clima de segurança (FOGARTY,2010).

No nível grupal, o mesmo pode ser afirmado em relação às Normas Subjetivas.

"Estudos de clima também tem olhado a influência das Normas Subjetivas. Indivíduos em organizações tendem a olhar para si mesmos como membros de grupos. As normas desenvolvidas por estes grupos influenciam o comportamento dos empregados que se sentem parte dos respectivos grupos. A inclusão de fatores no nível dos grupos em estudos de clima de segurança é suportada por pesquisas que tem olhado para o papel que as normas estabelecidas por estes grupos desempenham no comportamento seguro". ${ }^{28}$ (HOFMANN e STETZER, 1996; ZOHAR, 2000 apud FOGARTY, 2010).

No nível das práticas organizacionais, demonstrou-se que a "[...] mensuração do controle sobre segurança tem paralelo muito próximo com a noção de Controle comportamental Percebido e media o efeito do clima de segurança em acidentes auto- reportados." 29.

Em seu estudo, Fogarty, (2010) construiu itens que refletiam as influências do ambiente físico de trabalho, incluindo no instrumento de pesquisa utilizado questões relativas à falta de equipamentos, falta de pessoal, falta de tempo e pressão por produção. Na literatura de segurança esses fatores são frequentemente combinados sob o construto de pressões no local de trabalho, que pode impactar as habilidades percebidas dos trabalhadores em completar as tarefas em conformidade com procedimentos (FOGARTY, 2010). Consequentemente, o autor

\footnotetext{
27 “[...] To a certain extent, the constructs included in the TPB mirror the individual, group, and organizational level variables measured in safety climate studies" (FOGARTY, 2010)

28 "[...] Safety climate studies have also looked at the influence of subjective norms. Individuals in organizations tend to regard themselves as members of workgroups. The norms developed by these groups influence the behavior of employees who feel they are a part of any such group. The inclusion of group level factors in safety climate studies is supported by research that has looked at the role group norms play in safety ".

29 "[...] demonstrate that a measure of safety control that has close parallels with the notion of perceived behavioral control mediates the effect of safety climate on self-reported injuries". (HUANG et al., 2006 apud FOGARTY, 2010)
} 
antecipou que as pressões no local de trabalho estariam associadas com as Intenções dos empregados em violar procedimentos, bem como as violações em si (comportamento real em violar).

O estudo de Fogarty (2010) estendeu a Teoria da Ação Planejada sugerindo que a Atitude da gerência em relação à segurança é responsável pela correlação entre Atitudes individuais, Normas Subjetivas e Controle comportamental Percebido, os três fatores independentes do modelo da Teoria da Ação Planejada.

O Quadro 6 apresenta as definições dos construtos utilizados no trabalho de Fogarty (2010).

Quadro 6 - Construtos utilizados no estudo de Fogarty (2010)

\begin{tabular}{|l|l|}
\hline \multicolumn{1}{|c|}{ Construto } & \multicolumn{1}{c|}{ Variáveis/Definição } \\
\hline Atitude da Gerência em relação à Segurança & $\begin{array}{l}\text { Foi medida por uma escala de sete itens que } \\
\text { representam a percepção das crenças da gerência por } \\
\text { parte dos respondentes. }\end{array}$ \\
\hline A própria atitude em relação à Segurança & $\begin{array}{l}\text { Foi medida por medida por uma escala de nove itens } \\
\text { que representam as atitudes dos respondentes em } \\
\text { relação a realização de violações e atalhos nos } \\
\text { procedimentos. }\end{array}$ \\
\hline Normas do Grupo & $\begin{array}{l}\text { Foi medida por uma escala de sete itens que focada } \\
\text { nas crenças dos respondentes em relação a práticas de } \\
\text { grupo usuais em relação a violações. }\end{array}$ \\
\hline Pressão no Ambiente de Trabalho & $\begin{array}{l}\text { Foi medida por uma escala de oito itens focada na } \\
\text { percepção do quanto os respondentes se sentiam sob } \\
\text { pressão para realizar suas tarefas. }\end{array}$ \\
\hline Intenções em Violar & $\begin{array}{l}\text { Escala contendo cinco itens com questões diretas } \\
\text { sobre a intenção em violar de procedimentos. }\end{array}$ \\
\hline Violação (Comportamento em Violar) & $\begin{array}{l}\text { Foi medida por escala de quatro itens com questões } \\
\text { diretas e afirmativas sobre violação de procedimentos. }\end{array}$ \\
\hline
\end{tabular}

FONTE: adaptado de (FOGARTY, 2010) 
O modelo testado por Fogarty, (2010) com profissionais de manutenção de aeronaves no Departamento de Defesa da Austrália está apresentado na Figura 8.

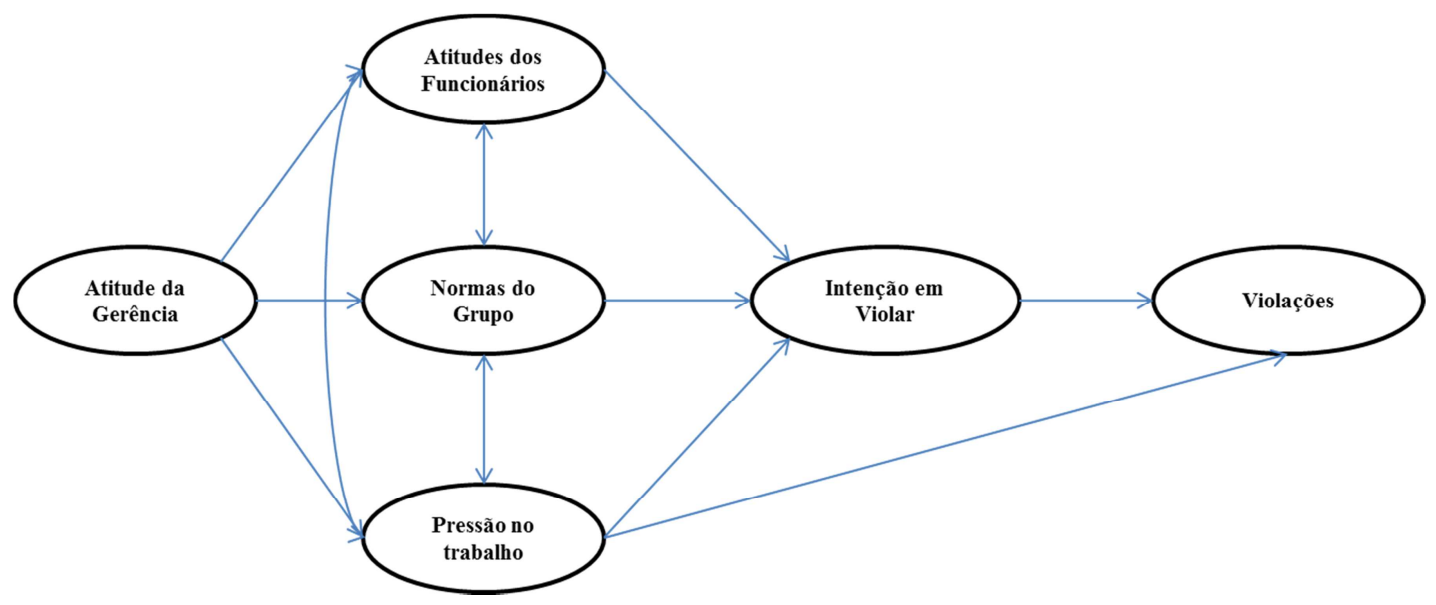

Figura 8 - Modelo de Fogarty

FONTE: adaptado de Fogarty (2010)

O resultado deste estudo demonstrou que as Atitudes da gerência exercem influência direta nas Atitudes dos indivíduos, nas Normas Subjetivas e no Controle comportamental Percebido e propõe que as relações estre estas três variáveis podem ser explicadas pela influência das atitudes da gerência. (FOGARTY, 2010).

O modelo proposto por Fogarty (2010) reflete então a estrutura da Teoria da Ação Planejada onde as normas de segurança de um grupo são tratadas de modo equivalente às normas subjetivas da Teoria da Ação Planejada e a pressão do local de trabalho como equivalente ao controle comportamental percebido.

Em estudo anterior, mas na mesma linha de Fogarty (2010), no qual a Teoria da Ação Planejada foi aplicada relacionada a comportamentos em relação à segurança, foi descoberto que a influência das Intenções nos Comportamentos em relação à segurança era mediada pelas Normas Subjetivas e pelo Controle comportamental Percebido. (JOHNSON e HALL, 2005).

Conforme já mencionado, a importância das Atitudes da gerência em relação à segurança é documentada nos trabalhos de Zohar (1980) em seus estudos iniciais sobre Clima de Segurança. Foi descoberto que a percepção dos empregados em relação às atitudes sobre 
segurança de seus gestores era o mais importante preditor do clima de segurança. (ZOHAR, 1980). Os estudos desse autor serviram como base para a pesquisa de Fogarty (2010), que demonstrou relação entre as Atitudes da Gerência e o comportamento dos trabalhadores.

Desde então, estudos que analisaram o Clima de Segurança em indústrias de mineração, aviação e construção civil ressaltaram o papel importante desempenhado pela gerência em assegurar a segurança da organização (FLIN et al., 2000; MEARNS et al., 2003). 


\section{METODOLOGIA DE PESQUISA}

\subsection{Modelo Conceitual}

Um modelo conceitual é uma abstração da realidade e tem o propósito de ordenar e simplificar a forma como é vista a realidade enquanto representa suas características essenciais. (GRIX, 2004).

O modelo conceitual apresentado na Figura 9 foi proposto com o objetivo de avaliar os construtos da Teoria da Ação Planejada e o Compromisso Percebido da Supervisão como fatores que explicam o comportamento de trabalhadores em relação à segurança, bem como analisar a relação existente entre esses fatores.

Este modelo tem como base os estudos realizados por Fogarty (2010), Zohar (1980, 2000, 2005), e pelos estudos desenvolvidos por Rundmo et al (1998), Tomas et al. (1999), Oliver et al (2000) e Seo et al (2005) contextualizados em um ambiente organizacional.

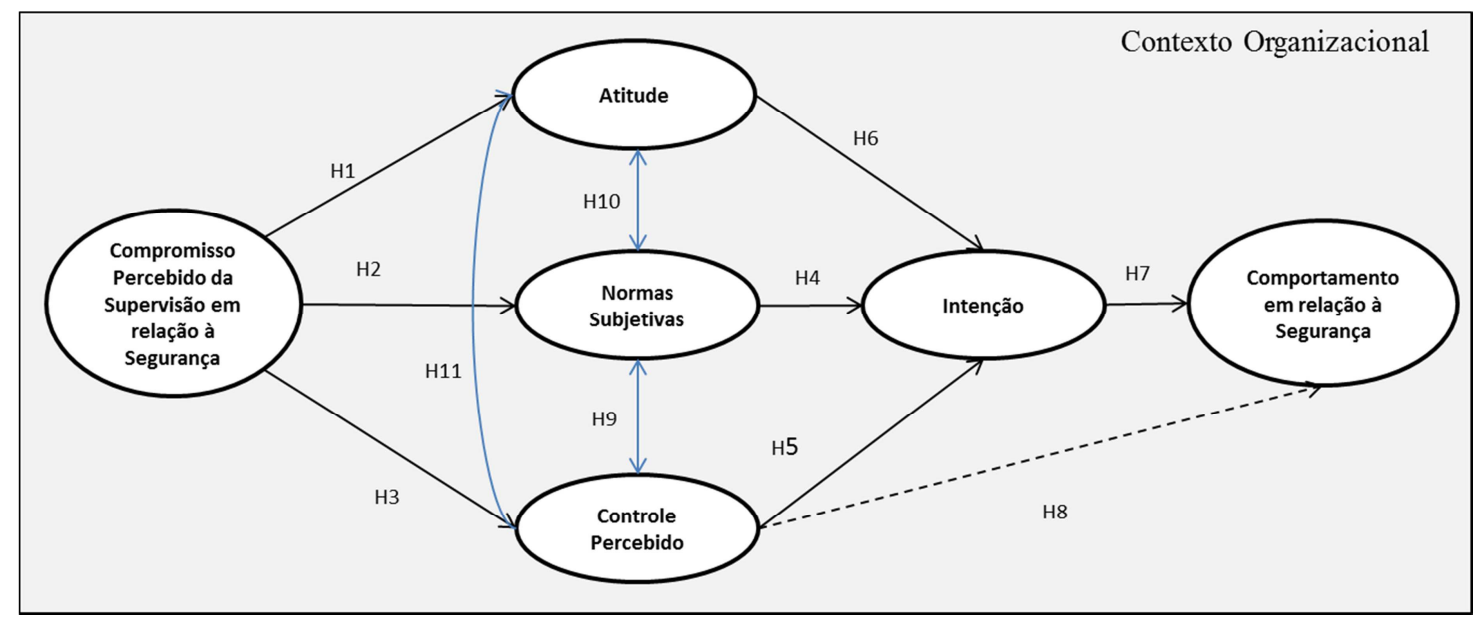

Figura 9 - Modelo Proposto

O Quadro 7 apresenta as dimensões do modelo proposto incluindo as definições operacionais e as respectivas bases conceituais. 
Quadro 7 - Definições Operacionais do Modelo Proposto

\begin{tabular}{|l|l|c|}
\hline \multicolumn{1}{|c|}{ Construtos } & \multicolumn{1}{|c|}{ Definição Operacional } & Base Conceitual \\
\hline $\begin{array}{l}\text { Compromisso da Supervisão } \\
\text { em relação à Segurança }\end{array}$ & $\begin{array}{l}\text { Grau em que os trabalhadores percebem as } \\
\text { atitudes e comportamentos da supervisão direta } \\
\text { em relação à Segurança }\end{array}$ & $\begin{array}{c}\text { Zohar (2005) } \\
\text { Zohar (2002) }\end{array}$ \\
\hline Atitudes & $\begin{array}{l}\text { Grau em que a pessoa avalia de forma favorável } \\
\text { ou não favorável um comportamento }\end{array}$ & $\begin{array}{c}\text { Ajzen e Fishbein (1975) } \\
\text { Ajzen (1991) }\end{array}$ \\
\hline Normas Subjetivas & $\begin{array}{l}\text { Percepção da pessoa quanto à pressão social } \\
\text { exercida sobre a mesma para que realize ou não } \\
\text { realize o comportamento em questão }\end{array}$ & $\begin{array}{c}\text { Ajzen e Fishbein (1975) } \\
\text { Ajzen (1991) }\end{array}$ \\
\hline Controle Percebido & $\begin{array}{l}\text { Facilidade ou dificuldade percebida de } \\
\text { desempenhar determinado comportamento } \\
\text { assumindo-se que este reflita experiências } \\
\text { passadas bem como impedimentos e obstáculos } \\
\text { antecipados }\end{array}$ & $\begin{array}{c}\text { Ajzen e Fishbein (1975) } \\
\text { Ajzen (1991) }\end{array}$ \\
\hline Intenção & $\begin{array}{l}\text { Indicador do quanto as pessoas se esforçam para } \\
\text { tentar, ou do quanto elas planejam de esforço } \\
\text { para realizar determinado comportamento }\end{array}$ & $\begin{array}{c}\text { Ajzen e Fishbein (1975) } \\
\text { Ajzen (1991) }\end{array}$ \\
\hline Comportamento & $\begin{array}{l}\text { Comportamento declarado em relação a } \\
\text { determinada situação em relação à Segurança no } \\
\text { Trabalho. }\end{array}$ & $\begin{array}{c}\text { Seo et al.(2005) } \\
\text { Oliver et al.(2000) } \\
\text { Tomas et al.( 1999) } \\
\text { Rundmo et al. (1998) }\end{array}$ \\
\hline
\end{tabular}

No modelo de Fogarty (2010) o construto que precede aqueles relativos à Teoria da Ação Planejada é a Atitude da Gerência. No modelo proposto o construto Compromisso Percebido da Supervisão em relação à Segurança precede os construtos da Teoria de Ação Planejada. Este construto é baseado diretamente no trabalho de Zohar (2005) sobre a correlação entre os climas de segurança percebidos em dois níveis hierárquicos nas organizações, a saber, a alta gerência e a supervisão operacional, bem como no trabalho de Zohar (2002) sobre os efeitos da liderança, do clima de segurança e das prioridades de segurança na organização.

O foco dado ao nível de Supervisão nesta pesquisa é justificado considerando que a Alta Liderança da organização tem o papel de definir políticas, enquanto que a Supervisão deve executar procedimentos e promover práticas tornando-os previsíveis em ações específicas do dia a dia. Dessa forma a Supervisão tem um grau de interação maior com os trabalhadores e, portanto, tende a ser influenciadora mais próxima dos mesmos.

Os demais construtos do modelo proposto seguem as definições estabelecidas na Teoria da Ação Planejada. 
Segue o Quadro 8 com as hipóteses de pesquisa baseadas no modelo teórico proposto.

\section{Quadro 8- Hipóteses de Pesquisa}

\begin{tabular}{|l|c|}
\hline \multicolumn{1}{|c|}{ Hipóteses de Pesquisa } & $\begin{array}{c}\text { Relação entre } \\
\text { Construtos }\end{array}$ \\
\hline $\begin{array}{l}\text { H1: quanto maior for o Compromisso Percebido da Supervisão em relação a Segurança maior } \\
\text { será a favorabilidade dos trabalhadores em relação à segurança (Atitude). }\end{array}$ & $(+)$ \\
\hline $\begin{array}{l}\text { H2: quanto maior for o Compromisso Percebido da Supervisão em relação a Segurança maior } \\
\text { será a percepção dos trabalhadores sobre as Normas Subjetivas. }\end{array}$ & $(+)$ \\
\hline $\begin{array}{l}\text { H3: quanto maior for o Compromisso Percebido da Supervisão em relação a Segurança maior } \\
\text { será a percepção sobre o Controle Percebido }\end{array}$ & $(+)$ \\
\hline $\begin{array}{l}\text { H4: quanto mais favorável for a Atitude em relação à segurança maior será a Intenção em } \\
\text { realizar um Comportamento em relação à segurança. }\end{array}$ & $(+)$ \\
\hline $\begin{array}{l}\text { H5: quanto mais fortes forem as Normas Subjetivas, maior será a Intenção em realizar um } \\
\text { Comportamento em relação à segurança. }\end{array}$ & $(+)$ \\
\hline $\begin{array}{l}\text { H6: quanto mais forte for o Controle Percebido maior será a Intenção em realizar um } \\
\text { Comportamento em relação à segurança. }\end{array}$ & $(+)$ \\
\hline H7: quanto maior a Intenção mais favorável será o Comportamento em relação à segurança. \\
\hline $\begin{array}{l}\text { H8: quanto mais forte for o Controle Percebido mais favorável será o Comportamento em } \\
\text { relação à segurança; }\end{array}$ \\
\hline $\begin{array}{l}\text { H9: quanto mais forte for o Controle Percebido maior será a percepção sobre as Normas } \\
\text { Subjetivas; }\end{array}$ & $(+)$ \\
\hline $\begin{array}{l}\text { H10: quanto mais forte for o Controle Percebido maior será a favorabilidade dos } \\
\text { trabalhadores em relação à segurança (Atitude) }\end{array}$ & $(+)$ \\
\hline $\begin{array}{l}\text { H11: quanto mais fortes forem as Normas Subjetivas, maior será a favorabilidade dos } \\
\text { trabalhadores em relação à segurança (Atitude); }\end{array}$ & $(+)$ \\
\hline
\end{tabular}

\subsection{Classificação de Pesquisa}

Uma pesquisa pode ser classificada em função dos seus objetivos e do grau de conhecimento que se tem sobre seu problema em exploratória ou conclusiva (MATTAR, 1997). A pesquisa exploratória tem como "[...] objetivo principal ajudar o pesquisador compreender o problema enfrentado pelo pesquisador e é utilizada nos casos onde é necessário definir o problema com maior precisão, identificar cursos relevantes de ação ou obter dados adicionais antes de poder desenvolver uma abordagem" (MALHORTA, 2010). Já a pesquisa conclusiva tem como objetivo testar hipóteses e avaliar situações específicas, geralmente é mais formal e estruturada em relação à pesquisa exploratória, baseia-se em amostras grandes e representativas e os dados obtidos estão sujeitos a análises quantitativas (MALHORTA, 2010). Portanto, com base nestas definições esta pesquisa pode ser classificada como Conclusiva. 
Em função da natureza dos relacionamentos entre as variáveis estudadas, as pesquisas também podem ser classificadas como descritivas ou causais (MATTAR, 1997). As pesquisas descritivas conclusivas têm como principal objetivo descrever alguma coisa (Malhorta, 2010) tais como as características de grupos estudados, estimar a proporção de elementos numa população específica que tenham determinadas características ou comportamentos ou descobrir ou verificar a existência de relação entre variáveis (Mattar, 1997). Já as pesquisas descritivas causais são utilizadas para obter evidências de relações de causa e efeito (relações causais) (MALHORTA, 2010). Portanto, com base nestas definições esta pesquisa pode ser classificada como Descritiva.

As pesquisas descritivas podem ainda ser divididas em função de como e onde os dados são coletados. Se os dados foram coletados de qualquer amostra de elementos de uma só vez, a pesquisa é classificada como sendo um estudo transversal. Os estudos transversais podem ser únicos ou múltiplos. Em um estudo transversal único os dados são extraídos de uma única amostra da população alvo. Em um estudo transversal múltiplo há duas ou mais amostras de respondentes e os dados de cada amostra são obtidos de uma vez. Se os dados são provenientes de uma amostra fixa de elementos da população e são medidas repetidamente as mesmas variáveis ao longo do tempo a pesquisa é classificada como sendo um estudo longitudinal (MALHORTA, 2010). Assim, esta pesquisa pode ser classificada como um estudo transversal.

As pesquisas podem ser classificadas em qualitativas e/ou quantitativas. Nas pesquisas de avaliação quantitativas os dados e as evidências coletados podem ser filtrados, organizados, tabulados e preparados para serem submetidos a técnicas ou testes estatísticos e a análise e interpretação dos mesmos estão sujeitas à conceituação das técnicas estatísticas (MARTINS, 2009). Quando os tipos de dados utilizados em uma pesquisa não são possíveis de serem mensurados, pedem descrições, compreensões, interpretações e análises de informações, fatos, evidências ou ocorrências, a pesquisa é classificada como sendo de avaliação qualitativa. (MARTINS, 2009). Segundo Malhorta (2010, p.110) “a pesquisa qualitativa proporciona melhor visão e compreensão do contexto do problema, enquanto que a pesquisa quantitativa procura quantificar os dados e, normalmente, aplica-se alguma forma de análise estatística". Vale ressaltar que em determinadas situações realiza-se uma pesquisa qualitativa para explicar os resultados obtidos pela pesquisa quantitativa (MALHORTA, 2010). Dados qualitativos e quantitativos serão coletados na realização desta pesquisa, 
entretanto os dados qualitativos terão a função apenas de contextualizar as análises realizadas com base nos dados quantitativos. Assim, esta pesquisa pode ser classificada como essencialmente quantitativa.

\subsection{Estrutura da Pesquisa}

Esta pesquisa está estruturada conforme indicado na Figura 10.

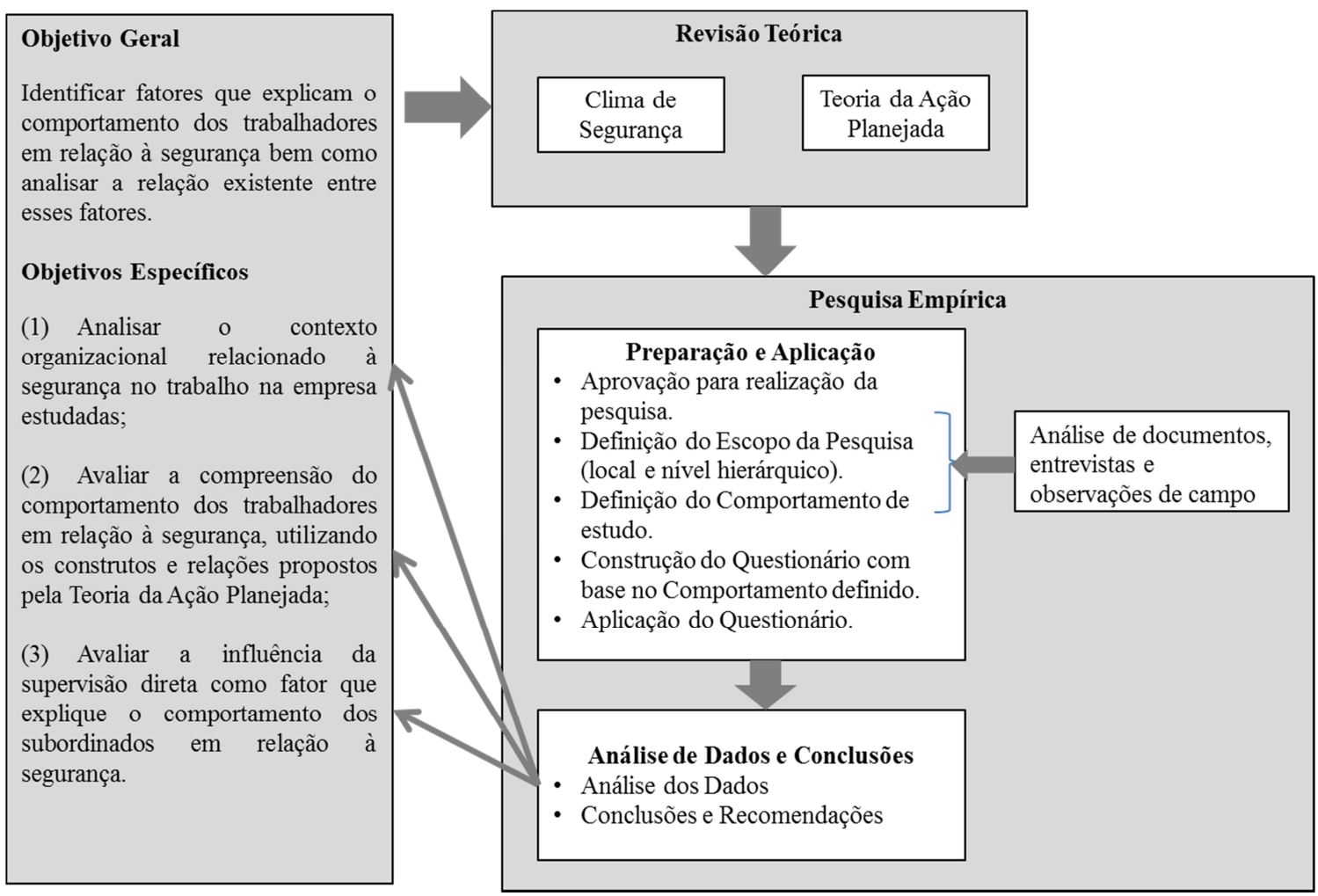

Figura 10 - Estrutura da Pesquisa

$\mathrm{Na}$ fase de Preparação e Aplicação foram identificadas potenciais organizações que poderiam servir como fonte de informação para a realização deste estudo. Foi obtida a aprovação para a realização deste trabalho na empresa estudada, mediante solicitação formal através de carta contendo a proposta e os objetivos da pesquisa, discutida com a Direção da organização.

Através de entrevistas, da análise de dados secundários e de observações de campo, foram coletados dados sobre a organização que embasaram as decisões sobre quais áreas, setores ou gerências fariam parte do escopo deste estudo; também foram coletados dados que 
permitiram a identificação de um comportamento de estudo, relacionado à Segurança no Trabalho, que fosse compatível com os limites de Teoria de Ação Planejada (comportamento intencional) sobre o qual o questionário foi construído, validado e aplicado.

A seguir, serão apresentadas as necessidades e fontes de dados, as técnicas e instrumentos de coleta, as técnicas de análise dos dados e a matriz de amarração.

\subsection{Necessidades e Fontes de Coleta de Dados}

De modo facilitar a compreensão das fontes de dados, a Figura 11 representa a estrutura organizacional da Área de Segurança e da Área Operacional da empresa, com seus respectivos níveis.

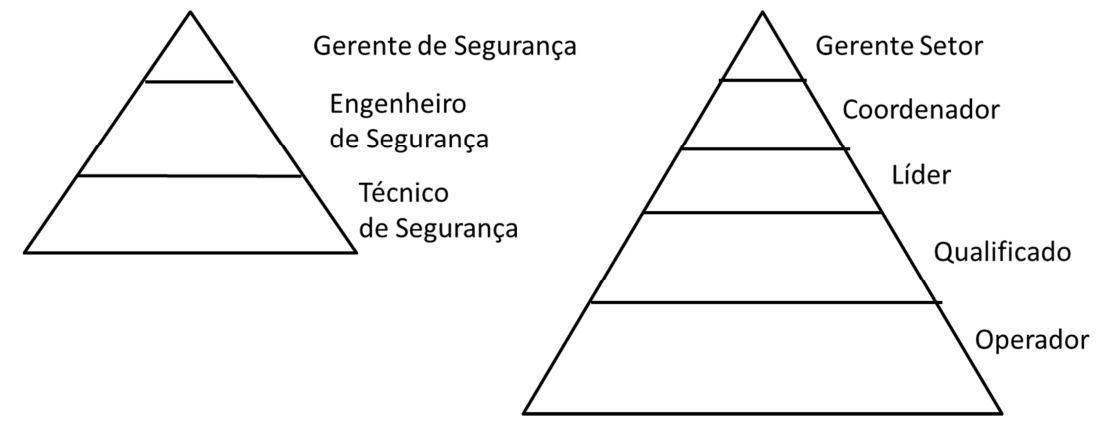

Figura 11 - Níveis Organizacionais

FONTE: organograma Unidade A

Os dados foram coletados considerando as seguintes fontes, conforme descrito no Quadro 9.

Quadro 9 - Necessidades e Fontes de Coleta de Dados

\begin{tabular}{|l|l|l|}
\hline \multicolumn{1}{|c|}{ Dado a ser coletado } & \multicolumn{1}{c|}{ Fontes de Dados } & Técnica de Coleta de Dados \\
\hline Estrutura organizacional & $\begin{array}{l}\text { Organograma da empresa (equipe de } \\
\text { Segurança do Trabalho) }\end{array}$ & Análise de Documentos \\
\hline $\begin{array}{l}\text { Frequência e natureza dos } \\
\text { acidentes nas áreas da } \\
\text { organização }\end{array}$ & $\begin{array}{l}\text { Banco de dados da empresa - } \\
\text { Relatório de Incidentes (equipe de } \\
\text { Segurança do Trabalho) }\end{array}$ & Análise de Documentos \\
\hline $\begin{array}{l}\text { Tipos de trabalhos realizados na } \\
\text { área escolhida. }\end{array}$ & $\begin{array}{l}\text { Colaboradores (Lideres e equipe de } \\
\text { Segurança do Trabalho). }\end{array}$ & 20 Observações de Campo \\
\hline $\begin{array}{l}\text { Políticas de Segurança } \\
\text { Levantamentos de } \\
\text { comportamentos intencionais. }\end{array}$ & $\begin{array}{l}\text { Colaboradores (Técnicos de } \\
\text { Segurança do Trabalho). }\end{array}$ & 2 Entrevistas \\
\hline $\begin{array}{l}\text { Percepções sobre as variáveis do } \\
\text { modelo proposto. }\end{array}$ & Colaboradores (Operadores) & $\begin{array}{l}\text { 4 Entrevistas com Líderes } \\
\text { 20 Observações de Campo }\end{array}$ \\
\hline
\end{tabular}




\subsection{Técnicas e Instrumentos de Coleta de Dados}

\subsubsection{Coleta de Dados Secundários}

Segundo Malhorta (2010, p.80) dados secundários são aqueles coletados com objetivos que não os do problema de pesquisa e podem ser localizados de forma rápida e barata. Os dados secundários ajudam a identificar, definir, desenvolver abordagens, formular uma concepção de pesquisa adequada, responder certas questões da pesquisa, testar algumas hipóteses e interpretar os dados primários com mais critério. Já os dados primários são aqueles gerados pelo pesquisador para a finalidade específica relacionada ao problema de pesquisa.

Nesta pesquisa foram utilizados dados secundários relativos ao desempenho organização em relação à segurança no trabalho, segmentado por áreas de trabalho, setores e gerências. Estes dados foram coletados diretamente de indicadores disponibilizados pela organização estudada e estão apresentados no tópico de descrição do perfil da empresa pesquisada

\subsubsection{Entrevistas}

De acordo com Martins (2009, p.88), a entrevista é “[...] uma técnica de pesquisa para coleta de informações, dados e evidências cujo objetivo básico é compreender o significado que entrevistados atribuem a questões e situações, em contextos que não foram estruturados anteriormente, com base em suposições e conjecturas do pesquisador". De acordo com o grau de estruturação das entrevistas elas podem ser classificadas em estruturadas, semiestruturadas e não-estrututradas.

Nesse trabalho as entrevistas foram utilizadas com o propósito de coletar informações sobre o contexto organizacional em relação a Políticas, Procedimentos e Regras de Segurança e Riscos, dimensões de Clima de Segurança previamente estudadas por diversos autores (vide Quadro2). Foram realizadas entrevistas semi-estruturadas, nas quais foram utilizados roteiros definidos, porém com liberdade para serem acrescentadas novas questões pelo entrevistador. Os roteiros de entrevistas foram elaborados de modo a permitir a análise das respostas obtidas nessas dimensões e encontram-se no APÊNDICE 2. 


\subsubsection{Observações de Campo}

Segundo Martins (2009, p.86) as técnicas de observação são procedimentos empíricos de natureza sensorial e que o planejamento e execução de trabalhos de campo onde o pesquisador interage com o sujeito da pesquisa não podem ser desconsiderados como técnica de coleta de dados. O autor recomenda a utilização de um protocolo de observação de modo a delimitar o fenômeno a ser observado, a maneira de observar, a duração, a periodicidade e o modo de registrar. Observações de campo foram utilizadas para a identificação e a escolha do comportamento de estudo, relacionado à segurança do trabalho, que posteriormente foi utilizado como base para a construção do questionário aplicado.

O protocolo utilizado na realização das observações de campo seguiu os seguintes passos:

(1) Entendimento preliminar do processo produtivo através da explicação do mesmo com base em fluxogramas de processo;

(2) Visita acompanhada na linha de produção;

(3) Discussão com o profissional acompanhante sobre situações de trabalho consideradas de risco (condições físicas das instalações e processos, comportamentos ou ambos) além de questões técnicas;

(4) Registros fotográficos e filmagens de situações relevantes para a definição de um comportamento de estudo adequado à aplicação da Teoria da Ação Planejada.

\subsubsection{Questionário}

Martins (2009, p.93) define um questionário como sendo “[...] um conjunto ordenado e consistente de perguntas a respeito de variáveis e situações que se deseja medir ou descrever".

Malhorta (2010) descreve o processo de elaboração de questionários como tendo 10 etapas, a saber:

1. Especificar as informações necessárias

2. Especificar o tipo de método de entrevista

3. Determinar o conteúdo das perguntas 
4. Planejar as perguntas de modo a minimizar a falta de vontade do entrevistado em responder

5. Decidir sobre a estrutura das perguntas

6. Determinar o enunciado das perguntas

7. Organizar as perguntas na ordem adequada

8. Identificar o formato e o leiaute do questionário

9. Reproduzir o questionário

10. Fazer um pré-teste do questionário.

Segundo Ajzen (2010), não existe um questionário padrão a ser utilizado para aplicação da Teoria da Ação Planejada. Segundo o autor, um levantamento preliminar de informações é requerido para a construção de um questionário adequado ao comportamento de estudo e a população de interesse.

Ajzen (2011, p.1116) afirma que a Teoria da Ação Planejada enfatiza os aspectos controláveis do processamento humano de informações e das tomadas de decisão e seu foco é dado primeiramente nos comportamentos que são dirigidos por processos auto-reguladores conscientes. A escolha de um comportamento de interesse deve, portanto, levar em consideração os limites de predição da própria teoria.

O passo inicial para a construção de um questionário é a definição de um comportamento de estudo, que deve ser claramente definido em termos de seu alvo, ação, contexto e tempo (AJZEN, 2010).

Com base no comportamento definido, outros itens do questionário devem ser construídos de modo a acessar outros construtos da Teoria da Ação Planejada. Estes itens devem ser validados antes da aplicação do questionário em sua versão final (AJZEN, 2010).

Para a construção dos outros indicadores foram utilizados como base os trabalhos de Johnson e Hall (2005), de Fogarty (2010) e Fishbein e Ajzen,(2010).

O estudo desenvolvido por Johnson e Hall (2005) teve como foco avaliar o comportamento em relação à segurança de trabalhadores envolvidos em movimentação de cargas e materiais. 
Neste trabalho o autor apresenta 14 assertivas utilizando uma escala de soma de Likert com sete pontos para a medição das escalas (vide APÊNDICE 3). A estrutura dos indicadores deste questionário é bastante aderente com as recomendações de Fishbein, M., \& Ajzen, I. (2010).

Fogarty, (2010) utilizou a Teoria da Ação Planejada como base para a elaboração de um modelo que relaciona variáveis características de Clima de Segurança com a Intenção dos funcionários em violar procedimentos de manutenção de aeronaves na Força de Defesa da Austrália. O questionário desenvolvido pelo autor é apresentado no APÊNDICE 4.

Para o construto Compromisso Percebido da Supervisão em relação à Segurança, foram elaboradas questões que tiveram como base o trabalho de Zohar (2005) sobre a correlação entre os climas de segurança percebidos em dois níveis hierárquicos nas organizações, a saber, a alta gerência e a supervisão operacional. O instrumento utilizado neste trabalho cobre uma gama de interações entre supervisores diretos e os seus trabalhadores através das quais os supervisores podem indicar a prioridade de segurança versus objetivos concorrentes tais como a velocidade de produção ou a programação da produção. O trabalho original de Zohar (2005) apresentava 16 questões na formação deste construto conforme apresentado APÊNDICE 5.

Com base nos autores acima, um questionário foi construído, aplicado e validado possibilitando a coleta dos dados quantitativos utilizados na avaliação do modelo proposto, em resposta aos objetivos da pesquisa. Mais detalhes sobre a preparação para aplicação da pesquisa serão apresentados no próximo capítulo.

\subsection{Técnicas de Análise dos Dados}

A escolha das técnicas para a análise dos dados foi definida em função dos objetivos da pesquisa, pela natureza dos dados e pelos requisitos exigidos nas técnicas de análise empregadas.

Os dados coletados através das entrevistas e das observações de campo tiveram seu conteúdo analisado e consolidado visando construir o questionário e complementar a análise dos dados 
quantitativos. Os dados secundários foram utilizados na definição do grupo de estudo (unidade, departamento, gerência)

Já os dados quantitativos, coletados através do questionário, foram analisados através da Modelagem de Equações Estruturais e da Análise Fatorial, conforme descrito a seguir.

\subsubsection{Modelagem de Equações Estruturais}

Segundo Hair (1998, p.542) a Modelagem de Equações Estruturais é uma técnica multivariada que permite ao pesquisador examinar simultaneamente uma série de relações de dependências múltiplas e inter-relacionadas.

O modelo proposto neste estudo apresenta variáveis (latentes), que por apresentarem problemas de mensuração direta, são calculadas por meio de indicadores mensuráveis e também um conjunto de variáveis inter-relacionadas, com relacionamento de dependência múltipla.

Uma maneira de utilizar a Modelagem de Equações Estruturais é aplicar uma estratégia confirmatória. Nessa, o pesquisador especifica apenas um conjunto de relações e através da técnica é possível avaliar o quão bem o modelo se ajusta aos dados. O pesquisador não demonstra dessa forma o modelo, mas apenas confirma que ele é um entre diversos modelos aceitáveis (HAIR, 1998, p 559).

Alguns programas são utilizados pelos pesquisadores para a modelagem de equações estruturais, tais como o PLS, AMOS, LISREL

PLS (Partial Least Square) é uma técnica de modelagem de equações estruturais baseado em um método de regressão que maximiza a variância explicada (HAIR et al, 2009). Esse programa foi utilizado na pesquisa por apresentar a possibilidade de estimar modelos com amostras de tamanho pequeno, conseguir lidar com modelos complexos e não exigir normalidade na distribuição dos dados (HENSLER et al, 2009). 
Chin (1998) apud Marcoulides (2006, p.iv) menciona que, como regra geral, o tamanho mínimo da amostra para a utilização do PLS deve ser igual ao maior dos seguintes critérios:

- Dez vezes o maior número de indicadores utilizados para a mensuração de um construto;

- Dez vezes o número de caminhos estruturais direcionados para um determinado construto latente no modelo estrutural;

\subsubsection{Análise Fatorial}

Segundo Hair (1998, p. 102) a "Análise fatorial é uma técnica de interdependência cujo propósito principal é definir a estrutura inerente entre as variáveis na análise". A análise fatorial através de seu ferramental fornece um método para o agrupamento das variáveis que são fortemente inter-relacionadas. Estas variáveis são chamadas de fatores.

Dependendo dos objetivos da pesquisa, a análise fatorial pode ser utilizada dentro de uma perspectiva exploratória, quando o pesquisador está em busca da estrutura em um conjunto de variáveis ou como um método de redução de dados. Sendo utilizada com uma perspectiva confirmatória, quando o pesquisador tem ideias pré-concebidas sobre a estrutura dos dados baseado em um referencial teórico ou em pesquisas anteriores, o objetivo desta técnica é o de avaliar em que grau os dados satisfazem a estrutura esperada (HAIR, 1998).

Neste estudo a Análise Fatorial foi utilizada sob a perspectiva confirmatória, como uma técnica auxiliar na construção do questionário utilizado para a coleta dos dados primários. Foi utilizado o programa SPSS como suporte à realização dessa análise.

\subsection{Matriz de amarração}

De modo evidenciar as relações entre os objetivos da pesquisa, o modelo conceitual proposto, as hipóteses relacionadas ao modelo, as questões utilizadas no questionário validado e as técnicas de análise para avaliação dos dados, Mazzon (1981) desenvolveu um instrumento denominado Matriz de Amarração.

O Quadro 10 apresenta a Matriz de Amarração desenvolvida para este trabalho: 
Quadro 10 - Matriz de Amarração

\begin{tabular}{|c|c|c|c|c|c|c|}
\hline $\begin{array}{c}\text { Objetivo } \\
\text { Geral }\end{array}$ & $\begin{array}{c}\text { Objetivos } \\
\text { Específicos }\end{array}$ & Hipóteses do Modelo - Descrição & Questões & Base Teórica & $\begin{array}{l}\text { Técnicas de } \\
\text { Análise de } \\
\text { Dados }\end{array}$ & Viabilidade \\
\hline \multirow{8}{*}{ 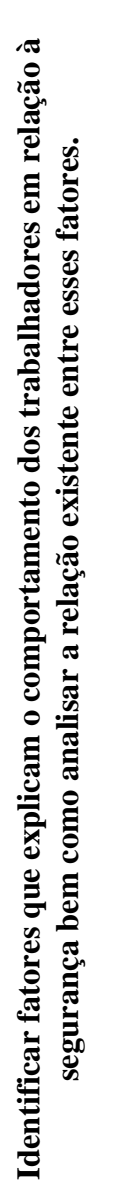 } & \multirow{8}{*}{ 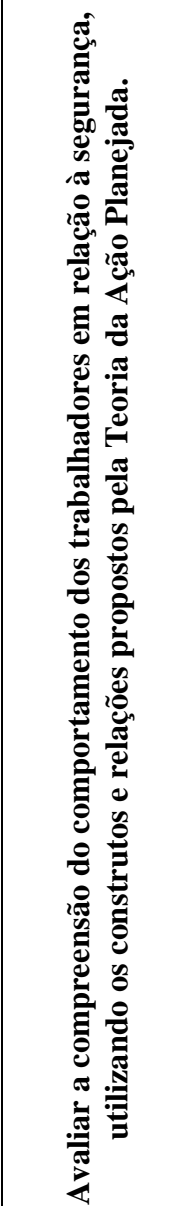 } & $\begin{array}{l}\text { H4: quanto mais favorável for a Atitude em relação à } \\
\text { segurança maior será a Intenção em realizar um } \\
\text { Comportamento em relação à segurança. }\end{array}$ & $\begin{array}{l}\mathrm{A} 1, \mathrm{~A} 2, \mathrm{~A} 3, \mathrm{~A} 4 \\
\mathrm{~B} 4, \mathrm{~B} 8, \mathrm{~B} 13, \mathrm{~B} 15\end{array}$ & $\begin{array}{l}\text { Atitude/ } \\
\text { Intenção }\end{array}$ & \multirow{8}{*}{ 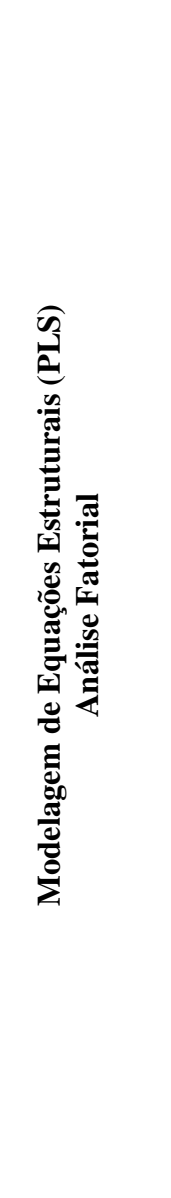 } & \multirow{8}{*}{$\begin{array}{l}\text { MODELAGEM DE } \\
\text { EQUACÕES } \\
\text { ESTRUTURAIS } \\
\text { Análise do Modelo de } \\
\text { Mensuração } \\
\text { - Confiabilidade Composta } \\
\text { - AVE } \\
\text { - Confiabilidade dos } \\
\text { Indicadores } \\
\text { - Validade Discriminante } \\
\text { Análise do Modelo Estrutural } \\
\text { 1. Coeficiente de } \\
\text { Determinação } \\
\text { 2. T-student } \\
\\
\text { - Número de Fatores } \\
\text { Extraídos } \\
\text { - KMÓL }\end{array}$} \\
\hline & & $\begin{array}{l}\text { H5: quanto mais fortes forem as Normas Subjetivas, } \\
\text { maior será a Intenção em realizar um Comportamento } \\
\text { em relação à segurança. }\end{array}$ & $\begin{array}{l}\text { B2,B6,B9,B11, } \\
\text { B4,B8,B13,B15 }\end{array}$ & $\begin{array}{l}\text { Normas } \\
\text { Subjetivas/ } \\
\text { Intenção }\end{array}$ & & \\
\hline & & $\begin{array}{l}\text { H6: quanto mais forte for o Controle Percebido maior } \\
\text { será a Intenção em realizar um Comportamento em } \\
\text { relação à segurança. }\end{array}$ & $\begin{array}{l}\mathrm{B} 3, \mathrm{~B} 7, \mathrm{~B} 12, \mathrm{~B} 14, \\
\mathrm{~B} 4, \mathrm{~B} 8, \mathrm{~B} 13, \mathrm{~B} 15\end{array}$ & $\begin{array}{l}\text { Controle } \\
\text { Percebido/ } \\
\text { Intenção }\end{array}$ & & \\
\hline & & $\begin{array}{l}\text { H7: quanto maior a Intenção mais favorável será o } \\
\text { Comportamento em relação à segurança. }\end{array}$ & $\begin{array}{l}\text { B4,B8,B13,B15, } \\
\text { B1,B5,B10 }\end{array}$ & $\begin{array}{c}\text { Intenção/ } \\
\text { Comportamento }\end{array}$ & & \\
\hline & & $\begin{array}{l}\text { H8: quanto mais forte for o Controle Percebido mais } \\
\text { favorável será o Comportamento em relação à } \\
\text { segurança; }\end{array}$ & $\begin{array}{l}\text { B3,B7,B12,B14, } \\
\text { B1,B5,B10 }\end{array}$ & $\begin{array}{c}\text { Controle } \\
\text { Percebido/ } \\
\text { Comportamento }\end{array}$ & & \\
\hline & & $\begin{array}{l}\text { H9: quanto mais forte for o Controle Percebido maior } \\
\text { será a percepção sobre as Normas Subjetivas; }\end{array}$ & $\begin{array}{l}\mathrm{B} 3, \mathrm{~B} 7, \mathrm{~B} 12, \mathrm{~B} 14, \\
\mathrm{~B} 2, \mathrm{~B} 6, \mathrm{~B} 9, \mathrm{~B} 11\end{array}$ & $\begin{array}{l}\text { Controle } \\
\text { Percebido/ } \\
\text { Normas } \\
\text { Subjetivas }\end{array}$ & & \\
\hline & & $\begin{array}{l}\text { H10: quanto mais forte for o Controle Percebido maior } \\
\text { será a favorabilidade dos trabalhadores em relação à } \\
\text { segurança (Atitude) }\end{array}$ & $\begin{array}{l}\mathrm{B} 3, \mathrm{~B} 7, \mathrm{~B} 12, \mathrm{~B} 14 \\
\mathrm{~A} 1, \mathrm{~A} 2, \mathrm{~A} 3, \mathrm{~A} 4\end{array}$ & $\begin{array}{l}\text { Controle } \\
\text { Percebido/ } \\
\text { Atitude }\end{array}$ & & \\
\hline & & $\begin{array}{l}\text { H11: quanto mais fortes forem as Normas Subjetivas, } \\
\text { maior será a favorabilidade dos trabalhadores em } \\
\text { relação à segurança (Atitude); }\end{array}$ & $\begin{array}{l}\text { B2,B6,B9,B11, } \\
\text { A1,A2,A3,A4, }\end{array}$ & $\begin{array}{l}\text { Normas } \\
\text { Subjetivas/ } \\
\text { Atitude }\end{array}$ & & \\
\hline
\end{tabular}




\begin{tabular}{|c|c|c|c|c|c|c|}
\hline $\begin{array}{c}\text { Objetivo } \\
\text { Geral }\end{array}$ & $\begin{array}{c}\text { Objetivos } \\
\text { Específicos }\end{array}$ & Hipóteses do Modelo - Descrição & Questões & Base Teórica & $\begin{array}{c}\text { Técnicas de } \\
\text { Análise de } \\
\text { Dados }\end{array}$ & Viabilidade \\
\hline 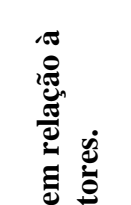 & 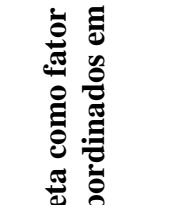 & $\begin{array}{l}\text { H1: quanto maior for o Compromisso Percebido da } \\
\text { Supervisão em relação a Segurança maior será a } \\
\text { favorabilidade dos trabalhadores em relação à } \\
\text { segurança (Atitude). }\end{array}$ & $\begin{array}{l}\mathrm{C} 1, \mathrm{C} 2, \mathrm{C} 3, \mathrm{C} 4, \mathrm{C} 5, \mathrm{C} 6 \\
\text {,C7,C8,C9, } \\
\text { A1,A2,A3,A } 4\end{array}$ & $\begin{array}{l}\text { Compromisso } \\
\text { Percebido/ } \\
\text { Atitude }\end{array}$ & \multirow{3}{*}{ 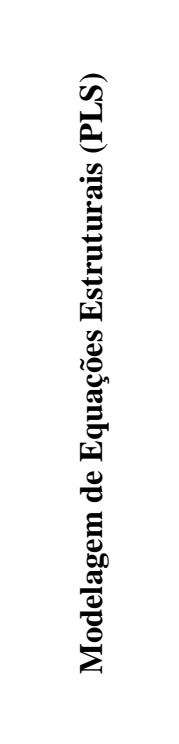 } & \multirow{3}{*}{$\begin{array}{l}\frac{\text { MODELAGEM DE }}{\text { EQUACÕES }} \\
\text { ESTRUTURAIS } \\
\text { Análise do Modelo de } \\
\text { Mensuração } \\
\text { - Confiabilidade Composta } \\
\text { - AVE } \\
\text { - Confiabilidade dos } \\
\text { Indicadores } \\
\text { - Validade Discriminante } \\
\text { Análise do Modelo Estrutural } \\
\text { 3. Coeficiente de } \\
\text { Determinação } \\
\text { 4. T-student }\end{array}$} \\
\hline 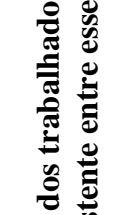 & 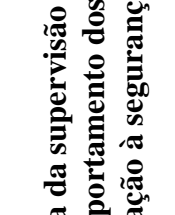 & $\begin{array}{l}\text { H2: quanto maior for o Compromisso Percebido da } \\
\text { Supervisão em relação a Segurança maior será a } \\
\text { percepção do trabalhadores sobre as Normas } \\
\text { Subjetivas. }\end{array}$ & $\begin{array}{c}\mathrm{C} 1, \mathrm{C} 2, \mathrm{C} 3, \mathrm{C} 4, \mathrm{C} 5, \mathrm{C} 6 \\
\text {,C7,C8,C9, } \\
\text { B2,B6,B9,B11 }\end{array}$ & $\begin{array}{l}\text { Compromisso } \\
\text { Percebido/ } \\
\text { Normas } \\
\text { Subjetivas }\end{array}$ & & \\
\hline 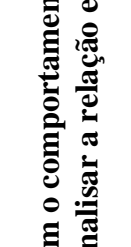 & 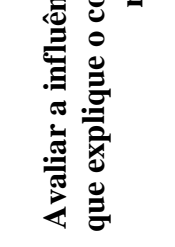 & $\begin{array}{l}\text { H3: quanto maior for o Compromisso Percebido da } \\
\text { Supervisão em relação a Segurança maior será a } \\
\text { percepção sobre o Controle Percebido }\end{array}$ & $\begin{array}{l}\text { B3,B7,B12,B14, } \\
\text { C1,C2,C3,C4,C5,C6 } \\
\text {,C7,C } 8, \mathrm{C} 9\end{array}$ & $\begin{array}{l}\text { Compromisso } \\
\text { Percebido/ } \\
\text { Controle } \\
\text { Percebido }\end{array}$ & & \\
\hline 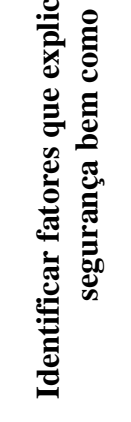 & 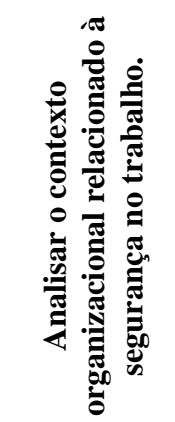 & Não se aplica. & $\begin{array}{c}\text { C1,C2,C3,C4,C5,C6 } \\
\text {,C7,C8,C9 } \\
\\
\text { Roteiros de } \\
\text { Entrevistas } \\
\\
\text { Roteiro de } \\
\text { Observação }\end{array}$ & Não se aplica & 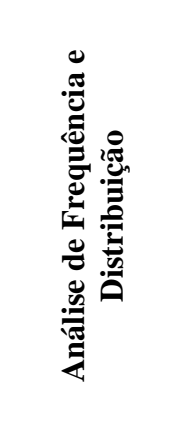 & Não se aplica \\
\hline
\end{tabular}




\section{PREPARAÇÃO E APLICAÇÃO DA PESQUISA}

\subsection{Descrição do Perfil da Empresa Pesquisada}

A pesquisa foi realizada em uma empresa que atua no setor metalúrgico, como fornecedora de componentes de aço para os mercados automobilísticos e de construção civil. Esta organização é de origem brasileira, tem mais de 75 anos de operação desde sua fundação e emprega aproximadamente 10.000 empregados divididos nas duas unidades operacionais no Brasil. Devido a questões de sigilo, a pedido da organização estudada, seu nome não será divulgado neste trabalho.

Com base em arquivos armazenados no banco de dados da empresa e disponibilizados pela Gerência de Segurança e Saúde Ocupacional da organização foram obtidas informações relativas à taxa de frequência de acidentes com afastamento. Essas informações mostram que a organização apresenta alta taxa de frequência de acidentes de trabalho inclusive com a ocorrência de uma fatalidade (morte no trabalho) no ano de 2011. A taxa de frequência de acidentes em 2013 não apresentava tendência de melhoria e ainda se apresentava aproximadamente três vezes acima da meta estabelecida para o ano.

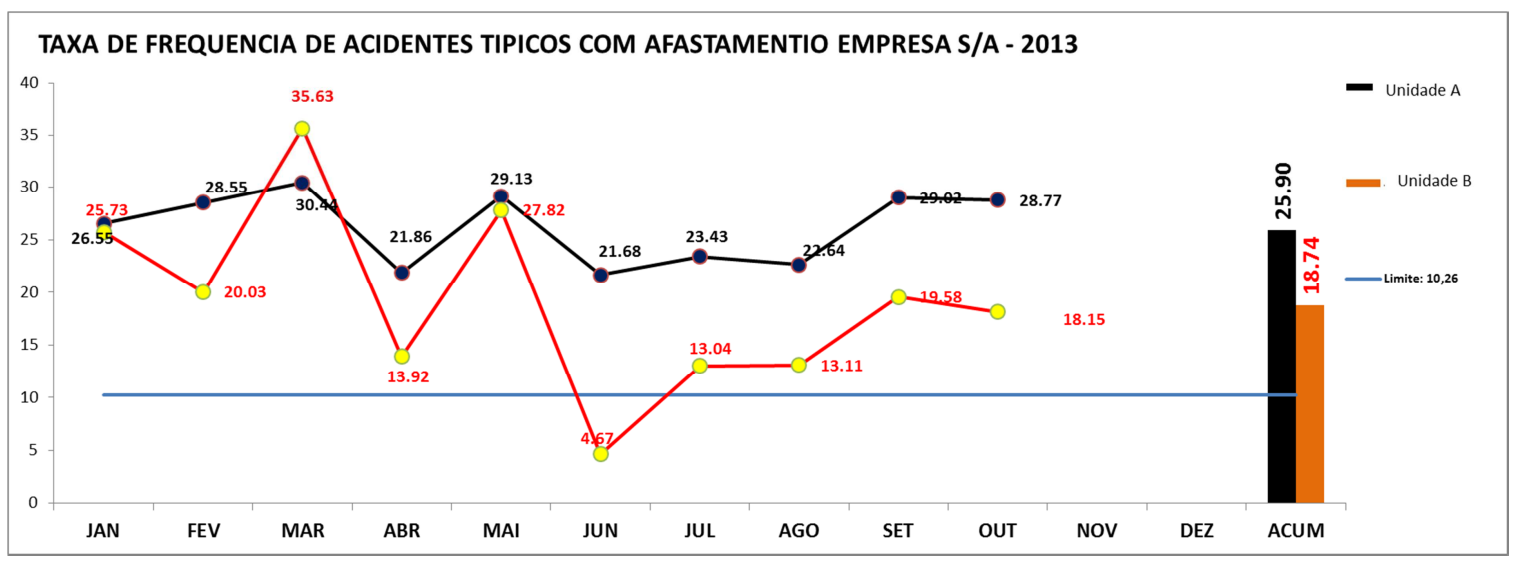

Figura 12 - Taxa de Frequência de Acidentes (*) FONTE: Banco de dados da empresa estudada

(*) Acidentes com Afastamento por Unidade (A e B). Número de acidentes por milhão de horas trabalhadas. 
Com base no seu perfil e na necessidade da organização em melhorar seu desempenho em segurança houve interesse da liderança em participar dessa pesquisa contribuindo com informações relevantes.

Foi escolhida a Unidade A para condução da pesquisa.

\subsection{Definição do Escopo da Pesquisa}

A definição do escopo da pesquisa na organização estudada considerou duas variáveis: os níveis organizacionais a serem estudados e os diferentes setores operacionais.

Considerando que os acidentes de trabalho majoritariamente acontecem com funcionários do nível operacional e que os Qualificados são seus superiores imediatos, tomou-se a decisão de focar o estudo nos níveis dos Qualificados e Operadores.

Devido ao tamanho e à complexidade da organização a pesquisa foi concentrada em um setor e uma gerência específica da Unidade A. Este setor (Setor X) emprega na Unidade A aproximadamente 3800 (três mil e oitocentos) funcionários e apresenta as maiores taxas de frequência de acidentes de trabalho com afastamento na empresa (Taxa de frequência em torno de 47.00 x 28.77 para a média da unidade A). Dentro deste setor há ainda quatro gerências, sendo que especificamente uma delas (Gerência B) foi escolhida como foco para esta pesquisa por apresentar aproximadamente $80 \%$ dos acidentes ocorridos dentro neste setor. Esta gerência conta com aproximadamente 2300 (dois mil e trezentos funcionários) trabalhando em três turnos, cinco dias por semana.

\section{Área de Estudo (Escopo da Pesquisa) = Gerência B pertencente ao Setor X da Unidade A}

Segue a Figura 13 a distribuição do número de acidentes que resultaram em afastamentos de funcionários no mês de novembro/2013, por gerência. Esta distribuição não apresentou variação significativa ao longo do ano de 2013. (dados de 26/11/2013). 


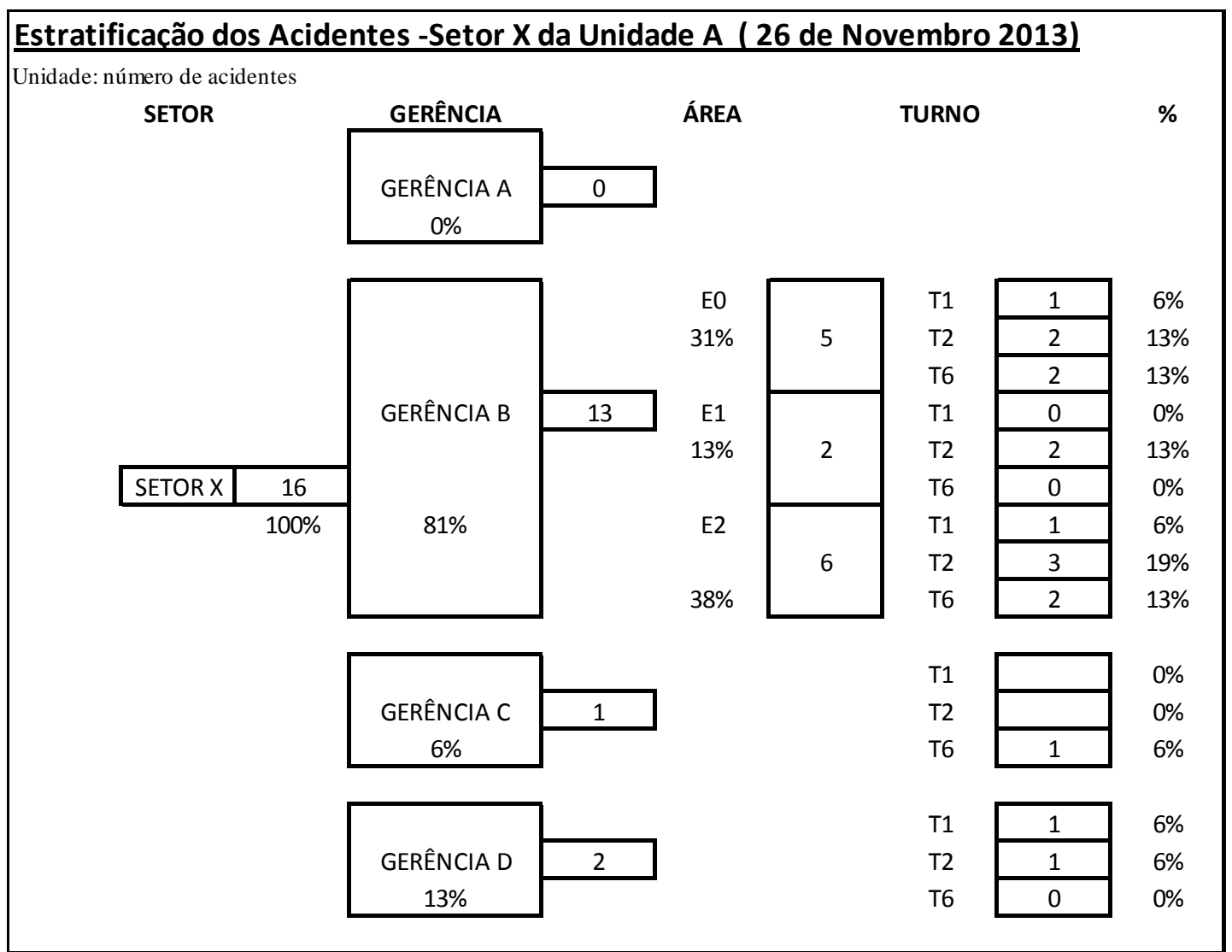

Figura 13 - Número de Acidentes por Gerência no Setor X FONTE: banco de dados de acidentes de trabalho

\subsection{Caracterização da Área de Estudo}

Os dados a seguir foram coletados com base em observações de campo dentro da Gerência B. Nessas observações o pesquisador sempre esteve acompanhado por profissionais das áreas de Segurança do Trabalho ou da Produção (Gerente, Coordenador ou Líder). As observações de campo foram realizadas de acordo com o protocolo apresentado no capítulo de metodologia (item 4.5.3).

Foram realizadas aproximadamente 20 observações de campo em três meses de trabalho.

A Gerência B é uma área dentro da organização que funcionalmente pode ser caracterizada como sendo responsável pelos últimos processos dentro de uma linha de produção. Os produtos invariavelmente são blocos de aço usinados com pesos entre $30 \mathrm{~kg}$ a $150 \mathrm{~kg}$. Em 
seus processos, mais de cem tipos de produtos são finalizados, com especificações diferentes, requisitos de inspeção de qualidade diferentes e rotas alternativas para produzi-los.

O trabalho nestas linhas de produção é intensivo em mão-de-obra e com baixo grau de automação em função da multiplicidade de produtos fabricados. Os operadores executam suas tarefas com interação física com os produtos, interação esta realizada através do uso de ferramentas. As peças a serem trabalhadas são transportadas por esteiras nas quais os trabalhadores ficam posicionados, realizando então diferentes trabalhos nas mesmas, de forma especializada e sequencial. Os operadores em geral trabalham próximos, com distâncias variando entre 1,0 a 1,5 metros uns dos outros.

Diversos tipos de ferramentas são utilizados durante os processos de fabricação. Estas ferramentas podem ser divididas em dois grupos: as de corte e acabamento, tais como martelos, esmeris, rebolos; e as de transporte, tais como talhas, ganchos, paleteiras e empilhadeiras. As ferramentas são a interface entre o trabalho físico dos operadores e o produto em processo (blocos de aço). Cada operador durante sua jornada de trabalho carrega ou manuseia o seu conjunto de ferramentas de trabalho, sem as quais o mesmo não pode ser realizado.

\subsection{Escolha do Comportamento de Estudo}

Durante a realização das entrevistas e das observações de campo buscou-se identificar comportamentos intencionais relacionados à segurança dentro da área de estudo delimitada (Gerência B). A realização de tais comportamentos deve envolver uma tomada de decisão por parte do executor, ou seja, o comportamento deve ser intencional de modo a utilizarmos a Teoria da Ação Planejada como base para o estudo.

Os comportamentos avaliados para a realização deste estudo foram:

- Posicionamento das mãos sobre as esteiras transportadoras de peças

- Posicionamento das mãos sobre as peças nas esteiras de transporte

- Realização de inspeção das ferramentas de trabalho pelos operadores 
Com base na análise dos registros dos acidentes com afastamento reportados nos meses de outubro e novembro de 2013, observou-se que na Gerência B 37\% destes eventos apresentaram alguma relação com a utilização inadequada de ferramentas, seja por não estarem em condições de uso, seja por serem utilizadas para um propósito para as quais não foram projetadas. (vide APÊNDICE 6).

Neste contexto, inspecionar as ferramentas no início do turno de trabalho tem relevância como medida preventiva para evitar a ocorrência de acidentes. Durante as entrevistas realizadas com Líderes e Profissionais de Segurança e Saúde foi possível a validação de que as inspeções nas ferramentas em todo início de turno é de responsabilidade dos operadores e que estes estão orientados e treinados para realizar tais inspeções.

Considerando que a realização da inspeção nas ferramentas de trabalho é um comportamento intencional dos operadores, este comportamento foi então utilizado como base para a elaboração do questionário que foi aplicado para a avaliação do modelo teórico proposto nesta pesquisa.

De modo formal o comportamento relacionado à segurança utilizado para a avaliação do modelo proposto está descrito abaixo e sua definição é coerente com as orientações de Fishbein e Ajzen (2010).

Comportamento de Estudo: inspecionar minhas ferramentas de trabalho no início do turno todos os dias.

\subsection{Construção, Aplicação e Validação do Questionário.}

Uma vez definido um comportamento de estudo, tem-se que os demais construtos relacionados à Teoria da Ação Planejada devem ser construídos mantendo os mesmos termos propostos por Fishbein e Ajzen (2010), a saber, alvo, ação, contexto e tempo.

Considerando o comportamento de estudo definido, as condições de trabalho observadas e limitações práticas a coleta das respostas (complexidade das perguntas e tempo de resposta) indicadores foram então definidos para cada um dos construtos Atitude, Normas Subjetivas, 
Controle Percebido e Intenção. O Quadro 11 ilustra as questões elaboradas bem como aquelas apresentadas nos estudos citados como suas referências. De modo a evitar interpretações sobre as questões originais foram mantidas no idioma inglês, original de seus autores, as questões utilizadas como referência. 
Quadro 11 - Questões Adaptadas e Referências (Teoria da Ação Planejada)

\begin{tabular}{|c|c|c|c|c|}
\hline Construto & Questão Adaptada & Fishbein, e Ajzen (2010), & Johnson e Hall (2005) & Fogarty, (2010) \\
\hline \multirow{2}{*}{ Comportamento } & $\begin{array}{l}\text { Eu inspeciono minhas } \\
\text { ferramentas de trabalho no } \\
\text { início do turno todos os dias. }\end{array}$ & $\begin{array}{l}\text { In the past three months, I have } \\
\text { exercised for at least } 20 \text { minutes, three } \\
\text { times per week. }\end{array}$ & $\begin{array}{l}\text { During the past } 30 \text { days, I } \\
\text { always/never lifted materials from/to } \\
\text { locations within my strike-zone }\end{array}$ & $\begin{array}{l}\text { I have performed a familiar task without } \\
\text { referring to the maintenance manual or } \\
\text { other approved documentation. }\end{array}$ \\
\hline & $\begin{array}{l}\text { Eu normalmente inicio meu } \\
\text { trabalho sem inspecionar as } \\
\text { ferramentas que utilizo. } \\
\text { (reverse) }\end{array}$ & & & \\
\hline \multirow{3}{*}{ Atitude } & $\begin{array}{l}\text { Eu considero importante } \\
\text { inspecionar minhas } \\
\text { ferramentas de trabalho no } \\
\text { início do turno todos os dias. }\end{array}$ & $\begin{array}{l}\text { My exercising for at least } 20 \text { minutes, } \\
\text { three times per week for the next three } \\
\text { months would be good/bad } \\
\text { pleasant/unpleasant }\end{array}$ & $\begin{array}{l}\text { Lifting materials from/to locations } \\
\text { within my strike-zone is good/bad. }\end{array}$ & $\begin{array}{l}\text { I will say something if my peers take } \\
\text { shortcuts (Reverse-scored). }\end{array}$ \\
\hline & $\begin{array}{l}\text { Inspecionar minhas } \\
\text { ferramentas de trabalho no } \\
\text { início do turno todos os dias } \\
\text { é uma prática segura. }\end{array}$ & & & $\begin{array}{l}\text { I will say something if my supervisor takes } \\
\text { shortcuts (Reverse-scored). }\end{array}$ \\
\hline & $\begin{array}{l}\text { Eu não acho necessário } \\
\text { inspecionar minhas } \\
\text { ferramentas de trabalho no } \\
\text { início do turno todos os dias. } \\
\text { (reverse) }\end{array}$ & $\begin{array}{l}\text { My exercising for at least } 20 \text { minutes, } \\
\text { three times per week for the next three } \\
\text { months would be necessary/unnecessary }\end{array}$ & $\begin{array}{l}\text { Lifting materials from/to locations } \\
\text { within my strike-zone is } \\
\text { important/unimportant. }\end{array}$ & $\begin{array}{l}\text { Bending a procedure is not the same as } \\
\text { breaking it. }\end{array}$ \\
\hline \multirow{2}{*}{$\begin{array}{l}\text { Normas } \\
\text { Subjetivas }\end{array}$} & $\begin{array}{l}\text { A maioria dos meus colegas } \\
\text { me chama atenção quando } \\
\text { eu não inspeciono as } \\
\text { ferramentas de trabalho ao } \\
\text { iniciar minha jornada. }\end{array}$ & $\begin{array}{l}\text { Most people who are important to me } \\
\text { approve of my exercising for at least } 20 \\
\text { minutes, three times per week for the } \\
\text { next three months. }\end{array}$ & $\begin{array}{l}\text { Most people who are important to } \\
\text { me would strongly } \\
\text { encourage/discourage me to lift } \\
\text { materials within my strike-zone. }\end{array}$ & $\begin{array}{l}\text { Undocumented and unauthorized } \\
\text { workarounds exist in my workplace. }\end{array}$ \\
\hline & $\begin{array}{l}\text { A maioria dos meus colegas } \\
\text { não inspecionam suas } \\
\text { ferramentas de trabalho no } \\
\text { início do turno todos os dias. }\end{array}$ & $\begin{array}{l}\text { Most people like me exercised for at } \\
\text { least } 20 \text { minutes, three times per week } \\
\text { in the three months following their } \\
\text { major heart surgery }\end{array}$ & $\begin{array}{l}\text { The people in my life whose } \\
\text { opinions I value would strongly } \\
\text { approve/disapprove of me lifting } \\
\text { materials from/to locations within } \\
\text { my strike-zone. }\end{array}$ & $\begin{array}{l}\text { I am under pressure not to follow } \\
\text { approved procedures in order to get a task } \\
\text { done. }\end{array}$ \\
\hline
\end{tabular}




\begin{tabular}{|c|c|c|c|c|}
\hline \multirow[t]{2}{*}{ Construto } & Questão Adaptada & Fishbein, e Ajzen (2010), & Johnson e Hall (2005) & Fogarty, (2010) \\
\hline & $\begin{array}{l}\text { A maioria dos meus colegas } \\
\text { de trabalho me incentiva a } \\
\text { inspecionar as ferramentas } \\
\text { no início do turno todos os } \\
\text { dias. }\end{array}$ & & & $\begin{array}{l}\text { Other people in my workplace violate } \\
\text { procedures. }\end{array}$ \\
\hline \multirow{3}{*}{$\begin{array}{l}\text { Controle } \\
\text { Percebido }\end{array}$} & $\begin{array}{l}\text { Eu tenho tempo para } \\
\text { inspecionar minhas } \\
\text { ferramentas de trabalho no } \\
\text { início do turno todos os dias. }\end{array}$ & $\begin{array}{l}\text { I am confident that I can exercise for at } \\
\text { least } 20 \text { minutes, three times per week } \\
\text { for the next three months. }\end{array}$ & $\begin{array}{l}\text { I have complete/incomplete control } \\
\text { over lifting materials from/to } \\
\text { locations within my strike-zone. }\end{array}$ & $\begin{array}{l}\text { Adequate time is allocated to complete } \\
\text { assigned tasks. (Reverse-scored) }\end{array}$ \\
\hline & $\begin{array}{l}\text { Eu sei identificar defeitos e } \\
\text { problemas em minhas } \\
\text { ferramentas de trabalho. }\end{array}$ & $\begin{array}{l}\text { My exercising for at least } 20 \text { minutes, } \\
\text { three times per week for the next three } \\
\text { months is up to me }\end{array}$ & $\begin{array}{l}\text { I have complete/incomplete control } \\
\text { over the conditions (facilities, area } \\
\text { layout, resources, etc.) that enable } \\
\text { me to lift materials from/to locations } \\
\text { within my strike-zone. }\end{array}$ & $\begin{array}{l}\text { The physical conditions of my workplace } \\
\text { are satisfactory. (Reverse-score) }\end{array}$ \\
\hline & $\begin{array}{l}\text { Eu sou autorizado a } \\
\text { inspecionar minhas } \\
\text { ferramentas de trabalho no } \\
\text { início do turno todos os dias. }\end{array}$ & & & $\begin{array}{l}\text { I have access to the necessary tools that I } \\
\text { need to carry out assigned tasks. (Reverse- } \\
\text { score) }\end{array}$ \\
\hline \multirow{3}{*}{ Intenção } & $\begin{array}{l}\text { Eu pretendo inspecionar } \\
\text { minhas ferramentas de } \\
\text { trabalho no início do turno } \\
\text { todos os dias. }\end{array}$ & $\begin{array}{l}\text { I intend to exercise for at least } 20 \\
\text { minutes, three times per week for the } \\
\text { next three months. }\end{array}$ & $\begin{array}{l}\text { I intend to lift materials from/to } \\
\text { locations within my strike-zone } \\
\text { every time I lift materials in my work } \\
\text { area over the next } 30 \text { days } \\
\text { agree/disagree. }\end{array}$ & $\begin{array}{l}\text { I am prepared to take shortcuts to get a } \\
\text { task done. }\end{array}$ \\
\hline & $\begin{array}{l}\text { Eu planejo inspecionar } \\
\text { minhas ferramentas de } \\
\text { trabalho no início do turno } \\
\text { todos os dias. }\end{array}$ & & $\begin{array}{l}\text { I plan to lift materials from/to } \\
\text { locations within my strike-zone } \\
\text { every time I lift materials in my work } \\
\text { area over the next } 30 \text { days } \\
\text { agree/disagree. }\end{array}$ & $\begin{array}{l}\text { It is necessary for me to take risks, other } \\
\text { than those inherent in my job, to get a task } \\
\text { done. }\end{array}$ \\
\hline & $\begin{array}{l}\text { A partir de amanhã, é } \\
\text { provável que eu inspecione } \\
\text { minhas ferramentas de } \\
\text { trabalho no início do turno } \\
\text { todos os dias. }\end{array}$ & & $\begin{array}{l}\text { I am extremely likely/unlikely to lift } \\
\text { materials to/from locations in my } \\
\text { strike zone every time I lift materials } \\
\text { in my work area over the next } 30 \\
\text { days. }\end{array}$ & $\begin{array}{l}\text { I am prepared to undertake a task a better } \\
\text { way if I consider the approved }\end{array}$ \\
\hline
\end{tabular}


Completando o modelo, o Quadro 12 ilustram as questões elaboradas para o construto Compromisso Percebido da Supervisão, com base no estudo de Zohar (2005).

Quadro 12 - Questões Adaptadas - Compromisso Percebido da Supervisão

\begin{tabular}{|c|c|c|}
\hline Construto & Questão Adaptada & Zohar (2005) \\
\hline \multirow{9}{*}{$\begin{array}{l}\text { Compromisso } \\
\text { Percebido da } \\
\text { Supervisão }\end{array}$} & $\begin{array}{l}\text { Meu Qualificado verifica frequentemente se } \\
\text { todos na minha equipe inspecionam as } \\
\text { ferramentas no início do turno todos os dias. }\end{array}$ & $\begin{array}{l}\text { Meu supervisor direto verifica } \\
\text { frequentemente se todos estão obedecendo às } \\
\text { regras de segurança. }\end{array}$ \\
\hline & $\begin{array}{l}\text { Meu Qualificado conversa comigo sobre } \\
\text { como as inspeções de ferramentas devem } \\
\text { ser feitas. }\end{array}$ & $\begin{array}{l}\text { Meu supervisor direto discute conosco } \\
\text { (comigo) como melhorar a segurança no } \\
\text { trabalho. }\end{array}$ \\
\hline & $\begin{array}{l}\text { Meu Qualificado me orienta sobre a } \\
\text { importância de inspecionar as ferramentas } \\
\text { de trabalho no início do turno todos os dias. }\end{array}$ & $\begin{array}{l}\text { Meu supervisor direto faz explicações de } \\
\text { modo a fazer como que nós ajamos de forma } \\
\text { segura. }\end{array}$ \\
\hline & $\begin{array}{l}\text { O Qualificado da linha reforça para a equipe } \\
\text { que as ferramentas devem ser inspecionadas } \\
\text { no início do turno mesmo quando estamos } \\
\text { com pressa. }\end{array}$ & $\begin{array}{l}\text { Meu supervisor direto reforça os } \\
\text { procedimentos de segurança quando estamos } \\
\text { trabalhando sob pressão. }\end{array}$ \\
\hline & $\begin{array}{l}\text { O Qualificado da linha frequentemente fala } \\
\text { para minha equipe sobre os perigos de não } \\
\text { inspecionar ferramentas no início do turno. }\end{array}$ & $\begin{array}{l}\text { Meu supervisor direto frequentemente nos } \\
\text { fala sobre os perigos em nosso trabalho. }\end{array}$ \\
\hline & $\begin{array}{l}\text { O Qualificado chama a atenção dos colegas } \\
\text { que não inspecionam suas ferramentas no } \\
\text { início do turno. }\end{array}$ & $\begin{array}{l}\text { Meu supervisor direto chama a atenção dos } \\
\text { trabalhadores que precisam ser cobrados para } \\
\text { trabalharem de forma segura. }\end{array}$ \\
\hline & $\begin{array}{l}\text { O Qualificado insiste que nós devemos } \\
\text { inspecionar as ferramentas que utilizamos } \\
\text { no início do turno todos os dias. }\end{array}$ & $\begin{array}{l}\text { Meu supervisor direto insiste que nós } \\
\text { devemos obedecer às regras de segurança } \\
\text { quando consertamos máquinas e } \\
\text { equipamentos. }\end{array}$ \\
\hline & $\begin{array}{l}\text { O Qualificado da linha elogia os colegas que } \\
\text { sempre inspecionam as ferramentas que } \\
\text { utilizamos no início do turno todos os dias. }\end{array}$ & $\begin{array}{l}\text { Meu supervisor direto reconhece (elogia) os } \\
\text { trabalhadores que tem atenção especial (são } \\
\text { cuidadosos) com a segurança. }\end{array}$ \\
\hline & $\begin{array}{l}\text { Meu Qualificado frequentemente fala sobre } \\
\text { questões de segurança ao longo da semana } \\
\text { de trabalho. }\end{array}$ & $\begin{array}{l}\text { Meu supervisor direto frequentemente fala } \\
\text { sobre questões de segurança ao longo da } \\
\text { semana de trabalho. }\end{array}$ \\
\hline
\end{tabular}

Também foram elaboradas questões para a caracterização da amostra com o levantamento de dados sobre a idade dos respondentes, tempo na empresa, grau de escolaridade e a ocorrência de acidentes que ocasionaram afastamento do trabalho por parte dos respondentes. 
Com base nestas questões adaptadas foi elaborado o modelo de questionário que se encontra no APÊNDICE 7 - Questionário Inicial.

Este questionário, a título de pré-teste, foi aplicado inicialmente para um grupo de 66 operadores, no formato de formulários em papel. Os dados coletados foram tabelados e tratados com o programa IBM SPSS Statistic Versão 19. Os valores calculados para o Alfa de Cronbach para os construtos deste questionário mostraram baixa confiabilidade interna dos mesmos (Tabela 3). Segundo Hair (1998), valore de 0.6 a 0.7 são considerados o limite inferior de aceitabilidade.

Tabela 1 - Alfa de Cronbach (Questionário Versão Inicial)

\begin{tabular}{|l|c|c|}
\hline \multicolumn{1}{|c|}{ Construto } & Alfa de Cronbach & $\begin{array}{c}\text { Número de } \\
\text { Indicadores }\end{array}$ \\
\hline Atitude & 0.507 & 3 \\
\hline Controle Percebido & 0.423 & 3 \\
\hline Intenção & 0.495 & 3 \\
\hline Comportamento & 0.071 & 2 \\
\hline Normas Subjetivas & 0.552 & 3 \\
\hline Compromisso Percebido da Supervisão & 0.868 & 9 \\
\hline
\end{tabular}

Também foi realizada uma Análise Fatorial com os dados coletados, utilizando a Análise do Componente Principal como método de extração. Como método de rotação foi utilizado o Varimax com normalização Kaiser. Foram caracterizados oito fatores para estes dados. A Matriz de Componentes Rotacionados encontra-se no APÊNDICE oito.

Com base nestes resultados foi tomada a decisão de revisar o questionário e repetir o processo de validação que foi realizado por mais duas vezes.

Com base no conjunto de questões formuladas nas versões anteriores, as respectivas avaliações do Alfa de Cronbach e da Análise Fatorial realizada para os dados relativos ao questionário inicial, foram formuladas outros indicadores para a construção do questionário. Algumas questões também foram retiradas dos construtos utilizados nas versões anteriores dos questionários e foram calculadas suas respectivas confiabilidades internas. Foram também alteradas todas as questões inicialmente formuladas com escalas reversas uma vez que se observou que tais indicadores reduziam a confiabilidade dos respectivos construtos, o que pode ser atribuído ao entendimento não consistente das questões por parte dos respondentes. Conforme recomendado por Fishbein e Ajzen (2010) e utilizado no trabalho de 
Johnson e Hall (2005), para o construto Atitude foi utilizada uma escala de diferencial semântico para sua medição.

A versão final do questionário é apresentada no Quadro 13. O modelo de questionário se encontra no APÊNDICE 9 - Questionário Versão Final.

\section{Quadro 13 - Questões (Versão Final)}

\begin{tabular}{|c|c|}
\hline Definição Operacional & Questão Adaptada \\
\hline \multirow{3}{*}{ Comportamento } & $\begin{array}{l}\text { Eu inspeciono minhas ferramentas de trabalho no início do } \\
\text { turno todos os dias. }\end{array}$ \\
\hline & $\begin{array}{l}\text { Esta semana eu inspecionei minhas ferramentas de trabalho no } \\
\text { início do turno todos os dias. }\end{array}$ \\
\hline & $\begin{array}{l}\text { Hoje eu inspecionei minhas ferramentas de trabalho no início } \\
\text { do turno. }\end{array}$ \\
\hline \multirow{4}{*}{ Atitude } & $\begin{array}{l}\text { Eu considero importante inspecionar minhas ferramentas de } \\
\text { trabalho no início do turno todos os dias. }\end{array}$ \\
\hline & $\begin{array}{l}\text { Eu acho seguro inspecionar minhas ferramentas de trabalho no } \\
\text { início do turno todos os dias. }\end{array}$ \\
\hline & $\begin{array}{l}\text { Eu acho bom inspecionar minhas ferramentas de trabalho no } \\
\text { início do turno todos os dias. }\end{array}$ \\
\hline & $\begin{array}{l}\text { Eu acho necessário inspecionar minhas ferramentas de trabalho } \\
\text { no início do turno todos os dias. }\end{array}$ \\
\hline \multirow{4}{*}{ Normas Subjetivas } & $\begin{array}{l}\text { A maioria dos meus colegas me chama atenção quando eu não } \\
\text { inspeciono as ferramentas de trabalho ao iniciar minha jornada. }\end{array}$ \\
\hline & $\begin{array}{l}\text { A maioria dos meus colegas inspeciona as ferramentas de } \\
\text { trabalho no início do turno todos os dias. }\end{array}$ \\
\hline & $\begin{array}{l}\text { A maioria dos meus colegas de trabalho me incentiva a } \\
\text { inspecionar as ferramentas no início do turno todos os dias. }\end{array}$ \\
\hline & $\begin{array}{l}\text { A maioria dos meus colegas acha importante inspecionar as } \\
\text { ferramentas de trabalho todos os dias. }\end{array}$ \\
\hline \multirow{4}{*}{ Controle Percebido } & $\begin{array}{l}\text { Eu tenho tempo para inspecionar minhas ferramentas de } \\
\text { trabalho no início do turno todos os dias. }\end{array}$ \\
\hline & $\begin{array}{l}\text { Eu sei inspecionar minhas ferramentas de trabalho no início do } \\
\text { turno todos os dias. }\end{array}$ \\
\hline & $\begin{array}{l}\text { Eu consigo inspecionar minhas ferramentas de trabalho no } \\
\text { início do turno todos os dias. }\end{array}$ \\
\hline & $\begin{array}{l}\text { Eu sou capaz de inspecionar minhas ferramentas de trabalho no } \\
\text { início do turno todos os dias. }\end{array}$ \\
\hline \multirow{4}{*}{ Intenção } & $\begin{array}{l}\text { Eu pretendo inspecionar minhas ferramentas de trabalho no } \\
\text { início do turno todos os dias. }\end{array}$ \\
\hline & $\begin{array}{l}\text { Eu tenho a intenção de inspecionar minhas ferramentas de } \\
\text { trabalho no início do turno todos os dias. }\end{array}$ \\
\hline & $\begin{array}{l}\text { A partir de amanhã, é provável que eu inspecione minhas } \\
\text { ferramentas de trabalho no início do turno todos os dias. }\end{array}$ \\
\hline & $\begin{array}{l}\text { Eu quero inspecionar minhas ferramentas de trabalho no início } \\
\text { do turno todos os dias. }\end{array}$ \\
\hline Compromisso Percebido da Supervisão & $\begin{array}{l}\text { Meu Qualificado verifica frequentemente se todos na minha } \\
\text { equipe inspecionam as ferramentas no início do turno todos os } \\
\text { dias. }\end{array}$ \\
\hline
\end{tabular}




\begin{tabular}{|l|l|}
\hline Definição Operacional & \multicolumn{1}{|c|}{ Questão Adaptada } \\
\hline \multirow{y}{*}{} & $\begin{array}{l}\text { Meu Qualificado conversa comigo sobre como as inspeções de } \\
\text { ferramentas devem ser feitas. }\end{array}$ \\
\cline { 2 - 3 } & $\begin{array}{l}\text { Meu Qualificado me orienta sobre a importância de inspecionar } \\
\text { as ferramentas de trabalho no início do turno todos os dias. }\end{array}$ \\
\cline { 2 - 3 } $\begin{array}{l}\text { O Qualificado da linha reforça para a equipe que as ferramentas } \\
\text { devem ser inspecionadas no início do turno mesmo quando } \\
\text { estamos com pressa. }\end{array}$ \\
\cline { 2 - 3 } $\begin{array}{l}\text { O Qualificado da linha frequentemente fala para minha equipe } \\
\text { sobre os perigos de não inspecionar ferramentas no início do } \\
\text { turno. }\end{array}$ \\
\cline { 2 - 3 } $\begin{array}{l}\text { O Qualificado chama a atenção dos colegas que não } \\
\text { inspecionam suas ferramentas no início do turno. }\end{array}$ \\
\cline { 2 - 3 } $\begin{array}{l}\text { O Qualificado da linha elogia os colegas que sempre } \\
\text { inspecionam as ferramentas que utilizamos no início do turno } \\
\text { todos os dias. }\end{array}$ \\
\hline
\end{tabular}

De acordo com Martins (2001, p.20) população ou universo é a totalidade dos itens, objetos ou pessoas consideradas e amostra é uma parte da população que é considerada para análise. A população da presente pesquisa é formada pelo quadro de funcionários da Gerência B composto por aproximadamente 2300 funcionários.

Nesta etapa do trabalho foi aplicada a versão final do questionário para três grupos de operadores em três turnos e linhas de produção diferentes dentro da Gerência B.

O questionário foi aplicado nas salas de descanso localizadas nas áreas de produção, ambiente onde os operadores em geral não tem contato com os níveis hierárquicos superiores. Os operadores em grupos de até 10 pessoas foram orientados pelo pesquisador sobre o objetivo do trabalho e também sobre instruções de preenchimento. A pesquisa foi apresentada aos operadores como sendo uma pesquisa sobre práticas operacionais e não sobre comportamentos em relação à segurança com o objetivo de minimizar o viés social nas respostas.

O tempo de resposta ao questionário variou entre 10 e 15 minutos por operador. Através de abordagem direta do pesquisador com os operadores, foi possível verificar que não havia dúvidas significativas em relação ao entendimento das questões. Foram coletados 273 questionários respondidos dos quais doze (12) foram descartados (aproximadamente 10\% do quadro). 


\section{ANÁLISE DOS DADOS}

\subsection{Perfil dos Participantes da Pesquisa}

Os participantes da pesquisa foram envolvidos na realização de entrevistas, acompanhamento a observações de campo e na resposta aos questionários aplicados.

As entrevistas foram realizadas com dois profissionais de Seguranças do Trabalho e quatro Líderes de Produção. As observações de campo foram acompanhadas por dois Técnicos de Segurança do Trabalho. O tempo de trabalho na empresa dos profissionais citados encontrase indicado no Quadro 14, indicando sólida experiência dentro da organização.

\section{Quadro 14 - Participantes das Entrevistas e Observações de Campo}

\begin{tabular}{|l|c|}
\hline \multicolumn{1}{|c|}{ Profissional } & Tempo de Trabalho na Empresa \\
\hline Engenheiro de Segurança do Trabalho A & 12 anos \\
\hline Engenheiro de Segurança do Trabalho B & 13 anos \\
\hline Líder de Turno de Produção A & 12 anos \\
\hline Líder de Turno de Produção B & 11 anos \\
\hline Líder de Turno de Produção C & 13 anos \\
\hline Líder de Turno de Produção D & 9 anos \\
\hline Técnico de Segurança do Trabalho A & 10 anos \\
\hline Técnico de Segurança do Trabalho B & \\
\hline
\end{tabular}

O perfil dos respondentes do questionário da pesquisa foi obtido através das perguntas contidas na Parte D do mesmo e apresenta as características apresentadas nas Tabelas 4 e 5:

Tabela 2 - Tempo de Trabalho na Empresa

\begin{tabular}{|c|c|c|}
\hline Tempo de Trabalho na Empresa & Número de Funcionários & $\%$ \\
\hline Mais de 1 ano & 142 & $52 \%$ \\
\hline Menos de 1 ano & 131 & $48 \%$ \\
\hline Total & 273 & $100 \%$ \\
\hline
\end{tabular}

De acordo com estes dados aproximadamente metade dos operadores entrevistados trabalha na empresa a menos de um ano. 
Esses dados podem sugerir uma menor contribuição da supervisão direta dos Qualificados no comportamento dos operadores em função do pouco tempo de trabalho na organização da maioria desses.

Por outro lado, segundo Dias e Cabrera (1997), ter menos tempo de trabalho na organização pode levar a uma menor familiarização (costume) dos trabalhadores com os riscos, o que no caso desse estudo contribuiria positivamente para a realização das inspeções de segurança. Os operadores, por não estarem acostumados com os riscos, tenderiam a realizar as inspeções.

Tabela 3 - Idade

\begin{tabular}{|l|c|c|}
\hline \multicolumn{1}{|c|}{ Idade } & Número de Funcionários & $\%$ \\
\hline Até 20 anos & 15 & $6 \%$ \\
\hline Entre 21 e 30 anos & 118 & $45 \%$ \\
\hline Entre 31 e 40 anos & 89 & $34 \%$ \\
\hline Entre 41 e 50 anos & 36 & $14 \%$ \\
\hline Mais de 50 anos & 2 & $1 \%$ \\
\hline \multicolumn{1}{|c|}{ Total } & 260 & $100 \%$ \\
\hline
\end{tabular}

(*) 260 foram os respondentes que declararam a idade de um total de 273

De acordo com esses dados aproximadamente $45 \%$ dos operadores tem entre 21 e 30 anos e $78 \%$ dos operadores com idades entre 21 e 40 anos. Aproximadamente $60 \%$ dos Qualificados têm aproximadamente entre 21 e 40 anos. Esses dados podem sugerir uma maior contribuição da supervisão direta dos Qualificados no comportamento dos operadores em função de pertencerem à mesma geração, o que facilitaria a comunicação entre Qualificados e operadores.

Tabela 4 - Acidentes no Trabalho

\begin{tabular}{|c|c|c|}
\hline \multicolumn{1}{|c|}{ Acidentes no Trabalho } & Número de Funcionários & $\%$ \\
\hline Já sofreram acidentes & 82 & $33 \%$ \\
\hline Nunca sofreram acidentes & 191 & $67 \%$ \\
\hline Total & 273 & $100 \%$ \\
\hline
\end{tabular}

A questão perguntava aos operadores se já haviam sofrido algum acidente de trabalho onde tenham sido afastados por mais de um dia de trabalho. 33\% dos operadores responderam de modo afirmativo. Segundo Fishbein M. (1967, p. 257), atitudes são predisposições aprendidas para responder a um dado objeto de forma favorável ou não favorável. Segundo Ajzen (1991, pg.188), as pessoas passam a ser favoráveis a determinados comportamentos quando acreditam que estes possuam características positivas. Esses dados podem sugerir que, as experiências prévias de acidentes de trabalho com $33 \%$ dos respondentes contribuiria 
positivamente para a favorabilidade das Atitudes dos operadores em relação às boas práticas e regras de segurança, o que no caso desse estudo estaria relacionado à maior realização de inspeções nas ferramentas de trabalho.

\subsection{Análise do Contexto Organizacional}

Com o propósito de alcançar o primeiro objetivo específico desta pesquisa se encontram transcritas no APÊNDICE 10 as compilações das entrevistas realizadas com Líderes de Turno e profissionais de Segurança do Trabalho.

- Primeiro Objetivo Específico: analisar o contexto organizacional relacionado à segurança no trabalho.

São apresentadas a seguir as dimensões de Clima de Segurança definidas no item 4.5.2 consideradas relevantes para o entendimento da organização em relação a como o tema Segurança do Trabalho é abordado.

\section{Políticas de Segurança:}

Dias e Cabrera (1997) apresentam em seu trabalho resultados que podem ser interpretados para indicar que as políticas e práticas de segurança da organização estão relacionadas com a percepção global que os trabalhadores formam delas próprias e que as políticas têm impacto sobre o comportamento dos trabalhadores.

Segundo a OSHAS 18002, o grau de aplicação da política de segurança depende entre outros fatores da participação e do envolvimento da alta administração.

Seguem três pontos destacados na compilação das entrevistas em relação à Política de Segurança da organização estudada:

1. A Política de Segurança está em fase de desenvolvimento. Ainda não se tornou um valor para a organização. Não acontece na prática. As pessoas em geral são resistentes em relação a mudar seu modo de trabalhar. 
2. A empresa iniciou a formulação de uma Política de Segurança em setembro de 2011, data em que ocorreu uma fatalidade (acidente de trabalho com morte). Inicialmente a Área de Segurança liderou o processo realizando sua elaboração e buscando as devidas aprovações com as lideranças, porém essas não se sentiam responsáveis pelo tema Segurança em suas áreas.

3. A empresa tem 75 anos e apenas a três iniciou um trabalho de melhoria em Segurança.

Os dados acima podem sugerir que, em função do recente desenvolvimento da política de segurança iniciado pela alta administração e liderado pela Área de Segurança, parte significativa dos trabalhadores não tenham seus comportamentos alinhados com a política.

\section{Procedimentos e Regras de Segurança:}

No estudo de Glendon e Litherland (2001) sobre Clima de Segurança, foi descoberto que a Adequação dos Procedimentos é fator significante. As variáveis que compõem este fator segundo os autores, são relacionadas à acurácia técnica dos procedimentos de trabalho, ao quanto completos e compreensíveis eles são, ao quanto os procedimentos escritos são aplicáveis na prática e ao quanto os procedimentos estão disponíveis. Nesse mesmo estudo outro fator significante encontrado está relacionado às Regras de Segurança. Essas são avaliadas em função de sua praticidade, se são ou não utilizadas sem conflito com práticas de trabalho e se são seguidas mesmo quando os trabalhadores estão pressionados pelo tempo. Os autores citam estudos onde existe correlação entre Clima de Segurança e comportamento seguro.

Schneider (2000) coloca que o comportamento deve ser conceituado como o resultado de um processo de criação de significados (sensemaking) onde estímulos são processados pelos humanos que então se comportam ou talvez até construam as situações nas quais eles respondem.

Seguem quatro pontos destacados na compilação das entrevistas em relação aos Procedimentos e Regras de Segurança da organização estudada: 
1. A maioria dos trabalhadores não tem o entendimento das boas práticas e regras de segurança. Muitos não entendem o porquê das regras. Fazem porque alguém manda.

2. Ainda há muito espaço para melhorias na elaboração de procedimentos e regras de trabalho relacionadas à segurança. Faltam procedimentos e regras gerais mais claras para orientar o comportamento dos trabalhadores e gestores.

3. Em geral os operadores estão dispostos a seguir regras, desde que as entendam.

4. Com relação à inspeção de ferramentas os Líderes têm a percepção de que os operadores sabem e tem tempo suficiente para fazê-las.

Considerando que os operadores em geral não entendem os procedimentos e regras de segurança, parte em função da falta de clareza, parte pela indisponibilidade dos mesmos, é de se esperar que o comportamento desses não seja homogêneo em relação à segurança, o que poderia contribuir para uma maior variabilidade nas respostas obtidas no questionário em relação ao comportamento de estudo.

\section{Levantamento e Reconhecimento dos Riscos}

Seguem três pontos destacados na compilação das entrevistas em relação ao Reconhecimento dos Riscos de trabalho na organização estudada:

1. Os principais riscos associados ao trabalho estão relacionados a queimaduras com metal líquido, movimentação de cargas e prensamentos de mãos e pés. Existem muitos pontos de trabalho bastante perigosos, que oferecem risco alto e merecem adequações de engenharia para reduzir a exposição dos trabalhadores.

2. Entende-se que a maioria dos trabalhadores está acostumada aos riscos com o qual convive e apresenta baixa percepção em relação a esses.

3. Em relação à inspeção de ferramentas existe a percepção por parte dos Líderes de que a maioria dos operadores as realiza com frequência.

Seo (2005) cita pesquisas em que o risco percebido pelos trabalhadores (percepção da probabilidade de ocorrem um ferimento cruzada com seu grau de severidade) está 
relacionado com experiências em acidentes anteriores e com comportamentos inseguros no trabalho.

Aas respostas compiladas acima sugerem que os trabalhadores apresentam uma baixa percepção aos riscos e uma possível explicação para este dado pode estar no fato de que a maioria não sofreu nenhum acidente de trabalho. Entretanto, especificamente com relação à realização de inspeções nas ferramentas, o fato mencionado anteriormente de que $37 \%$ dos acidentes ocorridos na área estudada apresentarem alguma relação com a utilização de ferramentas sugere que os operadores reconhecem os riscos relativos a não realizarem as inspeções. Assim, é de se esperar que este fato contribua para a favorabilidade da Atitude desses em relação à realização de inspeções de segurança.

\subsection{Avaliação da Compreensão do Comportamento}

Seguem as análises das frequências das respostas obtidas no questionário bem como a avaliação do modelo proposto.

Estas análises visam alcançar o segundo objetivo específico desse trabalho.

- Segundo Objetivo Específico: Avaliar a compreensão do comportamento dos trabalhadores em relação à segurança, utilizando os construtos e relações propostos pela Teoria da Ação Planejada.

\subsubsection{Análise das Frequências das Respostas}

Os cálculos relativos às frequências das respostas encontram-se no APÊNDICE 11 e são apresentados nas Tabelas 7, 8, 9, 10 e 11. 
Tabela 5 - Frequências das Respostas sobre o Comportamento de Estudo

\begin{tabular}{|l|l|l|}
\hline Comportamento & $\begin{array}{l}\text { Concordo ou } \\
\text { Concordo } \\
\text { Fortemente }\end{array}$ & $\begin{array}{l}\text { Discordo ou } \\
\text { Discordo } \\
\text { Fortemente }\end{array}$ \\
\hline $\begin{array}{l}\text { B1: Eu inspeciono minhas ferramentas de trabalho no início do turno } \\
\text { todos os dias. }\end{array}$ & $72 \%$ & $4 \%$ \\
\hline $\begin{array}{l}\text { B5: Esta semana eu inspecionei minhas ferramentas de trabalho no } \\
\text { início do turno todos os dias. }\end{array}$ & $57 \%$ & $14 \%$ \\
\hline $\begin{array}{l}\text { B10: Hoje eu inspecionei minhas ferramentas de trabalho no início do } \\
\text { turno }\end{array}$ & $61 \%$ & $21 \%$ \\
\hline
\end{tabular}

Os números acima são compatíveis com a percepção dos Líderes de que a maioria dos operadores realiza inspeções de segurança nas ferramentas antes de iniciar a jornada de trabalho. Deve-se notar que $14 \%$ dos respondentes da questão $\mathrm{B5}$ e $21 \%$ dos respondentes da B10 declaram discordar das afirmações, o que são números expressivos. Considerando que a não realização de inspeções nas ferramentas apresenta um alto risco para o operador, pode ser considerada baixa a porcentagem de respondentes que concordam com as afirmações. Esses números podem sugerir que o procedimento para a realização das inspeções deva ser mais detalhado e de modo a prover maior clareza sobre qual a frequência de realização das inspeções, o tempo estimado para a realização e os passos da tarefa. Também pode sugerir que os Qualificados não estejam reforçando a necessidade de realização das inspeções para suas equipes.

Tabela 6 - Frequências das Respostas sobre Atitude

\begin{tabular}{|l|c|c|}
\hline Atitude & $\begin{array}{l}\text { Concordo ou } \\
\text { Concordo } \\
\text { Fortemente }\end{array}$ & $\begin{array}{l}\text { Discordo ou } \\
\text { Discordo } \\
\text { Fortemente }\end{array}$ \\
\hline $\begin{array}{l}\text { A1. Eu considero importante inspecionar minhas ferramentas de } \\
\text { trabalho no início do turno todos os dias. }\end{array}$ & $94 \%$ & $1 \%$ \\
\hline $\begin{array}{l}\text { A2. Eu acho seguro inspecionar minhas ferramentas de trabalho no } \\
\text { início do turno todos os dias. }\end{array}$ & $72 \%$ & $1 \%$ \\
\hline $\begin{array}{l}\text { A3 } \text { Eu acho bom inspecionar minhas ferramentas de trabalho no início } \\
\text { do turno todos os dias. }\end{array}$ & $80 \%$ & $3 \%$ \\
\hline $\begin{array}{l}\text { A4. Eu acho necessário inspecionar minhas ferramentas de trabalho no } \\
\text { início do turno todos os dias. }\end{array}$ & $92 \%$ & $3 \%$ \\
\hline
\end{tabular}


Os números demonstram uma forte favorabilidade dos respondentes em relação à prática de inspecionar ferramentas de trabalho no início do turno todos os dias, sugerindo que não há necessidade de um grande esforço das lideranças da organização para convencer os operadores da importância ou da necessidade de executar essa tarefa.

Tabela 7 - Frequências das Respostas sobre Controle Percebido

\begin{tabular}{|l|c|c|}
\hline Controle Percebido & $\begin{array}{l}\text { Concordo ou } \\
\text { Concordo Fortemente }\end{array}$ & $\begin{array}{l}\text { Discordo ou } \\
\text { Discordo Fortemente }\end{array}$ \\
\hline $\begin{array}{l}\text { B3. Eu tenho tempo para inspecionar minhas } \\
\text { ferramentas de trabalho no início do turno todos } \\
\text { os dias. }\end{array}$ & $58 \%$ & $18 \%$ \\
\hline $\begin{array}{l}\text { B7. Eu sei inspecionar minhas ferramentas de } \\
\text { trabalho no início do turno todos os dias. }\end{array}$ & $81 \%$ & $3 \%$ \\
\hline $\begin{array}{l}\text { B12. Eu consigo inspecionar minhas ferramentas } \\
\text { de trabalho no início do turno todos os dias. }\end{array}$ & $58 \%$ & $12 \%$ \\
\hline $\begin{array}{l}\text { B14. Eu sou capaz de inspecionar minhas } \\
\text { ferramentas de trabalho no início do turno todos } \\
\text { os dias. }\end{array}$ & $85 \%$ & $2 \%$ \\
\hline
\end{tabular}

Os números acima compatíveis com a percepção dos Líderes de que a maioria dos operadores tem tempo, sabem e conseguem realizar inspeções de segurança nas ferramentas antes de iniciar a jornada de trabalho. Deve-se notar que $18 \%$ dos respondentes discordam de ter tempo suficiente para realizar as inspeções (questão B3) e que $\mathbf{1 2 \%}$ discordam em conseguir realizar as inspeções todos os dias no início da jornada de trabalho (questão B12) o que pode reforçar a necessidade de prover maior clareza sobre frequência, tempo e passos da tarefa.

Tabela 8 - Frequências das Respostas sobre Normas Subjetivas

\begin{tabular}{|l|c|c|}
\hline Normas Subjetivas & $\begin{array}{l}\text { Concordo ou } \\
\text { Concordo Fortemente }\end{array}$ & $\begin{array}{l}\text { Discordo ou } \\
\text { Discordo Fortemente }\end{array}$ \\
\hline $\begin{array}{l}\text { B2. A maioria dos meus colegas me chama } \\
\text { atenção quando eu não inspeciono as ferramentas } \\
\text { de trabalho ao iniciar minha jornada. }\end{array}$ & $31 \%$ & $33 \%$ \\
\hline $\begin{array}{l}\text { B6. A maioria dos meus colegas inspeciona as } \\
\text { ferramentas de trabalho no início do turno todos } \\
\text { os dias. }\end{array}$ & $24 \%$ & $25 \%$ \\
\hline $\begin{array}{l}\text { B9. A maioria dos meus colegas de trabalho me } \\
\text { incentiva a inspecionar as ferramentas no início } \\
\text { do turno todos os dias. }\end{array}$ & $26 \%$ & $33 \%$ \\
\hline $\begin{array}{l}\text { B11. A maioria dos meus colegas acha importante } \\
\text { inspecionar as ferramentas de trabalho todos os } \\
\text { dias. }\end{array}$ & $52 \%$ & $11 \%$ \\
\hline
\end{tabular}


Analisando a questão B6 pode-se observar que a percepção dos operadores sobre seus pares em reação à realização da inspeção nas ferramentas é de que a maioria não as realiza. Em contrapartida, os operadores em sua maioria declaram que as realizam (vide Tabela 8).

Churchil (2009, p.221) afirma que quando um tema é embaraçoso ou mesmo ameaçador para os respondentes esses tendem a não cooperar com a pesquisa. Os dados acima podem sugerir um viés nas respostas relativas ao comportamento de estudo, indicando que a frequência dos respondentes que concordam com as questões apresentadas na Tabela 8 esteja superestimada quando comparada ao Comportamento real.

Também é possível observar pelas respostas dadas nas questões B2 e B9 que os operadores não percebem seus pares incentivando-os a realizarem as inspeções, podendo esse dado ser um indicador de pouca pressão social para a realização de inspeções nas ferramentas, o que reduziria a contribuição das Normas Sociais sobre a Intenção, relação prevista na Teoria da Ação Planejada.

Tabela 9 - Frequências das Respostas sobre Intenção

\begin{tabular}{|l|c|c|}
\hline Intenção & $\begin{array}{l}\text { Concordo ou } \\
\text { Concordo Fortemente }\end{array}$ & $\begin{array}{l}\text { Discordo ou } \\
\text { Discordo Fortemente }\end{array}$ \\
\hline $\begin{array}{l}\text { B4. Eu pretendo inspecionar minhas ferramentas } \\
\text { de trabalho no início do turno todos os dias. }\end{array}$ & $78 \%$ & $4 \%$ \\
\hline $\begin{array}{l}\text { B8. Eu tenho a intenção de inspecionar minhas } \\
\text { ferramentas de trabalho no início do turno todos } \\
\text { os dias. }\end{array}$ & $75 \%$ & $4 \%$ \\
\hline $\begin{array}{l}\text { B13. A partir de amanhã, é provável que eu } \\
\text { inspecione minhas ferramentas de trabalho no } \\
\text { início do turno todos os dias. }\end{array}$ & $71 \%$ & $6 \%$ \\
\hline $\begin{array}{l}\text { B15. Eu quero inspecionar minhas ferramentas de } \\
\text { trabalho no início do turno todos os dias. }\end{array}$ & $82 \%$ & $3 \%$ \\
\hline
\end{tabular}

Os números demonstram uma forte intenção dos operadores em realizar as inspeções nas ferramentas todos os dias no início da jornada de trabalho, de modo similar ao observado com relação ao construto Atitude (vide Tabela 9). 


\subsubsection{Avaliação do Modelo de Mensuração}

O modelo proposto foi submetido à técnica de Modelagem de Equações Estruturais utilizando o programa SMARTPLS versão 2.0 M3.

Segundo Malhorta (2010), a validade do modelo de mensuração depende da adequação dos resultados, da confiabilidade e da evidência da validade do construto e, especialmente das validades convergentes e discriminantes.

Foram utilizados os critérios abaixo para avaliação do modelo de mensuração, conforme recomendados por Hair (2011): Confiabilidade Composta, Variância Média Extraída, Confiabilidade de Indicadores e Validade Discriminante pelo critério de Fornell-Larcker. Também foi utilizado o Alfa de Cronbach como indicador de confiabilidade interna.

Alfa de Cronbach: definido como "[...] medida da confiabilidade da consistência interna que é a média de todos os coeficientes possíveis resultantes de diferentes divisões de uma escala em duas metades" (MALHORTA, 2010). Os valores calculados para o Alfa de Cronbach para os construtos deste questionário mostraram confiabilidades internas adequadas. Foi obtido um valor limite para o construto Controle Percebido. Segundo Hair (1998, p. 100), valores entre 0.6 a 0.7 são considerados o limite inferior de aceitabilidade.

Confiabilidade Composta (CC): definida como a quantidade total de variância de escore verdadeiro em relação à variância de escore total. É uma medida de confiabilidade do construto. Como orientação geral, valores para confiabilidade composta maiores que 0,7 são considerados bons. Estimativas entre 0,6 e 0,7 podem ser consideradas aceitáveis se as estimativas de validade do modelo forem boas. (HAIR, 2011).

Variância Média Extraída (AVE): AVE (Average Variance Extracted) é definida como a variância nos indicadores ou variáveis observadas que é explicada pelo construto latente. É uma medida de validade convergente e indica até que ponto a escala se correlaciona positivamente com outras variáveis do mesmo construto. A AVE varia de 0 a 1 e representa a razão da variância total que é devida à variável latente. Uma AVE maior do que 0,5 indica uma validade convergente satisfatória (HAIR, 2011). 
Validade Discriminante: para avaliar a validade discriminante cada variável deve partilhar sua variância mais com seu bloco de indicadores do que com qualquer outra variável latente. Assim a raiz quadrada do AVE de cada variável latente deve ser maior do que a correlação com as outras variáveis latentes. (HAIR, 2011).

Cross-Loading: Esta também é uma medida de avaliação da validade discriminante. Se um indicador possuir uma correlação maior com outra variável latente do que com a sua própria o modelo deverá ser revisto. (HAIR, 2011).

Para o modelo proposto foram obtidos os seguintes valores para os critérios acima definidos, apresentados nas Tabelas 12, 13 e 14:

Tabela 10 - Valores de AVE, Raiz AVE, Confiabilidade Composta e Alfa de Cronbach

\begin{tabular}{|c|c|c|c|c|}
\hline MODELO PROPOSTO & AVE & RAIZ2 (AVE) & $\begin{array}{c}\text { Confiabilidade } \\
\text { Composta }\end{array}$ & Cronbach Alpha \\
\hline ATITUDE & 0.548 & 0.740 & 0.828 & 0.724 \\
\hline COMPORTAMENTO & 0.683 & 0.827 & 0.865 & 0.765 \\
\hline CONTROLE PERC. & 0.494 & 0.703 & 0.792 & 0.654 \\
\hline INTENCAO & 0.565 & 0.752 & 0.839 & 0.745 \\
\hline SUPERVISÃO & 0.666 & 0.816 & 0.933 & 0.916 \\
\hline NORMA SUB. & 0.602 & 0.776 & 0.857 & 0.778 \\
\hline
\end{tabular}

Tabela 11 - Correlações entre Variáveis Latentes

\begin{tabular}{|c|c|c|c|c|c|c|}
\hline MODELO PROPOSTO & ATITUDE & $\begin{array}{c}\text { COMPORTA- } \\
\text { MENTO }\end{array}$ & $\begin{array}{c}\text { CONTRO- } \\
\text { LE PERC. }\end{array}$ & $\begin{array}{c}\text { INTEN- } \\
\text { CAO }\end{array}$ & $\begin{array}{c}\text { SUPERVI- } \\
\text { SÃO }\end{array}$ & $\begin{array}{c}\text { NORMA } \\
\text { SUB. }\end{array}$ \\
\hline ATITUDE & 1 & 0 & 0 & 0 & 0 & 0 \\
\hline COMPORTAMENTO & 0.2266 & 1 & 0 & 0 & 0 & 0 \\
\hline CONTROLE PERC. & 0.1641 & 0.5928 & 1 & 0 & 0 & 0 \\
\hline INTENCAO & 0.3418 & 0.5491 & 0.5161 & 1 & 0 & 0 \\
\hline SUPERVISÃO & 0.1167 & 0.461 & 0.4444 & 0.3975 & 1 & 0 \\
\hline NORMA SUB. & 0.0659 & 0.5482 & 0.5573 & 0.4522 & 0.5763 & 1 \\
\hline
\end{tabular}


Tabela 12 - Matriz de Cross-Loading - Modelo 1

\begin{tabular}{|c|c|c|c|c|c|c|}
\hline $\begin{array}{c}\text { VARIÁVEIS DO } \\
\text { MODELO PROPOSTO }\end{array}$ & ATITUDE & $\begin{array}{c}\text { COMPORTA } \\
\text {-MENTO }\end{array}$ & $\begin{array}{c}\text { CONTRO- } \\
\text { LE PERC. }\end{array}$ & $\begin{array}{c}\text { INTEN- } \\
\text { CAO }\end{array}$ & $\begin{array}{c}\text { SUPERVI } \\
\text { SÃO }\end{array}$ & $\begin{array}{c}\text { NORMA } \\
\text { SUB. }\end{array}$ \\
\hline A1 & 0.6723 & 0.141 & 0.0915 & 0.2005 & 0.0477 & -0.0525 \\
\hline A2 & 0.7739 & 0.1558 & 0.1319 & 0.2527 & 0.106 & 0.0536 \\
\hline A3 & 0.8035 & 0.215 & 0.1298 & 0.2828 & 0.1016 & 0.1225 \\
\hline A4 & 0.7038 & 0.1543 & 0.1276 & 0.2671 & 0.0832 & 0.05 \\
\hline B1 & 0.2336 & 0.7211 & 0.3923 & 0.4266 & 0.316 & 0.3254 \\
\hline B10 & 0.1973 & 0.8756 & 0.5115 & 0.4559 & 0.4072 & 0.4799 \\
\hline B11 & 0.1267 & 0.3511 & 0.439 & 0.4104 & 0.4651 & 0.7674 \\
\hline B12 & 0.0686 & 0.5168 & 0.8469 & 0.3713 & 0.3845 & 0.4855 \\
\hline B13 & 0.1594 & 0.4618 & 0.4878 & 0.7555 & 0.3468 & 0.4127 \\
\hline B14 & 0.1081 & 0.3038 & 0.5878 & 0.3813 & 0.1523 & 0.2193 \\
\hline B15 & 0.3413 & 0.3369 & 0.3378 & 0.7033 & 0.2487 & 0.2917 \\
\hline B2 & -0.0171 & 0.3941 & 0.3456 & 0.3039 & 0.376 & 0.6948 \\
\hline B3 & 0.1922 & 0.4317 & 0.7606 & 0.3745 & 0.4339 & 0.5074 \\
\hline B4 & 0.3506 & 0.4912 & 0.3572 & 0.7927 & 0.306 & 0.329 \\
\hline B5 & 0.1442 & 0.8738 & 0.5526 & 0.4793 & 0.4124 & 0.5338 \\
\hline B6 & 0.0868 & 0.4796 & 0.4883 & 0.3402 & 0.4331 & 0.7919 \\
\hline B7 & 0.0884 & 0.3888 & 0.5793 & 0.3501 & 0.2044 & 0.2789 \\
\hline B8 & 0.1727 & 0.3314 & 0.3562 & 0.7537 & 0.2838 & 0.3149 \\
\hline B9 & -0.0081 & 0.4783 & 0.4436 & 0.3403 & 0.5035 & 0.8412 \\
\hline C1 & 0.0292 & 0.4221 & 0.3606 & 0.3189 & 0.7696 & 0.4964 \\
\hline C2 & 0.1087 & 0.3351 & 0.3808 & 0.3242 & 0.8367 & 0.462 \\
\hline C3 & 0.0954 & 0.2935 & 0.2984 & 0.2308 & 0.8091 & 0.3724 \\
\hline C4 & 0.0703 & 0.374 & 0.3622 & 0.3128 & 0.8505 & 0.46 \\
\hline C5 & 0.1939 & 0.3565 & 0.3331 & 0.3701 & 0.7984 & 0.4501 \\
\hline C6 & 0.1148 & 0.4616 & 0.4667 & 0.4191 & 0.8798 & 0.5807 \\
\hline C7 & 0.0481 & 0.3576 & 0.2956 & 0.2508 & 0.7608 & 0.4264 \\
\hline
\end{tabular}

Com base nos critérios acima definidos temos que:

- AVE - os valores obtidos para todos os construtos (variáveis latentes) foram maiores do que 0.5, com exceção do construto Controle Percebido que foi de 0.494, considerada limítrofe.

- Confiabilidade Composta - os valores para todos os construtos (variáveis latentes) foram maiores do que 0,7 .

- Validade Discriminante: os valores para a RAIZ (AVE) para todos os construtos (variáveis latentes) foram maiores do que os valores das correlações entre as variáveis.

- Cross-Loading: todos os indicadores possuem valores de correlação com suas respectivas variáveis latentes maiores do que com outras variáveis.

Com base nesses critérios pode-se dizer que o modelo de mensuração utilizado é aceitável. 


\subsubsection{Avaliação do Modelo Estrutural}

A Figura 14 ilustra a avaliação do modelo estrutural.

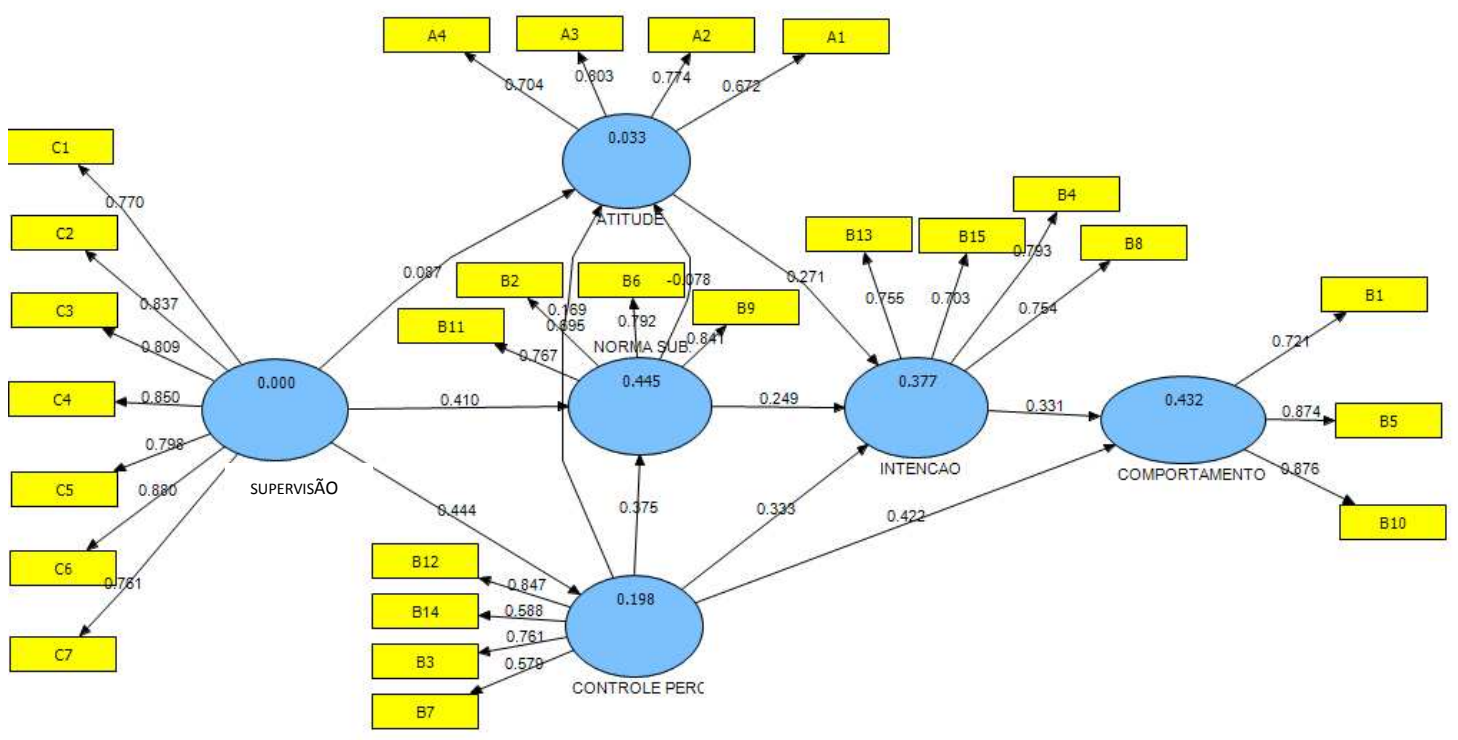

Figura 14 - Avaliação do Modelo Estrutural

De acordo com Hair (2011) os principais critérios para avaliação de um modelo estrutural são a avaliação do R2 e o grau e significância dos coeficientes de caminho. Para Tenehaus et al (2009), o principal critério de avaliação de confiabilidade de um modelo estrutural é a determinação de R2 para as variáveis latentes endógenas. O julgamento de qual nível de R2 pode ser considerado alto depende das disciplinas de pesquisa (HAIR, 2011). Chin (1988) considera os valores de R2 de 0.67, 0.33 e 0.19 no PLS, como sendo, substanciais, moderados e fracos, respectivamente. Hair (2012) aponta como uma desvantagem o fato do PLS não possuir um critério global de otimização o que resulta na falta de um índice de ajuste do modelo, possibilitando comparações.

Ao invés de considerar uma distribuição assumida dos dados a reamostagem permite calcular uma distribuição empírica de parâmetros estimados (HAIR, 1998). Por meio da remostarem são criadas múltiplas amostras da amostra original e calculados intervalos de confiança da distribuição de parâmetros estimados. 
Um dos métodos de remostarem é o bootstrapping utilizado na modelagem de caminho no PLS, que obtém sua amostra via amostragem com reposição da amostra original.

Utilizando esta técnica, foram geradas 300 amostras e realizado o teste $\mathrm{T}$ com os resultados apresentados na Tabela 15:

Tabela 13 - Bootstrapping

\begin{tabular}{|l|c|c|c|c|}
\hline \multicolumn{1}{|c|}{ MODELO PROPOSTO } & $\begin{array}{c}\text { Média da } \\
\text { Amostra } \\
\text { Original (Betas) }\end{array}$ & $\begin{array}{c}\text { Média das 300 } \\
\text { amostras geradas }\end{array}$ & Desvio Padrão & $\begin{array}{c}\text { Estatística T- } \\
\text { student }\end{array}$ \\
\hline ATITUDE -> INTENCAO & 0.271 & 0.281 & 0.112 & 2.425 \\
\hline $\begin{array}{l}\text { CONTROLE PERC. -> } \\
\text { ATITUDE }\end{array}$ & 0.169 & 0.190 & 0.119 & 1.422 \\
\hline $\begin{array}{l}\text { CONTROLE PERC. -> } \\
\text { COMPORTAMENTO }\end{array}$ & 0.422 & 0.419 & 0.116 & 3.635 \\
\hline $\begin{array}{l}\text { CONTROLE PERC. -> } \\
\text { INTENCAO }\end{array}$ & 0.333 & 0.341 & 0.128 & 2.602 \\
\hline $\begin{array}{l}\text { CONTROLE PERC. -> NORMA } \\
\text { SUB. }\end{array}$ & 0.375 & 0.379 & 0.082 & 4.600 \\
\hline $\begin{array}{l}\text { INTENCAO -> } \\
\text { COMPORTAMENTO }\end{array}$ & 0.332 & 0.339 & 0.121 & 2.749 \\
\hline SUPERVISÃO -> ATITUDE & 0.087 & 0.094 & 0.126 & 0.690 \\
\hline $\begin{array}{l}\text { SUPERVISÃO -> CONTROLE } \\
\text { PERC. }\end{array}$ & 0.444 & 0.453 & 0.086 & 5.174 \\
\hline SUPERVISÃO -> NORMA SUB. & 0.410 & 0.410 & 0.079 & 5.163 \\
\hline NORMA SUB. -> ATITUDE & -0.078 & -0.071 & 0.140 & 0.560 \\
\hline NORMA SUB. -> INTENCAO & 0.249 & 0.242 & 0.098 & 2.534 \\
\hline
\end{tabular}

O resultado do bootstrapping mostrou que não houve diferenças significativas entre a amostra original e as amostras geradas, com exceção de 3 (três), indicando que não foram evidenciadas relações significativas entre os construtos abaixo com base nos dados coletados com base no valor da estatística T-student (valores maiores que 1.96 indicam relação significativa entre os construtos).

- Controle Percebido $\rightarrow$ Atitude

- Normas Subjetivas $\rightarrow$ Atitude

- Compromisso Percebido da Supervisão $\rightarrow$ Atitude

No modelo proposto os valores de R2 obtidos estão indicados na Tabela 16: 
Tabela 14 - Valores de R2

\begin{tabular}{|c|c|}
\hline MODELO PROPOSTO & R Square \\
\hline ATITUDE & 0.033 \\
\hline COMPORTAMENTO & 0.432 \\
\hline CONTROLE PERC. & 0.198 \\
\hline INTENCAO & 0.377 \\
\hline SUPERVISÃO & 0.000 \\
\hline NORMA SUB. & 0.445 \\
\hline
\end{tabular}

A Teoria da Ação Planejada, como regra geral, sugere que quanto mais favoráveis forem as Atitudes e as Normas Subjetivas e quanto maior for à percepção de Controle sobre determinado comportamento, maior será a Intenção pessoal em realizar tal comportamento. Na medida em que a percepção se aproxima do real controle sobre o comportamento, a teoria também sugere que o Controle Percebido tem influência na realização do comportamento. (Ajzen, 2010). Essas relações foram observadas nesse estudo.

Ajzen (2010) cita vários autores que realizaram meta-análises de estudos anteriores utilizando a Teoria da Ação Planejada. São apresentadas na Tabela 17 as cargas fatoriais encontradas por esses autores e outros citados nesse trabalho. 
Tabela 15 - Valores de Cargas Fatoriais obtidos em outros estudos

\begin{tabular}{|c|c|c|c|}
\hline Relações & Pesquisa & $\begin{array}{c}\text { Meta-Análises e } \\
\text { outros estudos }\end{array}$ & Autores \\
\hline Atitude $\rightarrow$ Intenção & 0.271 & $\begin{array}{c}0.59 \text { a } 0.66 \\
0.40 \text { a } 0.57 \\
0.37 \\
0.00 \\
\end{array}$ & $\begin{array}{c}\text { Vários }(*) \\
\text { McEachan et al. (2011) } \\
\text { Fogarty (2010) } \\
\text { Johnson e Hall (2005) }\end{array}$ \\
\hline Norma Subjetiva $\rightarrow$ Intenção & 0.249 & $\begin{array}{c}0.59 \text { a } 0.66 \\
0.40 \text { a } 0.57 \\
0.36 \\
0.22\end{array}$ & $\begin{array}{c}\text { Vários }(*) \\
\text { McEachan et al. (2011) } \\
\text { Fogarty (2010) } \\
\text { Johnson e Hall (2005) }\end{array}$ \\
\hline Controle Percebido $\rightarrow$ Intenção & 0.333 & $\begin{array}{c}0.4 \\
0.59 \text { a } 0.66 \\
0.40 \text { a } 0.57 \\
0.32 \\
0.62\end{array}$ & $\begin{array}{c}\text { Armitage and Conner (2001) } \\
\text { Vários }(*) \\
\text { McEachan et al. }(2011) \\
\text { Fogarty (2010) } \\
\text { Johnson e Hall (2005) }\end{array}$ \\
\hline Controle Percebido $\rightarrow$ Comportamento & 0.422 & $\begin{array}{l}0.31 \\
0.65\end{array}$ & $\begin{array}{l}\text { McEachan et al. (2011) } \\
\text { Johnson e Hall (2005) }\end{array}$ \\
\hline Intenção $\rightarrow$ Comportamento & 0.333 & $\begin{array}{l}0.53 \\
0.40 \\
0.25 \\
0.44\end{array}$ & $\begin{array}{c}\text { Sheeran (2002) } \\
\text { McEachan et al. (2011) } \\
\text { Fogarty (2010) } \\
\text { Johnson e Hall (2005) }\end{array}$ \\
\hline
\end{tabular}

FONTE: Ajzen (2010), Fogarty (2010), Johnson e Hall (2005)

Vários (*): (Armitage \& Conner, 2001; Cheung \& Chan, 2000; Notani, 1998; Rivis \& Sheeran, 2003; Schulze \& Wittmann, 2003), citados por Ajzen (2010)

Embora os valores das cargas fatoriais obtidos estejam daqueles reportados em estudos que utilizaram a Teoria da Ação Planejada citados por Ajzen (2010), os resultados obtidos na avaliação do modelo estrutural deste trabalho validam as relações previstas na teoria. As relações obtidas entre os construtos neste estudo foram estatisticamente significantes (vide Tabela 17) e positivas, validando as hipóteses H4, H5, H6, H7, H8 e H9 (vide Quadro 14).

O Quadro 15 apresenta as hipóteses e suas respectivas validações: 


\section{Quadro 15- Validação das Hipóteses de Pesquisa}

\begin{tabular}{|c|c|}
\hline Hipóteses de Pesquisa & Validação \\
\hline $\begin{array}{l}\text { H1: quanto mais favorável for o Compromisso Percebido da Supervisão em relação a Segurança } \\
\text { maior será a favorabilidade dos trabalhadores em relação à segurança (Atitude). }\end{array}$ & $\begin{array}{l}\text { Não } \\
\text { suportada }\end{array}$ \\
\hline $\begin{array}{l}\text { H2: quanto mais favorável for o Compromisso Percebido da Supervisão em relação a Segurança } \\
\text { maior será a percepção dos trabalhadores sobre as Normas Subjetivas. }\end{array}$ & Suportada \\
\hline $\begin{array}{l}\text { H3: quanto mais favorável for o Compromisso Percebido da Supervisão em relação a Segurança } \\
\text { maior será a percepção sobre o Controle Percebido }\end{array}$ & Suportada \\
\hline $\begin{array}{l}\text { H4: quanto mais favorável for a Atitude em relação à segurança maior será a Intenção em } \\
\text { realizar um Comportamento em relação à segurança. }\end{array}$ & Suportada \\
\hline $\begin{array}{l}\text { H5: quanto mais fortes forem as Normas Subjetivas, maior será a Intenção em realizar um } \\
\text { Comportamento em relação à segurança. }\end{array}$ & Suportada \\
\hline $\begin{array}{l}\text { H6: quanto mais forte for o Controle Percebido maior será a Intenção em realizar um } \\
\text { Comportamento em relação à segurança. }\end{array}$ & Suportada \\
\hline H7: quanto maior a Intenção mais favorável será o Comportamento em relação à segurança. & Suportada \\
\hline $\begin{array}{l}\text { H8: quanto mais forte for o Controle Percebido maior será o Comportamento em relação à } \\
\text { segurança; }\end{array}$ & Suportada \\
\hline $\begin{array}{l}\text { H9: quanto mais forte for o Controle Percebido maior será a percepção dos trabalhadores sobre } \\
\text { as Normas Subjetivas; }\end{array}$ & Suportada \\
\hline $\begin{array}{l}\text { H10: quanto mais forte for o Controle Percebido maior será a favorabilidade dos trabalhadores } \\
\text { em relação à segurança (Atitude) }\end{array}$ & $\begin{array}{c}\text { Não } \\
\text { suportada }\end{array}$ \\
\hline $\begin{array}{l}\text { H11: quanto mais fortes forem as Normas Subjetivas, maior será a favorabilidade dos } \\
\text { trabalhadores em relação à segurança (Atitude); }\end{array}$ & $\begin{array}{c}\text { Não } \\
\text { suportada }\end{array}$ \\
\hline
\end{tabular}

\subsubsection{Avaliação dos Fatores que compõe o modelo}

De modo complementar à Modelagem de Equações Estruturais os dados obtidos nos questionários foram submetidos a uma Análise Fatorial cujo objetivo era confirmar os fatores assumidos no modelo teórico. Foi utilizado o programa SPSS Versão 19.

O método de análise fatorial utilizado foi o da Análise dos Componentes Principais. Segundo Malhorta (2010) este método é recomendado quando o objetivo é determinar o número mínimo de fatores que respondem pela máxima variância dos dados para utilização em análises multivariadas subsequentes. 
A determinação do número de fatores foi baseada com base em autovalores, quando são retidos apenas os fatores com autovalores superiores a 1.0. A rotação das cargas fatoriais expressas na matriz de fatores padronizados foi realizada utilizando-se o Método Varimax, por tratar-se de um método de rotação que minimiza o número de variáveis com altas cargas em um fator, melhorando assim a interpretação dos dados (MALHORTA, 2010).

Para avaliação da conveniência do modelo fatorial avaliado foram utilizados dois critérios:

Coeficiente de Esfericidade de Bartellet: teste utilizado para examinar a hipótese de que as variáveis não são correlacionadas na população. Valores altos do Qui-quadrado favorecem a rejeição da hipótese nula (Hipótese nula = variáveis não são correlacionadas na população) (MALHORTA, 2010).

Medida de adequação da amostra de Kaiser-Meier-Olkin (KMO): índice utilizado para avaliar a adequação da análise fatorial. Valores altos (entre 0,5 e 1,0) indicam que a análise fatorial é apropriada (MALHORTA, 2010).

Os valores obtidos no tratamento dos dados para a análise fatorial são apresentados na Tabela 18:

Tabela 16 - Análise Fatorial

\begin{tabular}{|l|l|c|}
\hline \multicolumn{1}{|c|}{ Critério de Análise } & \multicolumn{1}{|c|}{ Valore Obtidos } & \multicolumn{1}{c|}{ Referências } \\
\hline KMO & KMO $=0,895$ & KMO $>0,5$ \\
\hline \multirow{3}{*}{ Esfericidade de Bartellet } & Chi-Quadrado: 3258,537 & Valores altos \\
\cline { 2 - 3 } & Graus de Liberdade: 325 & - \\
\cline { 2 - 3 } & Significância: 0,000 & - \\
\hline
\end{tabular}

Com base nestes resultados pode-se concluir que a análise fatorial pode ser considerada uma técnica apropriada para o tratamento dos dados.

Obteve-se a matriz rotacionada dos fatores, conforme apresentado no APÊNDICE 10 e a matriz e a Variância Total Explicada apresentada no APÊNDICE 11. A análise fatorial resultou em seis (6) fatores para os dados obtidos, explicando $63 \%$ da variância dos dados. 
A interpretação dos fatores obtidos considerou o agrupamento das cargas maiores do que 0.4 para as questões utilizadas no questionário e a comparação desse agrupamento com os construtos definidos no modelo teórico proposto (HAIR, 1998). Seguem abaixo as interpretações dos fatores obtidos.

Fator 1: as cargas mais altas deste fator estão posicionadas nas questões relacionadas ao construto Compromisso Percebido da Supervisão do modelo proposto, que apresenta a seguinte definição: grau em que os trabalhadores percebem as atitudes e comportamentos da supervisão direta em relação à Segurança (vide Quadro 6).

Fator 2: as cargas mais altas deste fator estão posicionadas nas questões relacionadas ao construto Normas Subjetivas do modelo proposto, que apresenta a seguinte definição: percepção da pessoa quanto à pressão social exercida sobre a mesma para que realize ou não o comportamento em questão. (vide Quadro 6).

Nota-se que as maiores cargas fatoriais de duas questões relacionadas ao Controle Percebido também se encontram presentes neste fator.

Fator 3: as cargas mais altas deste fator estão posicionadas nas questões relacionadas ao construto Comportamento do modelo proposto, que apresenta a seguinte definição: comportamento declarado em relação a determinada situação em relação à Segurança no Trabalho. (vide Quadro 6).

Nota-se que a maior carga fatorial de uma questão relacionada ao Controle Percebido se encontra presente neste fator.

Fator 4: as cargas mais altas deste fator estão posicionadas nas questões relacionadas ao construto Atitude do modelo proposto, que apresenta a seguinte definição: grau em que a pessoa avalia de forma favorável ou não favorável um comportamento. (vide Quadro 6). 
Fator 5: as cargas mais altas deste fator estão posicionadas nas questões relacionadas ao construto Intenção do modelo proposto, que apresenta a seguinte definição: indicador do quanto as pessoas se esforçam para tentar, ou do quanto elas planejam de esforço para realizar determinado comportamento. (vide Quadro 6).

Nota-se que a maior carga fatorial de uma questão relacionada às Normas Subjetivas se encontra presente neste fator.

Fator 6: a carga mais alta deste fator está posicionada na questão B14 de Controle Percebido (eu sou capaz de inspecionar minhas ferramentas de trabalho no início do turno todos os dias). O Controle Percebido apresenta a seguinte definição: facilidade ou dificuldade percebida de desempenhar determinado comportamento assumindo-se que este reflita experiências passadas bem como impedimentos e obstáculos antecipados (vide Quadro 6).

Através desta análise pode-se concluir que o agrupamento das maiores cargas das questões utilizadas no questionário levou ao agrupamento de fatores compatíveis com os construtos definidos no modelo. Deve-se notar que as questões relacionadas ao Controle Percebido no modelo proposto não foram agrupadas em um só fator no resultado desta análise. Esse resultado é compatível com a avaliação do modelo de mensuração realizada no item 6.4.1, onde se obteve para este construto um valor de confiabilidade interna (Alfa de Cronbach) de 0.654 e AVE de 0.495, considerados limítrofes.

\subsubsection{Análise do Comportamento Estudado}

Considerando os resultados obtidos pela avaliação do modelo proposto é possível afirmar que o comportamento estudado pode ser explicado pelos construtos que compõe a Teoria da Ação Planejada.

A maior carga fatorial obtida no modelo foi para a relação entre Controle Percebido e Comportamento. Uma possível interpretação para esse resultado pode estar relacionada à percepção dos operadores em relação ao tempo disponível e às habilidades dos mesmos para a realização da inspeção das ferramentas. Segundo os resultados obtidos, ter tempo e habilidade para a realização da tarefa tem maior influência sobre a realização das inspeções 
do que a própria intenção em realiza-las, reforçando assim a percepção que os Líderes demostraram nas entrevistas sobre o comportamento dos operadores.

As relações obtidas entre Controle Percebido e Comportamento e Intenção e Comportamento estão em conformidade com a Teoria da Ação Planejada.

A relação obtida entre Normas Subjetivas e Intenção mostra influência da pressão social sobre os indivíduos, porém com menor intensidade quando comparada ao Controle Percebido.

A relação obtida entre Atitudes e Intenção mostra a influência das crenças de comportamento sobre os indivíduos, porém com menor intensidade quando comparada ao Controle Percebido e às Normas Subjetivas. Apesar das respostas obtidas no questionário demonstrarem forte favorabilidade dos respondentes em relação à prática de inspecionar ferramentas, a Atitude não é o construto que apresenta a maior relação com a Intenção na amostra estudada.

Com base no acima exposto, pode-se concluir que a Teoria da Ação Planejada apresenta utilidade como modelo teórico para a identificação de fatores que explicam o comportamento dos trabalhadores em relação à segurança, bem como para analisar a relação existente entre esses fatores, atendendo assim ao objetivo geral desse trabalho.

\subsection{Análise da Influência da Supervisão Direta}

Através das análises das frequências das respostas obtidas no questionário para o Compromisso Percebido dos Qualificados bem como a avaliação do modelo proposto realizada nos itens 6.3.3 e 6.3.4, busca-se alcançar o terceiro objetivo específico desse trabalho.

- Terceiro Objetivo Específico: Avaliar a influência da supervisão direta como fator que explique o comportamento dos subordinados em relação à segurança. 
São apresentadas abaixo as respostas compiladas das entrevistas com relação à influência dos Qualificados em relação aos operadores.

Influência dos Qualificados

1. O comportamento dos Líderes e Qualificados influenciam a postura dos operadores.

2. Os Qualificados em geral têm o comando de suas equipes.

3. Os comportamentos dos Líderes e Qualificados são bastante heterogêneos na forma de liderar suas equipes e na forma como demonstram as relações com a Segurança no Trabalho.

Os cálculos relativos às frequências das respostas encontram-se no APÊNDICE 11. A Tabela 19 traz a frequência das respostas para o Compromisso Percebido da Supervisão em relação à Segurança.

Tabela 17 - Frequências das Respostas - Compromisso Percebido

\begin{tabular}{|l|c|c|}
\hline Compromisso Percebido & $\begin{array}{l}\text { Concordo ou } \\
\text { Concordo Fortemente }\end{array}$ & $\begin{array}{l}\text { Discordo ou } \\
\text { Discordo Fortemente }\end{array}$ \\
\hline $\begin{array}{l}\text { C1. Meu Qualificado verifica frequentemente se } \\
\text { todos na minha equipe inspecionam as } \\
\text { ferramentas no início do turno todos os dias. }\end{array}$ & $31 \%$ & $37 \%$ \\
\hline $\begin{array}{l}\text { C2. Meu Qualificado conversa comigo sobre } \\
\text { como as inspeções de ferramentas devem ser } \\
\text { feitas. }\end{array}$ & $50 \%$ & $21 \%$ \\
\hline $\begin{array}{l}\text { C3 Meu Qualificado me orienta sobre a } \\
\text { importância de inspecionar as ferramentas de } \\
\text { trabalho no início do turno todos os dias. }\end{array}$ & $54 \%$ & $17 \%$ \\
\hline $\begin{array}{l}\text { C4.O Qualificado da linha reforça para a equipe } \\
\text { que as ferramentas devem ser inspecionadas no } \\
\text { início do turno mesmo quando estamos com } \\
\text { pressa. }\end{array}$ & $52 \%$ & $18 \%$ \\
\hline $\begin{array}{l}\text { C5. O Qualificado da linha frequentemente fala } \\
\text { para minha equipe sobre os perigos de não } \\
\text { inspecionar ferramentas no início do turno. }\end{array}$ & $58 \%$ & $17 \%$ \\
\hline $\begin{array}{l}\text { C6. O Qualificado chama a atenção dos colegas } \\
\text { que não inspecionam suas ferramentas no início } \\
\text { do turno. }\end{array}$ & $32 \%$ & \\
\hline $\begin{array}{l}\text { C7. O Qualificado da linha elogia os colegas que } \\
\text { sempre inspecionam as ferramentas que } \\
\text { utilizamos no início do turno todos os dias. }\end{array}$ & $33 \%$ & \\
\hline
\end{tabular}

Em relação às questões C2 e C3 observa-se que a maioria dos respondentes concorda em ter tido contato direto com seu Qualificado recebendo orientações sobre como e porque 
inspecionar as ferramentas de trabalho, o que pode servir de indicador sobre a presença física do Qualificado nas linhas de trabalho, além de seu cuidado com esta prática de segurança.

Em relação às questões C4 e C5 observa-se que a maioria dos respondentes concorda em ter observado o Qualificado passando orientações para as equipes de trabalho sobre a inspeção de ferramentas.

Já em relação à questão C6 observa-se que apenas 32\% concordam em ter observado o Qualificado tomar uma postura mais dura e corretiva em relação a não realização de inspeções nas ferramentas. Em relação à questão C7 observa-se que apenas $33 \%$ concordam em ter observado o Qualificado elogiar os operadores em relação à realização de inspeções nas ferramentas.

Estes números podem ser indicadores de que apesar da presença física dos Qualificados ser percebida em campo e de que orientações sejam passadas aos operadores individualmente e às equipes coletivamente, comportamentos de cobrança e reconhecimento por parte dos Qualificados não são observados pela maioria dos operadores, o que pode nos dar uma indicação que o estilo de liderança da maioria possa ser classificada como um estilo laissezfaire (Zohar,2002).

Segundo Fogarty (2010) as pesquisas relacionadas ao Clima de Segurança trazem como objetivo prático a determinação de um curso de ações para reduzir o número de acidentes nas organizações. Nesse contexto, por acreditar que os gestores são veículos pelos quais a organização influencia a força de trabalho, aspectos relacionados ao seu papel são considerados dentro de diversos estudos sobre Clima de Segurança (vide Quadro 2).

Neste trabalho o Compromisso Percebido da Supervisão com segurança foi posicionado no modelo conceitual proposto como um precursor dos construtos Atitude, Normas Subjetivas e Controle Percebido definidos na Teoria da Ação Planejada. De acordo com essa teoria esses construtos são precedidos por um conjunto de crenças comportamentais, normativas e de controle.

As hipóteses que foram definidas para este estudo tem o objetivo de avaliar se o Compromisso Percebido da Supervisão direta tem influência nas Atitudes, nas Normas 
Subjetivas e no Controle Percebido explicando assim, de forma indireta o comportamento dos subordinados.

Os resultados obtidos na avaliação do modelo estrutural deste trabalho (item 6.3.5) validam as hipóteses H2 e H3 (vide Quadro 14) onde relações significativas entre o Compromisso Percebido e as Normas Subjetivas e o Compromisso Percebido e o Controle Percebido foram demonstradas. Os resultados, entretanto, não suportam a hipótese H1 para a qual não foi demonstrando relação significativa entre o Compromisso Percebido dos Qualificados e a Atitude nos operadores.

O Compromisso Percebido da Supervisão direta (Qualificados) apresentou cargas fatoriais (betas) similares em suas relações com as Normas Subjetivas e com o Controle Percebido, bem como relações significativas e positivas. Uma possível interpretação para esses resultados sugere que apesar dos Qualificados exercerem influência na formação da pressão social em relação à tarefa de inspecionar ferramentas, essa não parece ser forte o bastante para ser percebida pela maioria dos operadores, vide as respostas do questionário relativas às Normas Subjetivas (Tabela 11). Uma relação que pode ser investigada em relação a esse dado faz menção ao estilo laissez-faire de liderança dos Qualificados.

Esses resultados também podem sugerir que pelo fato dos Qualificados terem presença física percebida em campo (vide Tabela 10) eles estejam contribuído com aspectos relacionados à capacitação dos operadores e orientação durante o trabalho o que pode influenciar nas percepções sobre o tempo e as habilidades para realizar as inspeções, questões essas relacionadas ao Controle Percebido.

Não foi obtida uma relação significativa entre o Compromisso Percebido da Supervisão e a Atitude dos subordinados. Observa-se que o construto Atitude caracteriza-se como um construto exógeno, pois não foi explicado por nenhum outro construto do modelo, sendo dessa forma determinado por fatores externos. Uma possível explicação para esse resultado pode estar relacionada à simplicidade da questão colocada aos operadores (exemplo: achar importante, necessário, seguro ou bom inspecionar ferramentas) o que resulta em alta porcentagem de concordância (vide Tabela 9). Sendo as questões simples ou até mesmo óbvias é razoável esperar que o construto formado por elas não seja influenciado por outros dentro do modelo. Outra explicação pode estar no formato das questões relacionadas à 
Atitude. A utilização de escala semântica e o agrupamento das questões sobre Atitude em uma mesma seção do questionário pode ter induzido viés nas respostas. Cabe neste caso a reflexão sobre uma oportunidade de melhoria no questionário desenvolvido em relação ao construto Atitude.

Assim, através das relações representadas pelas hipóteses $\mathrm{H} 2$ e H3, demonstrou-se a influência dos supervisores diretos no comportamento dos subordinados, através da medição dos construtos trazidos pela Teoria da Ação Planejada, atendendo assim ao terceiro objetivo específico da pesquisa. Resultados semelhantes também foram encontrados no estudo de Fogarty (2010).

Seguem apresentados na Figura 15 os fatores e relações observados neste estudo. As setas em negrito representam as relações com as maiores cargas fatoriais.

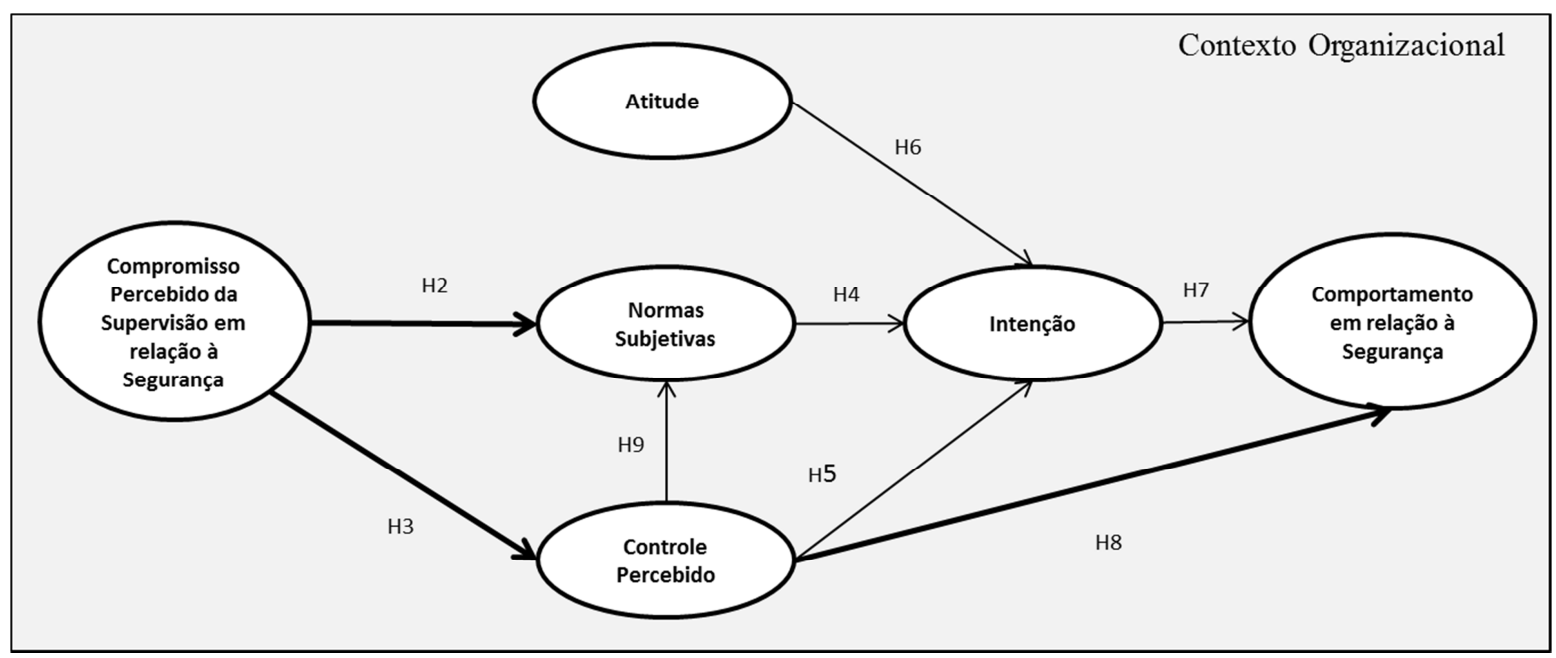

Figura 15 - Fatores e Relações 


\section{CONSIDERAÇÕES FINAIS}

\subsection{Conclusões e Contribuições da Pesquisa}

Este estudo teve como objetivo geral identificar fatores que explicam o comportamento dos trabalhadores em relação à segurança bem como analisar a relação existente entre esses fatores. Com base na Teoria da Ação Planejada e nos estudos de Clima de Segurança, fatores foram identificados e suas relações demonstradas. Dados sobre a política, procedimentos e regras de segurança, bem como alguns riscos nas atividades de trabalho, foram levantados com o objetivo de contextualizar a análise dos fatores identificados e possibilitar a identificação de ações práticas que poderiam ser tomadas pela organização.

Para a operacionalização da pesquisa foram definidos três objetivos específicos e os resultados encontrados são a base para as reflexões apresentadas a seguir.

No desenvolvimento do primeiro objetivo específico buscou-se avaliar o contexto organizacional em relação à segurança. A avaliação realizada teve um recorte que considerou duas dimensões agrupadas de Clima de Segurança conforme apresentado no Quadro 1: Políticas e Procedimentos e Condições Físicas de Trabalho. As demais dimensões apresentadas no Quadro 1, não foram utilizadas nessa etapa do trabalho e espelham os construtos utilizados no modelo proposto.

Os dados secundários e as respostas das entrevistas demonstraram que a Política de Segurança é recente e ainda não foi desdobrada em procedimentos e regras, dentro de um sistema consistente e entendido por todos. Situações de risco intrínsecas aos processos produtivos foram observadas e constatou-se que o tratamento dado a essas questões não é sistêmico. Situações de risco são tratadas com naturalidade por líderes e trabalhadores.

Schein (1984) considera que os valores de uma organização podem ser observados através de expressões manifestas, refletindo o que as pessoas dizem dentro de um grau expressivo de racionalização, que procura explicar os comportamentos das pessoas na organização. 
A análise do contexto organizacional, na perspectiva acima exposta, sugere que a empresa não tem segurança no trabalho como valor e que os trabalhadores em geral não apresentam comportamentos alinhados em relação à segurança.

No desenvolvimento do segundo objetivo específico procurou-se verificar as relações entre os construtos que compõe a Teoria da Ação Planejada. Essa teoria foi utilizada como base para a identificação de fatores que explicam o comportamento em relação à Segurança. Com base em um comportamento definido, os dados mostraram a utilidade do modelo proposto, em alinhamento com os trabalhos de Fogarty (2010) e Johnson e Hall (2005), validando também a Teoria da Ação Planejada.

Controle Percebido, Normas Subjetivas e Atitudes demostraram relações significativas com a Intenção em realizar o comportamento estudado. Pode-se destacar que o Controle Percebido teve maiores cargas sobre o Comportamento do que a Intenção, demostrando que a percepção de controle que os operadores têm em relação à realização das inspeções de segurança nas ferramentas é alta. Também pode se destacar que as Normas Subjetivas tiveram menor influência na Intenção do que o Controle Percebido e a Atitude, resultado que pode estar alinhado com a análise do contexto organizacional descrita anteriormente, sugerindo uma possível relação entre o valor que segurança tem para o grupo estudado e a influência menor das Normas Subjetivas na Intenção.

O terceiro objetivo específico consistiu em avaliar a influência da supervisão direta no comportamento dos trabalhadores.

No trabalho desenvolvido, o Compromisso da Supervisão em relação à Segurança, baseado em Zohar (2005), foi posicionado como um precursor dos construtos da Teoria da Ação Planejada.

Os dados coletados nesta pesquisa não demonstraram relação entre o Compromisso da Supervisão e a Atitude, relação que foi demonstrada no estudo de Fogarty (2010). Esse resultado pode ser explicado pela simplicidade das próprias questões em relação à atitude, utilizadas nesta pesquisa e por questões metodológicas, como mencionado no capítulo da análise (item 6.4). 
Foi demonstrado que o Compromisso da Supervisão apresenta relação significativa e positiva com as Normas Subjetivas e com o Controle percebido. A Supervisão direta tem influência sobre a percepção de controle que os funcionários têm em relação a inspecionar as ferramentas e também exerce influência na pressão social que existe entre o grupo de operadores, alinhado com o estudo de Fogarty (2010). No entanto, as relações observadas entre os construtos da Teoria da Ação Planejada nesse estudo, podem sugerir que a supervisão adota junto a seus operadores uma abordagem mais individual do que coletiva. Reforça a realização da inspeção de ferramentas de maneira individual, sendo percebida como presente em campo, porém não se posiciona frente ao grupo como uma liderança que promove pressão social para que as inspeções sejam realizadas. Fica também demonstrado que a Supervisão, mediada pelos construtos da Teoria da Ação Planejada, apresenta relação significativa com o comportamento dos operadores, o que corrobora estudos anteriores apresentados na revisão teórica dessa pesquisa.

Considerando os resultados expostos, ações no sentido de tornar o ambiente de trabalho mais colaborativo e aberto entre os operadores, propiciando o encorajamento mútuo na realização das inspeções, poderiam ser adotadas dentro de um programa de segurança.

Um desafio recorrente nos programas de segurança do trabalho é aumentar sua efetividade no sentido de fazer as pessoas adotarem comportamentos seguros. O entendimento dos fatores que explicam o comportamento dos trabalhadores em relação à segurança pode ser de grande utilidade para sugerir intervenções que contribuam para a redução dos índices de frequência e gravidade dos acidentes de trabalho. Os pesos (cargas) entre as relações dos fatores do modelo proposto podem variar de acordo com o grupo estudado, apontando diferenças na explicação de determinado comportamento, possibilitando assim a customização de ações, conforme sugere Johnson e Hall (2005).

Como contribuição desta pesquisa para a teoria, este trabalho demonstrou a utilidade da Teoria da Ação Planejada como um modelo para explicar o comportamento em relação à segurança dos trabalhadores dentro de uma organização brasileira. Uma questão metodológica a destacar nesse trabalho é a influência do comportamento estudado na construção dos instrumentos de coleta de dados (roteiro de entrevistas e questionário). 
Outra contribuição para a teoria é a demonstração da influência da supervisão direta no comportamento dos trabalhadores, e uma possível relação entre os valores culturais da organização e as Normas Subjetivas.

Como contribuição para os gestores da organização estudada, este trabalho traz informações sobre o ambiente organizacional que têm relação com o comportamento dos trabalhadores, permitindo o desenho de ações dentro de um programa de segurança. Considerando o risco das operações, procedimentos e regras de segurança poderiam ser mais prescritivos e merecem revisões.

\subsection{Limitações da Pesquisa}

As limitações desta pesquisa foram decorrentes das escolhas metodológicas adotadas com base na viabilidade de realização do trabalho.

Uma limitação da pesquisa está relacionada ao seu próprio escopo. A pesquisa foi realizada com base nos dados de um dos departamentos da empresa avaliada, fazendo com que a amostragem fosse bastante localizada. Outro ponto relativo ao escopo é a escolha do comportamento de estudo. Ajzen (2010) afirma que para a avaliação da Teoria da Ação Planejada um comportamento deve ser definido em termos de seu alvo, ação, contexto e tempo. Além disso, esse comportamento deve ser intencional para que seja possível a aplicação da Teoria da Ação Planejada como base para explica-lo. Buscando-se um maior aprofundamento e precisão no estudo das relações trazidas pelo modelo proposto, definiu-se dessa forma o escopo do trabalho, não possibilitando assim a generalização dos resultados.

A segunda limitação da pesquisa está relacionada ao modelo conceitual proposto. O estudo procurou verificar a relação entre os fatores que explicam o comportamento e não foi orientado de modo a estabelecer causalidade entre esses. O modelo estrutural sugere possíveis relações causais, porém também outras relações podem ser válidas. Não foi objetivo dessa pesquisa a avaliação de outros possíveis modelos para identificação de fatores e relações que expliquem o comportamento em relação à segurança, o que provavelmente existe. 
A terceira limitação é que o estudo está baseado na premissa de que o comportamento declarado é assumido como sendo o comportamento real dos respondentes. Isso pode ter introduzido algum grau de erro nas respostas. Apesar de alguns cuidados serem tomados no sentido de minimizar esse erro, é razoável esperar que o comportamento declarado tenha sido sobre ou subdeclarado em relação ao comportamento real dos respondentes. É importante ressaltar que em função das dificuldades operacionais em coletar dados relativos a comportamentos observados, a utilização de comportamentos declarados é utilizada em várias pesquisas (SEO, 2004), (OLIVER, 2002), (JOHNSON \& HALL, 2005), FOGARTY (2010).

A quarta limitação é metodológica. Foi utilizado um questionário auto preenchido para parte da coleta de dados. Apesar da presença do pesquisador durante a aplicação dos questionários, o viés presente no autopreenchimento refere-se à compreensão dos itens do questionário, sendo natural que os respondentes apresentem entendimentos diversos em relação a determinados termos do questionário.

\subsection{Sugestões para Estudos Futuros}

Este estudo também cumpre seu papel no que se refere à formulação de sugestões para pesquisas futuras. Primeiramente novos estudos em outros contextos organizacionais poderiam ser realizados. Estudos aplicados a outros departamentos ou unidades dentro da organização estudada, estudos relacionados a outros comportamentos e estudos aplicados em outras organizações poderiam ser considerados.

Outra sugestão se refere à utilização de outras metodologias como, por exemplo, realizar uma pesquisa qualitativa considerando o mesmo modelo proposto nesse trabalho. Nesse sentido, a realização de um estudo de caso com enfoque qualitativo pode favorecer o estudo de um conjunto de comportamentos relacionados à segurança ao invés de focar em apenas um comportamento específico.

Outra sugestão seria a realização de pesquisas com outros objetivos, como por exemplo, comparar diferentes modelos que expliquem o comportamento em relação à segurança. Nessa linha, outros construtos poderiam ser incluídos no modelo proposto, demonstrando outras 
relações ou ampliando sua validade para comportamentos que não necessariamente sejam intencionais, o que seria uma extensão da Teoria da Ação Planejada. 


\section{REFERÊNCIAS}

ASFALH, C.R Gestão de Segurança do Trabalho e Saúde Ocupacional 4ed. pg.41 1999 Pearson Education Inc. published as Prentice Hall

ALLPORT, G.W. Attitude Theory and Measurement, Edited by Martin Fishbein, John Wiley\&Sons Inc., New York, 1967, p 3.

AJZEN, I. The Theory of Planned Behaviour. Organizational Behaviour and Human Decision Process. University of Massachusetts at Amherst p. 179-211, 1991.

BENITE, A.G - Sistemas de Gestão de Segurança e Saúde no Trabalho para Empresas Construtoras - Dissertação de Mestrado - Escola Politécnica USP, 2004

BROWN, K.A., WILLIS, P.G. Predicting safe employee behavior in the steel industry: development and test of a sociotechnical model. Journal of Operations Management 2000 18 (4), 445- 465

CARO, A. Comportamento do Consumidor e a Compra On-Line (2010). Tese de Doutorado apresentada ao Departamento de Administração da Faculdade de Economia e Administração da USP

CHIN, W,W. The partial least square approach to structural equation model. In MARCOULIDES,G.A.(Ed). Modern Methods for Business Research (p. 295-358) Mahwah, NJ Lawrence Erlbaum Associates, 1998

CHIRCHILL Jr, G.A.; IACOBUCCI. D (2009) Marketing Research: methodological foundations. Fort Worth: Ed: The Dryden Press

DIAS, I, CABRERA, D. Safety Climate and Attitudes as Evaluation Measures of Organizational Safety Accid. Anal. and Prev., Vol. 29, No. 5, pp. 643-650, 1997 (C) 1997 Elsevier Science Ltd.

FILHO, A.P.G, ANDRADE, J.C.S, MARINHO, M, O Cultura e gestão da segurança no trabalho: uma proposta de modelo Gest. Prod., São Carlos, v. 18, n. 1, p. 205-220, 2011

FISHBEIN, M. - Attitude Theory and Measurement, Edited by Martin Fishbein, John Wiley\&Sons Inc., New York, 1967, p 257

FISHBEIN, M., \& AJZEN, I. (2010). Predicting and changing behavior: The reasoned action approach. New York: Psychology Press.

FLIN, R., MEARNS,K., O`CONNOR,P.,2000. Measuring safety climate: Identifying the common features. Safety Science 34 (1 3), 177192

GRIX, J. The Foundations of Research. Palgrave Macmillan. New York 2004.

GLENDON,A., LITHERLAND, D.K. Safety Climate Factors, group differences and Safety behavior in a road construction. Safety Science 39 (2001), 157-188 
IAEA, 1986. Summary report on the post-accident review meeting on the Chernobyl accident. International Atomic Energy Agency, Vienna.

HAIR JR. J. F. ANDERSON, R.E.,TATHAM, R.L.,BLACK,W.C. Multivariate Data Analysis, $5^{\text {th }}$ ed. New Jersey: Prentice Hall, 1998

HAIR, J. F.; RINGLE, C. M.; SARSTEDT, M. PLS-SEM: Indeed a silver bullet. Winter Park: Journal of Marketing Theory and Practice, v.19, n.2, p.139-152, 2011.

HAIR, J. F.; RINGLE, C. M.; SARSTEDT, M.PLS-SEM: An assessment of the use of partial least squares structural equation modeling in marketing research.

Park: Journal of the Academy Marketing Science, (2012) 40:414-433.

HAMMAMI, H.*, AMARA, N. LANDRY, R. - Organizational climate and its influence on brokers' knowledge transfer activities: A structural equation modeling. International Journal of Information Management 33 (2013) 105- 118

HALE, A.R., BARAM, M.,HOVDEN,J.,1998. Perspectives on safety management and change In: Hale,A.R., Baram,M (Eds), Safety Management: The Challenge of Change. Elsevier Science Ltd. Oxford, U.K

HEALTH AND SAFETY COMMISSION (HSC), 1993. Organizing for Safety. Third report of the human factors study group pf the advisory committee on the safety of nuclear installation. Her Majesty`s Stationery Office, London.

HEINRICH, H.W., 1959. Industrial Accident Prevention A Scientific Approach. McGraw-Hill, Inc., New York.

HENSELER, J.; RINGLEAND, C.M.; SINKOVICS, R.R The use of Partial Least Square Path Modeling in International Marketing. New Challenges to International Marketing Advances in International Marketing, Volume 20, 2009, p.277-319.

KRAUSE, T.R., 1995. Employee driven Systems for Safe Behaviour Van Nostrand Reinhold, New York.

MARTINS, G. A. Metodologia de Investigação Científica para Ciências Sociais Aplicadas. 2.ed. São Paulo: Atlas, 2009

MALHOTRA, N. K. Pesquisa de marketing: uma orientação aplicada. 6. ed. Porto Alegre: Bookman, 2010

MATTAR, F. N. Pesquisa de marketing: edição compacta. 3. ed. São Paulo: Atlas, 2001

MOUTINHO, K; ROAZI, A; 2010 As Teorias da Ação Racional e da Ação Planejada: Relações entre Intenções e Comportamentos Avaliação Psicológica, 2010, 9(2), pp. 279287

OLIVER, A., CHEYNE, A., TOMAS, J.M., COX, S., 2002. The effects of organizational and individual factors on Occupational accidents Journal of Occupational and Organizational Psychology 75, 473488 
OLIVEIRA, J.F, MARINHO, R. Liderança uma Questão de Competência São Paulo. Saraiva, 2005

PETERSEN, D., 1996. Human Error Reduction - Safety Management. New York Van Nostrand Reinhold, 1996 xvii

RUNDMO, T., HESTAD, H., ULLBEG, P., 1998. Organisational factors, safety attitudes and workload among $\mathrm{o} \square$ shore oil personnel. Safety Science 29 (2), 75-87.

SCHEIN, E - Coming to a New Awareness of Organizational Culture Sloan Management Review (pre-1986) Winter; 1984 ; 25,2; ABI INFORM Global

SCHEIN, E (2000) Sense and nonsense about culture and climate. In N, Ashkanasy, C. Wilderom, \& M. Peterson (Eds.), Handbook of organizational culture and climate (pp. xxiiixxx). California: Sage Publications.

SCHNEIDER, B. -Organizational Climates: An Essay. Personal Psychology 1975, 28, p.473.

SCHNEIDER, B. Handbook of Organizational Culture and Climate. The Psychological Life of Organizations, Sage Publications, Inc.2000,

SCHIFFMAN, L. G - Consumer Behaviour. Prentice Hall, Englewoods Cliffs, New Jersey 07632, 5th Edition

SEO, D.C, TORABI, M.R., BLAIR, E.H., ELLIS, N.T., 2004 - A cross-validation of safety climate scale using confirmatory factor analytic approach. Journal of Safety Research 35 (4),427 445 .

SEO, D.C, 2005 - An explicative model of unsafe work behaviour. Safety Science 43 (2005), 187211.

SWARTZ, S.M, DOUGLAS, M.A 2009 - The Independence of Independents: Influences on Commercial Driver Intention to Commit Unsafe Acys. Transportation Journal Winter (2009).

TAYLOR, S.,TODD, P. Decomposition and crossover effects in the theory of planned behavior: a study of consumer adoption intentions. International Journal of Research in Marketing vol.12 1995, p.137-155

TENENHAUS,M.; VINZI,W.E.; CHATELIN, Y.M.; LAURO,C PLS Path Modeling. Computational Statistic and Data Analysis Vol. 48, p.159-205,2005

TOMAS, J.M., MELIA, J.L., OLIVER, A., 1999. A cross-validation of a structural equation model of accidents: organizational and psychological variables as predictors of work safety. Work and Stress 13 (1), 49-58

ZOHAR, D., Safety Climate in industrial organizational: theoretical and applied implications. Journal of Applied Psychology 198065 (1), 96102 
ZOHAR, D., The effects of leadership dimensions, safety climate, and assigned priorities on minor injuries in work. Journal of Organizational Behavior. 23, 75-92 (2002)

ZOHAR, D., LURIA,G. A Multilevel Model of Safety Climate: Cross-Level Relationships Between Organization and Group-Level Journal of Applied Psychology 2005, Vol. 90, No. 4, 616-628 


\section{APÊNDICE 1 - Estudos de Clima de Segurança (SE0, 2004)}

\begin{tabular}{|c|c|c|c|}
\hline $\begin{array}{c}\text { Autor(es) e } \\
\text { Ano }\end{array}$ & Amostra & Dimensões de Clima & Comentários do Autor (SEO, 2004) \\
\hline Zohar (1980) & $\begin{array}{l}20 \text { fábricas em } \\
\text { Israel (metal, } \\
\text { alimentos, } \\
\text { química e têxtil) } \\
\mathrm{N}=400\end{array}$ & $\begin{array}{l}\text { 1. Importância de } \\
\text { programas de treinamento } \\
\text { em segurança; } \\
\text { 2. Atitudes gerenciais } \\
\text { percebidas em relação a } \\
\text { programas de segurança; } \\
\text { 3. Efeitos percebidos de } \\
\text { conduta segura em } \\
\text { promoções; } \\
\text { 4. Nível percebido de risco } \\
\text { no local de trabalho; } \\
\text { 5. Efeito percebido do } \\
\text { ritmo de trabalho sobre } \\
\text { segurança; } \\
\text { 6. Status percebido dos } \\
\text { gestores de segurança; } \\
\text { 7. Efeito percebido da } \\
\text { conduta segura no status } \\
\text { social; } \\
\text { 8. Status percebido do } \\
\text { comitê de segurança. }\end{array}$ & $\begin{array}{l}\text { Entre os oito fatores, somente dois - } \\
\text { percepção das atitudes da gerência em relação } \\
\text { à segurança e a importância relativa de } \\
\text { programas de treinamento - contabilizaram } \\
60 \% \text { da variância. } \\
\text { Também, todas as questões exceto aquelas } \\
\text { sobre risco percebido e ritmo de trabalho } \\
\text { foram muito próximas em relação ao } \\
\text { comprometimento da gerência com } \\
\text { segurança. } \\
\text { Isto implica que o comprometimento da } \\
\text { gerência com segurança é um dos fatores mais } \\
\text { importantes no clima de segurança. }\end{array}$ \\
\hline $\begin{array}{l}\text { Brown e } \\
\text { Holmes } \\
(1986)\end{array}$ & $\begin{array}{l}10 \text { empresas de } \\
\text { manufatura nos } \\
\text { Estados Unidos } \\
\mathrm{N}=425\end{array}$ & $\begin{array}{l}\text { 1. Percepção dos } \\
\text { empregados do quão } \\
\text { preocupada a gerência está } \\
\text { com seu bem-estar; } \\
\text { 2. Percepção de quanto } \\
\text { ativa foi a gerência em } \\
\text { responder a esta } \\
\text { preocupação; } \\
\text { 3. Percepção dos } \\
\text { empregados em relação do } \\
\text { risco físico; }\end{array}$ & $\begin{array}{l}\text { Tentaram replicar a estrutura de fatores de } \\
\text { Zohar (1980) usando análise fatorial } \\
\text { confirmatória, mas falharam ao tentar } \\
\text { suportar a estrutura de fatores proposta } \\
\text { anteriormente. } \\
\text { Uma limitação a este estudo foi a de não } \\
\text { estabelecer uma relação da escala de clima de } \\
\text { segurança com um critério externo como, por } \\
\text { exemplo, o comportamento inseguro no } \\
\text { trabalho o que limita a validade desta escala. }\end{array}$ \\
\hline $\begin{array}{l}\text { Dedobbeleer } \\
\text { and Beland } \\
(1991)\end{array}$ & $\begin{array}{l}9 \text { construções } \\
\text { não residenciais } \\
\text { nos Estados } \\
\text { Unidos } \\
\mathrm{N}=272\end{array}$ & $\begin{array}{l}\text { 1. Compromisso da } \\
\text { gerência com segurança; } \\
\text { 2. Envolvimento dos } \\
\text { trabalhadores com } \\
\text { segurança; }\end{array}$ & $\begin{array}{l}\text { Estes autores testaram a estrutura de clima de } \\
\text { segurança de três fatores de Brown e Holmes } \\
\text { (1986). }\end{array}$ \\
\hline $\begin{array}{l}\text { Cox and Cox } \\
\text { (1991) }\end{array}$ & $\begin{array}{l}\text { Um grande } \\
\text { número de } \\
\text { localidades em } \\
\text { cinco países } \\
\text { europeus. } \\
\mathrm{N}=630\end{array}$ & $\begin{array}{l}\text { 1. Ceticismo pessoal; } \\
\text { 2. Responsabilidade } \\
\text { individual; } \\
\text { 3. Segurança no ambiente } \\
\text { de trabalho; } \\
\text { 4. Arranjos efetivos de } \\
\text { segurança; } \\
\text { 5. Imunidade pessoal; }\end{array}$ & $\begin{array}{l}\text { Ao contrário das três escalas de clima de } \\
\text { segurança anteriores que foram focadas nas } \\
\text { percepções compartilhadas em relação à } \\
\text { segurança este estudo incorporou mais } \\
\text { construtos individuais como atitudes pessoais } \\
\text { em relação à segurança. } \\
\text { Nenhuma associação foi estabelecida entre as } \\
\text { atitudes de segurança medidas e o } \\
\text { desempenho de segurança medido. Também, } \\
\text { o desenvolvimento dos itens do questionário } \\
\text { foi primariamente baseado em uma discussão } \\
\text { com o Gerente de Segurança da companhia, } \\
\text { ao invés de utilizar as descobertas acumuladas } \\
\text { de pesquisas anteriores. }\end{array}$ \\
\hline
\end{tabular}




\begin{tabular}{|c|c|c|c|}
\hline $\begin{array}{c}\text { Autor(es) e } \\
\text { Ano }\end{array}$ & Amostra & Dimensões de Clima & Comentários do Autor (SEO, 2004) \\
\hline $\begin{array}{l}\text { Niskanen } \\
\text { (1994) }\end{array}$ & $\begin{array}{l}\text { Empresa de } \\
\text { manutenção de } \\
\text { estradas e } \\
\text { construção de } \\
\text { rodovias e } \\
\text { pontes e em sua } \\
\text { oficina de } \\
\text { reparos. } \\
\mathrm{N}=1890 \\
\text { trabalhadores } \\
\mathrm{N}=562 \\
\text { supervisores }\end{array}$ & $\begin{array}{l}\text { 1. Atitude em relação à } \\
\text { segurança na organização; } \\
\text { 2. Mudanças na demanda } \\
\text { de trabalho; } \\
\text { 3. Apreciação do trabalho; } \\
\text { 4. Segurança como parte } \\
\text { integrante do trabalho } \\
\text { produtivo. }\end{array}$ & $\begin{array}{l}\text { O pesquisador agregou dados separadamente } \\
\text { de trabalhadores e supervisores e conduziu } \\
\text { uma análise fatorial exploratória para os dois } \\
\text { grupos de dados. } \\
\text { Pouca relevância, entretanto, deveria ser } \\
\text { colocada às descobertas de Niskanen porque } \\
\text { ele não testou a validade e a confiabilidade do } \\
\text { instrumento de clima de segurança. }\end{array}$ \\
\hline $\begin{array}{l}\text { Diaz e } \\
\text { Cabrera } \\
(1997)\end{array}$ & $\begin{array}{l}\text { Três companhias } \\
\text { de transportes de } \\
\text { carga em } \\
\text { aeroportos da } \\
\text { Espanha. } \\
\mathrm{N}=166 \\
\text { trabalhadores }\end{array}$ & $\begin{array}{l}\text { 1. Políticas da companhia } \\
\text { em relação à segurança; } \\
\text { 2. Ênfase na produtividade } \\
\text { versus segurança; } \\
\text { 3. Atitudes de grupo em } \\
\text { relação à segurança; } \\
\text { 4. Estratégias específicas } \\
\text { de prevenção; } \\
\text { 5. Nível de segurança } \\
\text { percebido no aeroporto; } \\
\text { 6. Nível de segurança } \\
\text { percebido no trabalho. }\end{array}$ & $\begin{array}{l}\text { Uma avaliação do conteúdo dos fatores não } \\
\text { foi possível porque os itens do questionário } \\
\text { não foram publicados em artigos. } \\
\text { De } 60.8 \% \text { do total da variância explicada, } \\
38.9 \% \text { foram atribuídos às políticas de } \\
\text { segurança da companhia, o que reflete o } \\
\text { comprometimento da gerência com } \\
\text { segurança. } \\
\text { O ponto forte deste estudo segundo Seo } \\
\text { (2004) foi de que Diaz e Cabrera mostraram } \\
\text { critérios de validade em sua escala de clima } \\
\text { de segurança. Limitações para este estudo } \\
\text { estão relacionadas ao tamanho da amostra } \\
\text { utilizada (Seo, 2004). }\end{array}$ \\
\hline $\begin{array}{l}\text { Williamson } \\
\text { et al. (1997) }\end{array}$ & $\begin{array}{l}7 \text { locais de } \\
\text { trabalho na } \\
\text { Austrália } \\
\text { (indústrias de } \\
\text { manufatura } \\
\text { pesada e leve e } \\
\text { trabalhadores } \\
\text { contratados). } \\
\mathrm{N}=660 \\
\text { trabalhadores }\end{array}$ & $\begin{array}{l}\text { 1. Motivação pessoal para } \\
\text { o comportamento seguro; } \\
\text { 2. Práticas de segurança } \\
\text { positivas; } \\
\text { 3. Justificação do risco; } \\
\text { 4. Fatalismo; } \\
\text { 5. Otimismo. }\end{array}$ & $\begin{array}{l}\text { Eles incluíram itens atitudinais e perceptivos } \\
\text { no conjunto de seus itens e descobriram } \\
\text { durante a análise que a maioria dos itens que } \\
\text { apresentaram os maiores vieses foram os } \\
\text { atitudinais. Isto implica que itens baseados em } \\
\text { percepções tem mais probabilidade de terem } \\
\text { poder discriminatório do que aqueles } \\
\text { baseados em atitudes. }\end{array}$ \\
\hline $\begin{array}{l}\text { Brown et al. } \\
(2000)\end{array}$ & $\begin{array}{l}2 \text { plantas de uma } \\
\text { siderúrgica nos } \\
\text { Estados Unidos } \\
\mathrm{N}=551\end{array}$ & $\begin{array}{l}\text { 1. Influência dos } \\
\text { Supervisores; } \\
\text { 2. Influência da Alta } \\
\text { Gerência em Segurança; }\end{array}$ & \\
\hline $\begin{array}{l}\text { Lee e } \\
\text { Harrison } \\
(2000)\end{array}$ & $\begin{array}{l}3 \text { usinas } \\
\text { nucleares no } \\
\text { Reino Unido, } \\
\mathrm{N}=683\end{array}$ & $\begin{array}{l}\text { 1. Confiança nas medidas } \\
\text { de controle; } \\
\text { 2. Confiança na } \\
\text { antecipação de respostas; } \\
\text { 3. Confiança na } \\
\text { reorganização; } \\
\text { 4. Confiança nos padrões } \\
\text { de segurança; } \\
\text { 5. Suporte da empresa aos } \\
\text { terceiros; }\end{array}$ & $\begin{array}{l}\text { O estudo destes autores foi muito diferente } \\
\text { dos outros } 15 \text { desenvolvimentos de escalas } \\
\text { em termos do escopo da mensuração. } \\
\text { Lee e Harrison tentaram medir vários } \\
\text { aspectos da cultura de segurança, a maioria } \\
\text { deles relacionados a atitudes em relação à } \\
\text { segurança, usando um questionário de } 120 \\
\text { itens que cobria oito diferentes domínios. } \\
\text { Entre eles haviam } 23 \text { questões relacionadas a }\end{array}$ \\
\hline
\end{tabular}




\begin{tabular}{|c|c|c|c|}
\hline $\begin{array}{c}\text { Autor(es) e } \\
\text { Ano }\end{array}$ & Amostra & Dimensões de Clima & Comentários do Autor (SEO, 2004) \\
\hline & & $\begin{array}{l}\text { 6. Satisfação com a } \\
\text { segurança dos terceiros; } \\
\text { 7. Respeito ao papel dos } \\
\text { terceiros; } \\
\text { 8. Contentamento com o } \\
\text { trabalho; } \\
\text { 9. Satisfação com as } \\
\text { relações de trabalho; } \\
\text { 10. Interesse no trabalho; } \\
\text { 11. Confiança nos colegas; } \\
\text { 12. Empoderamento } \\
\text { percebido; } \\
\text { 13. Preocupação da } \\
\text { Gerência com Segurança; } \\
\text { 14. Moral em geral; } \\
\text { 15. Nível de risco da } \\
\text { organização; } \\
\text { 16. Tomada de risco } \\
\text { pessoal; } \\
\text { 17. Risco associado a } \\
\text { multi-tarefas; } \\
\text { 18. Risco versus } \\
\text { produtividade; } \\
\text { 19. Complexidade das } \\
\text { instruções; } \\
\text { 20. Proficiência na } \\
\text { identificação de perigos; } \\
\text { 21. Resposta a alarmes; } \\
\text { 22. Procedimentos de } \\
\text { Emergência; } \\
\text { 23. Estresse pessoal; } \\
\text { 24. Insegurança no } \\
\text { trabalho; } \\
\text { 25. Preocupação da } \\
\text { Gerência com saúde; } \\
\text { 26. Qualidade do } \\
\text { treinamento; } \\
\text { 27. Efetividade da seleção } \\
\text { do pessoal de suporte } \\
\text { (staff); } \\
\text { 28. Qualidade geral dos } \\
\text { treinamentos. }\end{array}$ & 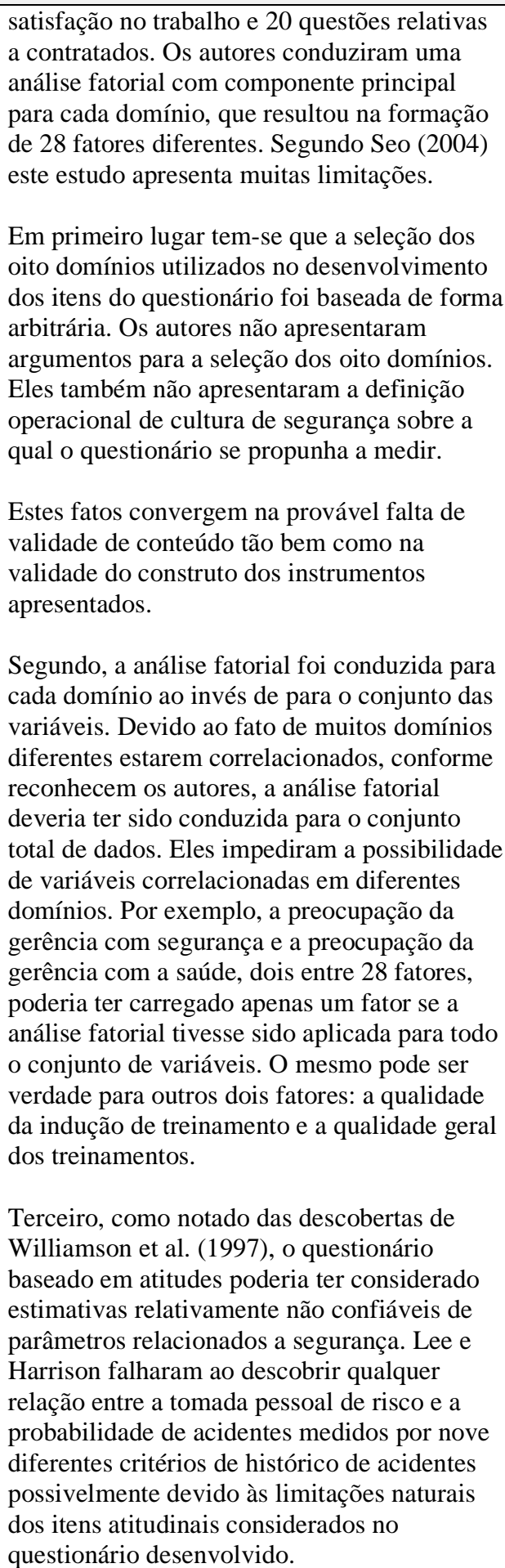 \\
\hline Seo (2004) & $\begin{array}{l}\text { Indústria de } \\
\text { grãos nos }\end{array}$ & $\begin{array}{l}\text { 1. Comprometimento da } \\
\text { gerência com segurança; }\end{array}$ & $\begin{array}{l}\text { O trabalho de Seo (2004) teve como base os } \\
\text { estudos anteriormente apresentados onde o }\end{array}$ \\
\hline
\end{tabular}




\begin{tabular}{|c|c|c|c|}
\hline $\begin{array}{c}\text { Autor(es) e } \\
\text { Ano }\end{array}$ & Amostra & Dimensões de Clima & Comentários do Autor (SEO, 2004) \\
\hline & $\begin{array}{l}\text { Estados Unidos. } \\
\mathrm{N}=722\end{array}$ & $\begin{array}{l}\text { 2. Suporte dos } \\
\text { supervisores com a } \\
\text { segurança; } \\
\text { 3. Suporte dos colegas de } \\
\text { trabalho com a segurança; } \\
\text { 4. Participação dos } \\
\text { empregados; } \\
\text { 5. Nível de competência; }\end{array}$ & $\begin{array}{l}\text { autor procura partir de pontos comuns } \\
\text { observados nestes estudos para então decidir } \\
\text { por } 5 \text { dimensões para o clima de segurança. } \\
\text { O comprometimento da gerência foi } \\
\text { descoberto como influenciador de outros } \\
\text { indicadores medidos tais como suporte da } \\
\text { supervisão e outros. O suporte da supervisão } \\
\text { influenciou outros indicadores tais como o } \\
\text { suporte dos colegas de trabalho, o nível de } \\
\text { competência e o comprometimento da } \\
\text { gerência bem como seus próprios indicadores. } \\
\text { Sendo assim, sem considerar a influência do } \\
\text { comprometimento da gerência e o suporte da } \\
\text { supervisão sobre outras variáveis, a } \\
\text { abordagem analítica dos fatores da escala de } \\
\text { clima de segurança provavelmente não } \\
\text { produzirá uma estrutura de fatores estáveis e } \\
\text { consistentes. } \\
\text { Em termos de implicações práticas, estas } \\
\text { descobertas sugerem que mais ênfase deveria } \\
\text { ser dada no papel do comprometimento dos } \\
\text { gerentes e suporte dos supervisores entre os } \\
\text { vários aspectos do esforço de prevenção de } \\
\text { acidentes, considerando suas substanciais } \\
\text { influências sobre outras dimensões de } \\
\text { segurança. }\end{array}$ \\
\hline
\end{tabular}

FONTE: adaptado de SEO (2004) 


\section{APÊNDICE 2 - Roteiro de Entrevistas}

\section{Roteiro de Entrevista com Especialista de Segurança e Saúde Ocupacional da Empresa}

1. Apresentação pessoal e propósito da pesquisa.

2. A empresa possui uma política de Segurança e Saúde no Trabalho?

3. Em sua opinião, esta política está incorporada ao valor que a empresa dá para a questão da Segurança no Trabalho?

4. Existem procedimentos, regras e boas práticas de segurança, implantados e devidamente divulgados dentro da empresa/setor?

5. Em sua opinião, os trabalhadores tem conhecimento das principais regras e boas práticas de segurança relacionadas às suas atividades diárias?

6. Em sua opinião, os trabalhadores são encorajados ao longo de suas atividades diárias por seus Supervisores a seguir os procedimentos, regras boas práticas de segurança?

7. Em sua opinião, os trabalhadores em geral são favoráveis a seguir procedimentos e boas práticas de segurança?

8. Quais são os principais riscos mapeados nas atividades dos trabalhadores na empresa/setor?

9. Em sua opinião, os trabalhadores tem conhecimento dos principais riscos relacionados às suas atividades diárias?

10. Em sua opinião, a postura dos Supervisores influencia a opinião dos trabalhadores sobre questões relacionadas à Segurança no Trabalho?

11. Você poderia disponibilizar alguns indicadores de desempenho em relação a Segurança no Trabalho?

12. Próximos passos e feedback. 


\section{Roteiro de Entrevista com Líder da unidade pesquisada}

1. Apresentação pessoal e propósito da pesquisa.

2. Como você vê a questão da Segurança no Trabalho dentro do contexto da organização?

3. Em sua opinião, você acha que os trabalhadores percebem a questão da Segurança no Trabalho na organização?

4. Em sua opinião, você acha que os trabalhadores têm comportamentos seguros durante a jornada de trabalho?

5. Poderia citar alguns comportamentos considerados seguros os quais você acha que os trabalhadores em geral adotam?

6. Poderia citar alguns comportamentos considerados seguros os quais você acha que os trabalhadores em geral NÃO adotam?

7. Em sua opinião por que alguns trabalhadores ainda não adotaram tais comportamentos (faltam incentivos, regras, condições de trabalho, o grupo em si é muito fechado)?

8. Existem procedimentos, regras e boas práticas de segurança implantadas e devidamente divulgadas dentro da empresa? Pode citar alguns?

9. Em sua opinião os trabalhadores tem conhecimento das principais regras e boas práticas de segurança relacionadas às suas atividades diárias? Pode citar alguns exemplos?

10. Em sua opinião, os trabalhadores são encorajados ao longo de suas atividades diárias por seus Qualificados a seguir procedimentos, regras e boas práticas de segurança?

11. Em sua opinião, os trabalhadores em geral são favoráveis a seguir procedimentos e boas práticas de segurança?

12. Em sua opinião a postura dos Qualificados influencia a opinião dos trabalhadores sobre questões relacionadas à Segurança do Trabalho?

13. Próximos passos e feedback. 


\section{APÊNDICE 3 - Questionário aplicado por Johnson e Hall (2005)}

\begin{tabular}{|c|c|}
\hline Construto & Pergunta Original/Indicadores \\
\hline \multirow{6}{*}{$\begin{array}{c}\text { Atitude } \\
(\text { Alpha Cronbach }=0.83)\end{array}$} & Lifting materials from/to locations within my strike-zone is good/bad. \\
\hline & Lifting materials from/to locations within my strike-zone is satisfactory/unsatisfactory. \\
\hline & Lifting materials from/to locations within my strike-zone is healthy/unhealthy. \\
\hline & Lifting materials from/to locations within my strike-zone is important/unimportant. \\
\hline & Lifting materials from/to locations within my strike-zone is safe/unsafe. \\
\hline & Lifting materials from/to locations within my strike-zone is valuable/worthless. \\
\hline \multirow{2}{*}{$\begin{array}{l}\text { Normas Subjetivas } \\
\text { (Alpha Cronbach }=\mathbf{0 . 6 5 )}\end{array}$} & $\begin{array}{l}\text { Most people who are important to me would strongly encourage/discourage me to lift } \\
\text { materials within my strike-zone. }\end{array}$ \\
\hline & $\begin{array}{l}\text { The people in my life whose opinions I value would strongly approve/disapprove of me } \\
\text { lifting materials from/to locations within my strike-zone. }\end{array}$ \\
\hline \multirow{2}{*}{$\begin{array}{l}\text { Controle Percebido } \\
\text { (Alpha Cronbach }=\mathbf{0 . 8 2})\end{array}$} & $\begin{array}{l}\text { I have complete/incomplete control over lifting materials from/to locations within my } \\
\text { strike-zone. }\end{array}$ \\
\hline & $\begin{array}{l}\text { I have complete/incomplete control over the conditions (facilities, area layout, resources, } \\
\text { etc.) that enable me to lift materials from/to locations within my strike-zone. }\end{array}$ \\
\hline \multirow{3}{*}{$\begin{array}{c}\text { Intenção } \\
(\text { Alpha Cronbach }=\mathbf{0 . 8 3})\end{array}$} & $\begin{array}{l}\text { I plan to lift materials from/to locations within my strike-zone every time I lift materials in } \\
\text { my work area over the next } 30 \text { days agree/disagree. }\end{array}$ \\
\hline & $\begin{array}{l}\text { I intend to lift materials from/to locations within my strike-zone every time I lift materials } \\
\text { in my work área over the next } 30 \text { days agree/disagree. }\end{array}$ \\
\hline & $\begin{array}{l}\text { I am extremely likely/unlikely to lift materials to/from locations in my strike zone every } \\
\text { time I lift materials in my work area over the next } 30 \text { days. }\end{array}$ \\
\hline Comportamento & $\begin{array}{l}\text { During the past } 30 \text { days, I always/never lifted materials } \\
\text { from/to locations within my strike-zone }\end{array}$ \\
\hline
\end{tabular}

FONTE: Johnson e Hall (2005). 


\section{APÊNDICE 4 - Questionário aplicado por Fogarty (2010)}

\begin{tabular}{|c|c|}
\hline Construto & Pergunta Original/Indicador \\
\hline \multirow{9}{*}{$\begin{array}{c}\text { Atitude } \\
(\text { Alpha Cronbach }=0.73)\end{array}$} & I will say something if my peers take shortcuts (Reverse-scored). \\
\hline & I will say something if my supervisor takes shortcuts (Reverse-scored). \\
\hline & "Good guts books" can be used in lieu of the publications and manuals (Reverse scored). \\
\hline & $\begin{array}{l}\text { There are better ways of performing a task that those described in the publications } \\
\text { and manuals. }\end{array}$ \\
\hline & $\begin{array}{l}\text { There are better ways of performing a task than those described in local standing } \\
\text { instructions/orders. }\end{array}$ \\
\hline & Bending a procedure is not the same as breaking it. \\
\hline & Shortcuts, in order to get a task done, are still violations of procedures (Reverse scored). \\
\hline & Reporting mistakes helps other people learn from them (Reverse-scored). \\
\hline & Personnel should be encouraged to report their mistakes (Reverse-scored). \\
\hline \multirow{7}{*}{$\begin{array}{l}\text { Normas Subjetivas } \\
\text { (Alpha Cronbach }=\mathbf{0 . 7 8})\end{array}$} & $\begin{array}{l}\text { Where I work, tasks are performed in accordance with maintenance policy, } \\
\text { processes, and procedures. (Reverse-scored) }\end{array}$ \\
\hline & $\begin{array}{l}\text { It is normal practice within my unit to use publications and manuals on } \\
\text { rectification tasks. (Reverse-scored) }\end{array}$ \\
\hline & Undocumented and unauthorised workarounds exist in my workplace. \\
\hline & I am under pressure not to follow approved procedures in order to get a task done. \\
\hline & "Good guts books" are used in my workplace in lieu of the proper manual. \\
\hline & Other people in my workplace violate procedures. \\
\hline & Violations of procedure are common in my workplace. \\
\hline \multirow{8}{*}{$\begin{array}{c}\text { Controle Percebido } \\
\text { Pressão no Ambiente de } \\
\text { Trabalho } \\
\text { (Alpha Cronbach }=\mathbf{0 . 8 4} \text { ) }\end{array}$} & $\begin{array}{l}\text { I have access to the necessary tools that I need to carry out assigned tasks. } \\
\text { (Reverse-scored) }\end{array}$ \\
\hline & $\begin{array}{l}\text { I have access to the necessary personal protective clothing/equipment that I need } \\
\text { to carry out assigned tasks. (Reverse-scored) }\end{array}$ \\
\hline & $\begin{array}{l}\text { I have access to the necessary test equipment that I need to carry out assigned } \\
\text { tasks. (Reverse-scored) }\end{array}$ \\
\hline & $\begin{array}{l}\text { I have access to the necessary ground support equipment that I need to carry out } \\
\text { assigned tasks. (Reverse-scored) }\end{array}$ \\
\hline & The physical conditions of my workplace are satisfactory. (Reverse-scored) \\
\hline & Adequate time is allocated to complete assigned tasks. (Reverse-scored) \\
\hline & $\begin{array}{l}\text { The required number of people and resources are present when a task is } \\
\text { commenced. (Reverse-scored) }\end{array}$ \\
\hline & $\begin{array}{l}\text { I am expected to take risks or short cut maintenance policy/process/procedure to } \\
\text { meet the flying program or task deadline. }\end{array}$ \\
\hline \multirow{5}{*}{$\begin{array}{c}\text { Intenção } \\
(\text { Alpha Cronbach }=0.74)\end{array}$} & I am prepared to take risks, other than those inherent in my job, to get a task done. \\
\hline & I am prepared to take shortcuts to get a task done. \\
\hline & $\begin{array}{l}\text { It is necessary for me to take risks, other than those inherent in my job, to get a } \\
\text { task done. }\end{array}$ \\
\hline & $\begin{array}{l}\text { I am willing to sign for a task that I either did not perform or only partially } \\
\text { performed. }\end{array}$ \\
\hline & $\begin{array}{l}\text { I am prepared to undertake a task a better way if I consider the approved } \\
\text { procedure or process to be overly cautious or inefficient. }\end{array}$ \\
\hline \multirow{4}{*}{$\begin{array}{c}\text { Comportamento } \\
\text { Violação } \\
\text { (Alpha Cronbach = 0.72) }\end{array}$} & When given a task, I ensure that approved procedures are followed. (Reverse scored) \\
\hline & $\begin{array}{l}\text { I have performed a familiar task without referring to the maintenance manual or } \\
\text { other approved documentation. }\end{array}$ \\
\hline & I have deliberately 'bent" formal procedures in order to complete a task on time. \\
\hline & $\begin{array}{l}\text { I have temporarily disconnected or removed a part to make a job easier, but not } \\
\text { documented the disconnection/removal. }\end{array}$ \\
\hline
\end{tabular}

FONTE: Fogarty (2010). 


\section{APÊNDICE 5 - Questionário aplicado por Zohar (2005)}

\begin{tabular}{|c|c|}
\hline Construto & Pergunta Original/Indicador \\
\hline \multirow{16}{*}{$\begin{array}{c}\text { Compromisso Percebido } \\
\text { da Supervisão em relação } \\
\text { à Segurança }\end{array}$} & $\begin{array}{l}\text { My direct supervisor...Makes sure we receive all the equipment needed to do the job } \\
\text { safely. }\end{array}$ \\
\hline & My direct supervisor...Frequently checks to see if we are all obeying the safety rules. \\
\hline & My direct supervisor... Discusses how to improve safety with us. \\
\hline & My direct supervisor...Uses explanations (not just compliance) to get us to act safely. \\
\hline & $\begin{array}{l}\text { My direct supervisor...Emphasizes safety procedures when we are working under } \\
\text { pressure. }\end{array}$ \\
\hline & My direct supervisor...Frequently tells us about the hazards in our work. \\
\hline & My direct supervisor...Refuses to ignore safety rules when work falls behind schedule. \\
\hline & My direct supervisor...Is strict about working safely when we are tired or stressed. \\
\hline & My direct supervisor... Reminds workers who need reminders to work safely. \\
\hline & $\begin{array}{l}\text { My direct supervisor... Makes sure we follow all the safety rules (not just the most } \\
\text { important ones). }\end{array}$ \\
\hline & $\begin{array}{l}\text { My direct supervisor...Insists that we obey safety rules when fixing equipment or } \\
\text { machines. }\end{array}$ \\
\hline & My direct supervisor... Says a "good word" to workers who pay special attention to safety. \\
\hline & $\begin{array}{l}\text { My direct supervisor... s strict about safety at the end of the shift, when we want to go } \\
\text { home. }\end{array}$ \\
\hline & My direct supervisor...Spends time helping us learn to see problems before they arise. \\
\hline & My direct supervisor...Frequently talks about safety issues throughout the work week. \\
\hline & $\begin{array}{l}\text { My direct supervisor... Insists we wear our protective equipment even if it is } \\
\text { uncomfortable. }\end{array}$ \\
\hline
\end{tabular}

FONTE: Zohar (2005). 


\section{APÊNDICE 6 - Acidentes Reportados}

Acidentes reportados nos meses de outubro de novembro de 2013 na Gerência B.

\begin{tabular}{|c|c|c|}
\hline Data Evento & Descrição & $\begin{array}{l}\text { Relacionado a } \\
\text { Ferramentac }\end{array}$ \\
\hline 4-Nov-13 & $\begin{array}{l}\text { Ao retirar manualmente com auxilio de outro funcionário o pallet da camada superior, o bloco que } \\
\text { estava na camada inferior caiu no chão e resvalou sobre seu pé direito }\end{array}$ & Não \\
\hline 4-Nov-13 & $\begin{array}{l}\text { ESCAPOU A MANGUEIRA DA MÁQUINA PNEUMÁTICA(LIXADEIRA),ONDE A MANGUEIRA COM O ESPIGÃO NA } \\
\text { PONTA ,ACERTOU O COTOVELO DIREITO DO OPERADOR. OBS:FOI NO FINAL DO TURNO E VEIO HOJE } \\
\text { AVISAR,MAS COMO TEVE TESTEMUNHA QUE VIU O OCORRIDO FOI ABERTO O ROS. }\end{array}$ & Sim \\
\hline 5-Nov-13 & OPERADOR AO COLOCAR BLOCO NA EMBALAGEM TRANCOU O DEDO NO ELO DA CORRENTE DO GANCHO. & Sim \\
\hline 6-Nov-13 & Ao descer a passarela da moldagem EO desequilibrou-se vindo a bater com o joelho direito no piso. & Não \\
\hline 7-Nov-13 & $\begin{array}{l}\text { Funcionário ao manusear peças sobre a linha de roletes na área de inspeção de refugos da linha E2 } \\
\text { teve seu dedo do meio da mão esquerda prensado entre duas peças, ocasionando um pequeno corte } \\
\text { na ponta do dedo. }\end{array}$ & Não \\
\hline 7-Nov-13 & $\begin{array}{l}\text { Operador estava retirando bloco GMI } 8131003 \text { do jato, quando realizou o tombamento do mesmo na } \\
\text { linha de roletes presensou o dedo anelar da mão direita entre o rolete e a peça. }\end{array}$ & Não \\
\hline 8-Nov-13 & $\begin{array}{l}\text { AO EMPURAR O BLOCO } 8104065 \text { COM A MÃO NA CABEÇEIRA DA PEÇA BATEU CONTRA OUTRO BLOCO } \\
\text { VINDO A ATINGUIR SEU 3ㅇ DEDO DA MÃO ESQUEDA. O MESMO RELATOU O OCORIDO SÓ NO DIA } \\
\text { 11/11/2013 E POR ESTE MOTIVO FOI REPREENDIDO E DUAS PESSOAS TESTEMUNHARAM. WAGNER 78133- } \\
5 \text { E MARCOS 78721- }\end{array}$ & Não \\
\hline 9-Nov-13 & $\begin{array}{l}\text { Funcionario ao quebrar a rebarba da peça } 2507013 \text { com auxilio de martelo e punção, foi atingido por } \\
\text { uma (lasca) que saltou do martelo atingindo seu abdomem. }\end{array}$ & Sim \\
\hline 12-Nov-13 & $\begin{array}{l}\text { FUNCIONÁRIO ESTAVA PEGANDO A PEÇA } 3003015 \text { DA LINHA PARA LEVAR AO REBOLO EM0206, QUANDO } \\
\text { BATEU A PEÇA NO DEDO INDICADOR DA MÃO ESQUERDA QUE ESTAVA APOIADA NA MESA DO REBOLO }\end{array}$ & Não \\
\hline 13-Nov-13 & $\begin{array}{l}\text { OPERADOR AO COLOCAR O BAD PLATE NA GANCHEIRA, O MASSALOTE DA PEÇA QUEBROU ONDE VEIO A } \\
\text { ACERTAR SUA CANELA ESQUERDA }\end{array}$ & Sim \\
\hline 15-Nov-13 & $\begin{array}{l}\text { AO ABASTECER A LINHA COM AUXILIO DE TALHA, QUANDO AO POSICIONAR A PEÇA } 8104047 \text { SOBRE A } \\
\text { LINHA DE ROLETES A MESMA VEIO A PRENSAR SEU DEDO MÍNIMO DA MAO ESQUERDA ENTRE A PEÇA E O } \\
\text { ROLETE. }\end{array}$ & Não \\
\hline 19-Nov-13 & $\begin{array}{l}\text { FUNCIONÁRIO ESTAVA POSICIONANDO OS CONJUNTOS DE PEÇAS } 2004097 \text { MANUALMENTE, QUANDO } \\
\text { VIROU UM DOS CONJUNTOS TRANCOU A MÃO DIREITA CONTRA OUTRO CONJUNTO QUE ESTAVA NA } \\
\text { TALISCA. }\end{array}$ & Não \\
\hline 24-Nov-13 & $\begin{array}{l}\text { Ao baixar a peça da linha de rolete para o palet com auxilio da talha, a peça veio a escapar do gancho } \\
\text { batendo no pallet e tombando sobre o pé do colaborador. }\end{array}$ & Sim \\
\hline
\end{tabular}




\begin{tabular}{|c|c|c|}
\hline Data Evento & Descrição & $\begin{array}{l}\text { Relacionado a } \\
\text { Ferramenta }\end{array}$ \\
\hline 1-Oct-13 & $\begin{array}{l}\text { Ao voltar da janta, o colaborador tropeçou/bateu seu pé contra uma sapata de um gerador que estava } \\
\text { embalado aguardando disposição. A àrea estava isolada, mas a sapata estava ligeiramente para fóra } \\
\text { da area protegida pelo isolamento. }\end{array}$ & Não \\
\hline $1-$ Oct-13 & $\begin{array}{l}\text { Operador estava manuseando peças com auxilio de talha quando a ajeitar a peça no palete o dedo } \\
\text { indicador da mão direita ficou entre as duas peças vindo a prensar o mesmo }\end{array}$ & Sim \\
\hline $1-$ Oct-13 & $\begin{array}{l}\text { Operador estava manuseando peças com auxilio de talha abastecendo a linha, após a quebra da } \\
\text { rebarba tombou bloco na linha prensando o polegar esquerdo contra a peça e o rolete }\end{array}$ & Não \\
\hline 2-Oct-13 & $\begin{array}{l}\text { Ao destravar a trava para passar a bloco GMI com sua mão empurrando a manivela de trava bateu } \\
\text { seu dedo contra a linha. }\end{array}$ & Não \\
\hline 2 -Oct-13 & $\begin{array}{l}\text { Operador estava manuseando peças com auxilio de talha quando colocou o bloco } 2519001 \text { na linha } \\
\text { motorizada e o mesmo veio a cair prensando seu dedo positivo esquerdo contra o gancho da talha, e } \\
\text { a peça }\end{array}$ & Sim \\
\hline $2-$ Oct-13 & $\begin{array}{l}\text { OPERADOR AO EMPURRAR AS PEÇAS DEIXOU A MÃO NA CABECEIRA VINDO A SER ATINGIDO POR OUTRA } \\
\text { PEÇA }\end{array}$ & Não \\
\hline $4-$-Oct-13 & $\begin{array}{l}\text { O colaborador foi a molar o rebolo com auxílio de um drezador onde escapou a máquina de sua mão } \\
\text { batendo seu dedo menor na linha. }\end{array}$ & Sim \\
\hline 7-Oct-13 & $\begin{array}{l}\text { FUNCIONÁRIO ESTAVA REALIZANDO A QUEBRA DE CANAIS QUANDO CAIU AREIA QUENTE DENTRO DO SEU } \\
\text { CALÇADO }\end{array}$ & Não \\
\hline 7-Oct-13 & $\begin{array}{l}\text { O OPERADOR AO VIRAR O CABEÇOTE 81-25-002 PARA FAZER A INSPEÇÃO VISUAL, ANTES DA OLEADORA } \\
\text { PRENDEU O DEDO DA MÃO ESQUERDA ENTRE ROLETE E PEÇA. }\end{array}$ & Não \\
\hline 7-Oct-13 & ao virar o bloco 2507010 bateu seu dedo contra a outra peça. & Não \\
\hline 7-Oct-13 & $\begin{array}{l}\text { Funcionário ao levantar a peça com auxílio de uma alavanca a peça se movimentou bruscamente, } \\
\text { jogando sua mão direita contra outra peça que já es tava na linha }\end{array}$ & Sim \\
\hline 8-Oct-13 & $\begin{array}{l}\text { Ao descarregar o Bloco Perkins do correntão da Pintura, teve sua mão esquerda prensada entre } \\
\text { gancho e peça. }\end{array}$ & Sim \\
\hline 9-Oct-13 & $\begin{array}{l}\text { Funcionário ao rebarbar a peça } 20.04 .216 \text {, teve seu dedo anelar da mão esquerda atingido por uma } \\
\text { rebarba (estava usando luva e os demais EPI's exigidos). }\end{array}$ & Não \\
\hline 9-Oct-13 & $\begin{array}{l}\text { Operador estava empaletando peças com auxilio de tal ha com o bloco } 2507010 \text {, quando levou a peça } \\
\text { até o palete a mesma escapou do gancho vindo atingir sua perna esquerda }\end{array}$ & Sim \\
\hline 9-Oct-13 & $\begin{array}{l}\text { Operador estava descarregando a maquina de limpeza } 1042 \text { com auxilio de talha, quando foi retirar o } \\
\text { bloco } 2519001 \text { da gancheira, o mesmo veio a enroscar puxando a gancheira batendo contra o seu } \\
\text { joelho direito }\end{array}$ & Sim \\
\hline $10-$ Oct-13 & $\begin{array}{l}\text { OPERADOR COLOCOU A LIXADEIRA NA BANCADA E AO SE VIRAR PARA PROSEGUIR A OPERAÇÃO A } \\
\text { LIXADEIRA VEIO A CAIR NO SEU PÉ VINDO A BATER NO SEU DEDO MENOR. OBS:OPERADOR TRABALHOU } \\
\text { ATÉ DIA O8/10/13 E VEIO HOJE COM O ATESTADO SOBRE O OCORRIDO. } \\
\end{array}$ & Sim \\
\hline $10-$ Oct-13 & $\begin{array}{l}\text { Funcionario foi elevar a peça (2004224)com auxilio de talha para abastecer a gancheira da máquina } \\
1046 \text {, quando veio a pisar sobre rebarba que estava sobre a grade, vindo a sentir dor no joel ho. }\end{array}$ & Não \\
\hline $15-$-Oct-13 & FUNCIONÁRIO PRENSOU SUA MÃO DIREITA AO DESCARREGAR A LINHA DE JATOS DO CDC. & Não \\
\hline $15-$-Oct-13 & $\begin{array}{l}\text { Ao manusear uma gancheira que se encontrava no chão com as duas mãos para realizar limpeza no } \\
\text { local a mesma escapou de uma de suas mãos vindo a prensar a mão esquerda com outra gancheira } \\
\text { que estava no mesmolocal. }\end{array}$ & Sim \\
\hline 15-Oct-13 & $\begin{array}{l}\text { Ao retirar a peça que travou no final da linha após a maquina fluxo o funcionario veio a prenssar o } \\
\text { seu dedo da mão direita. Por a mesma ter acionada a linha automaticamente. }\end{array}$ & Não \\
\hline 15-Oct-13 & $\begin{array}{l}\text { Funcionário, ao segurar as peças da LRO059, para liberar as peças da linha reta LROO53 (Iinha da } \\
\text { magna flux), deixou sua mão na cabeceira da peça vindo a prensar com bloco que vinha atráz. }\end{array}$ & Não \\
\hline $16-$-Oct-13 & $\begin{array}{l}\text { Funcionário ao atravessar sobre a linha de descida da quebra de canais tropessou na escada, vindo a } \\
\text { se a poiar sobre o bloco que estava sobre a talisca. Feriu levemente a mão esquerda. }\end{array}$ & Não \\
\hline $16-$-Oct-13 & $\begin{array}{l}\text { OPERADOR AO LEVANTAR O BIOMBO PARA COLOCAR NA LINHA COMO PROTEÇÃO E SEPARADOR DE UM } \\
\text { OPERADOR PARA OUTRO,QUANDO ESTAVA QUASE NA POSIÇÃO VEIO A ESCAPAR DA SUA MÃO E CAINDO } \\
\text { EM CIMA DO SEU DEDO MENOR DO PÉ DIREITO. }\end{array}$ & Não \\
\hline 17-Oct-13 & $\begin{array}{l}\text { ao enganchar a peça deixou o dedo entre o gancho e a peça e acionou o comando da tal ha prensando } \\
\text { seu dedo. }\end{array}$ & Sim \\
\hline 17-Oct-13 & $\begin{array}{l}\text { Ao manusear uma gancheira que se encontrava no chão com as duas mãos para realizar limpeza no } \\
\text { local a mesma escapou de uma de suas mãos vindo a prensar a mão esquerda com outra gancheira } \\
\text { que estava no mesmo local. }\end{array}$ & Sim \\
\hline $20-$-Oct-13 & $\begin{array}{l}\text { Colaborador es tava colocando bloco sobre palete de madeira, ao virar de costa para o palete, caiu } \\
\text { o1(um) bloco no piso batendo no seu calcanhar do pé esquerdo. }\end{array}$ & Sim \\
\hline 20-Oct-13 & $\begin{array}{l}\text { APÓS A PEÇA SAIR DO JATO AUTOMÁTICO, O FUNCIONÁRIO FOI EMPURRAR MANUALMENTE A PEÇA PARA } \\
\text { A LINHA, QUANDO SUA MÃO FOI ATINGIDA POR UMA OUTRA PEÇA QUE FOI EMPURRADA PELO } \\
\text { DISPOSITIVO (PISTÃO). }\end{array}$ & Não \\
\hline 22-Oct-13 & $\begin{array}{l}\text { O Mesmo estava quebrando canal da peça } 2507013 \text { e foi atingido por um pedaço de rebarba que seu } \\
\text { colega rebarbava no lado oposto. }\end{array}$ & Não \\
\hline $22-0 c t-13$ & $\begin{array}{l}\text { FUNCIONÁRIO AO LEVANTAR PALET,SENTIU DOR LOMBAR. OBS: FUNCIONÁRIO NÃO ME PROCUROU PARA } \\
\text { FALAR DO OCORRIDO,FOI PARA O AMBULATÓRIO,PEGOU ATESTADO, RETORNANDO HOJE DO } \\
\text { ATESTADO,AO MENCIONAR O OCORRIDO,FOI CHAMADO PESSOAS QUE TRABALHAM PRÓXIMO A ELE } \\
\text { ONDE TEVE A CONFIRMAÇÃO. }\end{array}$ & Não \\
\hline $24-$ Oct-13 & $\begin{array}{l}\text { Funcionario ao puxar um pallet que es tava sobre a pilha de peças atinguiu sem querer a perna de seu } \\
\text { colega que estava ao lado. }\end{array}$ & Não \\
\hline $25-$-Oct-13 & $\begin{array}{l}\text { OPERADOR AO TROCAR DISPOSITIVO DA ESMERILHADORA VEIO A BATER SEU DEDO NO DISPOSITIVO DE } \\
\text { LEVE VINDO A LESIONAR O DEDO. }\end{array}$ & Sim \\
\hline $25-$-Oct-13 & $\begin{array}{l}\text { AO ACIONAR A TALHA,PARA LEVANTAR A GANCHEIRA,VEIO A ARREBENTAR O CABO DE AÇO DO ACIONADOR } \\
\text { DA TALHA,CAINDO A GANCHEI RA,VINDO A ATINGIR DE LEVE SEU DEDO E ROSTO SEM GRÁVIDADE. }\end{array}$ & Sim \\
\hline 25-Oct-13 & O operador prensou a mão esquerda embaixo da peça quando abastecia a linha de estanqueidade & Não \\
\hline 26-Oct-13 & $\begin{array}{l}\text { Funcionario ao abastecer o jato de granalha com a peça } 8104067 \text { (cabeçote) deixou sua mão } \\
\text { esquerda entre duas peças vindo a atingir } 30 \text { dedo. }\end{array}$ & Não \\
\hline $26-0 c t-13$ & $\begin{array}{l}\text { Funcionário ao empurrar uma peça do } 81-04-47 \text { que se movimentava em pé para recuperar a mesma } \\
\text { veio a virar sobre sua mão esquerda }\end{array}$ & Não \\
\hline 29-Oct-13 & $\begin{array}{l}\text { FUNCIONÁRIO ESTAVA REALIZANDO A LIMPEZA EM BAIXO DA PLATAFORMA DO MANIPULADOR, QUANDO } \\
\text { CAIU AREIA QUENTE SOBRE SUAS COSTAS. }\end{array}$ & Não \\
\hline 30-Oct-13 & $\begin{array}{l}\text { Durante o abastecimento da linha do meio com auxílio de talha, quando ao içar as peças } 2507013 \\
\text { houve o prensamento do } 3 \text { o quirodáctilo da mão esquerda entre duas peças. }\end{array}$ & Não \\
\hline 30-Oct-13 & $\begin{array}{l}\text { O FUNCIONARIO ESTAVA NA 1O FIBRA E O OUTRO FUNCIONARIO QUE ESTAVA ABASTECENDO A LINHA } \\
\text { EMPURROU AS PEÇAS E UMA VIROU E AS DEMAIS EMPURRARAM ATÉ A MESMA CAIU E ATINGIU O PÉ DO } \\
\text { OPERADOR. }\end{array}$ & Não \\
\hline
\end{tabular}




\section{APÊNDICE 7 - Questionário Inicial}

PARTE A - Em sua área você diariamente trabalha com várias ferramentas necessárias a realização de seu trabalho tais como, talhas, ganchos, ferramentas pneumáticas e marteletes. Considerando estas ferramentas, avalie o grau de concordância que você tem em relação às questões abaixo:

1. Eu considero importante inspecionar minhas ferramentas de trabalho no início do turno todos os dias.

2. Eu tenho tempo para inspecionar minhas ferramentas de trabalho no início do turno todos os dias.

3. Eu planejo inspecionar minhas ferramentas de trabalho no início do turno todos os dias.

4. Eu normalmente inicio meu trabalho sem inspecionar as ferramentas que utilizo.

5. A maioria dos meus colegas me chama atenção quando eu não inspeciono as ferramentas de trabalho ao iniciar minha jornada.

6. Eu inspeciono minhas ferramentas de trabalho no início do turno todos os dias.

7. Eu não acho necessário inspecionar minhas ferramentas de trabalho no início do turno todos os dias.

8. Eu sei identificar defeitos e problemas em minhas ferramentas de trabalho.

9. A partir de amanhã, é provável que eu inspecione minhas ferramentas de trabalho no início do turno todos os dias.

10. A maioria dos meus colegas de trabalho me incentiva a inspecionar as ferramentas no início do turno todos os dias.

11. Inspecionar minhas ferramentas de trabalho no início do turno todos os dias é uma prática segura.

12. Eu sou autorizado a inspecionar minhas ferramentas de trabalho no início do turno todos os dias.

13. Eu pretendo inspecionar minhas ferramentas de trabalho no início do turno todos os dias.

14. A maioria dos meus colegas não inspeciona suas ferramentas de trabalho no início do turno todos os dias.

(2)

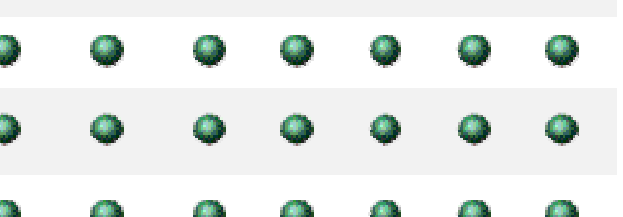

.

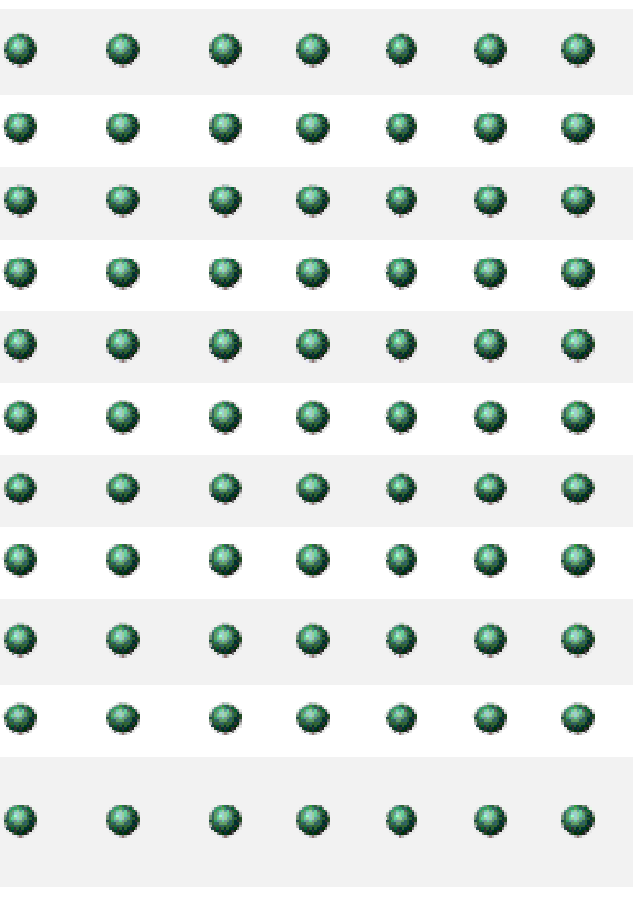


PARTE B - Com relação a seu Qualificado em sua área de trabalho, avalie o grau de concordância em relação às questões abaixo:

1. Meu Qualificado verifica frequentemente se todos na minha equipe inspecionam as ferramentas no início do turno todos os dias.

2. Meu Qualificado conversa comigo sobre como as inspeções de ferramentas devem ser feitas.

3. Meu Qualificado me orienta sobre a importância de inspecionar as ferramentas de trabalho no início do turno todos os dias.

4. O Qualificado da linha reforça para a equipe que as ferramentas devem ser inspecionadas no início do turno mesmo quando estamos com pressa.

5. O Qualificado da linha frequentemente fala para minha equipe sobre os perigos de não inspecionar ferramentas no início do turno.

6. O Qualificado chama a atenção dos colegas que não inspecionam suas ferramentas no início do turno.

7. Meu Qualificado frequentemente fala sobre questões de segurança ao longo da semana de trabalho.

8. O Qualificado insiste que nós devemos inspecionar as ferramentas que utilizamos no início do turno todos os dias.

9. O Qualificado da linha elogia os colegas que sempre inspecionam as ferramentas que utilizamos no início do turno todos os dias.

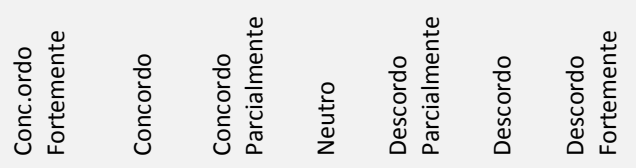

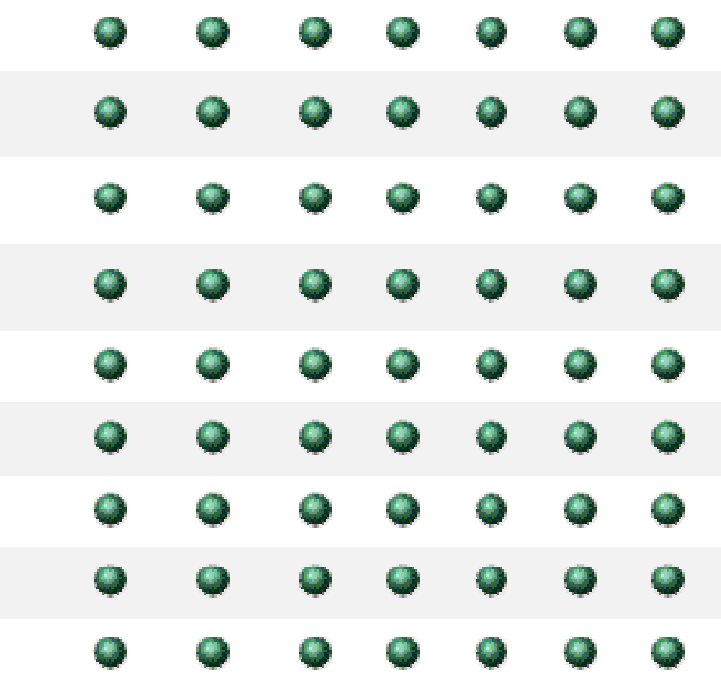

PARTE C - Por favor, forneça algumas informações sobre você:

\section{Mais de 1}

ano

1. Há quanto tempo trabalha na empresa?
SIM

2. Já sofreu algum acidente de trabalho onde ficou afastado por mais de um (1) dia de trabalho?
Menos de 1 ano

Q

NÃO

\begin{tabular}{ccc} 
& \multicolumn{2}{c}{} \\
Primário & $\begin{array}{c}\text { Ensino } \\
\text { Médio }\end{array}$ & Ensino \\
$\varphi$ & $\varphi$ & $\varphi$
\end{tabular}

4. Qual sua idade? (preencher com idade em anos). 


\section{APÊNDICE 8 - Matriz Rotacionada Pré-Teste}

Matriz Rotacionada relativa aos dados coletados no pré-teste utilizando o Questionário Inicial.

\begin{tabular}{|c|c|c|c|c|c|c|c|c|c|}
\hline \multicolumn{10}{|c|}{ Rotated Component Matrixa } \\
\hline & & \multicolumn{8}{|c|}{ Component } \\
\hline & & 1 & 2 & 3 & 4 & 5 & 6 & 7 & 8 \\
\hline Atitude (1) & $\begin{array}{l}\text { Eu considero importante inspecionar minhas } \\
\text { ferramentas de trabalho no início do turno } \\
\text { todos os dias. }\end{array}$ & -.147 & .151 & .823 & -.022 & .215 & .048 & .133 & -.041 \\
\hline Controle Perc (2) & $\begin{array}{l}\text { Eu tenho tempo para inspecionar minhas } \\
\text { ferramentas de trabalho no início do turno } \\
\text { todos os dias. }\end{array}$ & .185 & .302 & -.020 & -.076 & .114 & .622 & -.108 & .334 \\
\hline Intenção (3) & $\begin{array}{l}\text { Eu planejo inspecionar minhas ferramentas } \\
\text { de trabalho no início do turno todos os dias. }\end{array}$ & -.035 & .186 & -.044 & -.286 & -.052 & .566 & .152 & -.526 \\
\hline Comportamento (4) & $\begin{array}{l}\text { Eu normalmente inicio meu trabalho sem } \\
\text { inspecionar as ferramentas que } \\
\text { utilizo.(reverse) } \\
\end{array}$ & .080 & -.153 & .231 & -.044 & .793 & .056 & -.064 & -.003 \\
\hline Normas Subj (5) & $\begin{array}{l}\text { A maioria dos meus colegas me chama } \\
\text { atenção quando eu não inspeciono as } \\
\text { ferramentas de trabalho ao iniciar minha } \\
\text { jornada. }\end{array}$ & .224 & .819 & .021 & .116 & -.075 & -.024 & .014 & -.034 \\
\hline Comportamento (6) & $\begin{array}{l}\text { Eu ins peciono minhas ferramentas de } \\
\text { trabalho no início do turno todos os dias. }\end{array}$ & .149 & -.160 & .125 & .084 & -.019 & .831 & .093 & .042 \\
\hline Atitude (7) & $\begin{array}{l}\text { Eu não acho necessário inspecionar minhas } \\
\text { ferramentas de trabalho no inicio do turno } \\
\text { todos os dias. (reverse) }\end{array}$ & .155 & .066 & .408 & -.659 & .124 & .021 & -.068 & -.036 \\
\hline Controle Perc (8) & $\begin{array}{l}\begin{array}{l}\text { Eu sei identificar defeitos e problemas em } \\
\text { minhas ferramentas de trabalho. }\end{array} \\
\end{array}$ & -.023 & .114 & .068 & -.031 & .044 & .175 & .007 & .791 \\
\hline Intenção (9) & $\begin{array}{l}\text { A partir de amanhã, é provável que eu } \\
\text { inspecione minhas ferramentas de trabalho } \\
\text { no inicio do turno todos os dias }\end{array}$ & .024 & .151 & -206 & .156 & -.034 & .145 & .825 & .122 \\
\hline Normas Subj (10) & $\begin{array}{l}\text { A maioria dos meus colegas de trabalho me } \\
\text { incentiva a inspecionar as ferramentas no } \\
\text { inicio do turno todos os dias. }\end{array}$ & .116 & .730 & .132 & .049 & .171 & .090 & .408 & .122 \\
\hline Atitude (11) & $\begin{array}{l}\text { Inspecionar minhas ferramentas de trabalho } \\
\text { no inicio do turno todos os dias é uma prática } \\
\text { segura. }\end{array}$ & -.090 & |.221 & .495 & -.178 & .191 & -.077 & -.059 & .307 \\
\hline Controle Perc (12) & $\begin{array}{l}\text { Eu sou autorizado a inspecionar minhas } \\
\text { ferramentas de trabalho no início do turno } \\
\text { todos os dias. }\end{array}$ & .701 & .105 & -.140 & -.323 & .293 & .205 & .063 & -.028 \\
\hline Intenção (13) & $\begin{array}{l}\text { Eu pretendo inspecionar minhas ferramentas } \\
\text { de trabalho no início do turno todos os dias. }\end{array}$ & .017 & .053 & .260 & - .144 & -.046 & -.068 & .809 & -.196 \\
\hline Normas Subj (14) & $\begin{array}{l}\text { A maioria dos meus colegas não ins pecionam } \\
\text { suas ferramentas de trabalho no início do } \\
\text { turno todos os dias. (reverse) }\end{array}$ & .141 & .184 & .053 & .054 & .829 & -.031 & .004 & .068 \\
\hline Supervisão (1) & $\begin{array}{l}\text { Meu Qualifica do verifica frequentemente se } \\
\text { todos na minha equipe inspecionam as } \\
\text { ferramentas no inicio do turno todos os dias. }\end{array}$ & .466 & .334 & -.125 & .5 & .100 & -.044 & .042 & -.265 \\
\hline Supervisão (2) & $\begin{array}{l}\text { Meu Qualifica do conversa comigo sobre como } \\
\text { as insepeções de ferramentas devem ser } \\
\text { feitas. }\end{array}$ & .737 & .068 & .157 & .169 & .168 & -.106 & .036 & -.277 \\
\hline Supervisão (3) & $\begin{array}{l}\text { Meu Qualificado me orienta sobre a } \\
\text { importância de inspecionar as ferramentas de } \\
\text { trabalho no início do turno todos os dias. }\end{array}$ & .840 & .059 & -.111 & .103 & .179 & .070 & .081 & .044 \\
\hline Supervisão (4) & $\begin{array}{l}\text { O Qualificado da linha reforça para a equipe } \\
\text { que as ferramentas devem ser inspecionadas } \\
\text { no início do turno mesmo quando estamos } \\
\text { com pressa. }\end{array}$ & .830 & .126 & -.011 & .054 & -.041 & .035 & .018 & .090 \\
\hline Supervisão (5) & $\begin{array}{l}\text { O Qualificado da linha frequentemente fala } \\
\text { para minha equipe sobre os perigos de não } \\
\text { inspecionar ferramentas no início do turno. }\end{array}$ & .742 & -.110 & .193 & .267 & -.134 & .183 & -.067 & .063 \\
\hline Supervisão (6) & $\begin{array}{l}\text { O Qualificado chama a atenção dos colegas } \\
\text { que não inspecionam suas ferramentas no } \\
\text { início do turno. }\end{array}$ & .258 & .165 & .013 & & .067 & -.018 & -.030 & -.018 \\
\hline Supervisão (7) & $\begin{array}{l}\text { O Qual lificado insiste que nós devemos } \\
\text { inspecionar as ferramentas que utilizamos no } \\
\text { início do turno todos os dias. }\end{array}$ & .451 & .105 & 687 & -.104 & -.028 & .159 & -.041 & .001 \\
\hline Supervisão (8) & $\begin{array}{l}\begin{array}{l}\text { O Qual lificado da linha elogia os colegas que } \\
\text { sempre inspecionam as ferramentas que } \\
\text { utilizamos no inicio do turno todos os dias. }\end{array} \\
\end{array}$ & .758 & .270 & .029 & -.016 & .032 & .080 & -.044 & -.077 \\
\hline Supervisão (9) & $\begin{array}{l}\text { Meu Qualifica do frequentemente fala sobre } \\
\text { questôes de segurança ao longo da semana } \\
\text { de trabalho. }\end{array}$ & .437 & .368 & .149 & .343 & .064 & .136 & -.020 & -.472 \\
\hline
\end{tabular}




\section{APÊNDICE 9 - Questionário Final}

Em sua área você diariamente utiliza várias ferramentas necessárias à realização de seu trabalho tais como, talhas, ganchos, ferramentas pneumáticas e marteletes.

PARTE A - Considerando estas ferramentas, qual sua opinião em relação às questões abaixo.

A1. Eu considero que inspecionar minhas ferramentas no início do turno todos os dias é:

\begin{tabular}{|c|c|c|c|c|c|c|}
\hline \multicolumn{3}{|c|}{ IMPORTANTE } & \multicolumn{4}{|c|}{$\begin{array}{c}\text { NÃO } \\
\text { IMPORTANTE }\end{array}$} \\
\hline 7 & 6 & 5 & 4 & 3 & 2 & 1 \\
\hline$\varphi$ & $Q$ & $\varphi$ & $\Theta$ & 9 & $\varphi$ & $\theta$ \\
\hline
\end{tabular}

A2. Eu considero que inspecionar minhas ferramentas no início do turno todos os dias é:

\begin{tabular}{llllllll}
\multicolumn{3}{c}{ SEGURO } & \multicolumn{5}{c}{ INSEGURO } \\
7 & 6 & 5 & 4 & 3 & 2 & 1 \\
9 & 9 & 9 & 9 & 9 & 9 & $\varphi$
\end{tabular}

A3. Eu considero que inspecionar minhas ferramentas no início do turno todos os dias é:

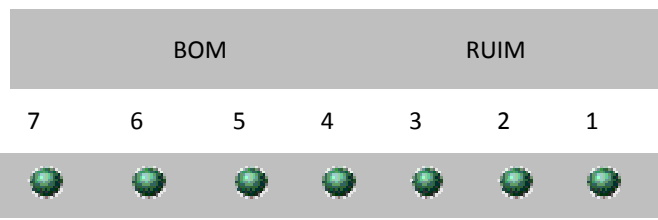

A4. Eu considero que inspecionar minhas ferramentas no início do turno todos os dias é:

\begin{tabular}{|c|c|c|c|c|c|c|}
\hline \multicolumn{3}{|c|}{ NECESSÁRIO } & \multicolumn{4}{|c|}{ DESNECESSÁRIO } \\
\hline 7 & 6 & 5 & 4 & 3 & 2 & 1 \\
\hline$\varphi$ & 4 & $\varphi$ & $Q$ & 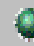 & 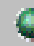 & $Q$ \\
\hline
\end{tabular}


PARTE B - Agora, responda assinalando um $\mathrm{X}$ na alternativa na qual parece mais adequada para você:

B1. Eu inspeciono minhas ferramentas de trabalho no início do turno todos os dias.

B.2 A maioria dos meus colegas me chama atenção quando eu não inspeciono as ferramentas de trabalho ao iniciar minha jornada.

B.3 Eu tenho tempo para inspecionar minhas ferramentas de trabalho no início do turno todos os dias.

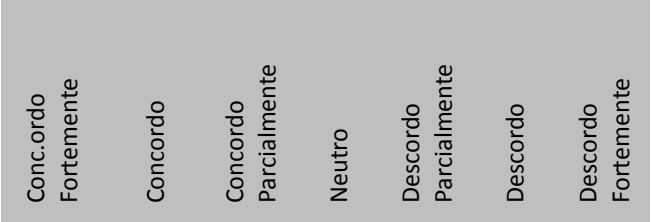

\begin{tabular}{|c|c|c|c|c|c|c|c|}
\hline $\begin{array}{l}\text { B. } 4 \text { Eu pretendo inspecionar minhas ferramentas de trabalho no início do turno } \\
\text { todos os dias. }\end{array}$ & $\varphi$ & 0 & 0 & $\odot$ & 0 & 0 & $\varphi$ \\
\hline $\begin{array}{l}\text { B. } 5 \text { Esta semana eu inspecionei minhas ferramentas de trabalho no início do turno } \\
\text { todos os dias. }\end{array}$ & $\varphi$ & 0 & 0 & $\varphi$ & 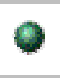 & $\varphi$ & $\varphi$ \\
\hline $\begin{array}{l}\text { B. } 6 \text { A maioria dos meus colegas inspeciona as ferramentas de trabalho no início do } \\
\text { turno todos os dias. }\end{array}$ & 0 & 0 & 0 & 0 & 0 & 0 & 0 \\
\hline
\end{tabular}

B.7 Eu sei inspecionar minhas ferramentas de trabalho no início do turno todos os dias.

B.8 Eu tenho a intenção de inspecionar minhas ferramentas de trabalho no início do turno todos os dias.

B.9 A maioria dos meus colegas de trabalho me incentiva a inspecionar as ferramentas no início do turno todos os dias.

\begin{tabular}{|c|c|c|c|c|c|c|}
\hline B.10 Hoje eu inspecionei minhas ferramentas de trabalho no início do turno. & $Q$ & $\varphi$ & $Q$ & $\varphi$ & $\varphi$ & $Q$ \\
\hline
\end{tabular}

B.11 A maioria dos meus colegas acha importante inspecionar as ferramentas de trabalho todos os dias.

B.12 Eu consigo inspecionar minhas ferramentas de trabalho no início do turno todos os dias.

B.13 A partir de amanhã, é provável que eu inspecione minhas ferramentas de trabalho no início do turno todos os dias

B.14 Eu sou capaz de inspecionar minhas ferramentas de trabalho no início do turno todos os dias.

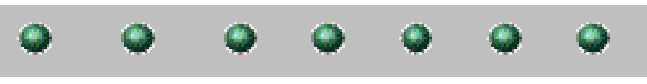

B.15 Eu quero inspecionar minhas ferramentas de trabalho no início do turno todos os dias. 
PARTE C - Com relação a seu Qualificado em sua área de trabalho, avalie o grau de concordância em relação às questões abaixo:

C1. Meu Qualificado verifica frequentemente se todos na minha equipe inspecionam as ferramentas no início do turno todos os dias.

C2. Meu Qualificado conversa comigo sobre como as inspeções de ferramentas
devem ser feitas.

C3. Meu Qualificado me orienta sobre a importância de inspecionar as ferramentas de trabalho no início do turno todos os dias.

C4. O Qualificado da linha reforça para a equipe que as ferramentas devem ser inspecionadas no início do turno mesmo quando estamos com pressa.

C5. O Qualificado da linha frequentemente fala para minha equipe sobre os perigos de não inspecionar ferramentas no início do turno.

C6. O Qualificado chama a atenção dos colegas que não inspecionam suas ferramentas no início do turno.

C7. O Qualificado da linha elogia os colegas que sempre inspecionam as ferramentas que utilizamos no início do turno todos os dias.

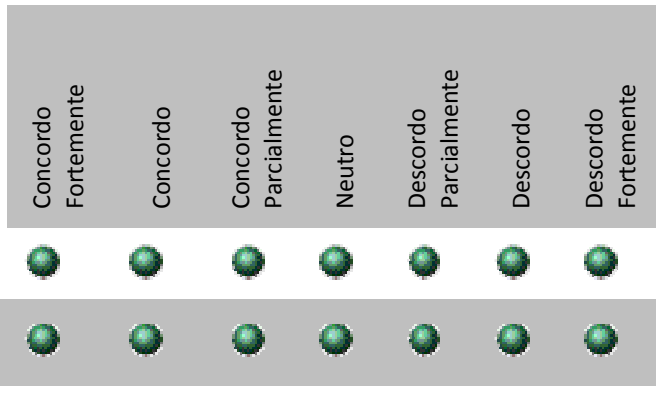

$\begin{array}{llllllll} & 0 & 0 & 0 & 0 & 0 & 0 & 0 \\ \text { ser } & 0 & 0 & 0 & 0 & 0 & 0 & 0 \\ \text { os } & 0 & 0 & 0 & 0 & 0 & 0 & 0 \\ \text { s } & 0 & 0 & 0 & 0 & 0 & 0 & 0 \\ & 0 & 0 & 0 & 0 & 0 & 0 & 0\end{array}$

PARTE D - Por favor, forneça algumas informações sobre você:

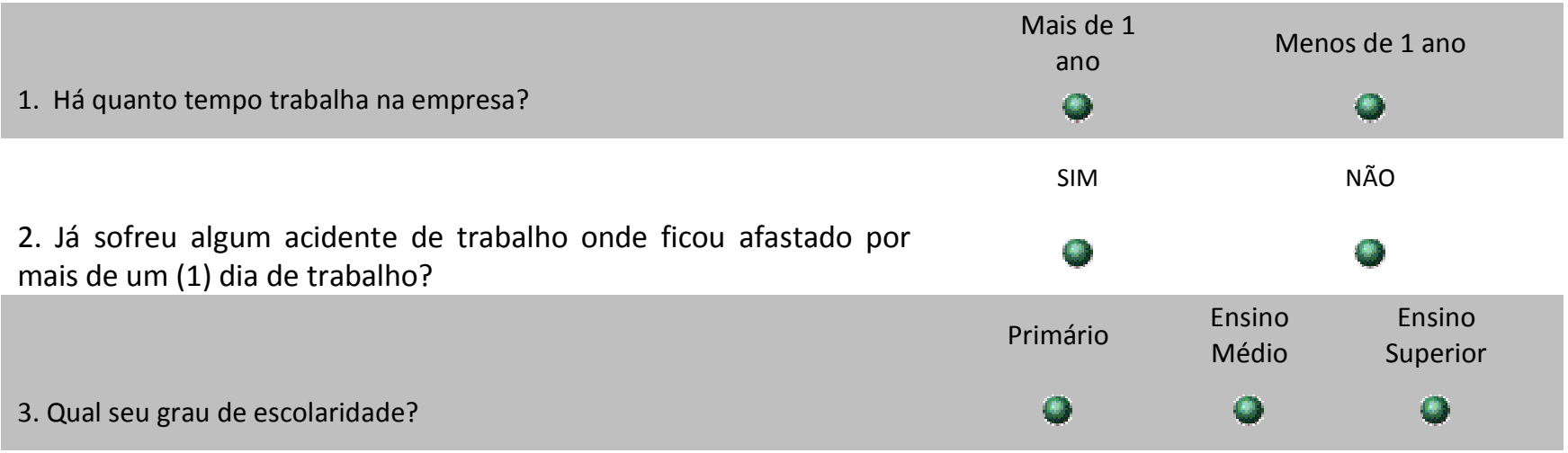

4. Quantos anos você tem? 


\section{APÊNDICE 10 - Compilação das Entrevistas}

\section{PROFISSIONAIS DE SEGURANÇA DO TRABALHO}

\begin{tabular}{|c|c|c|c|c|c|c|c|c|c|}
\hline 0 & 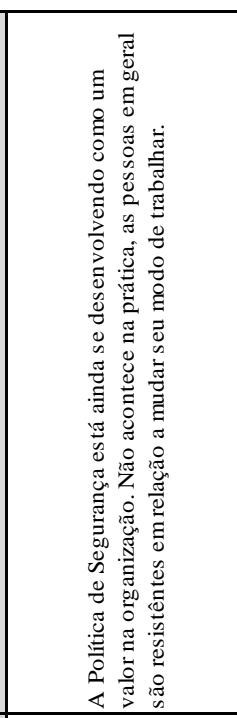 & 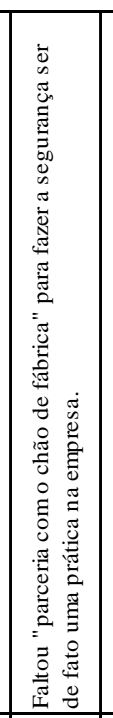 & 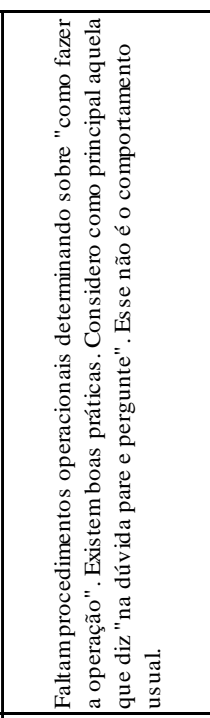 & 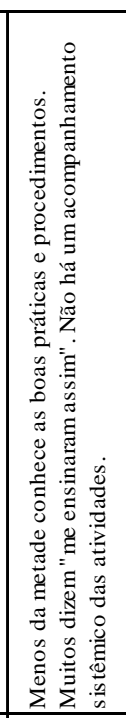 & 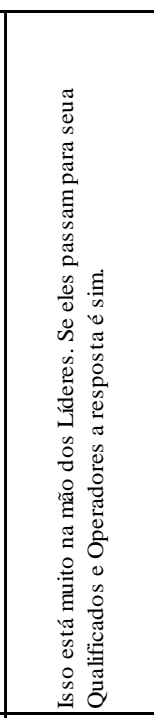 & 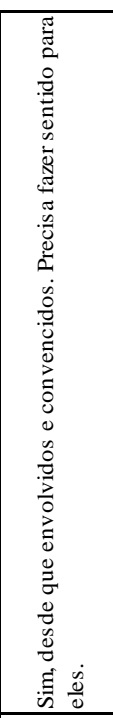 & 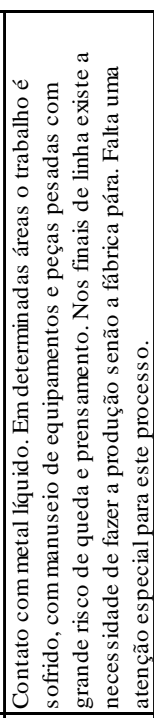 & 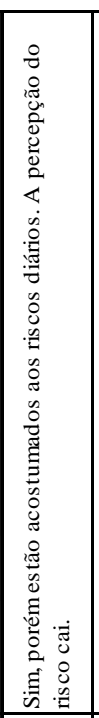 & 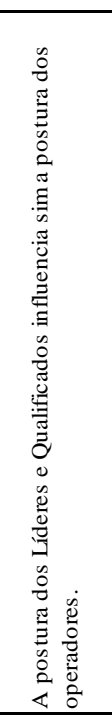 \\
\hline & 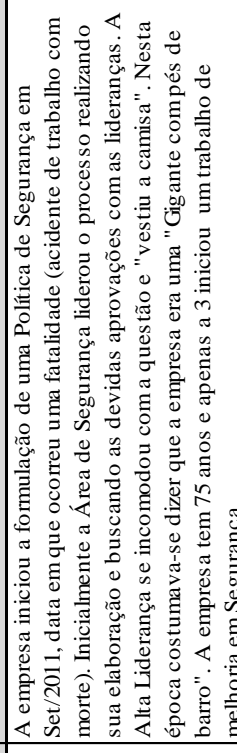 & 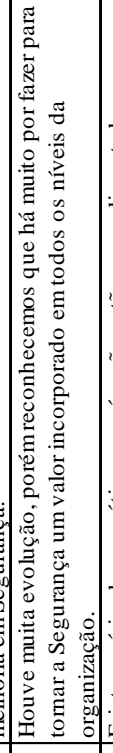 & 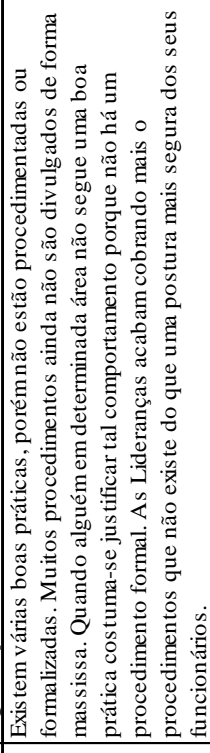 & 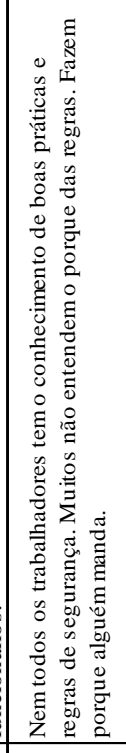 & 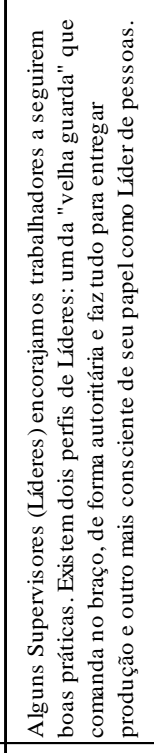 & 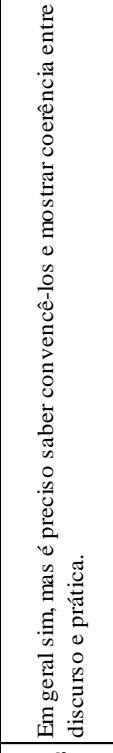 & 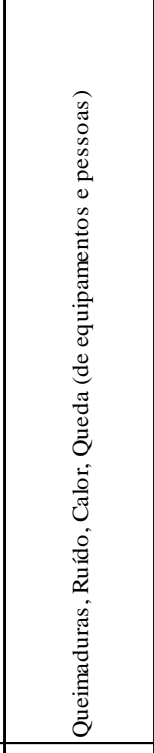 & 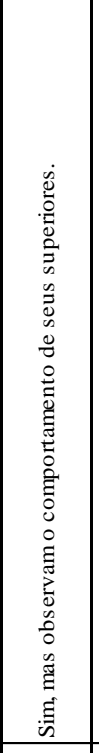 & 㒸 \\
\hline $\mathscr{g}$ & 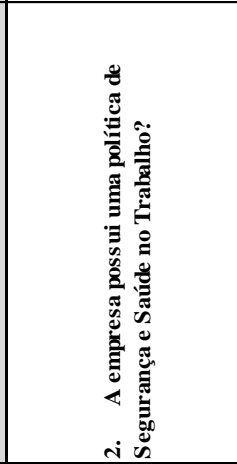 & 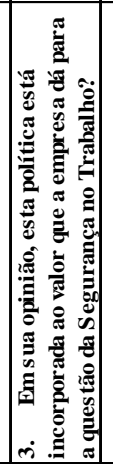 & 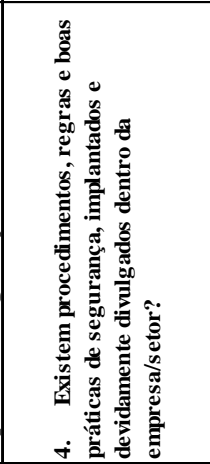 & 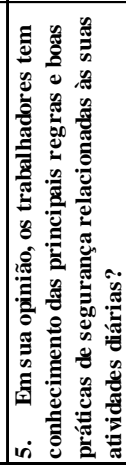 & 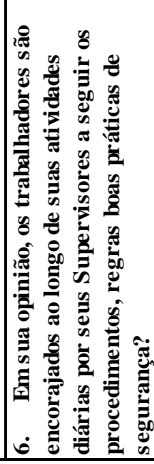 & 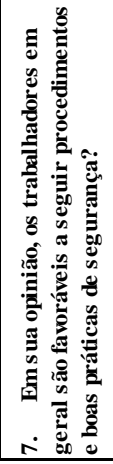 & 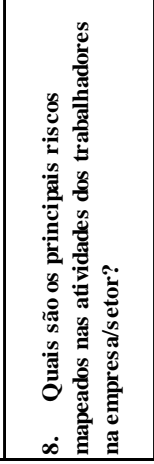 & 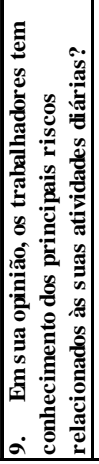 & 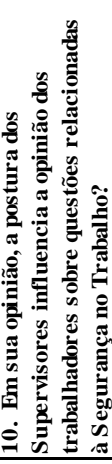 \\
\hline
\end{tabular}


LÍDERES DE PRODUÇÃO

\begin{tabular}{|c|c|c|c|c|c|c|c|c|c|c|c|}
\hline 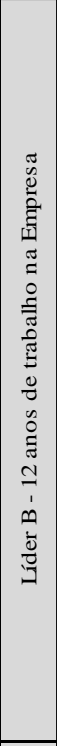 & 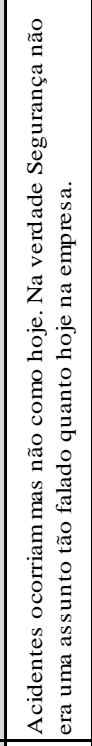 & 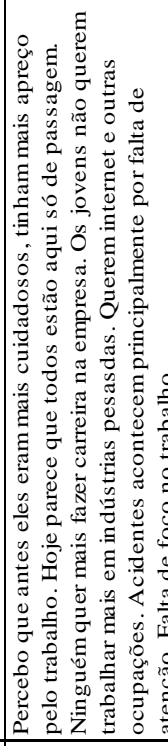 & 茡 & 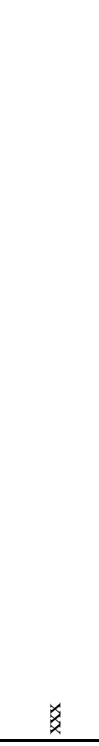 & 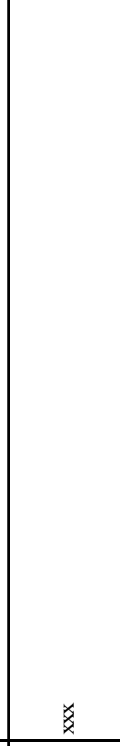 & 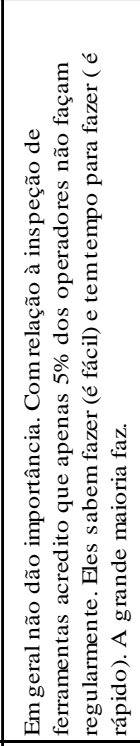 & 芝 & 荌 & 兑 & 曾 & 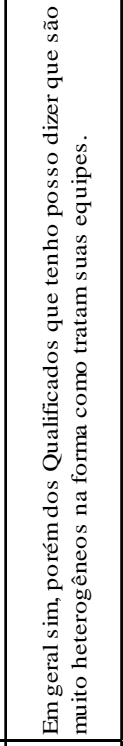 \\
\hline 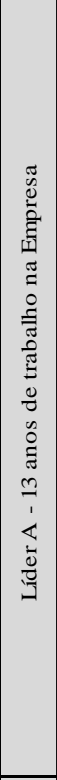 & 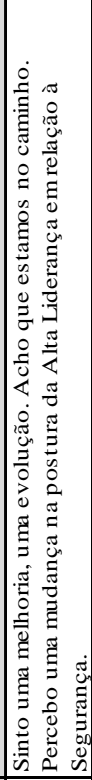 & $x$ & 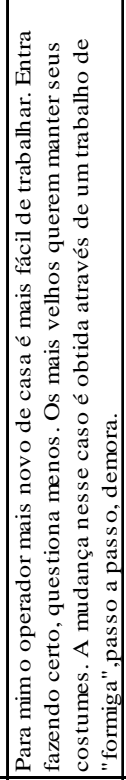 & 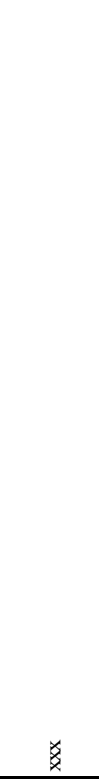 & 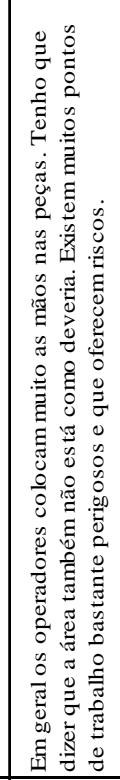 & 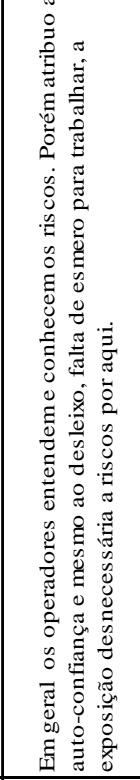 & 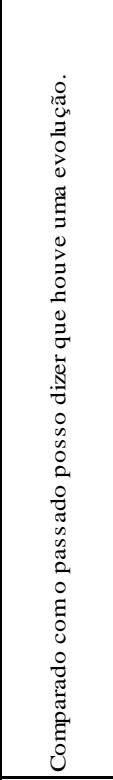 & 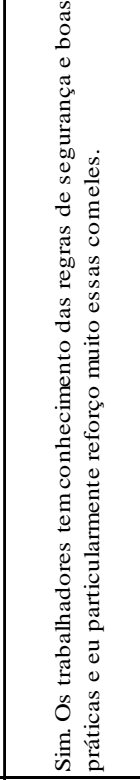 & 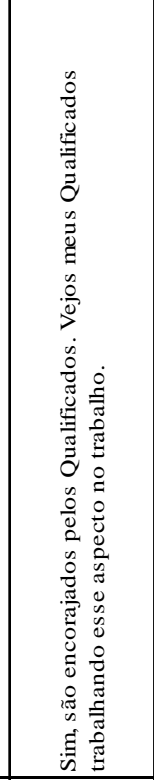 & $\frac{x}{x}$ & \\
\hline $\mid$\begin{tabular}{|c}
0 \\
0 \\
0 \\
$\tilde{y}$ \\
$\tilde{u}$ \\
$\tilde{z}$
\end{tabular} & 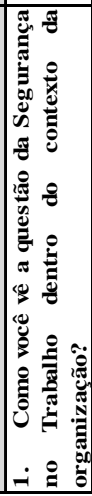 & 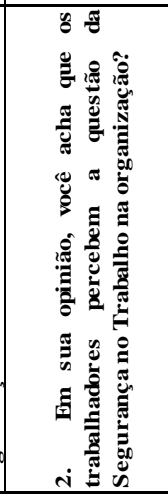 & 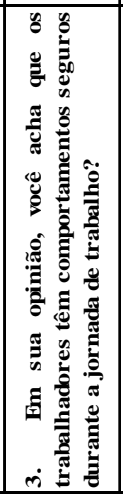 & 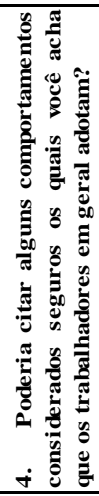 & 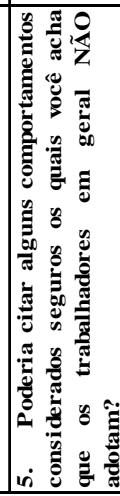 & 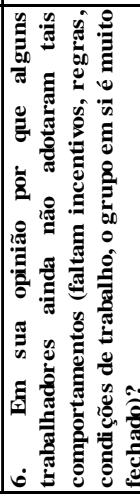 & 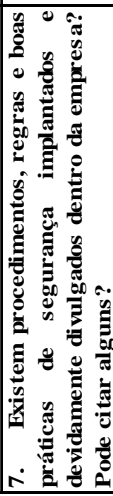 & 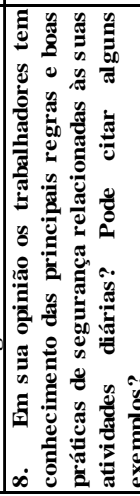 & 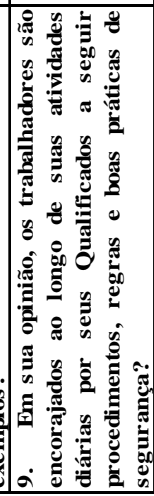 & 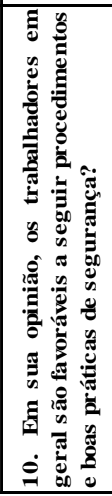 & 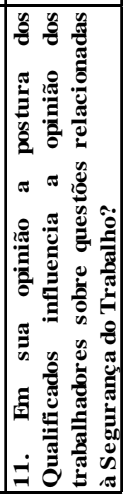 \\
\hline
\end{tabular}




\section{LÍDERES DE PRODUÇÃO}

\begin{tabular}{|c|c|c|c|c|c|c|c|c|c|c|c|}
\hline 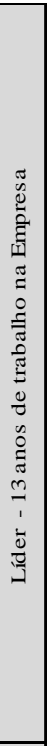 & 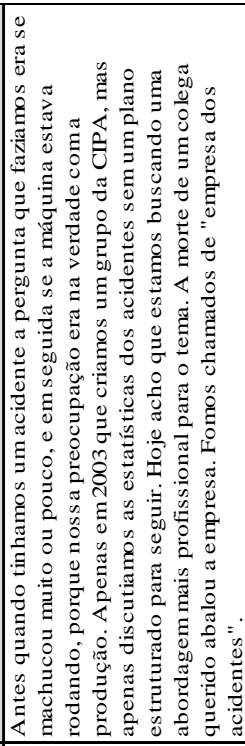 & & 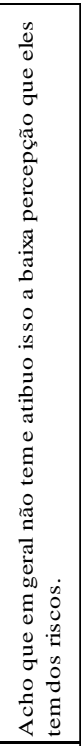 & & 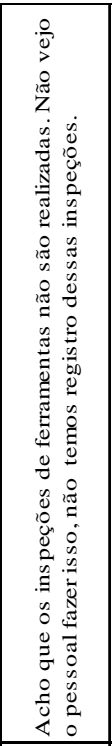 & 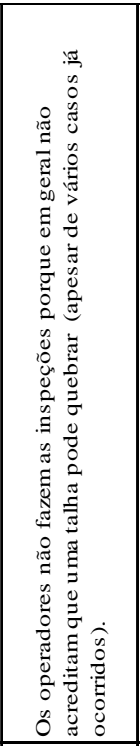 & & 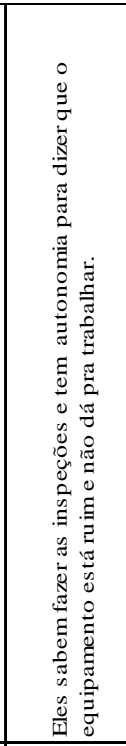 & 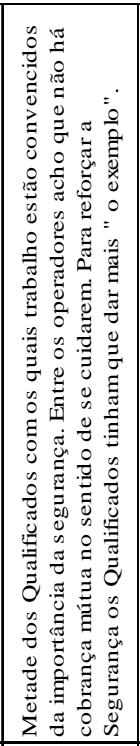 & 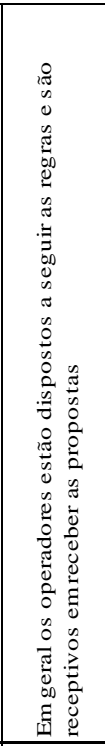 & 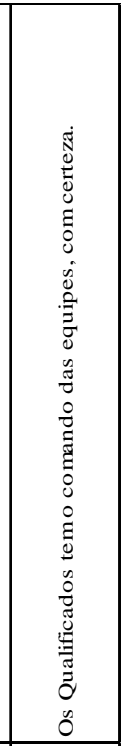 \\
\hline 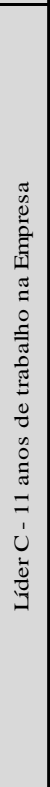 & 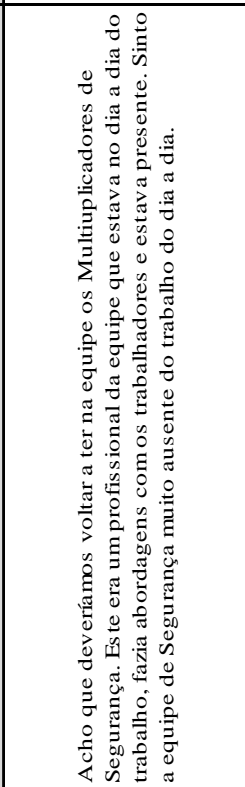 & 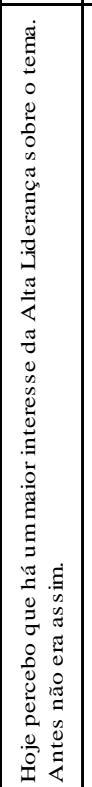 & 苫 & 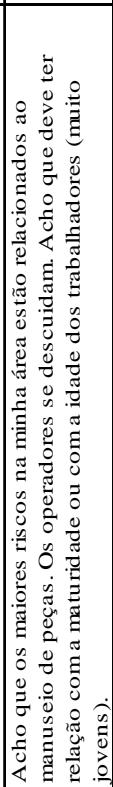 & 苏 & 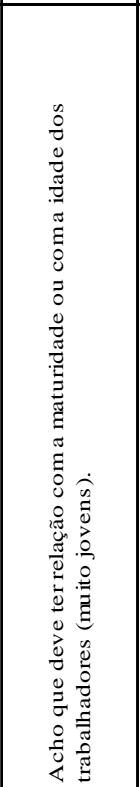 & 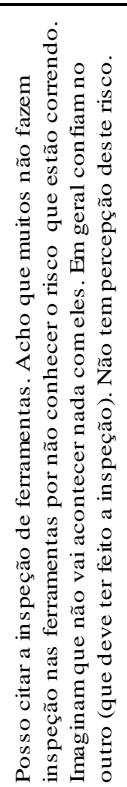 & 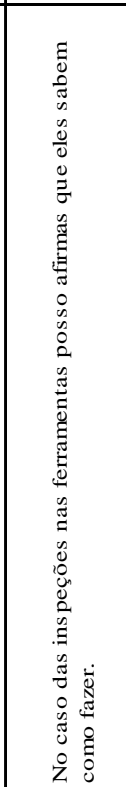 & 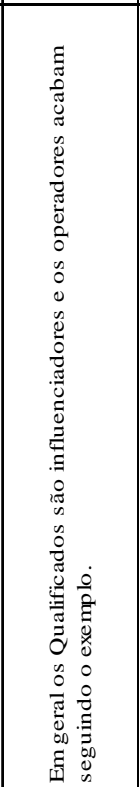 & 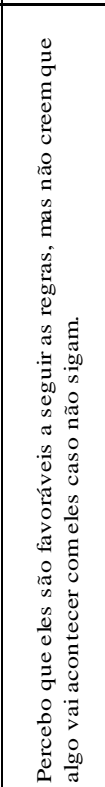 & 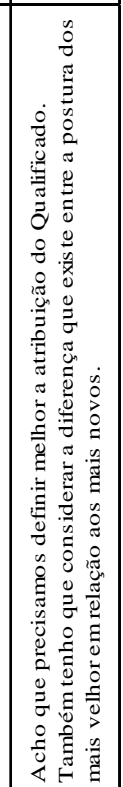 \\
\hline 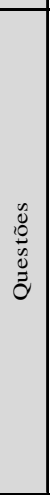 & 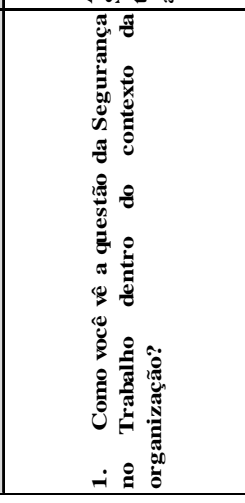 & 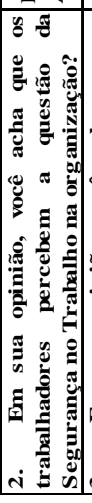 & 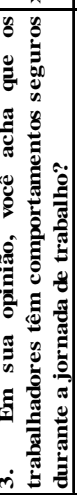 & 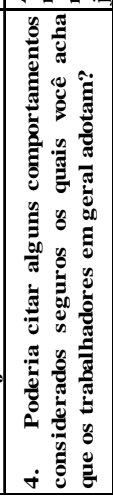 & 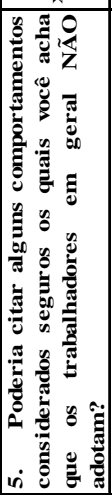 & 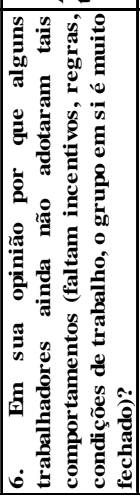 & 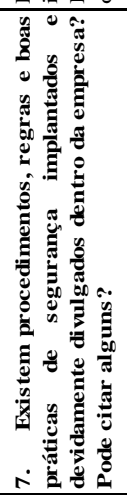 & 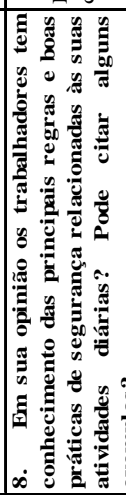 & 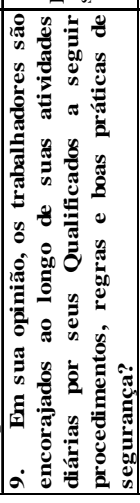 & 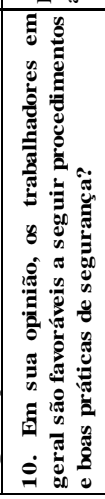 & 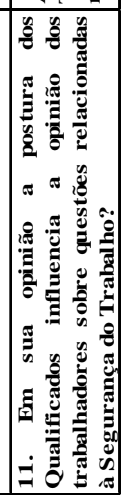 \\
\hline
\end{tabular}


APÊNDICE 11 - Análise do Questionário

\begin{tabular}{|c|c|c|c|c|c|}
\hline \multicolumn{6}{|c|}{ C1 } \\
\hline & & Frequency & Percent & Valid Percent & $\begin{array}{c}\text { Cumulative } \\
\text { Percent }\end{array}$ \\
\hline \multirow[t]{9}{*}{ Valid } & .00 & 3 & 1.1 & 1.1 & 1.1 \\
\hline & 1.00 & 59 & 21.6 & 21.6 & 22.7 \\
\hline & 2.00 & 40 & 14.7 & 14.7 & 37.4 \\
\hline & 3.00 & 17 & 6.2 & 6.2 & 43.6 \\
\hline & 4.00 & 37 & 13.6 & 13.6 & 57.1 \\
\hline & 5.00 & 33 & 12.1 & 12.1 & 69.2 \\
\hline & 6.00 & 39 & 14.3 & 14.3 & 83.5 \\
\hline & 7.00 & 45 & 16.5 & 16.5 & 100.0 \\
\hline & Total & 273 & 100.0 & 100.0 & \\
\hline \multicolumn{6}{|c|}{ QUESTÃO C2 } \\
\hline & & Frequency & Percent & Valid Percent & $\begin{array}{c}\text { Cumulative } \\
\text { Percent }\end{array}$ \\
\hline \multirow[t]{9}{*}{ Valid } & .00 & 11 & 4.0 & 4.0 & 4.0 \\
\hline & 1.00 & 27 & 9.9 & 9.9 & 13.9 \\
\hline & 2.00 & 27 & 9.9 & 9.9 & 23.8 \\
\hline & 3.00 & 10 & 3.7 & 3.7 & 27.5 \\
\hline & 4.00 & 26 & 9.5 & 9.5 & 37.0 \\
\hline & 5.00 & 41 & 15.0 & 15.0 & 52.0 \\
\hline & 6.00 & 78 & 28.6 & 28.6 & 80.6 \\
\hline & 7.00 & 53 & 19.4 & 19.4 & 100.0 \\
\hline & Total & 273 & 100.0 & 100.0 & \\
\hline
\end{tabular}

QUESTÃO C3

\begin{tabular}{|rl|r|r|r|r|}
\hline & & & & \multicolumn{2}{c|}{$\begin{array}{c}\text { Cumulative } \\
\text { Percent }\end{array}$} \\
\hline Valid & .00 & 10 & 3.7 & 3.7 & 3.7 \\
& & Frequency & Percent & Valid Percent & 10.6 \\
& 1.00 & 7.0 & 7.0 & 19.8 \\
2.00 & 25 & 9.2 & 9.2 & 24.9 \\
3.00 & 14 & 5.1 & 5.1 & 35.9 \\
4.00 & 30 & 11.0 & 11.0 & 48.0 \\
5.00 & 33 & 12.1 & 12.1 & 72.2 \\
6.00 & 66 & 24.2 & 24.2 & 100.0 \\
7.00 & 76 & 27.8 & 27.8 & \\
\hline & 273 & 100.0 & 100.0 & \\
\hline
\end{tabular}


QUESTÃO C4

\begin{tabular}{|c|c|c|c|c|c|}
\hline & & Frequency & Percent & Valid Percent & $\begin{array}{c}\text { Cumulative } \\
\text { Percent }\end{array}$ \\
\hline \multirow[t]{9}{*}{ Valid } & .00 & 5 & 1.8 & 1.8 & 1.8 \\
\hline & 1.00 & 27 & 9.9 & 9.9 & 11.7 \\
\hline & 2.00 & 21 & 7.7 & 7.7 & 19.4 \\
\hline & 3.00 & 11 & 4.0 & 4.0 & 23.4 \\
\hline & 4.00 & 30 & 11.0 & 11.0 & 34.4 \\
\hline & 5.00 & 39 & 14.3 & 14.3 & 48.7 \\
\hline & 6.00 & 76 & 27.8 & 27.8 & 76.6 \\
\hline & 7.00 & 64 & 23.4 & 23.4 & 100.0 \\
\hline & Total & 273 & 100.0 & 100.0 & \\
\hline
\end{tabular}

QUESTÃO C5

\begin{tabular}{|rl|r|r|r|r|}
\hline & & & & \multicolumn{2}{c|}{$\begin{array}{c}\text { Cumulative } \\
\text { Percent }\end{array}$} \\
\hline Valid & .00 & Frequency & Percent & Valid Percent & \multicolumn{2}{|c|}{3.3} \\
& 9 & 3.3 & 3.3 & 11.7 \\
& 23 & 8.4 & 8.4 & 19.4 \\
& 21.00 & 7.7 & 7.7 & 24.9 \\
& 21 & 5.5 & 5.5 & 30.4 \\
& 15 & 5.5 & 5.5 & 43.6 \\
4.00 & 15 & 13.2 & 13.2 & 69.2 \\
5.00 & 36 & 25.6 & 100.0 \\
6.00 & 70 & 25.6 & 30.8 & \\
7.00 & 84 & 30.8 & 100.0 & \\
Total & 273 & 100.0 & &
\end{tabular}

QUESTÃO C6

\begin{tabular}{|rl|r|r|r|r|}
\hline & & & & \multicolumn{2}{|c|}{$\begin{array}{c}\text { Cumulative } \\
\text { Percent }\end{array}$} \\
\hline Valid & .00 & Frequency & Percent & Valid Percent & \multicolumn{2}{|c|}{2.2} \\
& 6 & 2.2 & 2.2 & 20.1 \\
& 1.00 & 49 & 17.9 & 17.9 & 33.7 \\
& 2.00 & 37 & 13.6 & 13.6 & 38.8 \\
3.00 & 14 & 5.1 & 5.1 & 53.5 \\
4.00 & 40 & 14.7 & 14.7 & 68.5 \\
& 41 & 15.0 & 15.0 & 84.6 \\
6.00 & 44 & 16.1 & 16.1 & 100.0 \\
7.00 & 42 & 15.4 & 15.4 & \\
\hline
\end{tabular}


QUESTÃO C7

\begin{tabular}{|ll|r|r|r|r|}
\hline & & & & \multicolumn{2}{c|}{$\begin{array}{c}\text { Cumulative } \\
\text { Percent }\end{array}$} \\
\hline Valid & 1.00 & 59 & 21.6 & 21.7 & 21.7 \\
& 2.00 & 28 & 10.3 & 10.3 & 32.0 \\
& 3.00 & 11 & 4.0 & 4.0 & 36.0 \\
& 4.00 & 15.4 & 15.4 & 51.5 \\
& 5.00 & 42 & 15.8 & 15.8 & 67.3 \\
& 6.00 & 46 & 16.8 & 16.9 & 84.2 \\
& 7.00 & 43 & 15.8 & 15.8 & 100.0 \\
& Total & 272 & 99.6 & 100.0 & \\
Missing & System & 1 & .4 & & \\
Total & & 273 & 100.0 & & \\
\hline
\end{tabular}

QUESTÃO B1

\begin{tabular}{|r|r|r|r|r|}
\hline & & & & \multicolumn{2}{|c|}{$\begin{array}{c}\text { Cumulative } \\
\text { Percent }\end{array}$} \\
\hline Valid & Frequency & Percent & Valid Percent & 7.7 \\
& 21 & 7.7 & 7.7 & 10.6 \\
1.00 & 8 & 2.9 & 2.9 & 11.7 \\
2.00 & 3 & 1.1 & 1.1 & 13.2 \\
3.00 & 1.5 & 1.5 & 19.0 \\
4.00 & 16 & 5.9 & 5.9 & 33.7 \\
5.00 & 40 & 14.7 & 14.7 & 65.2 \\
6.00 & 86 & 31.5 & 31.5 & 100.0 \\
7.00 & 95 & 34.8 & 34.8 & \\
Total & 273 & 100.0 & 100.0 & \\
\hline
\end{tabular}

QUESTÃO B5

\begin{tabular}{|c|c|c|c|c|c|}
\hline & & Frequency & Percent & Valid Percent & $\begin{array}{c}\text { Cumulative } \\
\text { Percent }\end{array}$ \\
\hline \multirow[t]{9}{*}{ Valid } & .00 & 12 & 4.4 & 4.4 & 4.4 \\
\hline & 1.00 & 19 & 7.0 & 7.0 & 11.4 \\
\hline & 2.00 & 17 & 6.2 & 6.2 & 17.6 \\
\hline & 3.00 & 12 & 4.4 & 4.4 & 22.0 \\
\hline & 4.00 & 29 & 10.6 & 10.6 & 32.6 \\
\hline & 5.00 & 36 & 13.2 & 13.2 & 45.8 \\
\hline & 6.00 & 73 & 26.7 & 26.7 & 72.5 \\
\hline & 7.00 & 75 & 27.5 & 27.5 & 100.0 \\
\hline & Total & 273 & 100.0 & 100.0 & \\
\hline
\end{tabular}


QUESTÃO B10

\begin{tabular}{|r|r|r|r|r|}
\hline & & & & \multicolumn{2}{|c|}{$\begin{array}{c}\text { Cumulative } \\
\text { Percent }\end{array}$} \\
\hline Valid & Frequency & Percent & Valid Percent & 5.9 \\
& 16 & 5.9 & 5.9 & 16.1 \\
& 1600 & 10.3 & 10.3 & 26.0 \\
2.00 & 27 & 9.9 & 9.9 & 27.5 \\
3.00 & 4 & 1.5 & 1.5 & 35.2 \\
4.00 & 21 & 7.7 & 7.7 & 42.9 \\
5.00 & 21 & 7.7 & 7.7 & 67.4 \\
6.00 & 67 & 24.5 & 24.5 & 100.0 \\
7.00 & 89 & 32.6 & 32.6 & \\
Total & 273 & 100.0 & 100.0 & \\
\hline
\end{tabular}

\begin{tabular}{|c|c|c|c|c|c|}
\hline \multicolumn{6}{|c|}{ QUESTÃO B3 } \\
\hline & & Frequency & Percent & Valid Percent & $\begin{array}{c}\text { Cumulative } \\
\text { Percent }\end{array}$ \\
\hline \multirow[t]{9}{*}{ Valid } & .00 & 11 & 4.0 & 4.0 & 4.0 \\
\hline & 1.00 & 22 & 8.1 & 8.1 & 12.1 \\
\hline & 2.00 & 26 & 9.5 & 9.5 & 21.6 \\
\hline & 3.00 & 14 & 5.1 & 5.1 & 26.7 \\
\hline & 4.00 & 13 & 4.8 & 4.8 & 31.5 \\
\hline & 5.00 & 36 & 13.2 & 13.2 & 44.7 \\
\hline & 6.00 & 75 & 27.5 & 27.5 & 72.2 \\
\hline & 7.00 & 76 & 27.8 & 27.8 & 100.0 \\
\hline & Total & 273 & 100.0 & 100.0 & \\
\hline
\end{tabular}

\begin{tabular}{|c|c|c|c|c|c|}
\hline & & Frequency & Percent & Valid Percent & $\begin{array}{c}\text { Cumulative } \\
\text { Percent }\end{array}$ \\
\hline \multirow[t]{9}{*}{ Valid } & .00 & 13 & 4.8 & 4.8 & 4.8 \\
\hline & 1.00 & 4 & 1.5 & 1.5 & 6.2 \\
\hline & 2.00 & 4 & 1.5 & 1.5 & 7.7 \\
\hline & 3.00 & 4 & 1.5 & 1.5 & 9.2 \\
\hline & 4.00 & 13 & 4.8 & 4.8 & 13.9 \\
\hline & 5.00 & 24 & 8.8 & 8.8 & 22.7 \\
\hline & 6.00 & 94 & 34.4 & 34.4 & 57.1 \\
\hline & 7.00 & 117 & 42.9 & 42.9 & 100.0 \\
\hline & Total & 273 & 100.0 & 100.0 & \\
\hline
\end{tabular}


QUESTÃO B12

\begin{tabular}{|r|r|r|r|r|}
\hline & & & & \multicolumn{2}{|c|}{$\begin{array}{c}\text { Cumulative } \\
\text { Percent }\end{array}$} \\
\hline Valid & Frequency & Percent & Valid Percent & 4.0 \\
& 11 & 4.0 & 4.0 & 9.5 \\
& 1.00 & 5.5 & 5.5 & 15.8 \\
2.00 & 15 & 6.2 & 6.2 & 20.5 \\
3.00 & 4.8 & 4.8 & 27.8 \\
4.00 & 13 & 7.3 & 7.3 & 44.0 \\
5.00 & 20 & 16.1 & 16.1 & 74.0 \\
6.00 & 44 & 30.0 & 30.0 & 100.0 \\
7.00 & 71 & 26.0 & 26.0 & \\
Total & 273 & 100.0 & 100.0 & \\
\hline
\end{tabular}

QUESTÃO B14

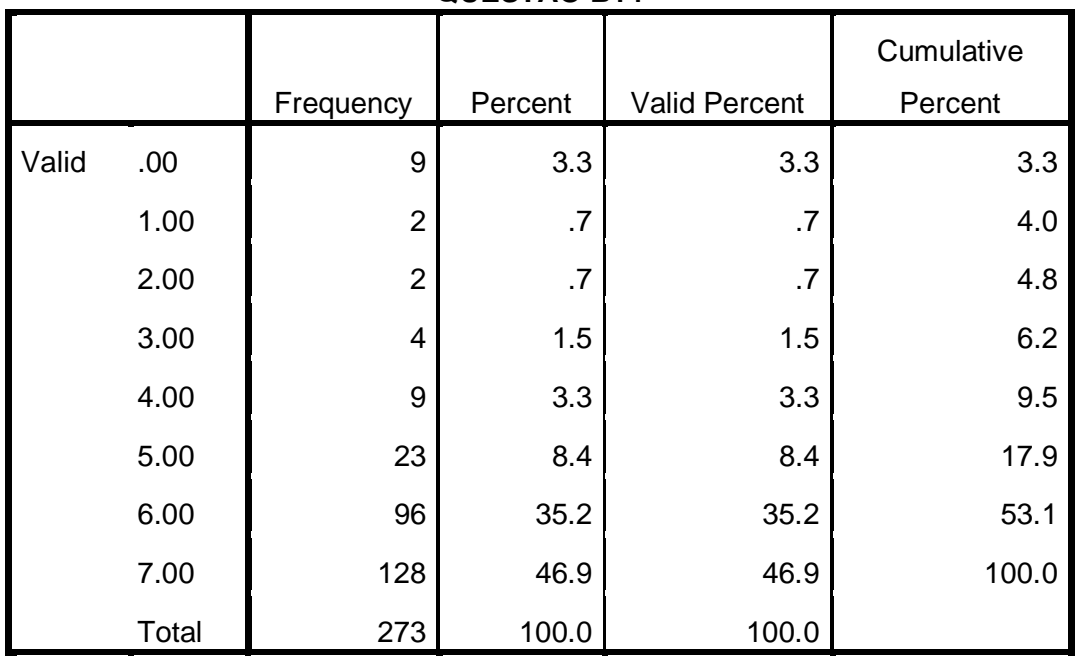

QUESTÃO A1

\begin{tabular}{|ll|r|r|r|r|}
\hline & & & & \multicolumn{2}{|c|}{$\begin{array}{c}\text { Cumulative } \\
\text { Percent }\end{array}$} \\
\hline Valid & .00 & Frequency & Percent & Valid Percent & .7 \\
& 2 & .7 & .7 & 1.1 \\
& 1.00 & 1 & .4 & .4 & 1.8 \\
2.00 & 2 & .7 & .7 & 2.6 \\
4.00 & 2 & .7 & .7 & 6.3 \\
5.00 & 10 & 3.7 & 3.7 & 20.2 \\
6.00 & 38 & 14.0 & 14.0 & 100.0 \\
7.00 & 217 & 79.8 & 79.8 & \\
\hline
\end{tabular}


QUESTÃO A2

\begin{tabular}{|ll|r|r|r|r|}
\hline & & & & \multicolumn{2}{|c|}{$\begin{array}{c}\text { Cumulative } \\
\text { Percent }\end{array}$} \\
\hline Valid & Frequency & Percent & Valid Percent & \multicolumn{2}{|c|}{1.1} \\
& 4.00 & 3 & 1.1 & 1.1 & 2.2 \\
& 5.00 & 3 & 1.1 & 1.1 & 8.1 \\
& 6.00 & 16 & 5.9 & 5.9 & 29.9 \\
& 7.00 & 59 & 21.7 & 21.8 & 100.0 \\
& Total & 190 & 69.9 & 70.1 & \\
Missing & System & 271 & 99.6 & 100.0 & \\
Total & & 272 & .4 & & \\
\hline
\end{tabular}

QUESTÃO A3

\begin{tabular}{|ll|r|r|r|r|}
\hline & & & & \multicolumn{2}{|c|}{$\begin{array}{c}\text { Cumulative } \\
\text { Percent }\end{array}$} \\
\hline Valid & .00 & Frequency & Percent & Valid Percent & .4 \\
& 1.00 & .4 & .4 & 1.8 \\
& 2.00 & 4 & 1.5 & 1.5 & 3.0 \\
& 3.00 & 1.1 & 1.1 & 3.7 \\
& 4.00 & 2 & .7 & .7 & 5.2 \\
& 5.00 & 4 & 1.5 & 1.5 & 19.9 \\
& 6.00 & 60 & 14.7 & 14.8 & 42.8 \\
& 7.00 & 155 & 57.0 & 22.9 & 100.0 \\
& Total & 271 & 99.6 & 100.0 & \\
Missing & System & 1 & .4 & & \\
Total & & 272 & 100.0 & & \\
\hline
\end{tabular}

QUESTÃO A4

\begin{tabular}{|ll|r|r|r|r|}
\hline & & & & \multicolumn{2}{|c|}{$\begin{array}{c}\text { Cumulative } \\
\text { Percent }\end{array}$} \\
\hline Valid & 2.00 & Frequency & Percent & Valid Percent & 1.1 \\
& 3.00 & 3 & 1.1 & 1.1 & 2.6 \\
& 4.00 & 4 & 1.5 & 1.5 & 4.1 \\
& 5.00 & 4 & 1.5 & 1.5 & 8.1 \\
& 6.00 & 11 & 4.0 & 4.1 & 26.6 \\
& 7.00 & 50 & 18.4 & 18.5 & 100.0 \\
& Total & 199 & 73.2 & 73.4 & \\
Missing & System & 271 & 99.6 & 100.0 & \\
Total & & 272 & .4 & & \\
\hline
\end{tabular}




\begin{tabular}{|c|c|c|c|c|c|}
\hline \multicolumn{6}{|c|}{ QUESTÃO B7 } \\
\hline & & Frequency & Percent & Valid Percent & $\begin{array}{c}\text { Cumulative } \\
\text { Percent }\end{array}$ \\
\hline \multirow[t]{9}{*}{ Valid } & .00 & 8 & 2.9 & 3.0 & 3.0 \\
\hline & 1.00 & 4 & 1.5 & 1.5 & 4.5 \\
\hline & 2.00 & 4 & 1.5 & 1.5 & 6.0 \\
\hline & 3.00 & 4 & 1.5 & 1.5 & 7.5 \\
\hline & 4.00 & 13 & 4.8 & 4.9 & 12.3 \\
\hline & 5.00 & 24 & 8.8 & 9.0 & 21.3 \\
\hline & 6.00 & 94 & 34.4 & 35.1 & 56.3 \\
\hline & 7.00 & 117 & 42.9 & 43.7 & 100.0 \\
\hline & Total & 268 & 98.2 & 100.0 & \\
\hline Missing & System & 5 & 1.8 & & \\
\hline Total & & 273 & 100.0 & & \\
\hline \multicolumn{6}{|c|}{ B12 } \\
\hline & & Frequency & Percent & Valid Percent & $\begin{array}{c}\text { Cumulative } \\
\text { Percent }\end{array}$ \\
\hline \multirow[t]{9}{*}{ Valid } & .00 & 5 & 1.8 & 1.9 & 1.9 \\
\hline & 1.00 & 15 & 5.5 & 5.6 & 7.5 \\
\hline & 2.00 & 17 & 6.2 & 6.4 & 13.9 \\
\hline & 3.00 & 13 & 4.8 & 4.9 & 18.7 \\
\hline & 4.00 & 20 & 7.3 & 7.5 & 26.2 \\
\hline & 5.00 & 44 & 16.1 & 16.5 & 42.7 \\
\hline & 6.00 & 82 & 30.0 & 30.7 & 73.4 \\
\hline & 7.00 & 71 & 26.0 & 26.6 & 100.0 \\
\hline & Total & 267 & 97.8 & 100.0 & \\
\hline Missing & System & 6 & 2.2 & & \\
\hline Total & & 273 & 100.0 & & \\
\hline
\end{tabular}


B14

\begin{tabular}{|ll|r|r|r|r|}
\hline & & & & \multicolumn{2}{|c|}{$\begin{array}{c}\text { Cumulative } \\
\text { Percent }\end{array}$} \\
\hline Valid & .00 & Frequency & Percent & Valid Percent & 1.1 \\
& 1.00 & 1.1 & 1.1 & .7 \\
& 2.00 & .7 & .7 & 1.9 \\
& 2 & .7 & 1.5 & 2.6 \\
& 2.00 & 1.5 & 3.4 & 4.1 \\
& 4.00 & 3 & 8.3 & 7.5 \\
& 5.00 & 23 & 8.4 & 36.0 & 16.1 \\
& 6.00 & 96 & 35.2 & 47.9 & 52.1 \\
& 7.00 & 128 & 46.9 & 100.0 & 100.0 \\
& Total & 267 & 97.8 & & \\
Missing & System & 6 & 2.2 & & \\
\hline Total & & 273 & 100.0 & & \\
\hline
\end{tabular}

QUESTÃO B2

\begin{tabular}{|ll|r|r|r|r|}
\hline & & & & \multicolumn{2}{c|}{$\begin{array}{c}\text { Cumulative } \\
\text { Percent }\end{array}$} \\
\hline Valid & .00 & Frequency & Percent & Valid Percent & 1.5 \\
& 1.00 & 4 & 1.5 & 1.5 & 18.3 \\
& 2.00 & 45 & 16.5 & 16.8 & 33.6 \\
& 3.00 & 41 & 15.0 & 15.3 & 39.9 \\
& 4.00 & 17 & 6.2 & 6.3 & 58.2 \\
& 5.00 & 39 & 17.9 & 18.3 & 69.8 \\
& 6.00 & 11.4 & 11.6 & 91.0 \\
& 7.00 & 24 & 20.9 & 21.3 & 100.0 \\
& Total & 268 & 9.8 & 9.0 & \\
Missing & System & 5 & 1.8 & 100.0 & \\
Total & 273 & 100.0 & & \\
\hline
\end{tabular}




\begin{tabular}{|ll|r|r|r|r|}
\hline & & & & \multicolumn{2}{c|}{$\begin{array}{c}\text { Cumulative } \\
\text { Percent }\end{array}$} \\
\hline Valid & .00 & Frequency & Percent & Valid Percent & 4.1 \\
& 1.00 & 36 & 4.0 & 4.1 & 17.5 \\
& 2.00 & 13.2 & 13.4 & 28.4 \\
& 3.00 & 10.6 & 10.8 & 38.4 \\
& 4.00 & 51 & 18.7 & 10.1 & 57.5 \\
& 5.00 & 53 & 19.4 & 19.0 & 77.2 \\
& 6.00 & 31 & 11.4 & 19.8 & 88.8 \\
& 7.00 & 30 & 11.0 & 11.6 & 100.0 \\
& Total & 268 & 98.2 & 11.2 & \\
\hline Missing & System & 5 & 1.8 & 100.0 & \\
\hline Total & & 273 & 100.0 & & \\
\hline
\end{tabular}

\begin{tabular}{|ll|r|r|r|r|}
\hline & & & & \multicolumn{2}{|c|}{$\begin{array}{c}\text { Cumulative } \\
\text { Percent }\end{array}$} \\
\hline Valid & .00 & Frequency & Percent & Valid Percent & \multicolumn{2}{|c|}{1.9} \\
& 1.00 & 5 & 1.8 & 1.9 & 16.9 \\
& 2.00 & 14.7 & 15.0 & 34.5 \\
& 3.00 & 47 & 17.2 & 17.6 & 41.9 \\
& 4.00 & 20 & 7.3 & 7.5 & 58.4 \\
& 5.00 & 44 & 16.1 & 16.5 & 74.5 \\
& 6.00 & 43 & 15.8 & 16.1 & 87.6 \\
& 7.00 & 35 & 12.8 & 13.1 & 100.0 \\
& Total & 33 & 12.1 & 12.4 & \\
Missing & System & 6 & 97.8 & 100.0 & \\
Total & & 267 & & & \\
\hline
\end{tabular}


B11

\begin{tabular}{|ll|r|r|r|r|}
\hline & & & & \multicolumn{2}{|c|}{$\begin{array}{c}\text { Cumulative } \\
\text { Percent }\end{array}$} \\
\hline Valid & .00 & Frequency & Percent & Valid Percent & 2.6 \\
& 1.00 & 7 & 2.6 & 2.6 & 6.7 \\
& 2.00 & 11 & 4.0 & 4.1 & 13.1 \\
& 17 & 6.2 & 6.4 & 19.9 \\
& 18 & 6.6 & 6.7 & 34.8 \\
& 4.00 & 40 & 14.7 & 15.0 & 49.8 \\
& 5.00 & 40 & 14.7 & 15.0 & 76.0 \\
& 6.00 & 70 & 25.6 & 26.2 & 100.0 \\
& 7.00 & 64 & 23.4 & 24.0 & \\
& Total & 267 & 97.8 & 100.0 & \\
Missing & System & 6 & 2.2 & & \\
\hline Total & & 273 & 100.0 & & \\
\hline
\end{tabular}

B4

\begin{tabular}{|ll|r|r|r|r|}
\hline & & & & \multicolumn{2}{|c|}{$\begin{array}{c}\text { Cumulative } \\
\text { Percent }\end{array}$} \\
\hline Valid & .00 & Frequency & Percent & Valid Percent & 2.2 \\
& 1.00 & 6 & 2.2 & 2.2 & 4.5 \\
& 2.00 & 6 & 2.2 & 2.2 & 6.0 \\
& 3.00 & 1.5 & 1.5 & 7.1 \\
& 4.00 & 1.1 & 1.1 & 12.3 \\
& 5.00 & 14 & 5.1 & 5.2 & 23.5 \\
& 6.00 & 30 & 11.0 & 11.2 & 60.8 \\
& 7.00 & 100 & 36.6 & 37.3 & 100.0 \\
& Total & 105 & 38.5 & 39.2 & \\
Missing & System & 268 & 98.2 & 100.0 & \\
Total & & 5 & 1.8 & & \\
\hline
\end{tabular}


B8

\begin{tabular}{|ll|r|r|r|r|}
\hline & & & & \multicolumn{2}{|c|}{$\begin{array}{c}\text { Cumulative } \\
\text { Percent }\end{array}$} \\
\hline Valid & .00 & Frequency & Percent & Valid Percent & 4.1 \\
& 1.00 & 4.0 & 4.1 & 6.0 \\
& 2.00 & 5 & 1.8 & 1.9 & 7.5 \\
& 3.00 & 4 & 1.5 & 1.5 & .7 \\
& 4.00 & 2 & .7 & 7.1 & 8.2 \\
& 5.00 & 19 & 7.0 & 12.7 & 15.4 \\
& 6.00 & 102 & 34.4 & 38.2 & 28.1 \\
& 7.00 & 90 & 33.0 & 33.7 & 66.3 \\
& Total & 267 & 97.8 & 100.0 & 100.0 \\
Missing & System & 6 & 2.2 & & \\
\hline Total & & 273 & 100.0 & & \\
\hline
\end{tabular}

B13

\begin{tabular}{|ll|r|r|r|r|}
\hline & & & & \multicolumn{2}{c|}{$\begin{array}{c}\text { Cumulative } \\
\text { Percent }\end{array}$} \\
\hline Valid & Frequency & Percent & Valid Percent & 4.1 \\
& 1.00 & 11 & 4.0 & 4.1 & 7.1 \\
& 2.00 & 8 & 2.9 & 3.0 & 10.1 \\
& 3.00 & 8 & 2.9 & 3.0 & 13.1 \\
& 4.00 & 8 & 2.9 & 3.0 & 20.2 \\
& 5.00 & 19 & 7.0 & 7.1 & 31.8 \\
& 6.00 & 31 & 11.4 & 11.6 & 66.3 \\
& 7.00 & 92 & 33.7 & 34.5 & 100.0 \\
& Total & 90 & 33.0 & 33.7 & \\
Missing & System & 267 & 97.8 & 100.0 & \\
Total & & 2.2 & & \\
\hline
\end{tabular}


B15

\begin{tabular}{|ll|r|r|r|r|}
\hline & & & & \multicolumn{2}{c|}{$\begin{array}{c}\text { Cumulative } \\
\text { Percent }\end{array}$} \\
\hline Valid & Frequency & Percent & Valid Percent & .8 \\
& 2.00 & 2 & .7 & .8 & 2.6 \\
& 2.00 & 5 & 1.8 & 1.9 & 3.0 \\
& 3.00 & 1 & .4 & .4 & 7.9 \\
& 4.00 & 13 & 4.8 & 4.9 & 18.4 \\
& 5.00 & 28 & 10.3 & 10.5 & 52.6 \\
& 6.00 & 91 & 33.3 & 34.2 & 100.0 \\
& 7.00 & 126 & 46.2 & 47.4 & \\
& Total & 266 & 97.4 & 100.0 & \\
Missing & System & 7 & 2.6 & & \\
Total & & 273 & 100.0 & & \\
\hline
\end{tabular}




\section{APÊNDICE 12 - Matriz Rotacionada e Questões (Final)}

\begin{tabular}{|c|c|c|c|c|c|c|c|}
\hline \multicolumn{7}{|c|}{ Rotated Component Matrixa } & \multirow{3}{*}{ Questões } \\
\hline & \multicolumn{6}{|c|}{ Component } & \\
\hline & 1 & 2 & 3 & 4 & 5 & 6 & \\
\hline Atitude (1) & .052 & -.138 & .108 & .676 & .017 & .151 & $\begin{array}{l}\text { Eu considero importante inspecionar minhas ferramentas de trabalho } \\
\text { no início do turno todos os dias. }\end{array}$ \\
\hline Atitude (2) & .040 & .032 & .019 & .755 & .146 & -.045 & $\begin{array}{l}\text { Eu acho seguro inspecionar minhas ferramentas de trabalho no início } \\
\text { do turno todos os dias. }\end{array}$ \\
\hline Atitude (3) & -.004 & .115 & .080 & .774 & .168 & -.180 & $\begin{array}{l}\text { Eu acho bom inspecionar minhas ferramentas de trabalho no início do } \\
\text { turno todos os dias. }\end{array}$ \\
\hline Atitude (4) & .031 & .063 & .035 & .676 & .057 & .082 & $\begin{array}{l}\text { Eu acho necessario inspecionar minhas ferramentas de trabalho no } \\
\text { início do turno todos os dias. }\end{array}$ \\
\hline Comportamento(B1) & .160 & .059 & .699 & .147 & .246 & .041 & $\begin{array}{l}\text { Eu inspeciono minhas ferramentas de trabalho no início do turno } \\
\text { todos os dias. }\end{array}$ \\
\hline NS(B2) & .203 & .376 & .313 & -.179 & .351 & -.249 & $\begin{array}{l}\text { A maioria dos meus colegas me chama atenção quando eu não } \\
\text { inspeciono as ferramentas de trabalho ao iniciar minha jornada. }\end{array}$ \\
\hline Controle(B3) & .246 & .692 & .086 & .182 & .103 & .181 & $\begin{array}{l}\text { Eu tenho tempo para inspecionar minhas ferramentas de trabalho no } \\
\text { início do turno todos os dias. }\end{array}$ \\
\hline Intenção (B4) & .125 & .089 & .407 & .302 & .565 & -.030 & $\begin{array}{l}\text { Eu pretendo inspecionar minhas ferramentas de trabalho no início do } \\
\text { turno todos os dias. }\end{array}$ \\
\hline Comportamento (B5) & .174 & .470 & .687 & .090 & .072 & .076 & $\begin{array}{l}\text { Esta semana eu inspecionei minhas ferramentas de trabalho no início } \\
\text { do turno todos os dias. }\end{array}$ \\
\hline NS(B6) & .235 & .726 & .194 & .028 & .125 & -.036 & $\begin{array}{l}\text { A maioria dos meus colegas inspeciona as ferramentas de trabalho no } \\
\text { início do turno todos os dias. }\end{array}$ \\
\hline Controle (B7) & .084 & .031 & .475 & -.052 & .315 & .366 & $\begin{array}{l}\text { Eu sei inspecionar minhas ferramentas de trabalho no início do turno } \\
\text { todos os dias. }\end{array}$ \\
\hline Intenção (B8) & .164 & .171 & .088 & .109 & .674 & .153 & $\begin{array}{l}\text { Eu tenho a intenção de inspecionar minhas ferramentas de trabalho no } \\
\text { início do turno todos os dias. }\end{array}$ \\
\hline NS(B9) & .313 & .682 & .158 & -.121 & .207 & -.102 & $\begin{array}{l}\text { A maioria dos meus colegas de trabalho me incentiva a inspecionar as } \\
\text { ferramentas no início do turno todos os dias. }\end{array}$ \\
\hline Comportamento (B10) & .203 & .359 & .692 & .144 & .081 & .120 & Hoje eu inspecionei minhas ferramentas de trabalho no início do turno. \\
\hline NS(B11) & .319 & .484 & -.030 & .008 & .507 & -.047 & $\begin{array}{l}\text { A maioria dos meus colegas acha importante inspecionar as } \\
\text { ferramentas de trabalho todos os dias. }\end{array}$ \\
\hline Controle (B12) & .164 & .667 & .279 & .009 & .030 & .411 & $\begin{array}{l}\text { Eu consigo inspecionar minhas ferramentas de trabalho no início do } \\
\text { turno todos os dias. }\end{array}$ \\
\hline Intenção (B13) & .135 & .332 & .288 & .072 & .472 & .208 & $\begin{array}{l}\text { A partir de amanhã, é provável que eu inspecione minhas ferramentas } \\
\text { de trabalho no início do turno todos os dias }\end{array}$ \\
\hline Controle (B14) & .057 & .147 & .185 & .024 & .302 & .744 & $\begin{array}{l}\text { Eu sou capaz de inspecionar minhas ferramentas de trabalho no início } \\
\text { do turno todos os dias. }\end{array}$ \\
\hline Intenção (B15) & .102 & .020 & .159 & .259 & .699 & .152 & $\begin{array}{l}\text { Eu quero inspecionar minhas ferramentas de trabalho no início do } \\
\text { turno todos os dias. }\end{array}$ \\
\hline Supervisão $(\mathrm{C} 1)$ & .634 & .273 & .279 & -.082 & .167 & -.248 & $\begin{array}{l}\text { Meu Qualificado verifica frequentemente se todos na minha equipe } \\
\text { inspecionam as ferramentas no início do turno todos os dias. }\end{array}$ \\
\hline Supervisão (C2) & .808 & .217 & .038 & .049 & .153 & .124 & $\begin{array}{l}\text { Meu Qualificado conversa comigo sobre como as insepeções de } \\
\text { ferramentas devem ser feitas. }\end{array}$ \\
\hline Supervisão (C3) & .863 & .088 & .012 & .070 & .022 & .195 & $\begin{array}{l}\text { Meu Qualificado me orienta sobre a importância de inspecionar as } \\
\text { ferramentas de trabalho no início do turno todos os dias. }\end{array}$ \\
\hline Supervisão (C4) & .855 & .183 & .052 & .020 & .085 & .122 & $\begin{array}{l}\text { O Qualificado da linha reforça para a equipe que as ferramentas devem } \\
\text { ser inspecionadas no início do turno mesmo quando estamos com } \\
\text { pressa. }\end{array}$ \\
\hline Supervisão (C5) & .783 & .079 & .123 & .132 & .196 & .053 & $\begin{array}{l}\text { O Qualificado da linha frequentemente fala para minha equipe sobre os } \\
\text { perigos de não inspecionar ferramentas no início do turno. }\end{array}$ \\
\hline Supervisão (C6) & .749 & .308 & .236 & .017 & .212 & -.071 & $\begin{array}{l}\text { O Qualificado chama a atenção dos colegas que não inspecionam suas } \\
\text { ferramentas no início do turno. }\end{array}$ \\
\hline Supervisão (C7) & .684 & .229 & .256 & -.019 & .009 & -.227 & $\begin{array}{l}\text { O Qualificado da linha elogia os colegas que sempre inspecionam as } \\
\text { ferramentas que utilizamos no início do turno todos os dias. }\end{array}$ \\
\hline
\end{tabular}


APÊNDICE 13 - Variância Total Explicada

\begin{tabular}{|c|c|c|c|c|c|c|c|c|c|}
\hline \multirow[b]{2}{*}{ Component } & \multicolumn{3}{|c|}{ Initial Eigenvalues } & \multicolumn{3}{|c|}{$\begin{array}{l}\text { Extraction Sums of Squared } \\
\text { Loadings }\end{array}$} & \multicolumn{3}{|c|}{$\begin{array}{l}\text { Rotation Sums of Squared } \\
\text { Loadings }\end{array}$} \\
\hline & Total & $\begin{array}{c}\% \text { of } \\
\text { Variance } \\
\end{array}$ & $\begin{array}{c}\text { Cumulative } \\
\% \\
\end{array}$ & Total & $\begin{array}{c}\% \text { of } \\
\text { Variance } \\
\end{array}$ & $\begin{array}{c}\text { Cumulative } \\
\% \\
\end{array}$ & Total & $\begin{array}{c}\% \text { of } \\
\text { Variance }\end{array}$ & $\begin{array}{c}\text { Cumulative } \\
\% \\
\end{array}$ \\
\hline 1 & 8.423 & 32.397 & 32.397 & 8.423 & 32.397 & 32.397 & 4.740 & 18.230 & 18.230 \\
\hline 2 & 2.753 & 10.588 & 42.985 & 2.753 & 10.588 & 42.985 & 3.169 & 12.190 & 30.420 \\
\hline 3 & 2.020 & 7.769 & 50.755 & 2.020 & 7.769 & 50.755 & 2.466 & 9.485 & 39.905 \\
\hline 4 & 1.262 & 4.854 & 55.608 & 1.262 & 4.854 & 55.608 & 2.425 & 9.329 & 49.234 \\
\hline 5 & 1.050 & 4.040 & 59.648 & 1.050 & 4.040 & 59.648 & 2.393 & 9.204 & 58.438 \\
\hline 6 & 1.015 & 3.904 & 63.552 & 1.015 & 3.904 & 63.552 & 1.330 & 5.114 & 63.552 \\
\hline 7 & .933 & 3.590 & 67.142 & & & & & & \\
\hline 8 & .803 & 3.088 & 70.230 & & & & & & \\
\hline 9 & .778 & 2.993 & 73.223 & & & & & & \\
\hline 10 & .699 & 2.688 & 75.912 & & & & & & \\
\hline 11 & .658 & 2.531 & 78.442 & & & & & & \\
\hline 12 & .603 & 2.320 & 80.762 & & & & & & \\
\hline 13 & .585 & 2.248 & 83.011 & & & & & & \\
\hline 14 & .557 & 2.141 & 85.152 & & & & & & \\
\hline 15 & .502 & 1.931 & 87.083 & & & & & & \\
\hline 16 & .435 & 1.674 & 88.757 & & & & & & \\
\hline 17 & .423 & 1.627 & 90.384 & & & & & & \\
\hline 18 & .375 & 1.442 & 91.826 & & & & & & \\
\hline 19 & .354 & 1.363 & 93.189 & & & & & & \\
\hline 20 & .335 & 1.290 & 94.479 & & & & & & \\
\hline 21 & .296 & 1.139 & 95.618 & & & & & & \\
\hline 22 & .287 & 1.103 & 96.720 & & & & & & \\
\hline 23 & .253 & .973 & 97.693 & & & & & & \\
\hline 24 & .235 & .903 & 98.596 & & & & & & \\
\hline 25 & .210 & .808 & 99.405 & & & & & & \\
\hline 26 & .155 & .595 & 100.000 & & & & & & \\
\hline
\end{tabular}

Extraction Method: Principal Component Analysis. 